\title{
Identification and quantification of the effects of flow regime and matrix-conduit interaction in the characterization of karst aquifers
}

\author{
Dissertation \\ zur Erlangung des mathematisch-naturwissenschaftlichen Doktorgrades \\ "Doctor rerum naturalium" \\ der Georg-August-Universität Göttingen \\ im Promotionsprogramm Geowissenschaften / Geographie \\ der Georg-August-University School of Science (GAUSS)
}

vorgelegt von

Markus Giese

aus Pinneberg 


\section{Betreuungsausschuss:}

Prof. Dr. Martin Sauter, Abteilung Angewandte Geologie, Georg-AugustUniversität Göttingen

Dr. Tobias Geyer, Abt. 9 - Landesamt für Geologie, Rohstoffe und Bergbau, Regierungspräsidium Freiburg

Dr. Jean-Christophe Maréchal, Bureau de Recherches Géologiques et Minières (BRGM)- D3E/NRE, Montpellier, France

\section{Mitglieder der Prüfungskommission:}

Referent: Prof. Dr. Martin Sauter, Abteilung Angewandte Geologie, GeorgAugust-Universität Göttingen

Korreferent: Prof. Dr. Rudolf Liedl, Institut für Grundwasserwirtschaft, Technische Universität Dresden

weitere Mitglieder der Prüfungskommission:

Prof. Dr. Thomas Ptak, Abteilung Angewandte Geologie, Georg-AugustUniversität Göttingen

Prof. Dr. Sebastian Bauer, Arbeitsgruppe Geohydromodellierung, ChristianAlbrecht-Universität zu Kiel

Dr. Tobias Geyer, Abt. 9 - Landesamt für Geologie, Rohstoffe und Bergbau, Regierungspräsidium Freiburg

Dr. Jean-Christophe Maréchal, Bureau de Recherches Géologiques et Minières (BRGM)- D3E/NRE, Montpellier, France

Tag der mündlichen Prüfung: $\quad$ 03.05.2017 
Thousands have lived without love but not one without water.

W. H. AUDEN 


\section{Abstract}

In addition to alluvial aquifers, karst aquifers are counted among the most important groundwater resources. Besides the high benefit of karstic springs, they also pose risks to the user or people living close to those springs. The highly permeable structures within the lowpermeable hard rock, which are the result of chemical solution processes, can result in high contaminant concentration and high flow velocity towards the sources. In addition to the high susceptibility to water quality, karst sources have a high potential for damage caused by flooding in the downstream area of the sources.

The characterization of karst aquifers is usually based on the evaluation of karst spring hydrographs as an integral signal of the entire catchment area. The spatial distribution of karstspecific heterogeneities and thus their interactions are excluded. A further disadvantage with the analyses of spring discharge is the usually unknown input signal into the system. Due to the application of large-scale pumping tests in karst aquifers, i.e. the intensive and long-term water abstraction from the conduit system, the system can be triggered by a clearly defined input signal.

The aim of this thesis is the systematic analysis of pumping tests with regard to the heterogeneities and hydraulic properties for the large number of different conceptual models of karst systems. The work focuses on the changes of local and regional flow patterns caused by different hydraulic properties on different scales of the karstified catchment, discrete and diffuse boundary conditions as well as the interactions between the conduit system and the hard rock matrix. For this purpose, a discrete conduit-continuum model is employed, which was adapted according to the intended use. The analysis is divided into several sections, focusing on different phases and processes of a pumping test.

The first section of a pumping test is dominated by internal boundary conditions caused by fast-responding storage and interactions with the adjacent, low permeable environment. Two model parameters are converted into two dimensionless parameters, which are frequently used for the interpretation of classical pump tests, in order to approximate the drawdown behavior of an analytical solution. The conceptual process description associated with the analytical solution allows the two dimensionless parameters to create a characterization scheme for the saturated zone of a karst aquifer. By combining the numerical model parameters with conceptual models, a further conceptual model can be defined in which the exchange flow between the conduit system and the uniformly karstified matrix is limited by the hydraulic interface properties and the resulting effects.

Following the period affected by the interface interactions, the flow period is dominated by conduit flow. Scientific sources make a distinction between laminar and turbulent pipe/conduit flow. In general, in karst aquifers there is a lack of information regarding the conduit properties, especially the diameter or the roughness of the conduit, which are required for determining the current state of flow. Applying a defined pump rate, these tube-specific parameters remain as the residual members. Those can be used to calculate quantitative differences, i.e. head losses along the flow direction, between laminar and turbulent flow. These head losses influence the conduit flow behavior as well as the flow pattern on a regional scale. The results of the analysis show that the errors caused by applying laminar flow equations are very small in mature karst systems, whereas the application of turbulent flow equations is demanded for less developed karst systems.

For large-scale pumping tests in karst aquifers, such effects superpose both temporally and spatially, which must be considered for the interpretation of drawdown curves. Therefore, a holistic approach is needed that can detect the influences of heterogeneity on the drawdown behavior. The starting point for this analysis is a large-scale pumping test at the Cent Fonts catchment (Languedoc, France). The measured drawdown curve shows that flow regimes 
during water abstraction in karst aquifers differ from the idealized solutions. The application of the flow dimension concept is an advanced analysis tool without further research demand. The effects of different boundary conditions on the propagation of the cone of depression and thus on the shape of the drawdown curve can be investigated for idealized catchments by applying the flow dimension approach. The results show that the flow behavior during the pumping test is strongly influenced by a radial flow component and is not dominated by a high permeability conduit as previously assumed. 


\section{Kurzfassung}

Karstgrundwasserleiter zählen neben alluvialen Grundwasserleitern zu den wichtigsten Grundwasserressourcen. Neben dem hohen Nutzen von Karstquellen bergen diese jedoch auch Risiken für den Nutzer oder Anrainer. Die hochdurchlässigen Strukturen innerhalb des geringdurchlässigen Festgesteinskörpers, welche die Folge von chemischen Lösungsprozessen sind, führen u.a. dazu, dass (Schad-)Stoffe sehr schnell und in hoher Konzentration zu den Quellen transportiert werden können. Zusätzlich zur hohen Anfälligkeit in Bezug auf die Wasserqualität geht von Karstquellen auch ein hohes Schadenspotential durch sturzflutartige Überschwemmungen im abstromigen Bereich aus.

Die Charakterisierung von Karstaquiferen basiert zumeist auf der Auswertung von Karstquellabflüssen als integrales Signal des gesamten Einzugsgebietes. Die räumliche Verteilung von karstspezifischer Heterogenität und damit auch deren Wechselwirkungen werden dabei ausgeklammert. Ein weiterer Nachteil bei der Verwendung von Quellabflüssen ist das zumeist unbekannte Eingangssignal in das System. Durch die Anwendung von Großpumpversuchen im Karst, d.h. durch die intensive und langzeitliche Wasserentnahme aus dem Röhrensystem, kann ein durch die Pumprate klar definiertes Eingangssignal in das System eingebracht werden.

Das Ziel der vorliegenden Arbeit ist die systematische Analyse von Pumpversuchen im Hinblick auf die Heterogenität und hydraulischen Eigenschaften für die Vielzahl an verschiedenen konzeptuellen Karstsystemen. Der Fokus liegt dabei auf den Veränderungen der lokalen und regionalen Strömungsregime, hervorgerufen durch die unterschiedlichen hydraulischen Eigenschaften auf verschiedenen Skalen des karstifizierten Einzugsgebietes, diskreten und diffusen Randbedingungen sowie den Wechselwirkungen zwischen dem Röhrensystem und der Festgesteinsmatrix. Dafür wird ein diskretes Röhren-KontinuumModell angewendet, welches entsprechend dem Verwendungszweck angepasst wurde. Die Analyse gliedert sich in mehrere Abschnitte, welche unterschiedliche Phasen und Prozesse eines Pumpversuches fokussieren.

Der erste Abschnitt eines Pumpversuches ist dominiert von inneren Randbedingungen, die durch schnell reagierende Speicher und den Wechselwirkungen mit der gering durchlässigen Umgebung hervorgerufen werden. Zwei Modellparameter werden in zwei, in der klassischen Pumpversuchsauswertung verwendeten, dimensionslose Parameter umgerechnet, um das Absenkungsverhalten einer analytischen Lösung zu approximieren. Durch die mit der analytischen Lösung verbundene, konzeptionelle Prozessbeschreibung, lassen sich die zwei dimensionslosen Parameter nutzen, um ein Charakterisierungsschema für die gesättigte Zone eines Karstgrundwasserleiters aufzustellen. Durch die Verbindung von Modellparametern mit konzeptionellen Modellen lässt sich ein weiteres konzeptionelles Karstmodell definieren, bei dem der Austausch zwischen Röhrensystem und gleichmäßig stark verkarsteter Matrix durch die hydraulischen Eigenschaften der Grenzfläche und deren Auswirkungen eingeschränkt wird.

In der zeitlichen Abfolge nach der Phase, die durch die Wechselwirkungen an der Grenzfläche bestimmt wird, folgt die durch die Röhrenströmung dominierte Fließphase. In Fachbüchern und Publikationen wird zwischen laminarer und turbulenter Röhrenströmung unterschieden. Generell fehlen für Karströhren Informationen über die Beschaffenheit der Röhren, wie zum Beispiel der Durchmesser oder die Rauigkeit der Röhre, welche für die Bestimmung des Strömungszustandes benötigt werden. Bei der Anwendung von Pumpversuchen mit einer definierten Pumprate bleiben diese röhrenspezifischen Parameter als Restglieder übrig. Dadurch lassen sich quantitative Unterschiede zwischen laminarer und turbulenter Strömung, in Form von Druckverlusten entlang der Strömungsrichtung, berechnen. Diese Druckverluste haben sowohl Einfluss auf das Fließverhalten in der Röhre 
als auch auf das Verhalten auf regionaler Skala. Die Ergebnisse der Analyse zeigen, dass die Fehler bei der Verwendung von laminaren Röhrenströmungen in stark verkarsteten Einzugsgebieten sehr gering sind, während für schwach verkarstete Einzugsgebiete die Verwendung von turbulenten Strömungsgleichungen erforderlich ist.

Bei Großpumpversuchen im Karst überschneiden sich solche Effekte sowohl zeitlich als auch räumlich, was bei der Interpretation der Absenkkurve berücksichtigt werden muss. Daher wird ein ganzheitlicher Ansatz benötigt, welcher die Einflüsse von Heterogenität auf das Absenkverhalten darstellen kann. Ausgangspunkt für diese Analyse ist ein Großpumpversuch im Gebiet der Cent Fonts Quelle (Languedoc, Frankreich). Die gemessene Absenkkurve dieses Pumpversuches zeigt, dass Strömungsregime im Karst von den idealisierten Lösungen abweichen. Die Anwendung des Flow Dimension-Ansatzes stellt eine erweiterte Auswertungsmethodik dar, für die keine zusätzlichen Informationen benötigt werden. Durch die Verwendung des Flow Dimension-Ansatzes auf idealisierte Einzugsgebiete werden die Auswirkungen von verschiedenen Randbedingungen auf die räumliche Ausbreitung des Absenktrichters und damit auf die Form der Absenkkurve untersucht. Die Ergebnisse werden genutzt um den Pumpversuch im Cent Fonts Einzugsgebiet hydraulisch zu interpretieren Die Ergebnisse zeigen, dass das Fließverhalten während des Pumpversuches stark durch radiale Strömung beeinflusst wird und nicht wie bisher angenommen durch eine durchgehende Röhre mit großer Durchlässigkeit dominiert wird. 


\section{Acknowledgement}

Even if a thesis is ultimately the result of (a period of suffering of) an individual, such work cannot be developed without the support of others. Help and support can be found in many ways, even those that are difficult to put into words. Therefore, I would like to thank everyone who supported me, whether scientifically at one of the conferences, or simply emotionally during a random chat. However, the following text is dedicated to those people whom I would like to explicitly thank for their support during my $\mathrm{PhD}$.

First and foremost, I would like to thank Martin Sauter and Tobias Geyer, who gave me the chance to start my $\mathrm{PhD}$ and then, with a lot of patience and ongoing funding (thanks to the Deutsche Forschungsgemeinschaft), ensured that this project could be successfully completed. I also thank both of them for supervising my $\mathrm{PhD}$ thesis. Furthermore, I would like to thank Rudolph Liedl for his role as an advisor, the careful proofreading, and his willingness to act as a second reviewer. I would also like to thank the members of the board of examiners: Sebastian Bauer, Thomas Ptak and Jean-Christophe Maréchal.

Special thanks to Thomas Reimann for his professional and mental support during the whole period of my $\mathrm{PhD}$ thesis. I thank him for all of the time he spared discussing different topics of my $\mathrm{PhD}$ thesis and the scientific community in general.

I would like to thank Jean-Christophe Maréchal, not for only being my supervisor and part of the board of examiners, but in his function as head of the directorate D3E/NRE at BRGM Montpellier. In this context, I also thank the BRGM, in particular Natalie Dörfliger, for the partial financial support of my thesis. In addition, I would like to express my thanks to all employees at the BRGM Montpellier for a memorable time with all of you. Although I do not really want to emphasize anyone by name, I would particularly like to thank Dominique Garcia for her support in the administrative tasks, as well as Vincent BaillyComte and Benoit Dewandel for their professional support during my time at the BRGM Montpellier.

To the same extent, I thank all members of the department of Applied Geology at the University of Göttingen for a pleasant time and various kinds of support. In addition to Beka Peters-Kewitz, who helped me a lot in the handling of bureaucratic tasks, I would especially like to thank Steffen Fischer, Jannes Kordilla, Sebastian Schmidt, and my longtime office colleague Sandra Oehlmann for their support at work and to a great extent for their distraction from work.

Further thanks to all members of the SMART-MOVE project for an interesting and informative time in Israel and Palestine. Additional to the already mentioned "SMARTIES", I thank Fabian Ries, Anwar Zuhluf and Mohammed Khalaf for plenty of memorable hours of fieldwork.

I would also like to thank Erika Myers for her support at the end of my $\mathrm{PhD}$ period.

My family and friends in Göttingen (especially: Marten and Neda), Montpellier (especially: Beatriz, Carmen, Eneritz and Fadellah) and elsewhere in the world, I would like to thank for supporting me and certainly somehow for putting up with me. 


\section{Table of Contents}

1 Introduction ................................................... 1

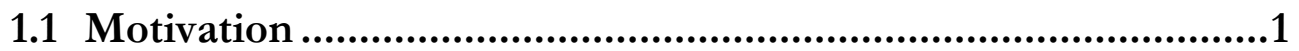

1.2 Karst aquifer systems .................................................. 2

1.3 Characterization methods of karst aquifer systems ................. 5

1.4 Interpretation of pumping tests in fractured rock aquifers .....10

1.5 Distributive numerical modeling approaches .......................12

1.6 Format of the thesis ..........................................................15

2 Discrete conduit-continuum model ........................... 26

2.1 Previous related work .....................................................26

2.2 Representation of water abstraction from a karst conduit with numerical discrete conduit-continuum models ......................28

3 Classical pumping test analysis using discrete conduit-continuum models - an approximation of inner boundary conditions for horizontal wellbores/fractures ...................................................... 36

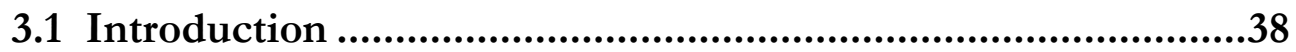

3.2 Discrete continuum model ..............................................41

3.3 Application of CFPM1 for traditional pumping test analysis ..42

3.4 Parameter transformation ...............................................44

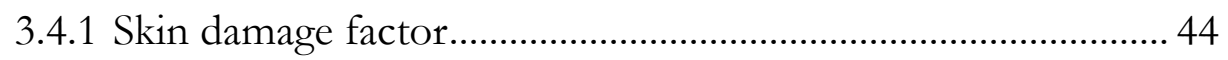

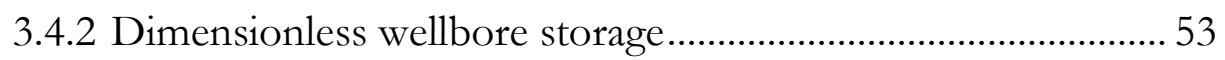

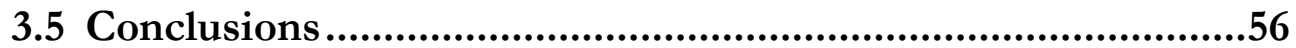

4 Turbulent and laminar flow in karst conduits under unsteady flow conditions - interpretation pumping tests by discrete conduit-continuum modeling.......... 62 


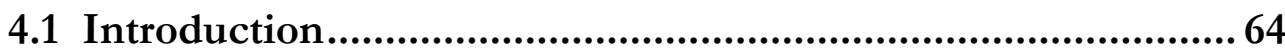

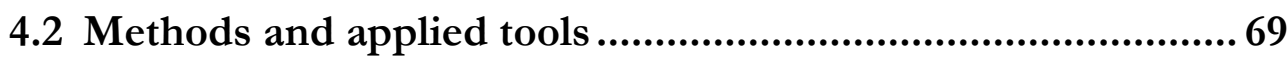

4.2.1 Numerical solution - discrete conduit-continuum model

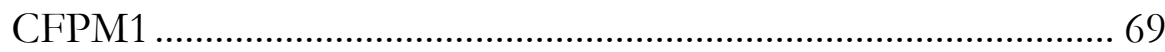

4.2.2 Idealized pumping test analyses .................................................... 71

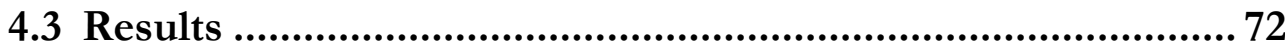

4.3.1 Analytical head loss differences .................................................... 73

4.3.2 Numerical flow pattern differences.............................................. 75

4.3.2.1 Influence on conduit flow pattern - conduit diameter............... 76

4.3.2.2 Influence on conduit flow pattern - mean roughness height....... 78

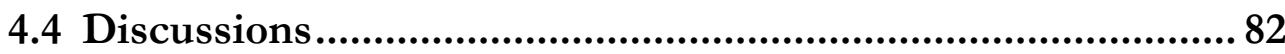

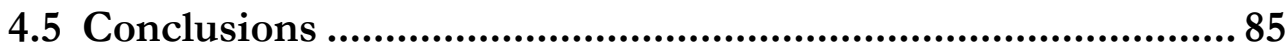

5 Scale-dependent hydraulic characterization by largescale pumping tests for idealized mature karst aquifers applying discrete conduit-continuum models

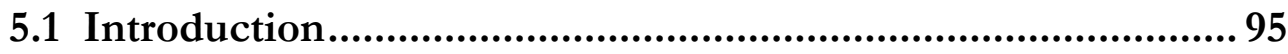

5.2 Analytical two media interaction .............................................98

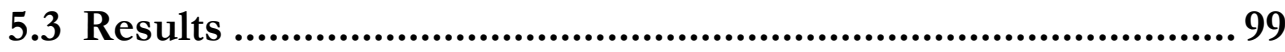

5.3.1 Interpretation of numerical model parameter............................ 99

5.3.2 Results of the reference scenario ................................................ 101

5.3.3 Effects of dimensionless wellbore storage variation............... 103

5.3.4 Effects of skin damage factor variation........................................ 105

5.4 Hydraulic interface properties of mixed-flow karst systems..107

5.5 Conclusions and Discussion .................................................... 111

6 Application of the flow dimension concept for numerical drawdown data analyses in mixed karst systems. 


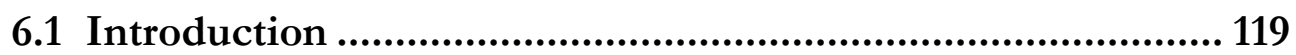

6.2 Methods for pumping test analysis in karst systems ........... 121

6.2.1 Traditional pumping test analyses............................................ 121

6.2.1.1 Diagnostic plots............................................................... 121

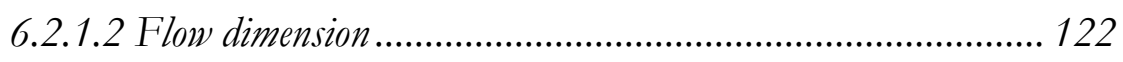

6.2.2 Numerical discrete-conduit continuum model ....................... 125

6.3 Effects of karst heterogeneities on the apparent flow dimension...................................................................... 127

6.3.1 Effects of conduit length on catchment scale ......................... 128

6.3.2 Effects of fixed head BC and areal boundary conditions...... 131

6.4 Case study - Cent Fonts (Languedoc, France) ..................... 135

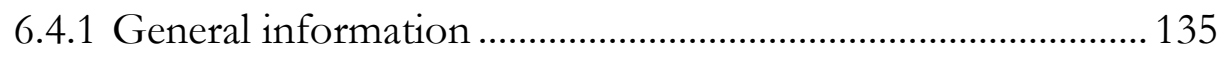

6.4.2 Conceptual and numerical representation of the Cent Fonts

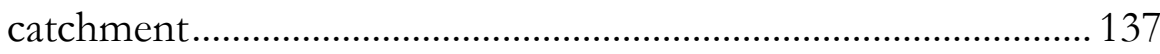

6.4.3 Inverse calibration results of the Cent Fonts pumping tests 140

6.4 Discussion and Conclusions............................................. 143

7 General conclusions and outlook ......................... 151

7.1 General conclusions ....................................................... 151

7.2 Conclusions for the Cent Fonts pumping test ..................... 154

7.3 Future research perspective.............................................. 155

7.3.1 Interpretation of the large-scale pumping test at the Cent Fonts

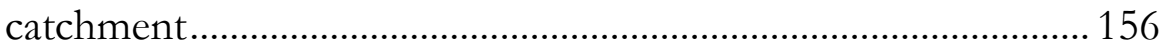

7.3.2 Karst characterization based on recharge signals ................... 156

7.2.3 Application of CFPM1 to horizontal wellbore hydraulics .... 157 


\section{List of Figures}

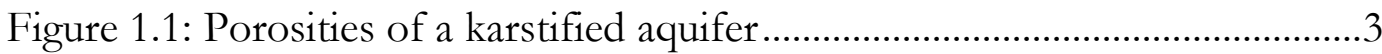

Figure 1.2: Scale dependence of the hydraulic conductivity ................................6

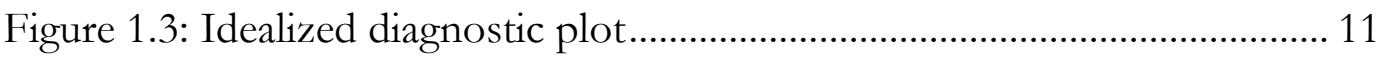

Figure 1.4: Distibutive modeling approaches for karst aquifer systems ........... 14

Figure 2.1: Conceptual similarities of the double porosity model and the

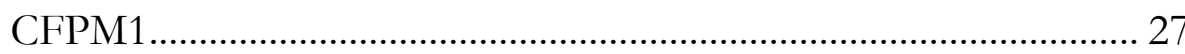

Figure 2.2: Sketch of the applied model set-up. ................................................. 29

Figure 2.3: Simulation results of the basic model................................................ 30

Figure 2.4: Conceptual representation of the CAD-storage............................. 31

Figure 3.1: Plan view of a conceptual infinite-conductivity vertical fracture with fluid loss damage ..................................................................... 40

Figure 3.2: Comparison of the analytical and the numerical drawdown behavior without the consideration of wellbore storage. ............... 46

Figure 3.3: Comparison of the analytical and the numerical drawdown behavior for different skin damage values without the consideration of wellbore storage. ..................................................... 51

Figure 3.4: Calibration curve for the exchange coefficient related to the halfpipe length ....................................................................................... 52

Figure 3.5: Representation of dimensionless wellbore storage .......................... 55

Figure 4.1: Influence of different conduit characteristics on the conduit flow

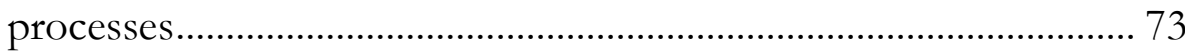

Figure 4.2: Influence of different conduit diameters on the conduit flow

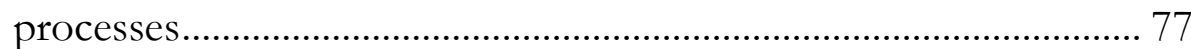

Figure 4.3: Influence of roughness height on the conduit flow processes ...... 79

Figure 4.4: Matrix head distirbution during large-scale constant groundwater

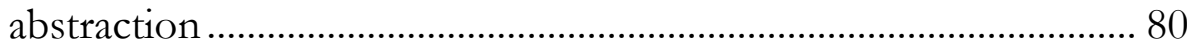

Figure 4.5: Head loss differences and friction factor ........................................ 83

Figure 5.1: Conceptual presentation of the CFPM1 interface by the double porosity approach............................................................................ 98

Figure 5.2: Log-Log plot as well as mass fluxes for the reference scenario... 102 Figure 5.3: Simulation results for dimensionless wellbore storage changes... 104 Figure 5.4: Simulation results for skin damage factor changes......................... 106 
Figure 5.5: Dimensionless type curves depending on the dimensionless wellbore storage and the skin damage factor.

Figure 5.6: Schematic representation of different degrees of local and regional karstification

Figure 6.1: Schematic representation of the drawdown derivative in a diagnostic plot.

Figure 6.2: Flow geometries for integral dimensions 124

Figure 6.3: Schematic representation of the numerical model domains 128

Figure 6.4: Flow dimension and drawdown behavior of different single conduit length

Figure 6.5: Flow dimension and drawdown behavior of different boundary conditions

Figure 6.6: Schematic sketch and geology of the Cent Fonts catchment....... 137

Figure 6.7: Conceptual representation of the large-scale pumping test scenario of the Cent Fonts catchment.

Figure 6.8: Simulation results for the Cent Fonts large-scale pumping test .. 140

Figure 6.9: Representation of the drawdown behavior for the simplified Cent

Fonts catchment 


\section{List of Tables}

Table 3.1: Parameter values for the terms of the exchange coefficient I........ 45

Table 3.2: Parameter values for the terms of the exchange coefficient II ...... 48

Table 3.3: Parameter values for the calculation of the dimensionless wellbore storage ............................................................................. 54

Table 7.1: Dominating parameters of the different periods during pumping

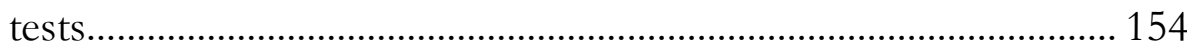




\section{Chapter 1}

\section{Introduction}

\subsection{Motivation}

The ancient Romans supplied the capital of their empire, Rome, with more than $13 \mathrm{~m}^{3} \mathrm{~s}^{-1}$ of fresh water, provided primarily by karstic springs (FIORILLO AND STEVANOVIC, 2015). Along the Mediterranean, especially in regions where permanent surface flow is limited in time and/or space, many settlements were founded around karstic springs that served as an exclusive source of fresh water (BAKALOWICZ, 2015). Today, springs emerging from karstified strata continue to supply millions of inhabitants with fresh water throughout the Mediterranean (FIORILlO AND STEVANOVIC, 2015). Not only the civil and economical water demand (over)exploit the scarce water resources of the region, but also mass tourism, which additionally increases the water demand and causes water stress, particularly during the dry summer seasons. One example of a Mediterranean region facing increased water management demand is located in the south of France. The available water amount of the karstic Lez spring already needs to be raised by additional resources to fulfil the water demand of the municipality Montpellier (KONG-A-SIOU ET AL., 2015). In view of the effects of climate change on the region, specifically a predicted decrease in precipitation up to $20 \%$ (IPCC, 2014), a precise evaluation of karstic springs became a fundamental necessity along the whole Mediterranean region (DÖRFLIGER ET AL., 2009).

Apart from the Mediterranean, karst aquifers are also an important fresh water source throughout the world. Carbonate outcrops cover roughly one third of the total area of France and the springs emerging from karstified outcrops account for $25 \%$ of the total French water supply (COST, 1995) from HARTMANN ET AL., 2014). This figure is slightly above the global average of 10$15 \%$ carbonate outcrop of the world's continental surface that supplying roughly $20-25 \%$ of the world's population with drinking water (FORD AND WiLLIAMS, 2007). Together with alluvial formations, karst aquifers can be 


\section{Chapter 1}

defined as the most efficient fresh water source (BAKALOWICZ, 2005), feeding large coastal and subsurface springs in the Mediterranean (BAKALOWICZ, 2015).

Due to the specific characteristics of karst aquifer systems, such as a strong contrast in hydraulic properties and partially limited soil coverage, karst aquifers in the Mediterranean region are not only vulnerable to climate change, but also to contamination and salt water intrusion as a direct consequence of overexploitation of coastal aquifers in present age. Besides these problems concerning the water quality, karst aquifers can also cause problems and even hazards for human life when intensive precipitation events induce flash floods, as reported by MARÉCHAL ET AL. (2008A).

Therefore, the characterization of karst aquifer systems is mandatory for the establishment of water management frameworks as well as for prediction purposes. Traditional aquifer characterization techniques, used for porous media, are based on single continuum approaches and provide estimates of hydraulic parameters and groundwater catchment boundaries. The characteristic dual flow system of karst systems (KIRALY, 2002), including an extremely complex flow pattern, requires a differentiated characterization approach suitable to cover the scale of dominant aquifer heterogeneities (GEYER ET AL., 2013). Large scale aquifer stimulation with defined and controlled hydraulic signals (MARÉCHAL ET AL., 2008B) results in a unique system response that can be used for scale continuous aquifer characterization. Analytical solutions, which are frequently used for the interpretation of pumping experiments, are normally based on assumptions that have limited validity when applied to karst aquifer systems. The assumption of laminar flow restricts the applicability of these solutions to karstic aquifers due to the limitations of Darcy's law in quantifying turbulent flow conditions, e.g. the underestimation of the hydraulic gradient within highly permeable fractures and conduits (REIMANN ET AL., 2011).

\subsection{Karst aquifer systems}

Karstification is the description of dissolution processes of soluble (carbonate) rocks by water with low bicarbonate hardness based on chemical processes (Worthington ET AL., 2000; BAKALOWICZ, 2005). Due to the dissolution 


\section{Introduction}

processes, the primary porosity (Fig. 1.1), defined for karstified aquifers as intergranular porosity of the unfractured bedrock (WHITE, 2002), can be enlarged along preferential flow paths driven by (1) the potential hydraulic gradient and (2) the carbonate solution capacity (BAKALOWICZ, 2015). Therefore, and in contrast to porous aquifers, karst aquifers conceptually need to be described as dual or triple porosity systems. The bedrock of karst aquifers is normally pervaded by a secondary porosity (Fig. 1.1) consisting of mechanical joints, bedding planes, karstic voids, and enlarged fractures (QUINLAN AND EWERS, 1985; WHITE, 2002). In the case of mature karst aquifers, a tertiary porosity (Fig. 1.1), resulting from solution enlarged flow features, e.g. pipe-like openings (conduits), commonly develops. The separation between the secondary and the tertiary porosity is not exactly defined. However, frequently used definitions state a void space of considerable size, starting at $1 \mathrm{~cm}$ (WHITE, 1988), which marks the onset of the tertiary porosity.
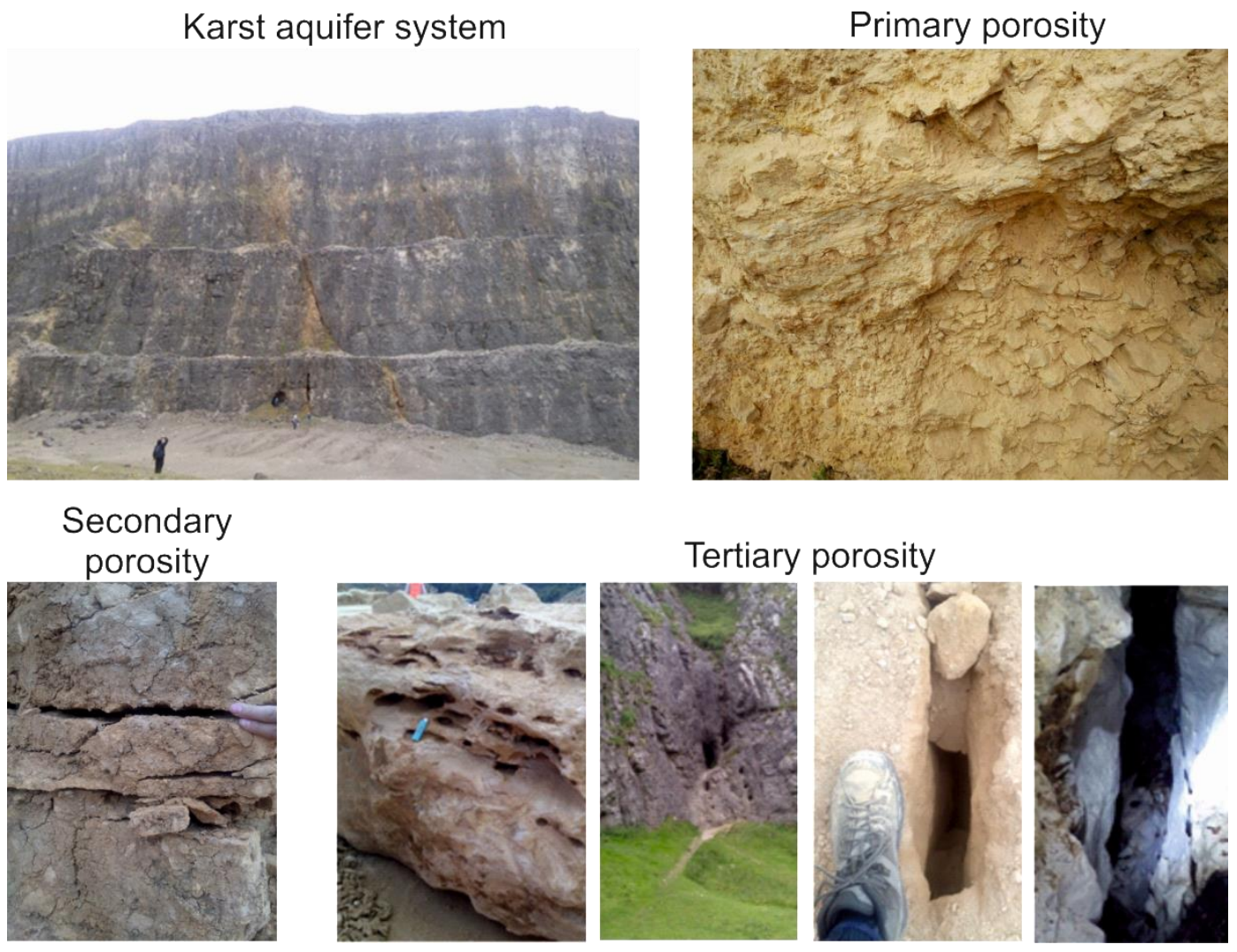

Fig. 1.1: Porosities of a karstified aquifer, pictures from different places in England and Palestine.

In karstic aquifer systems, the porosity generally correlates positively with the hydraulic conductivity so that the above classification can also be directly 


\section{Chapter 1}

applied to the permeability of karst aquifers (WHITE, 2002). Differences in hydraulic properties commonly influence the water movement, resulting in a duality of surface and subsurface flow and transport processes, especially in mature karst systems (KIRALY, 1995, KIRALY, 2002):

\section{Duality of infiltration processes}

According to AQUILINA ET AL. (2005), up to four different recharge processes can be determined from spring water analyses. Two fast processes can be explained by concentrated infiltration directly into the highly permeable features, or by flushing temporarily stored water out of the epikarst (highly permeable shallow part of karst systems) through vertical fractures/voids connected to the highly permeable features. Besides the rapid infiltration, diffuse infiltration of temporarily stored epikarst water or the diffuse percolation from the surface through the vadose zone occurs in karst aquifer systems. The dynamics of recharge highly influence the processes during high-flow conditions (BAILLY-COMTE ET AL., 2010). Furthermore, on long timescales, the recharge processes strongly influence the development of karst aquifers (e.g. PALMER, 1991; LIEDL ET AL., 2003).

\section{Duality of the groundwater flow field}

The primary porosity typically provides the majority of storage within karst aquifer systems, despite its comparably low permeability. In contrast, due to their high permeability, karst conduits commonly drain the (fissured/fractured) matrix. However, because of the small share in the total aquifer porosity, their storage is normally considered to be insignificant. As a consequence of the strong contrast in permeability, the flow patterns and hydrodynamics in both systems are entirely different. Flow within the (fractured) matrix is considered to be laminar with low velocity, assuming small fracture apertures as well as low hydraulic gradients (MANGIN, 1975). Flow inside the conduit is generally assumed to be turbulent with high velocity, constrained by the hydraulic properties 
of the conduit (e.g. roughness, tortuosity), the flow velocity and the hydraulic gradient along the conduit (WHITE, 1969).

\section{Duality of the discharge conditions}

In mature karst aquifers, the karstic springs are generally fed by concentrated discharge of solution enlarged features, such as conduits. This flow type can be divided into free surface flow and fully filled pipe flow (WHITE, 1969). The concentrated discharge, normally a fast flow component, interacts with the diffuse discharge of the matrix, which provides the base flow (ATKINSON, 1977). The proportion of the two components on spring discharge is difficult to derive and can vary widely between different karst systems (White, 1969; ATKINSON, 1977).

\subsection{Characterization methods of karst aquifer systems}

Depending on the geological history and degree of karstification, karst aquifer systems show a wide range of hydraulic properties at catchment scale (BAKALOWICZ, 2005), leading to spatial variation of flow pattern and transport phenomena. Within karst systems, the hydraulic properties, particularly the permeability, are highly scale-dependent (SAUTER, 1992; KIRALY, 2002). Karst systems can be divided into different scales dominated by unique hydraulic properties (Fig. 1.2). The laboratory scale represents the bedrock with a characteristically high storage, but low permeability due to the missing connections between the granular voids spaces. On a local scale, the permeability of the rock volume is increased by the secondary porosity. Analyses of hydraulic borehole tests (e.g. pumping or slug test) reveal the double-porosity behavior in the vicinity of the bore well (WHITE, 2002; WORTHINGTON, 2009) and are able to detect flow dominating heterogeneities (SPITZBERG UND UFRECHT, 2014). Flow patterns on a regional scale are dominated by solution enlarged features although the area covered by those features is low at catchment scale (SAUTER, 1992; WORTHINGTON, 2009). The regional scale contains all relevant heterogenities and processes to describe flow and transport. Therefore, characterization approaches on a regional scale require input signals 


\section{Chapter 1}

that excite the whole system, and thus provide sufficient contrasts between the individual hydraulic components

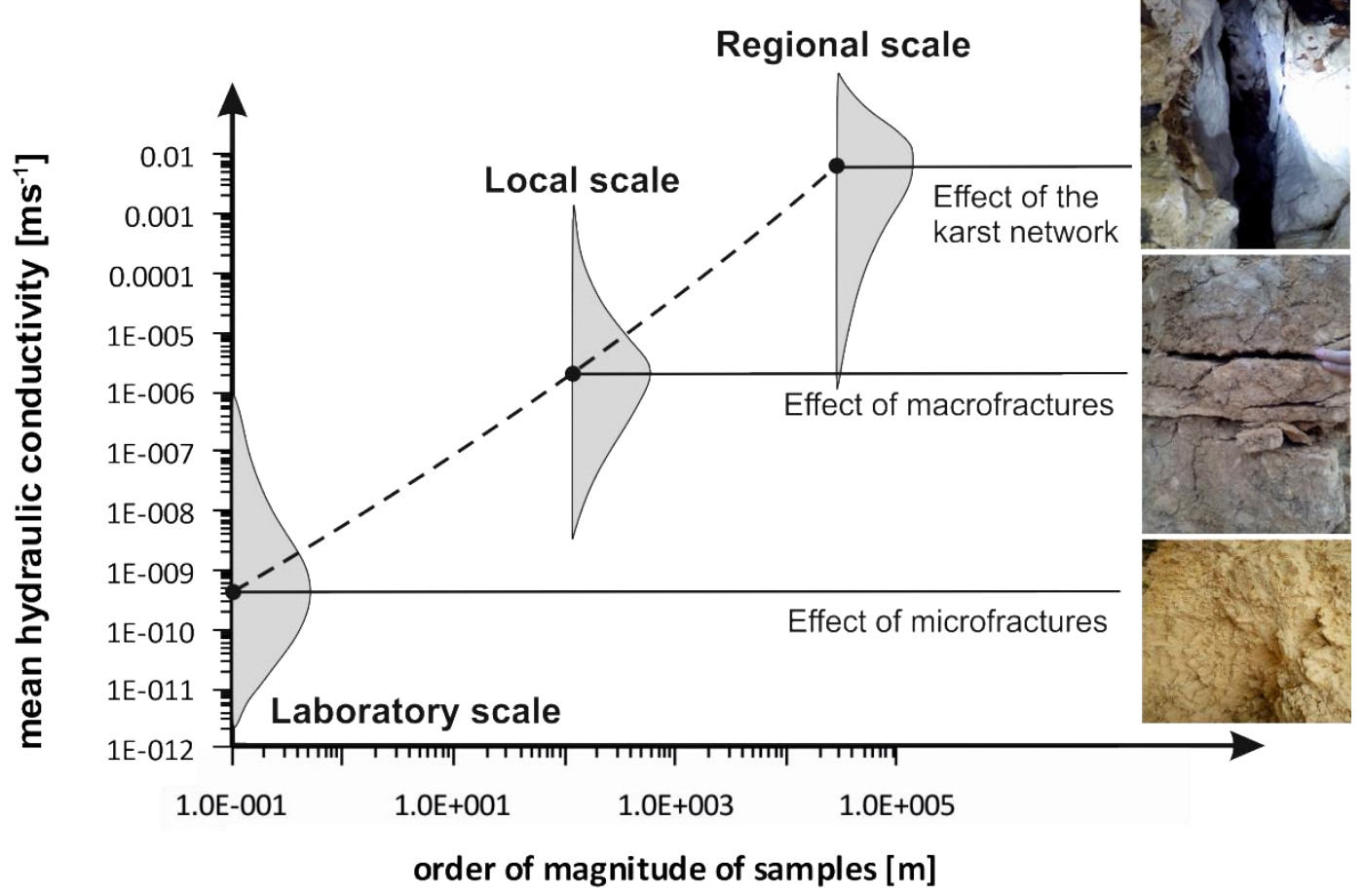

Fig. 1.2: Scale dependence of the hydraulic conductivity (after SAUTER, 1992; KIRALY, 2002).

According to QUINLAN AND EWERS (1985), karst aquifers can be divided into three different categories based on the degree of karstification, resulting in different hydraulic characteristics on a local and regional scale. Less developed karst systems, without well-developed tertiary porosity, are characterized by dominant water storage and flow inside the fissured matrix (diffuse flow karst systems - DFKS). Consequently, the permeability of the aquifer is relatively low and flow towards the spring is mainly laminar (QUINLAN AND EWERS, 1985). On the contrary, conduit flow karst systems (CFKS) are characterized by a welldeveloped tertiary porosity, corresponding to mature karst systems. Flow is mainly localized in conduits, and hence, under normal conditions in terms of hydraulic gradients, predominantly behaves turbulent (QUINLAN AND EWERS, 1985; WHITE, 2002). Storage is directly linked to solution-enlarged features, such as large fractures or caves. Due to the presence of a well-developed conduit system, no 'representative elementary volume' (REV) can be obtained (KIRALY, 2002), i.e. hydraulic parameter estimations as a result of laboratory and local scale experiments cannot be applied to regional scale. Between these two end 
members, a wide spectrum of mixed flow karst systems (MFKS) exists. Flow and storativity occurs in both conduits and matrix, and these systems interact through direct linkage (QUINLAN AND EWERS, 1985). In general, MFKSs can be characterized by a wide range of hydraulic properties and flow regimes resulting in superposition of turbulent flow inside the tertiary porosity as well as (diffuse) Darcy flow in the primary and secondary porosity.

For the collection of MFKSs, literature provides further descriptions of the hydraulic properties based on analysis and interpretation of field data. DROGUE (1992) proposed a conceptual model of karst systems, named 'double-fissured porosity approach', in which the fissured matrix provides the total storage of the karst aquifer. A localized, highly-permeable tertiary porosity with negligible direct storage drains fissured matrix blocks with low permeability. In contrast to Drogue (1992), MANGIN (1975) introduced the 'annex-to-drain system' concept. Here, the total system is conduit dominated and a large storage is provided by the secondary and tertiary porosity and tertiary, which is directly connected to the conduit, but with restricted flow.

MANGIN (1975) also introduced a classification scheme to characterize five different karstification degrees of spring catchments. The scheme uses two parameters based on the analysis of spring responses. The first parameter is defined as the ratio of dynamic water volume to the total water volume discharged within one year. The dynamic water characterizes the phreatic zone and provides the total volume of discharge water after the end of the infiltration process. The second parameter accounts for the delay of infiltration defined by the homographic function (infiltration recession curve). Spring responses with low values of both parameters can be related to karstic springs with a welldeveloped conduit network and fast infiltration. Although the classification is still used in France (JEANNIN AND SAUTER, 1998), different publications point out the drawback of the analysis (e.g GRASSO AND JEANNIN, 1994; JEANNIN AND SAUTER, 1998; FORD AND WILLIAMS, 2007). According to JEANNIN AND SAUTER (1998), the infiltration parameter is mainly influenced by the catchment size. Therefore, it cannot only be related to the infiltration processes through the vadose zone. In addition, the ratio of dynamic water volume to the total water volume discharged within one year depends on the recharge type (GRASSO AND JEANNIN, 1994), which is, together with the dependence on previous precipitation events, also a drawback of several other approaches based on the 


\section{Chapter 1}

analyses of spring responses, e.g. hyperbolic functions and cross correlations (JEANNIN AND SAUTER, 1998).

Many researchers use the spring hydrograph analysis to characterize karst systems at a regional (catchment) scale. These analyses reveal integral information about geometrical and physical properties (e.g. ASHTON, 1966), which can be used to build lumped parameter models (e.g. GEYER ET AL., 2008; BAILLY-COMTE ET AL., 2010; SCHMIDT ET AL., 2014). These models are able to represent the 'global signal', with an unknown temporal and spatial distribution of the signal source (WHITE, 2002; GEYER ET AL., 2013), but are not able to represent the flow on different scales to reliably represent fluid or heat transport (KOVACS AND SAUTER, 2007). In general, the recharge process is the primary boundary condition for karst aquifer responses on a regional scale (BAKALOWICZ, 2005). The hydrograph of karstic springs highly depends on the recharge pattern, especially the distribution of direct and diffuse recharge (WHITE, 2002; BIRK ET AL., 2006).

Another frequently applied characterization technique is the measurement of artificial or natural tracers at catchment outlets. A broader overview about the topic is provided by several authors, e.g. FORD AND WILLIAMS (2007); GOLDSCHEIDER ET AL. (2008); HARTMANN ET AL. (2014). In general, two different groups of tracers can be used for catchment characterization. The application of conservative artificial tracers, which are measured in timely highresolution, yields information about geometric and hydraulic properties (e.g. BIRK ET AL., 2005; GEYER ET AL., 2008; GOLDSCHEIDER ET AL., 2008; LUHMANN ET AL., 2012) and can be used for the delineation of spring catchments (e.g. ATKINSON, 1977). Thereby, information such as the mean flow velocity can be derived for the direct flow path between the injection point of the tracer material and the measurement point. Multitracer tests at the same injection point can be used for the estimation of geometric conduit parameters (e.g. GEYER ET AL., 2007). For the analyses of different flow paths during a certain flow state, multiple tracers can be injected at different points (e.g. MARÉCHAL ET AL., 2010). Apart from artificial tracers, natural tracers, radioactive or stable environmental isotopes are also used for the characterization of groundwater catchments (e.g. MALOSZEWSKI ET AL., 2002; ANDREO ET AL., 2004). Natural tracers give information about physical properties, e.g. a rough estimation of the catchment size, residence time of the 
groundwater or the recharge area. Over a short period the detection variability of natural tracers is insignificant and the residence time is high compared to artificial tracers. Therefore, the general assumption is a diffuse input over the whole groundwater catchment. Apart from isotopes, the physical properties of spring water, especially temperature or electrical conductivity, can be used for general catchment characterization (e.g. ASHTON, 1966, SAUTER 1992). LUHMANN ET AL. (2012) proved that a combination of artificial and natural tracers reduces the ambiguity of flow system characterization.

Traditional hydrogeological techniques, e.g. small-scale hydraulic borehole tests, are used to characterize the hydraulic parameters on 'local-scale'. Due to small investigation radii of traditional hydrogeological techniques (e.g. small scale hydraulic borehole tests) and the scale dependent phenomena (e.g. borehole storage, hydraulic bypass effects) these approaches often fail to characterize the system heterogeneity at a catchment scale (BAKALOWICZ, 2005; GEYER ET AL., 2013). In case of a direct connection between the pumping well and highly permeable features (e.g. fissure, fracture, conduit), the test is able to obtain information about the hydraulic properties of different karstic features stimulated by the hydraulic trigger. With short-lasting tests the response only reveals information about the highly permeable features, whereas long-lasting tests reflect the response of the system on a catchment scale (TEUTSCH AND SAUTER, 1991).

The review of different characterization techniques and approaches reveals that all the methods are facing the same problems. The major difficulty with large-scale characterization of karst aquifer systems is the lack of information about the input function (precipitation), which strongly influences the spring hydrograph. Another kind of input function, which is well-known and therefore suitable to overcome the information shortage of the mentioned characterization approaches, is the pumping rate of large-scale pumping tests. However, analyses of large-scale experiments with methods that consider the dual flow behavior of karst aquifers are rare. MARÉCHAL ET AL. (2008B) showed that water abstraction directly from the conduit system, with a defined pumping rate over a period of roughly one month, leads to high conduit drawdown. This also influences the hydraulic heads of the matrix. The analysis of the pumping test provides information about the hydraulic properties on the scale of the 


\section{Chapter 1}

conduit systems, which can be defined as flow dominating heterogeneity in the karst aquifer system.

\subsection{Interpretation of pumping tests in fractured rock aquifers}

Hydraulic borehole tests are frequently used and an essential tool for solving petroleum engineering or hydrogeological problems. A wide range of interpretation methods, especially for the characterization of fractured rock aquifers as potential groundwater resources and waste repositories, were developed (e.g. AgARWAL ET AL., 1970; GRINGARTEN, 1982; BOURDET, 2001). The analysis of pumping test data commonly relies on log-log plots of drawdown and additional drawdown derivative curves. The combination of these curves on log-scale allows the differentiation of at least three main periods during pumping (Fig. 1.4; e.g. SPANE AND WurSTNER, 1993; EHLIGECONOMIDES AND ECONOMIDES, 2000; BOURDET, 2001): (1) early time response, which is mainly influenced by the direct storage (well bore and/or conduit storage), (2) intermediate time response, which is influenced by the unrestricted reservoir flow (linear, radial and spherical flow) and (3) late time response, which is primarily influenced by reservoir boundary conditions. 


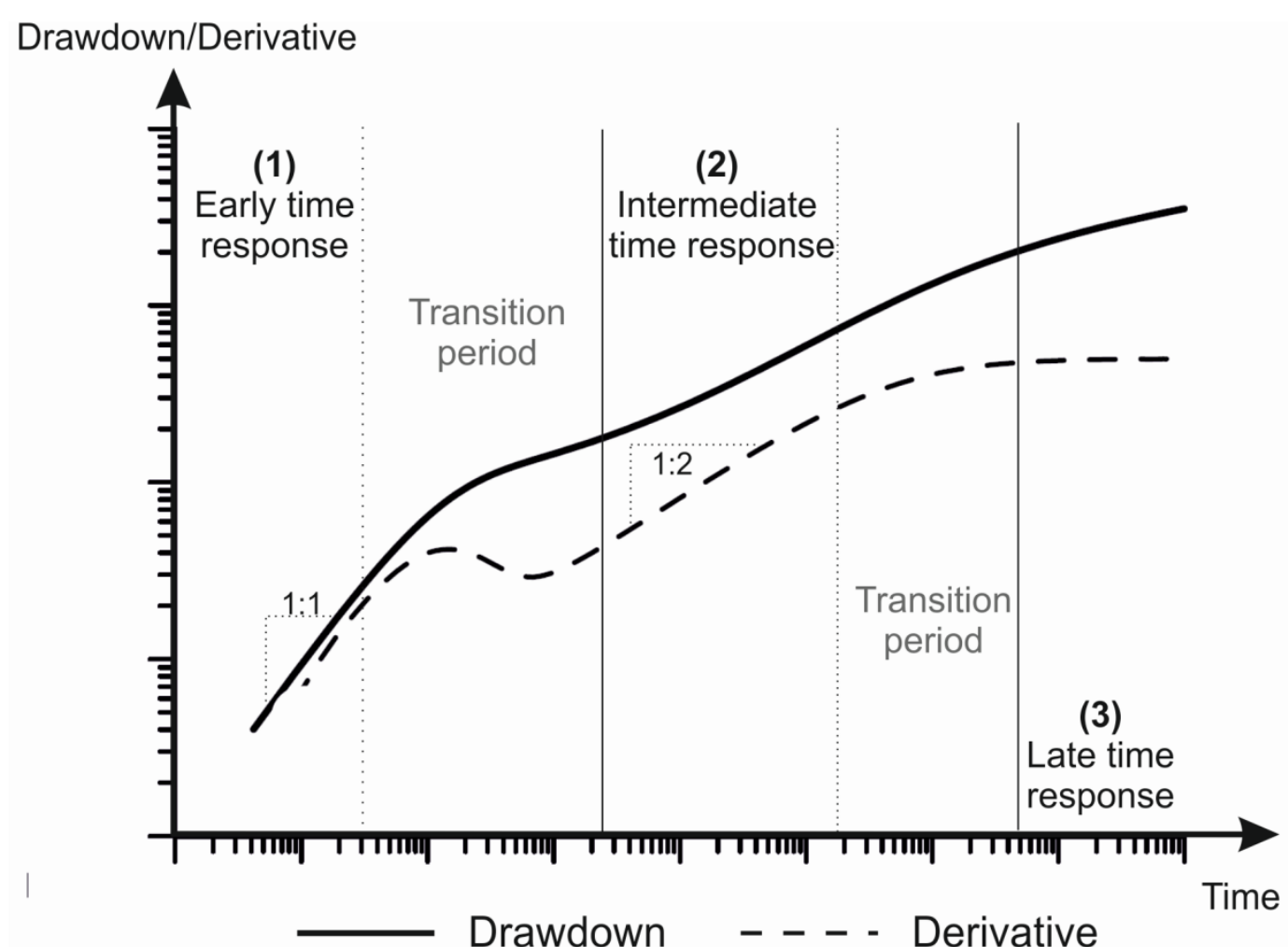

Fig. 1.3: Idealized diagnostic plot representing the main periods during large-scale pumping tests.

The drawdown curve of the diagnostic plot is the superposition of different flow regimes, normally described by analytical solutions (GRINGARTEN, 1982). Those analytical solutions can be divided into different groups, which can be linked to one of the three main periods. Inner boundary conditions (i.e. wellbore storage, skin effect) are used to describe the characteristic drawdown behavior during early times (storage period). Matrix contributions are negligible (BOURDET, 2001) and storage effects create a unit slope on log-log plots (e.g. EHLIG-ECONOMIDES AND ECONOMIDES, 2000). The storage period is followed by a transition period during which the two porous systems tend to establish an equilibrium condition of pressure (GRINGARTEN, 1987). Storage release slowly decreases and matrix contributions begin to dominate the drawdown behavior. The basic model describes the flow pattern during intermediate times. Normally, for fractured rock aquifers, the basic model is a single vertical fracture. The conductivity along the conduit can be infinite (e.g. GringarTEN ET AL., 1974) or finite (e.g. CinCO-LEY ET AL., 1978). The conduit conductivity has an influence on the drawdown curve. Drawdown and derivative curve for infinite conduit conductivity is defined as two linear parallel lines with half-slope, whereas finite conduit conductivity results in a quarter- 


\section{Chapter 1}

unit slope of the diagnostic plots (e.g. CINCO-LEY ET AL., 1978). Type curve methods commonly assume an idealized infinite catchment to calculate the matrix transmissivity. In case of an infinite aquifer system, the late time response is characterized by radial flow, which describes the linear increase of a Darcian flow area with increasing radius of the cone of depression (BARKER, 1988). The derivate during radial flow becomes constant (RENARD ET AL., 2009). Nevertheless, outer boundary conditions (Neumann-BC, Dirichlet-BC or Cauchy-BC) can be considered to influence the flow pattern on a large scale at the end of pumping (e.g. WALKER AND ROBERTS, 2003; BEAUHEIM ET AL., 2004).

As an additional tool to identify flow patterns on different scales, the flow dimension can be calculated as the second derivative of drawdown with respect to time. Under the assumption of constant hydraulic conductivity and storage, the flow dimension can be linked to the system geometry (BEAUHEIM ET AL., 2004). Under field conditions, the flow dimension describes the flow area change with distance to the wellbore, but does not necessarily represent the space filling nature of the flow (WALKER AND ROBERTS, 2003). Detailed information regarding the flow dimension concept and the application on several idealized catchments can be found in Chapter 6 .

\subsection{Distributive numerical modeling approaches}

The representation of dynamic groundwater flow fields on catchment scale nearly always requires the application of numerical modeling approaches (KIRALY, 2002; FORD AND WILLIAMS, 2007). Several approaches for the numerical representation of spatially distributed karst systems exist. An overview of different approaches is given by TEUTSCH AND SAUTER (1991). In the following, the different approaches will be briefly introduced according to Figure 1.4.

Single continuum models are the most simplified approaches concerning the parameter requirement and the numerical demand due to the representation of the whole aquifer as one continuum and thus a high level of abstraction (TEUTSCH AND SAUTER, 1991; REIMANN ET AL., 2011). This reduction of complexity has the advantage of a high adaptability along with a simplification 
of the processes and variability. Therefore, the single continuum approach can only be applied for large-scale models and less karstified aquifer systems (TEUTSCH AND SAUTER, 1991). In the case of mature karst systems, the conduitinfluenced regions can be simulated by highly conductive cells (smeared conduits) (WORTHINGTON, 2009; DOUMMAR ET AL, 2012). However, this approach is prone to underestimate the hydraulic conductivity due to the dimension differences of the cross section between model cells and conduit (WORTHINGTON, 2009). Normally, single continuum approaches do not consider turbulent flow. Recently, new modelling approaches, which consider non-linear continuum flow by the application of a power law with a flow exponent of two (REIMANN ET AL., 2011) or by the application of the Forchheimer Law (MAYAUD ET AL., 2016), were introduced to single continuum models.

Double continuum models fulfill the requirements of the karst specific dual flow behavior, i.e. they are able to preserve the strong hydraulic contrasts. The approach is based on the conceptual double-continuum model (e.g. BARENBLATT ET AL., 1960; WARREN AND ROOT, 1963). The model domain consists of two overlying continua in which one represents the fissured matrix and the second one the conduit systems. In every model cell the two continua are connected by a linear exchange coefficient (BARENBLATT ET AL., 1960). Laminar flow is accounted for in both continua, which reduces the application to mature karst systems (TEUTSCH AND SAUTER, 1991). Still, the approach can effectively handle karst systems with sparse information about aquifer geometry and exact conduit location. One of only a few case studies using the double continuum approach for a karst aquifer, also including the vadose zone, is presented by KORDILLA ET AL. (2012).

The discrete conduit/fracture approach represents discontinuities of the karst aquifer system by dimension reduction of the respective elements, i.e. onedimensional elements (conduit) or two-dimensional (fracture) planes. Normally, the distribution of fractures or conduits within an aquifer is unknown. However, in order to obtain sufficient accuracy of deterministic models, a high information density of geological structures is required (BODIN ET AL., 2012). Due to the scarcity of exact fracture/conduit location, fracture/conduit networks are also stochastically generated based on statistical field information (TEUTSCH AND SAUTER, 1991; KOVACS AND SAUTER, 2007). In the case of dual 


\section{Chapter 1}

porosity models, the fissured matrix permeability is assumed to be negligible (KOVACS AND SAUTER, 2007). Discrete conduit/fracture approaches have the strongest capability of the described approaches to simulate heterogeneities (Fig. 1.4). This can result in significant hydraulic head differences between discrete features and matrix continuum on small-scale, also known as compartmentalization phenomenon (KOVACS AND SAUTER, 2007). On the other hand, the high amount of discontinuities precludes the application of discrete conduit/fracture models on a catchment scale, if all involved length scales have to be explicitly represented (KIRALY, 1998).

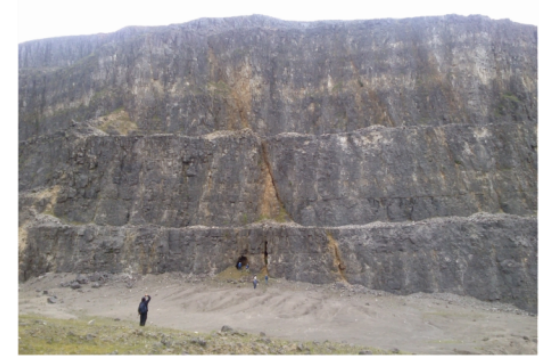

\section{Distributive modeling approaches}

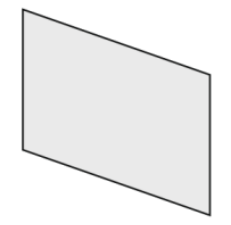

Single Continuum

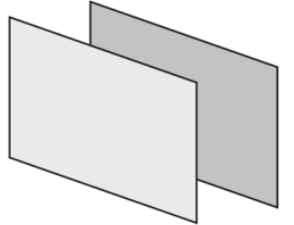

Double Continuum

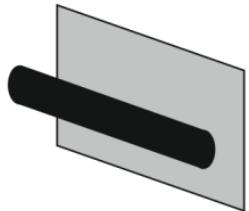

Discrete featurecontinuum model

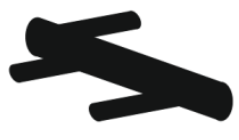

Discrete feature

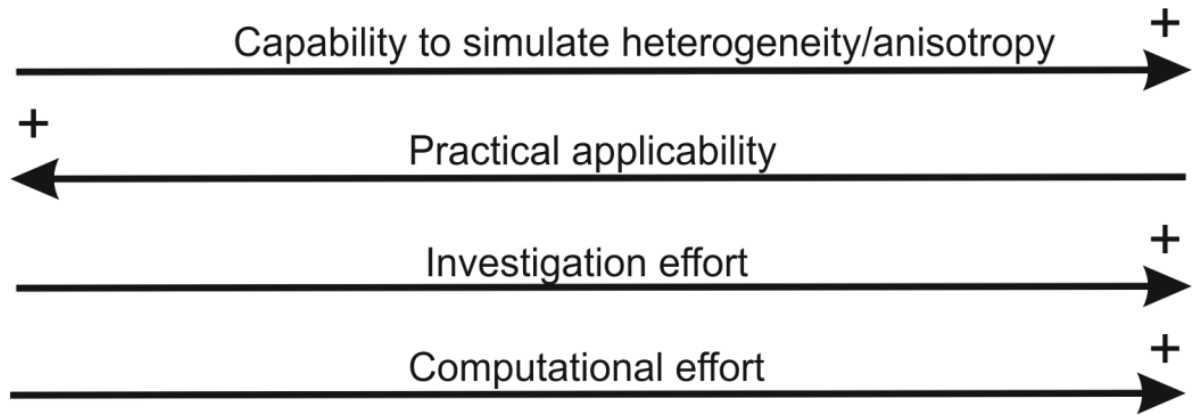

Fig. 1.4: Distributive modeling approaches for karst aquifer systems (modified after TEUTSCH AND SAUTER, 1991).

Discrete conduit-/fracture-/faults-continuum models (hybrid model) normally combine a matrix continuum with one-dimensional conduits and also 
allow the combination of additional two-dimensional features, e.g. fractures, faults. Therefore, they include all specific flow features on relevant scales of karst systems into one model approach (KOVACS AND SAUTER, 2007). Different flow equations can be applied to simulate flow within the one-dimensional conduits; hence it is also possible to consider turbulent flow, depending on the physical properties of the conduits and the flow stage (LIEDL ET AL., 2003). The application of discrete conduit-continuum models (DCC) on a catchment scale has a higher demand of data compared to the aforementioned approaches (Fig. 1.4). Information on the physical properties of the conduits and the exact location are usually not available (REIMANN ET AL., 2011). Therefore, DCC models were mainly used for modelling of karst aquifer genesis (e.g. CLEMENS, 1996; LIEDL ET AL., 2003). Recently, due to the increase of computational power and improved process understanding of karst aquifer systems and their components, several case studies of DCC models on catchment scale were published (e.g. DE ROOIJ ET AL., 2013; GALLEGOS ET AL., 2013; SALLER ET AL., 2013; OEHLMANN ET AL., 2015).

\subsection{Format of the thesis}

The characterization of karstic aquifer system faces different problems based on the duality and the resulting complexity of the systems. The application of largescale pumping tests with defined pumping rates is able to solve the problem of normally undefined input signals and therefore overcome one major drawback of karst characterization approaches. In conjunction with state-of-the-art numerical methods, the analyses of large-scale pumping tests can efficiently reduce some of the ambiguities associated with the interpretation of integral pumping tests and correlation with corresponding flow processes and/or geometric parameters of heterogeneities. Due to the defined hydraulic signal introduced by the abstraction rate, the input function as well as the resulting systems response, measured as drawdown of the pumping and/or observation wells are well known. During water abstraction from the highly permeable conduit system the drawdown signal propagates inside different karstic features and therefore represents the reaction of an integrative part of the karstified aquifer volume. As briefly described, it is possible to link the characteristic behavior of diagnostic plots and flow dimension to the hydraulic response of 


\section{Chapter 1}

such features. The numerical representation of karst aquifer systems by DCC models allows a systematic analysis of the effect of different heterogeneities on different flow scales.

The thesis aims at the application of the DCC model CFPM1 (Conduit Flow Process Mode 1 for MODFLOW 2005) on the diversity of conceptual karst models. Taking the abstraction test at the Cent Fonts catchment, a representative of mixed flow karst systems, as a starting point, the analysis is focused on the influences of different karst specific properties and the linkage to traditional pumping test evaluations. The work is structured in several chapters dealing with influences on the three main periods of pumping.

Chapter 2 is a brief overview about the development of discrete continuum models, general information and latest enhancements of the DCC model used for the thesis. Although the general function of the model is also described at the beginning of Chapter 3, and Chapter 4, the information is needed as an introduction of Chapter 5. More details about the latest enhancements of CFPM1 can also be found in

Reimann, T., Giese, M., Geyer, T., Liedl, R., Maréchal, J.-C. and Shoemaker, W. B. (2014): Representation of water abstraction from a karst conduit with numerical discrete-continuum models, Hydrol. Earth Syst. Sci., 18, 227-241, doi:10.5194/hess-18-227-2014.

Chapter 3 presents a comparison between the DCC model CFPM1 and an analytical solution that considers inner boundary conditions. The analytical solution is used to verify the approximation of dimensionless parameter with the numerical model. These parameters are used to describe effects on the drawdown curve related to pressure drops along the interface between highly conductive feature and the matrix (blocks) and directly linked storage at the beginning of pumping.

Chapter 4 focuses on the differences between laminar and turbulent conduit flow in karst systems. Those differences, detected during intermediate time, can change the flow behavior on different scales. Therefore, differences of conduit conductivity, which depend on the hydraulic properties of the conduits, can be measured inside the conduit as well in the matrix. 
Chapter 5 presents an idealized characterization tool for diagnostic drawdown plots based on the dimensionless parameter of Chapter 3. According to the results of Chapter 4, the characterization scheme is limited to matrix restrained karst systems. The characterization scheme is focused on the hydraulic properties influencing the exchange flow. Within the group of mature karst systems the scheme is able to add another conceptual representation of flow regimes in karst.

In Chapter 6, the flow dimension concept is applied to the large-scale abstraction test at the Cent Fonts catchment. In addition to an idealized representation of the catchment, which is focused on the influences of different boundary conditions on the extension of the cone of depression, the Cent Fonts pumping test is simulated. The diagnostic plots and the flow dimension of two different conceptual models are compared to each other and analyzed regarding the influences on the general flow pattern during abstraction.

The thesis is summarized by Chapter 7 with respect to the general conclusions. In addition, an outlook for future perspectives and research demands is given. 


\section{Chapter 1}

\section{References}

Agarwal, R. G., Al-Hussainy, R. and Ramey, H. J. (1970): An investigation of wellbore storage and skin effect in unsteady liquid flow: I. Analytical treatment, SPE J., 10-03, 279-290.

Andreo, B., Liñán, C., Carrasco, F., Jiménez de Cisneros, C., Caballero, F. and Mudry, J. (2004): Influence of rainfall quantity on the isotopic composition $\left({ }^{18} \mathrm{O}\right.$ and ${ }^{2} \mathrm{H}$ ) of water in mountainous areas. Application for groundwater research in the Yunquera-Nieves karst aquifers (S Spain), Applied Geochemistry, 19, 561574, doi:10.1016/j.apgeochem.2003.08.002.

Aquilina, L., Ladouche, B. and Dörfliger, N. (2005): Recharge processes in karstic systems investigated through the correlation of chemical and isotopic composition of rain and spring waters, Applied Geochemistry, 20 (12), 2189-2206, doi:10.1016/j.apgeochem.2005.07.011.

Ashton, K. (1966): The analysis of flow data from karst drainage systems, Trans. Cave Res. Group Great Britain, 7(2), 161-203.

Atkinson, T. C. (1977): Diffuse Flow and conduit flow in limestone terrain in the Mendip Hills, Somerset (Great Britain), Journal of Hydrology, 35, 93-110.

Bailly-Comte, V., Martin, J. B., Jourde, H., Screaton, E. J., Pistre, S. and Langston, A. (2010): Water exchange and pressure transfer between conduits and matrix and their influence on hydrodynamics of two karst aquifers with sinking streams, Journal of Hydrology, 386, 55-66, doi:10.1016/j.jhydrol.2010.03.005.

Bakalowicz, M. (2005): Karst groundwater: a challenge for new resources, Hydrogeology Journal, 13, 148-160, doi:10.1007/s10040-004-0402-9.

Bakalowicz, M. (2015): Karst and karst groundwater resources in the Mediterranean, Environmental Earth Science, 74, 5-14, doi:10.1007/s12665-0154239-4. 
Barenblatt, G. I., Zheltov, I. U. and Kochina, I. N. (1960): Basic concepts in the theory of seepage of homogeneous liquids in fissured rock, Journal of Applied Mathematics and Mechanics (PMM), 24(5), 1286-1303.

Barker J. A. (1988): A generalized radial flow model for hydraulic tests in fractured rocks, Water Resources Research, Vol.24, No.10, 1796-1804.

Beauheim R. L., Roberts R. M. and Avis, J. D. (2004) Well testing in fractured media: Flow dimensions and diagnostic plots, Journal of Hydraulic Research, 42 (Extra Issue), 69-76.

Birk, S., Geyer, T., Liedl, R. and Sauter, M. (2005): Process-based interpretation of tracer tests in carbonate aquifers, Ground Water, Vol. 43, 3, 381-388.

Birk, S., Liedl, R., and Sauter, M. (2006): Karst spring responses examined by process-based modeling, Ground Water, Vol. 44, 832-836, doi:10.1111/j.17456584.2006.00175.x.

Bodin, J., Ackerer, P., Boisson, A., Bourbiaux, B., Bruel, D., de Dreuzy, J.-R., Delay, G. and Pourpak, H. (2012): Predictive modelling of hydraulic head responses to dipole flow experiments in a fractured / karstified limestone aquifer: Insights from a comparison of five modelling approaches to real-field experiments, Journal of Hydrology, 454-455, 82-100, doi:10.1016/j.hydrol.2012.05.069.

Bourdet, D. (2001): Well test analysis: The use of advanced interpretation models, Elsevier, Amsterdam.

Cinco-Ley, H., Samaniego-V., F., Dominguez-A., N. (1978): Transient pressure behaviour for a well with a finite-conductivity vertical fracture, SPE J., 6014, 253-264.

Clemens, T. (1996): Simulation der Entwicklung von Karstaquiferen, Ph.D. thesis, University of Tübingen. 


\section{Chapter 1}

de Rooij, R., Perrochet, P. and Graham, W. (2013): From rainfall to spring discharge: Coupling conduit flow, subsurface matrix flow and surface flow in karst systems using a discrete-continuum model, Advances in water resources, 61, 21-41, doi:10.1016/j.advwatres.2013.08.009.

Doummar, J., Sauter, M. and Geyer, T. (2012): Simulation of flow processes in a large scale karst system with an integrated catchment model (Mike She) Identification of relevant parameters influencing spring discharge, Journal of Hydrology, 426-427, 112-123, doi:10.1016/j.jhydrol.2012.01.021.

Dörfliger, N., Fleury, P. and Ladouche, B. (2009): Inverse modeling approach to allogenic karst system characterization, Ground Water, Vol. 47, 414-426, doi:10.1111/j.1745-6584.2008.00517.x.

Drogue, C. (1992): International Contribution to Hydrogeology, 13, Verlag Heinz Heise, Hannover, Germany, 133-149.

Ehlig-Economides, C. A. and Economides, M. J (2000): Formation Characterization: Well and Reservoir testing, In: Reservoir stimulation, Chapter 2, edited by M. J. Ehlig-Economides and K. J. Nolte, Wiley, Chichester.

Fiorillo, F. and Stevanovic, Z. (2015): Introductory editorial thematic issue: Mediterranean karst hydrogeology, Environmental Earth Science, 74, 1-3, doi:10.1007/s12665-015-4548-7.

Ford, D. and Williams, P. (2007): Karst Hydrogeology and Geomorphology, John Wiley \& Sons Ltd, Chichester.

Gallegos J. J., Hu, B. X. and Davis, H. (2013): Simulating flow in karst aquifers at laboratory and sub-regional scales using MODFLOW-CFP, Hydrogeology Journal, 1749-1760; doi:10.1007/s10040-013-1046-4.

Geyer, T., Birk, S., Licha, T., Liedl, R. and Sauter, M. (2007): Multitracer test approach to characterize reactive transport in karst aquifers, Ground Water, Vol. 45, 1, 36-45, doi:10.1111/j.1745-6584.2006.00261.x. 
Geyer, T., Birk, S., Liedl, R. and Sauter, M. (2008): Quantification of temporal distribution of recharge in karst systems from spring hydrographs, Journal of Hydrology, 348, 452-463, doi:10.1016/j.jhydrol.2007.10.015.

Geyer, T., Birk, S., Reimann, T., Dörfliger, N. and Sauter, M. (2013): Differentiated characterization of karst aquifers: some contributions, Carbonates Evaporites, 28, 41-46, doi:10.1007/s13146-013-0150-9.

Goldscheider, N., Meiman, J., Pronk, M. and Smart, C. (2008): Tracer tests in karst hydrogeology and speleology, International Journal of Speleology, 37 (1), $27-$ 40.

Grasso, D. A. and Jeannin, P.-Y. (1994): Etude critique des méthodes d'analyse de la réponse globale des systemes karstique. Application au Site de Bure (JU, Suisse), Bulletin d'Hydrogéologie, No. 13, 87-113.

Gringarten, A. C. (1982): Flow-test evaluation of fractured reservoirs, In: Recent trends in hydrogeology, edited by: T.N. Narasimhan, Geological Society of America, Special Paper 189, 237-262.

Gringarten, A. C. (1987): How to recognize "double-porosity" systems from well tests, Journal of Petroleum Technology, SPE 16437, 631-633.

Gringarten, A. C., Ramey (Jr.), H. J. and Raghavan, R. (1974): Unsteady-state pressure distributions created by a well with a single infinite-conductivity vertical fracture, SPE J., 14, 347-360.

Hartmann, A., Goldscheider, N., Wagener, T., Lange, J. and Weiler, M. (2014): Karst water resources in a changing world: Review of hydrological modeling approaches, Rev. Geophys., 52, 218-242, doi:10.1002/2013RG000443.

IPCC (2014): Climate Change 201: Synthesis Report, Contribution of Working Group I, II and II to the Fifth Assessment Report of the Intergovernmental Panel on Climate Change [Core writing team, R. K. Pauchauri and L. A. Meyer (eds.)], IPCC, Geneva, Switzerland, 151 pp.

Jeannin, P.-Y. and Sauter, M. (1998): Analysis of karst hydrodynamic behavior using global approaches: a review, Bulletin d'Hydrogéologie, No. 16, 31-48. 


\section{Chapter 1}

Jenkins, D. N. and Prentice, J. K (1982): Theory for aquifer test analysis in fractured rocks under linear (nonradial) flow conditions, Ground Water, Vol. 20, No.1, 12-21.

Kiraly, L. (1995): Effects of the epikarst on the hydrograph of karst springs: a numerical approach, Bulletin d'Hydrogéologie, No. 14, 199-220.

Kiraly, L. (1998): Modelling karst aquifers by the combined discrete channel and continuum approach, Bulletin d'Hydrogéologie, No. 16, 77-98.

Kiraly, L. (2002): Karstification and groundwater flow, Evolution of karst: from prekarst to cessation, edited by: F. Gabrovšek, Postojna-Ljubljana, Zalozba ZRC, 155-190.

Kong-A-Siou, L., Johannet, A., Borrell Estupina, V. and Pistre, S. (2015): Neutral networks for karst groundwater management: Case of the Lez spring (Southern France), Environmental Earth Science, 74, 7617-7632, doi:10.1007/s12665-015-4708-9.

Kordilla, J., Sauter, M., Reimann, T. and Geyer, T. (2012): Simulation of saturated and unsaturated flow in karst systems at catchment scale using a double continuum approach, Hydrol. Earth Syst. Sci., 16, 3909-3923, doi:10.5194/hess-16-3909-2012.

Kovacs, A. and Sauter, M. (2007): Modelling Karst Hydrodynamics, In: Frontiers of Karst Research, Special Publication 13, edited by: J.B. Martin and W.B. White, Karst Water Institute, Leesburg, Virginia, 13-23.

Liedl, R., Sauter, M., Hückinghaus, D., Clemens, T. and Teutsch, G. (2003): Simulation of the development of karst aquifers using a coupled continuum pipe flow model, Water Resources Research, Vol. 39, 3, 1057, doi:10.1029/2001WR001206.

Luhmann, A. J., Covington, M. D., Alexander, S. C., Chai, S. Y., Schwartz, B. F., Groten, J. T. and Alexander (Jr), E. C. (2012): Comparing conservative and nonconservative tracers in karst and using them to estimate flow path geometry, Journal of Hydrology, 448-449, 201-211, doi:10.1016/j.hydrol.2012.04.044. 


\section{Introduction}

Maloszewski, P., Stichler, W., Zuber, A. and Rank, D. (2002): Identifying the flow systems in a karstic-fissured-porous aquifer, the Schneealpe, Austria, by modelling of environmental ${ }^{18} \mathrm{O}$ and ${ }^{3} \mathrm{H}$ isotopes, Journal of Hydrology, 256, 4859.

Mangin, A. (1975): Contribution à l'étude hydrodynamique de aquifères karstiques, PhD thesis, Université de Dijon, France.

Maréchal, J.-C., Ladouche, B. and Dörfliger, N. (2008a): Karst flash flooding in a Mediterranean karst, the example of Fontaine de Nîmes, Engineering Geology, 99, 138-146.

Maréchal, J.-C., Ladouche, B., Dörflinger, N. and Lachassagne, P. (2008b): Interpretation of pumping tests in a mixed flow karst system, $W$ ater Resources Research, Vol.44, W05401, doi:10.1029/2007WR006288.

Maréchal, J.-C., Courtois, N., Jouanen, G. and Meus, P. (2010): Multi-tracage de la fontaine de Nimes, Karstologia, 56, 1-8.

Mayaud, C., Walker, P., Hergarten, S. and Birk, S. (2016): Nonlinear Flow Process: A new package to compute nonlinear flow in MODFLOW, Ground Water, 53 (4), 645-650, doi:10.1111/gwat.12243.

Oehlmann, S., Geyer, T., Licha, T. and Sauter, M. (2015): Reducing the ambiguity of karst aquifer models by pattern matching of flow and transport on catchment scale, Hydrol. Earth Syst. Sci., 19, 893-912, doi:10.5194/hess-19-8932015.

Palmer, A. N. (1991): Origin and morphology of limestone caves, Geological Society of America Bulletin, 103, 1-21.

Quinlan, J. F. and Ewers, R. O. (1985): Ground water flow in limestone terranes: Strategy rationale and procedure for reliable, efficient monitoring of ground water quality in karst areas, In: Proceedings of the national symposium and exposition on aquifer restoration and ground water monitoring (5th, Columbus, Ohio), National Water Well Association, Worthington, Ohio, 197-243. 


\section{Chapter 1}

Reimann, T., Rehrl, C., Shoemaker, W. B., Geyer, T. and Birk, S. (2011): The significance of turbulent flow representation in single-continuum models, $W$ ater Resources Research, Vol. 47, W09503, doi:10.1029/2010WR010133.

Renard, P., Glenz, D. and Mejias, M. (2009): Understanding diagnostic plots for well-test interpretation, Hydrogeology Journal, 17(3), 589-600.

Saller, S. P., Ronayne, M. J. and Long, A .J. (2013): Comparison of a karst groundwater model with and without discrete conduit flow, Hydrogeology Journal, 21, 1555-1566, doi:10.1007/s10040-013-1036-6.

Sauter, M. (1992): Quantification and forecasting of regional groundwater flow and transport in a karst aquifer (Gallusquelle, Malm, SW Germany), Tübinger Geowissenschaftliche Arbeiten, Part C, 13, 151.

Schmidt, S., Geyer, T., Guttman, J., Marei, A., Ries, F. and Sauter, M. (2014): Characterization and modelling of conduit restricted karst aquifers - Example of the Auja spring, Jordan Valley, Journal of Hydrology, 511, 750-763, doi:10.1016/j.jhydrol.2014.02.019.

Spane (jr.), F. A. and Wurstner, S. K. (1993): A computer program for calculating pressure derivatives for use in hydraulic test analysis, Ground Water, 31(5), 814-822.

Spitzberg, S. and Ufrecht, W. (2014): Hydraulische Charakterisierung eines urbanen Karstgrundwasserleiters mit Pumpversuchen, Grundwasser, 19, 5-16, doi:10.1007/s00767-013-0241-5.

Teutsch, G. and Sauter, M. (1991): Groundwater modeling in karst terranes: scale effects, data acquisition and field validation, In: Proceedings of the 3rd Conference on Hydrogeology, Ecology, Monitoring and Management of Ground Water in Karst Terranes, Nashville, TN, 17-34.

Walker D. D. and Roberts, R. M. (2003): Flow dimensions corresponding to hydrogeological conditions, Water Resources Research, Vol.39, No.12, 1349, doi:10.1029/2002WR001511. 


\section{Introduction}

Warren, J. E. and Root, P. J. (1963): The behavior of naturally fractured reservoirs, SPE J., 3, 3, 245-255.

White, W. B. (1969): Conceptual models for carbonate aquifers, Ground Water, 7 (3), 1969.

White, W. B. (1988): Geomorphology and hydrology of karst terrains, Oxford University Press, New York.

White, W. B. (2002): Karst hydrology: recent development and open questions, Engineering Geology, 65, 85-105.

Worthington, S. R. H., Ford, D. C. and Davies G. J. (2000): Matrix, fractures and channel components of storage and flow in a Paleozoic limestone aquifer, In: Groundwater flow and contaminant transport in carbonate aquifers, edited by: I. D. Sasowsky and C. M. Wicks, 113-128.

Worthington, S. R .H. (2009): Diagnostic hydrogeologic characteristics of a karst aquifer (Kentucky, USA), Hydrogeology Journal, 17, 1665-1678, doi:10.1007/s10040-009-0489-0. 


\section{Chapter 2}

\section{Discrete conduit-continuum model}

\subsection{Previous related work}

The dual-flow behavior of karst aquifer systems has often been described by double porosity models (BARENBLATT ET AL, 1960). WARREN AND ROOT (1963) created an idealized conceptual model of a heterogeneous aquifer system (see Fig. 2.1, left) consisting of two different porosities, similar to the definition of primary and secondary porosity in Chapter 1. Therefore, the model incorporates heterogeneities on a macroscopic scale (WARREN AND ROOT, 1963). Quasi-steady state exchange flow inside the resulting REV depends on the hydraulic head difference $\Delta h[\mathrm{~L}]$ between the two porosities (BARENBLATT ET AL., 1960). Exchange flow is controlled by the lumped exchange coefficient $\alpha_{L}\left[\mathrm{~L}^{-2}\right]$ reflecting the geometry of matrix and fracture as well as their hydraulic properties (WARREN AND ROOT, 1963; MOENCH, 1984; CORNATON AND PERrochet, 2002). MOENCH (1984) quoted a general flux notation of the exchange flow per unit volume $q\left[\mathrm{~T}^{-1}\right]$ for a double porosity REV, which also expresses the dependence of the flow on the hydraulic conductivity $K_{p p}\left[\mathrm{LT}^{-1}\right]$ of the primary porosity matrix:

$$
q=\alpha_{L} K_{p p} \Delta h
$$

Depending on the development of the secondary porosity and therefore, the form and dimension of the matrix blocks (e.g. slab-shaped and sphere-shaped), the value of $\alpha_{L}$ varies (cf. WARREN AND ROOT, 1963; MOENCH, 1984; BOURDET, 2001). In general, $\alpha_{L}$ increases with the progressive development and interconnection of the fissured network. This can also be considered as increased specific surface of the secondary porosity per unit volume (BARENBLATT ET AL., 1960). 

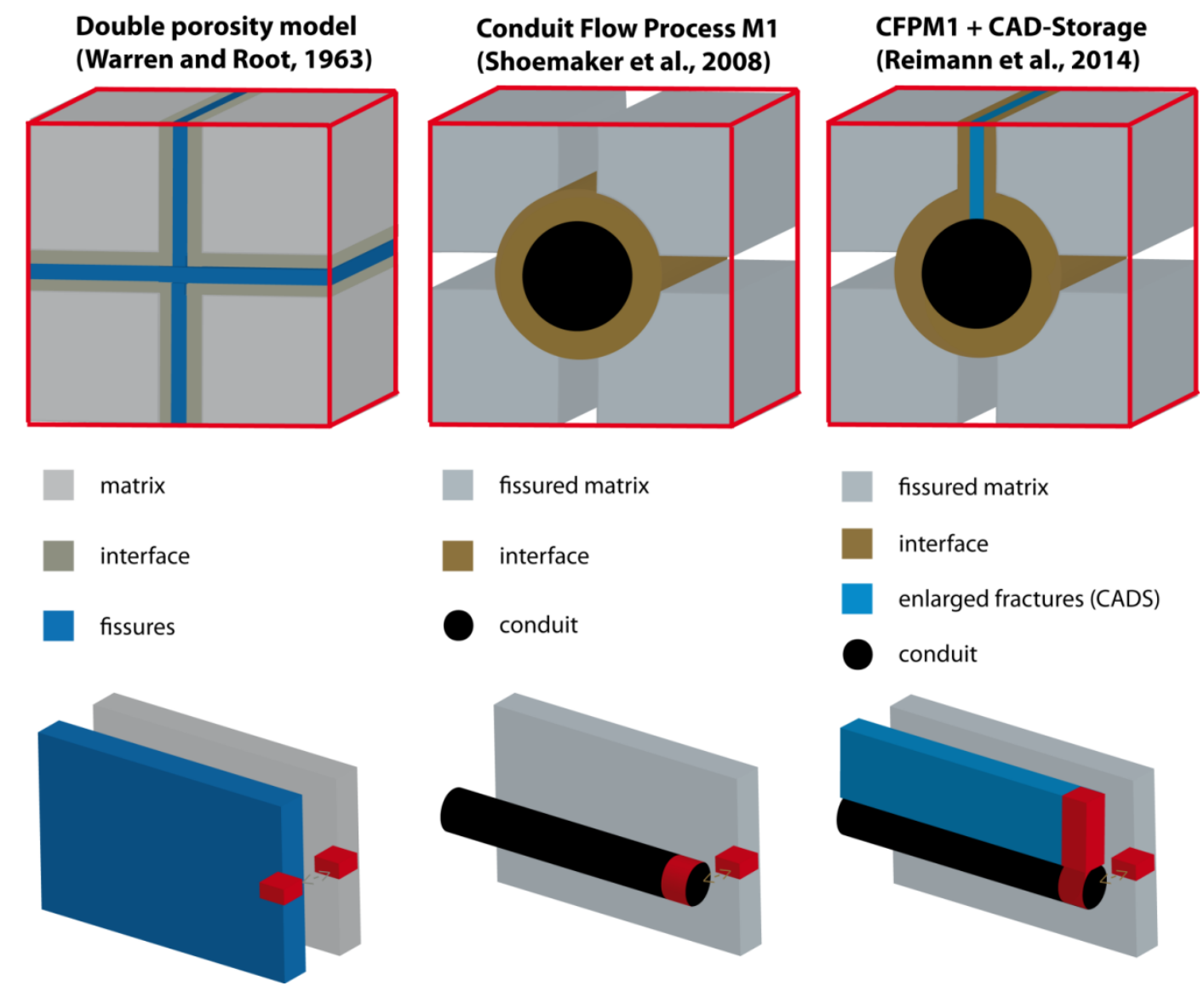

Fig. 2.1: Conceptual similarities of the double porosity model and the CFPM1.

DCC models are an enhancement of the double porosity model with the primary and secondary porosities merged together into one continuum. The resulting continuum is connected to a discrete conduit network. Originally developed for the simulation of karst aquifer genesis, the DCC model 'Carbonate Aquifer Void Evolution' (CAVE; ClEmENS, 1996; HÜCKINGHAUS, 1998) was partly incorporated into the single continuum model MODFLOW 2005 to create CFPM1 (ShOEMAKER ET AL., 2008). Similar to the double porosity model, CFPM1 also considers a linear quasi-steady state exchange coefficient $\alpha_{e x}\left[\mathrm{~L}^{2} \mathrm{~T}^{-1}\right]$ for the exchange flow $Q_{e x}\left[\mathrm{~L}^{3} \mathrm{~T}^{-1}\right]$, which is also a function of the hydraulic head difference $\Delta h[\mathrm{~L}]$ between the hydraulic head of the matrix $h_{m}$ [L] and the conduit $h_{c}$ [L] (BAUER ET AL., 2003; LIEDL ET AL., 2004; SHOEMAKER ET AL., 2008):

$$
Q_{e x}=\alpha_{e x} \Delta h=\alpha_{e x}\left(h_{c}-h_{m}\right)
$$




\section{Chapter 2}

BAUER ET AL. (2003) introduced the exchange coefficient $\alpha_{e x}$, for the interface between conduit and matrix, as a lumped conductance term due to the high uncertainty of the involved parameters (cf. Fig. 2.1, center). The coefficient represents the hydraulic matrix conductivity $K\left[\mathrm{LT}^{-1}\right]$ as well as the geometry of the interface between the conduit and matrix:

$$
\alpha_{e x}=\alpha K 2 \pi \frac{d_{c}}{2} \Delta l_{c} \tau
$$

with $\alpha$ a factor which might be interpreted as inverse fissure spacing $\left[\mathrm{L}^{-1}\right], d_{c}$ the diameter of the conduit segment $[\mathrm{L}], \Delta \mathrm{I}_{c}$ the length of the conduit segment associated to the conduit node [L] and $\tau$ the tortuosity of the conduit [-].

The exchange coefficient $\alpha_{e x}$ couples the discrete conduit features to the block-centered finite difference approximation of MODFLOW-2005. The equation for three-dimensional flow inside the continuum is (HARBAUGH, 2005)

$$
\frac{\partial}{\partial x}\left(K_{x x} \frac{\partial h_{m}}{\partial x}\right)+\frac{\partial}{\partial y}\left(K_{y y} \frac{\partial h_{m}}{\partial y}\right)+\frac{\partial}{\partial y}\left(K_{z z} \frac{\partial h_{m}}{\partial z}\right) \pm W=S_{S}\left(\frac{\partial h_{m}}{\partial t}\right)
$$

where $K$ is the hydraulic conductivity in $\mathrm{x}, \mathrm{y}$ and $\mathrm{z}$ direction $\left[\mathrm{LT}^{-1}\right], W$ is the volumetric flux per unit volume $\left[\mathrm{T}^{-1}\right], S_{S}$ the specific storage coefficient $\left[\mathrm{L}^{-1}\right]$ and $t$ the time $[\mathrm{T}]$.

\subsection{Representation of water abstraction from a karst conduit with numerical discrete conduit-continuum models}

In order to apply CFPM1 for the analysis of large-scale abstraction tests, significant model developments of the original DCC model were carried out. Only the basic changes and the influences on the head distribution and flow along the conduit are briefly described. For further information about the following content please refer to REIMANN ET AL. (2014). 


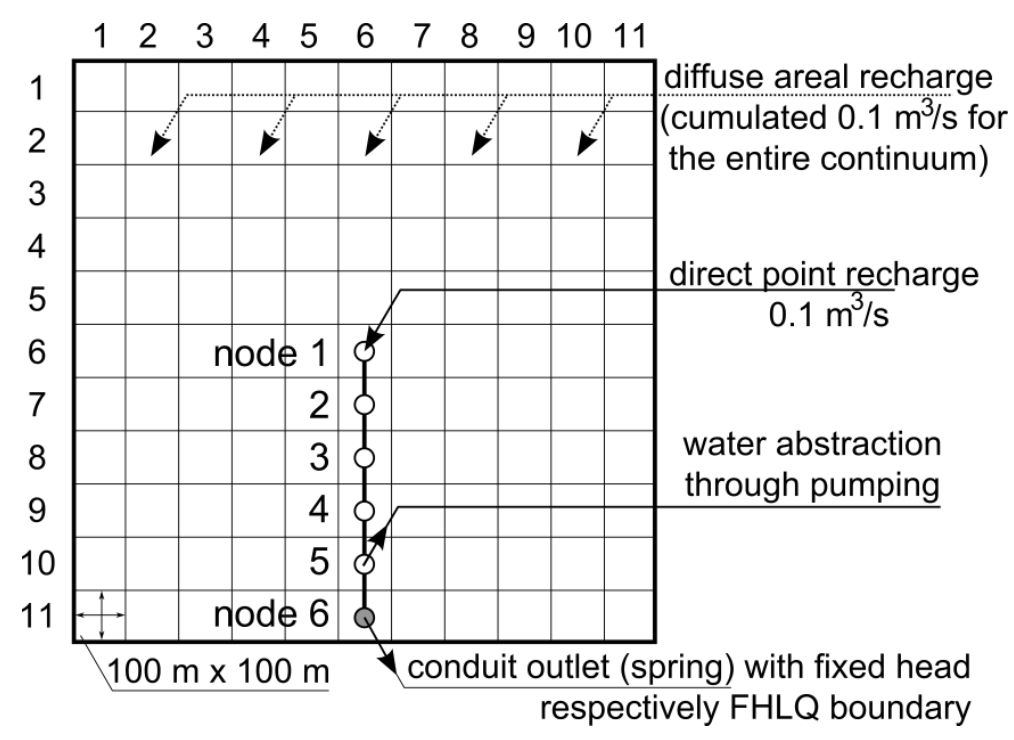

Fig. 2.2: Sketch of the applied basic model set-up (REIMANN ET AL., 2014).

Figure 2.2 presents the basic model set-up applied for the systematic process study. The set-up has an areal extent of $1100 \mathrm{~m}$ x $1100 \mathrm{~m}$, with a homogeneous cell size of $100 \mathrm{~m} \times 100 \mathrm{~m}$. The matrix consists of one layer with a hydraulic conductivity $K=1 \times 10^{-5} \mathrm{~ms}^{-1}$ and a storage coefficient $S_{m}=0.01$. The model domain is bounded by Neumann (no-flow) boundary conditions. The embedded conduit consists of five pipe segments, each with a length of $100 \mathrm{~m}$, connecting 6 nodes. The conduit is parameterized by a conduit diameter of $d_{c}=0.5 \mathrm{~m}$, an exchange coefficient $\alpha_{e x}=1 \times 10^{-4} \mathrm{~m}^{2} \mathrm{~s}^{-1}$ and a mean pipe roughness $k_{c}=0.01 \mathrm{~m}$. Within node 6 , a fixed head boundary is applied to represent a karst spring. Conduit recharge $\left(0.1 \mathrm{~m}^{3} \mathrm{~s}^{-1}\right)$ is applied to node 1 , to represent direct recharge via a sinkhole. In addition, diffuse recharge of the same rate is uniformly distributed over the whole model domain. The process study is subdivided in three different periods: (1) The steady state period lasts for $86400 \mathrm{~s}$; (2) during the second period, which lasts for three days (from 86400 to $345600 \mathrm{~s}$ ), water is abstracted from node 5, and finally, (3) the last period represents a recovery period of three days (from 345600 to $604800 \mathrm{~s}$ ). 

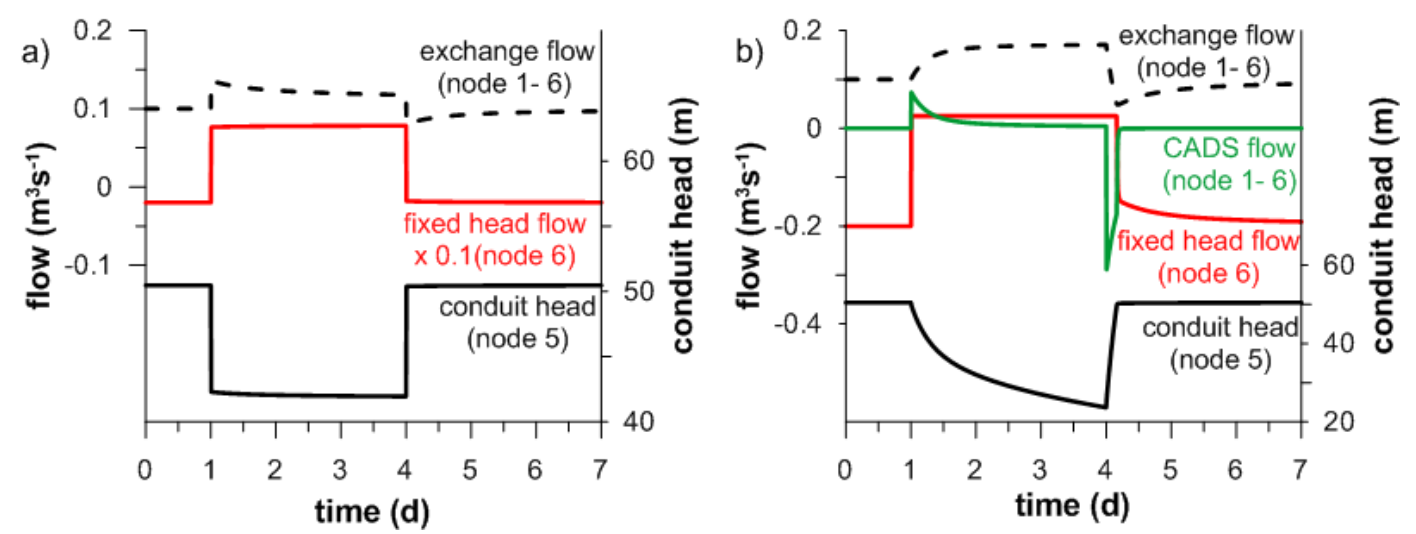

Fig. 2.3: Simulation results of the basic model (a) without and (b) with CAD-storage and FHLQ (modified after REIMANN ET AL., 2014).

Figure 2.3a shows the effect of water abstraction and exchange flow, as well as inflow from a fixed head node for the idealized set-up (Fig. 2.2) for the original CFPM1 by SHOEMAKER ET AL. (2008). The applied parameters are chosen to illustrate the effect of hydraulically limiting conditions causing high conduit drawdown in node 5. During the first period (one day duration) no water is abstracted from the conduit. The spring discharge of $0.2 \mathrm{~m}^{3} \mathrm{~s}^{-1}$ is supplied by the direct recharge in node $1\left(0.1 \mathrm{~m}^{3} \mathrm{~s}^{-1}\right)$ and the homogeneously distributed diffuse recharge $\left(0.1 \mathrm{~m}^{3} \mathrm{~s}^{-1}\right)$ that enters the conduit as exchange flow. During the second period, water is directly abstracted from the conduit at node 5 with rates of $Q_{p}=1.0 \mathrm{~m}^{3} \mathrm{~s}^{-1}$. The conduit head in node 5 drops immediately after the beginning of pumping and causes spontaneous inflow through the fixed head node 1. According to Equation 2.2, the matrix inflow also instantly increases, but the share of exchange flow is insignificant compared to the inflow through the fixed head node. At day four, immediately after the abstraction stops, the conduit head rises back to the initial value. In comparison to the observed drawdown behavior during the Cent Fonts pumping test (MARÉCHAL ET AL. 2008), two major differences occur: (a) immediate drawdown and head recovery; (b) nearly unhampered inflow from the fixed head node (spring).

To overcome this conceptual shortage, REIMANN ET AL. (2014) implemented a fast responding storage to the conduit system. Features such as solutionenlarged fractures or other cavities are assumed to provide additional storage, but do not participate in the flow processes of the conduit system (Fig. 2.4). The conduit-associated drainable storage (CADS) is in direct hydraulic contact with the pipe network: 


$$
h_{C A D S}=h_{c}
$$

hCADS is the hydraulic head in the CAD storage [L]. Due to the direct linkage, changes of the hydraulic conduit head are directly associated to storage outflow or inflow as (REIMANN ET AL. 2014)

$$
Q_{C A D S}=\frac{V_{C A D S, t}-V_{C A D S, t-\Delta t}}{\Delta t}
$$

with

$$
V_{C A D S}=l_{C A D S} W_{C A D S}\left(h_{c}-z_{B o t}\right)
$$

with ICADS the length of the conduit segment associated with the conduit node $[\mathrm{L}], W_{C A D S}$ the width of the CAD storage and $z_{B o t}$ the elevation of the conduit bottom [L]. The conceptual model of the CAD-storage is based on the conceptual approach of water storage in karst aquifers by MANGIN (1975). A difference between the CAD-storage and the annex-to-drain system (MANGIN, 1975 ) is the exchange capacity of the storage and the conduit system. Contrary to the CAD-storage, the annex-to-drainage system is only poorly connected to the conduit system. The direct connection to the conduit without any delay is comparable to the fissured flow of the double porosity flow. Therefore, the extended CFPM1 combines the double porosity approach with a onedimensional flow component along the conduit (cf. Fig. 2.1, right).
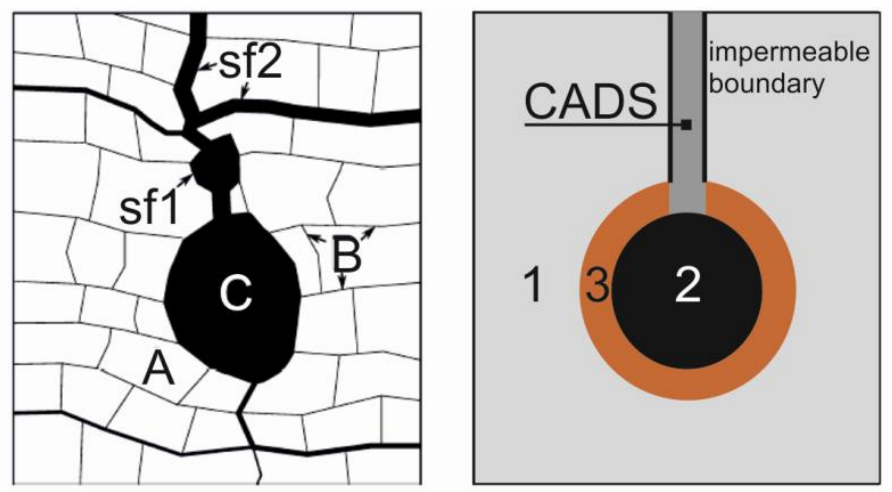

Fig. 2.4: Left: Sketch of a karst aquifer with (A) porous rock matrix, (B) small fissures/fractures, (C) solution-enlarged conduits with active flow; (sf1) solution enlarged fractures, and (sf2) other karst cavities, both without active flow. Right: discrete-continuum model concept with (1) matrix continuum, (2) discrete pipes, and conduit-associated drainable storage (CADS) and (3) interface between conduit and matrix (modified after REIMANN ET AL., 2014). 


\section{Chapter 2}

Furthermore, REIMANN ET AL. (2014) added a fixed head limited flow boundary condition (FHLQ; BAUER ET AL., 2005) to CFPM1. The FHLQ boundary condition allows switching from a fixed head boundary, as a good approximation for an outflow spring, to a fixed flow boundary (e.g. to limit inflow while pumping from the conduit):

$$
F H L Q= \begin{cases}h_{c}=H, & Q \leq Q_{L} \\ Q=Q_{L}, & \text { else }\end{cases}
$$

where $H$ is the fixed head value $(\mathrm{FH})[\mathrm{L}], Q$ is the discharge at the boundary $\left[\mathrm{L}^{3} \mathrm{~T}^{-1}\right]$ and $Q_{L}$ is the limiting discharge (LQ) $\left[\mathrm{L}^{3} \mathrm{~T}^{-1}\right]$.

Figure $2.3 \mathrm{~b}$ presents the effect of water abstraction from a conduit for an idealized set-up considering a CAD-storage with $W_{C A D S}=0.25 \mathrm{~m}$ uniformly distributed along the conduit. The fixed head boundary condition in node 6 is replaced by the FHLQ boundary condition with a fixed head at $50 \mathrm{~m}$ and a limited inflow of $Q_{L}=0.025 \mathrm{~m}^{3} \mathrm{~s}^{-1}$. The flow patterns during period one are similar to those in Fig. 2.3a. In comparison to the initial set-up, two major differences can be detected at the beginning of water abstraction. By applying the CAD-storage and the FHLQ boundary conditions, the drawdown in node 5 decreases over time instead of instantaneously after the start of pumping. The inflow from the boundary conditions is constrained and the exchange flow and the CAD-storage release balance the water deficit (Fig. 2.3b). Storage outflow ceases with progressing time and can be described by the recession function of MAILLET (1905). On the contrary, matrix exchange flow increases until a significant volume of water is supplied by the matrix. During the recession period, the inflow to the storage also buffers the increase of the conduit head. At the end of day seven, the system reaches the initial conditions.

REIMANN ET AL. (2014) demonstrate that the extended version of CFPM1 is able to represent the main hydraulic processes of water abstraction for an idealized representation of the Cent Fonts pumping test. The analysis reveals that, especially at the beginning of water abstraction and during pumping stops, the fast responding storage is required. Hence the general flow patterns during these periods can be used to parameterize the CAD-storage. The interaction of a matrix continuum with a discrete karst network, including the effects of transient water storage, is an important improvement over existing numerical 
approaches (e.g. HALIHAN AND WiCKS, 1998; COVINGTON ET AL., 2009). Therefore, the introduced DCC model is employed for the numerical simulations and subsequent analyses within this thesis. 


\section{Chapter 2}

\section{References}

Barenblatt, G .I., Zheltov, I. U. and Kochina, I. N. (1960): Basic concepts in the theory of seepage of homogeneous liquids in fissured rock, Journal of Applied Mathematics and Mechanics (PMM), 24(5), 1286-1303.

Bauer, S., Liedl, R. and Sauter, M. (2008): Modeling of karst aquifer genesis: Influence of exchange flow, Water Resources Research, Vol.39, Nr.10, http://dx.doi.org/10.1029/2003WR002218.

Bourdet, D. (2001): Well test analysis: The use of advanced interpretation models, Elsevier, Amsterdam.

Clemens, T. (1996): Simulation der Entwicklung von Karstaquiferen, PhD thesis, University of Tübingen, Germany.

Cornaton, F. and Perrochet, P. (2002): Analytical 1D dual-porosity solution to 3D discrete single-continuum models. Application to karstic hydrograph modelling, Journal of Hydrology, 262, 165-176.

Covington, M. D., Wicks, C. M. and Saar, M. O. (2009): A dimensionless number describing the effects of recharge and geometry on discharge from simple karstic aquifers, Water Resources Research, 45, W11410, doi:10.1029/2009WR008004.

Halihan, T. and Wicks, C. M. (1998): Modeling of storm responses in conduit flow aquifers with reservoirs, Journal of Hydrology, 208, 82-91.

Harbaugh, A. W. (2005): MODFLOW-2005, The U.S. Geological survey modular ground-water model - The Ground-Water Flow Process: U.S Geological Survey Techniques and Methods 6-A16.

Hückinghaus, D. (1998): Simulation der Aquifergenese und des Wärmetransports in Karstaquiferen, Tübinger Geowissenschaftliche Arbeiten, Part C, 42. 
Liedl, R., Sauter, M., Hückinghaus, D., Clemens, T. and Teutsch, G. (2003): Simulation of the development of karst aquifers using a coupled continuum pipe flow model, Water Resources Research, Vol. 39, 3, 1057, doi:10.1029/2001WR001206.

Reimann, T., Giese, M., Geyer, T., Liedl, R., Maréchal, J.-C. and Shoemaker, W. B. (2014): Representation of water abstraction from a karst conduit with numerical discrete-continuum models, Hydrol. Earth Syst. Sci., 18, 227-241, doi 10.5194/hess-18-227-2014.

Maillet, E. T. (1905): Essais d'hydraulique souterraine et fluviale, Herman et Cle, Paris.

Mangin, A. (1975): Contribution à l'étude hydrodynamique de aquifères karstiques, PhD thesis, Université de Dijon, France.

Maréchal, J.-C., Ladouche, B., Dörflinger, N. and Lachassagne P. (2008): Interpretation of pumping tests in a mixed flow karst system, Water Resources Research, Vol.44, W05401, doi:10.1029/2007WR006288.

Moench, A. F. (1984): Double-porosity model for a fissured groundwater reservoir with fracture skin, $W$ ater Resources Research, Vol. 20, No. 7, 831-846, 1984.

Shoemaker, W. B., Kuniansky, E. L., Birk, S., Bauer, S. and Swain, E. D. (2008): Documentation of a Conduit Flow Process (CFP) for MODFLOW-2005: U.S. Geological Survey Techniques and Methods, Book 6, Chapter A24.

Warren, J. E. and Root, P. J. (1963): The behavior of naturally fractured reservoirs, SPE J., 3: 245-255. 


\section{Chapter 3}

\section{Classical pumping test analysis using discrete conduit-continuum models - an approximation of inner boundary conditions for horizontal wellbores/fractures}

Markus Giese ${ }^{1}$, Thomas Reimann², Benoit Dewandel ${ }^{3}$, Jean-Christophe Maréchal ${ }^{3}$, Martin Sauter ${ }^{1}$

Manuscript:

Giese, M., Reimann, T., Dewandel, B., Maréchal, J.-C. and Sauter, M.: Classical pumping test analysis using discrete pipe-continuum models - an approximation of inner boundary condition for horizontal wellbores/fractures, In preparation for submission to a peer-reviewed journal.

${ }^{1}$ Geoscientific Centre, University of Goettingen, Göttingen, Germany

${ }^{2}$ Institute for Groundwater Management, TU Dresden, Dresden, Germany

${ }^{3}$ Bureau de Recherches Géologiques et Minières (BRGM)- D3E/NRE, Montpellier, France 


\section{Abstract}

Inner boundary conditions are used to describe the flow behavior during early times of pumping tests and are associated with storage inside the wellbore and inefficiencies of the wellbore or the interface. Analytical solutions generally lump the effects reducing the well productivity at the beginning of pumping. Originally developed for the analysis of vertical well screens, analytical solutions were also transferred to horizontal wellbores. For such horizontal wellbores, the design and the management plan are likely more complex and, therefore, the set-ups do not conform to requirements analytical solutions are based on. In general, numerical models are more flexible and can be used to overcome the limitations of analytical solutions. Transient hydraulics of horizontal wells can be simulated with numerical discrete conduit-continuum models. Specifically, a numerical method that allows considering laminar and turbulent flow appears to be useful for the interpretation of pumping test for technical advanced horizontal wellbores. The ability of the code to simulate effects of inner boundary conditions is successfully verified. Consequently, the presented numerical method is well suited for pumping test analysis of horizontal wells with laminar flow conditions. 


\section{Chapter 3}

\subsection{Introduction}

Classic well-test interpretation methods are based on conceptual well-aquifer models simplifying the general flow behavior. Usually these theoretical models consist of a basic model, inner boundary conditions, and outer boundary conditions (GRINGARTEN, 1982). The resulting pressure or drawdown over time is simply the superposition of different analytical solutions displayed on the same log-log plot (GRINGARTEN, 1982). Several analytical solutions are available for various basic models, e.g., (a) radial flow (THEIS, 1935), (b) double porosity (BARENBLATT ET AL., 1960; WARREN AND ROOT, 1963), (c) single vertical fracture (GRINGARTEN ET AL., 1974; CINCO-LEY AND SAMANIEGO-V., 1981). Similarly, inner boundary conditions are covered by various analytical solutions, e.g., (d) wellbore storage (VAN EVERDINGEN AND HURST, 1949; AgARWAL ET AL., 1970) and (e) skin effect (VAN EVERDINGEN, 1953; AGARWAL ET AL., 1970). Outer boundary conditions define the interaction of the catchment with heterogeneities on larger scale. Detailed investigations of effects in context with pumping test analysis are reported by, e.g., WALKER AND ROBERTS (2003), BEAUHEIM ET AL. (2004), and others. However, existing analytical methods show various deficits. Especially for the analysis of fractured rock aquifers, the inner boundary conditions representing well and/or formation inefficiencies need to be considered in detail (NOVAKOWSKI, 1990; SPANE AND WURSTNER, 1993).

Pumping from wells that are coupled with highly conductive structures, like horizontal wells or fractured aquifers, differ from general set-ups. A frequently used analytical solution for drawdown predictions in wellbores intersected by a plane vertical fracture is given by GRINGARTEN ET AL. (1974). This approach considers two different solutions: a) infinite conductivity fracture assuming constant pressure along the fracture, and b) uniform flux fracture where the flow per unit fracture surface is assumed to be constant (GRINGARTEN ET AL., 1974; BOURDET, 2001). In general, the pressure drop along uniform flux fractures is low (GRINGARTEN ET AL., 1974). The differences between the type curves are therefore marginal and only visible during the transition from linear to radial flow regimes (BOURDET, 2001). Fractures without a hydraulic gradient along the fracture can be referred to as an 'extension of the well (KRUSEMANN AND DE RIDDER, 1991), which represents the well together with the hydraulically 
connected productive fracture surface (JENKINS AND PRENTICE, 1982). However, previous studies of flow in highly conductive structures that interact with a surrounding low conductive matrix revealed that within the highly conductive structure: (1) flow can be laminar or turbulent, (2) pressure can significantly vary along the flow direction, and (3) due to the interaction with the surroundings, discharge varies along the flow direction (BIRK ET AL., 2005, REIMANN ET AL., 2011, GALlEgOS ET AL., 2013, XU ET AL., 2015). The dimensionless drawdown along an infinite-conductivity fracture, introduced by a central intersecting pumping well, which also considers effects caused by inner boundary conditions, is defined as (BERTRAND AND GRINGARTEN, 1978)

$$
\begin{gathered}
S_{D}=\frac{\sqrt{\pi t_{D}}}{2}\left[\operatorname{erf}\left(\frac{0.134}{\sqrt{t_{D}}}\right)+\operatorname{erf}\left(\frac{0.866}{\sqrt{t_{D}}}\right)\right]-0.067 \cdot \operatorname{Ei}\left(-\frac{0.018}{t_{D}}\right)-0.433 \cdot \\
E i\left(-\frac{0.750}{t_{D}}\right)+S_{f} \cdot e^{\left(\frac{-t_{D}}{s_{D} C_{D}}\right)}
\end{gathered}
$$

with $S_{D}$ the dimensionless drawdown [-], to the dimensionless time [-], $S_{f}$ the dimensionless wellbore skin [-] and $C_{D}$ the dimensionless wellbore storage [-].

The skin effect, as a lumped denotation of the effects of water abstraction on structure and formation inefficiencies (SPANE AND WURSTNER, 1993), was introduced by VAN EVERDINGEN (1953) as an additional pressure drop. The skin in the vicinity of the wellbore is a result of the employed drilling technique (VAN EVERDINGEN, 1953), particle deposition or the development of bacterial films (RENARD, 2005). According to BOURDET ET AL. (1983), skin effects are visible in the transition or pressure compensation period of highly conductive features and a low conductive reservoir. In general, two different determinations of wellbores with skin effects can be made (BOURDET, 2001): Firstly, damaged wells are characterized by high flow resistance between the well and the reservoir and, secondly, stimulated wells have low resistance and increased basic cylindrical vertical wellbore geometry for example fractured or horizontal wells. 


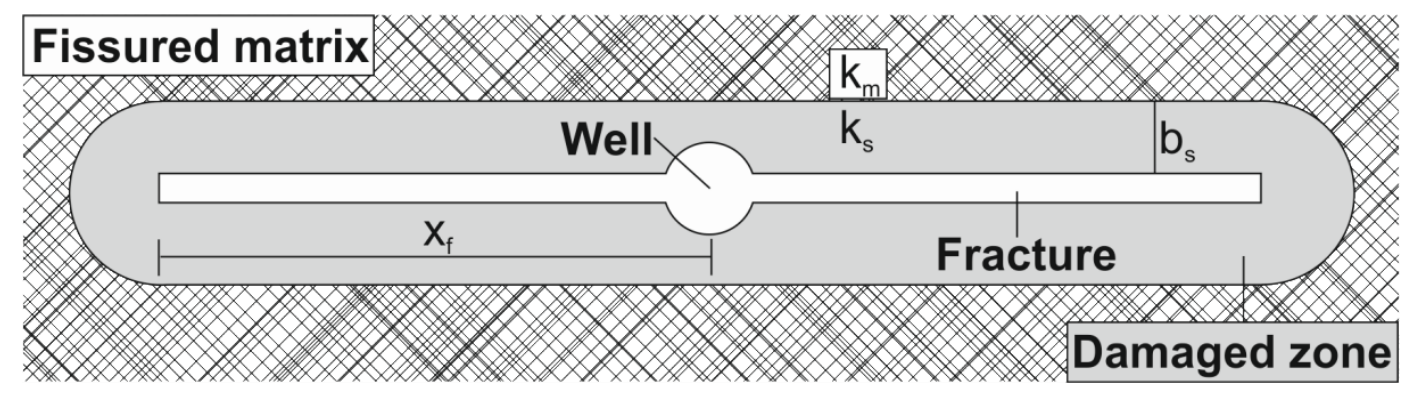

Fig. 3.1: Plan view of a conceptual infinite-conductivity vertical fracture with fluid loss damage (after: CinCO-LEY AND SAMANIEGO-V., 1981).

CINCO-LEY AND SAMANIEGO-V. (1981) transfer the skin approach to describe the effect of two different types of damaged wells on pumping tests in single fractures: a) choked vertical fracture and b) fluid loss damage. The fluid loss damage describes a damaged zone surrounding a single fracture (Fig. 3.1). CINCO-LEY AND SAMANIEGO-V. (1981) are using the term 'fluid loss damaged fracture' for reduced permeability around the fracture that results in an additional pressure loss during transient flow. The hydraulic properties of the damaged zone can be characterized by the skin damage factor $S_{f}[-]$ depending only on the ratio of the fissured matrix permeability $k m\left[\mathrm{~L}^{2}\right]$ and the damaged zone permeability $k_{s}\left[\mathrm{~L}^{2}\right]$ as

$$
S_{f}=\frac{\pi b_{s}}{2 x_{f}}\left(\frac{k_{m}}{k_{s}}-1\right)
$$

assuming a constant fracture half-length $X f[\mathrm{~L}]$ as well as a uniform damaged zone thickness $b_{s}[\mathrm{~L}]$ (cf. Fig. 3.1). Skin effects as well as wellbore storage are related to each other and both influence drawdown, mainly at the beginning of abstraction (MCCONNELL, 1993; PARK AND ZHAN, 2002). The first period of an abstraction test is normally dominated by storage effects, which create a unit slope on log-log plots (e.g. EHLIG-ECONOMIDES AND ECONOMIDES, 2000; BOURDET, 2001). With fixed wellbore storage the skin conductance affects the transformation of the drawdown signal from the wellbore to the matrix. High skin conductance results in an early transformation of the drawdown signal from the conduit system into the matrix (PARK AND ZHAN, 2002). During the storage period matrix contributions are negligible (BOURDET, 2001). Over time, the effect of the wellbore storage is reduced and the matrix starts to contribute water (MCCONNELL, 1993). The storage of the skin is normally assumed to be infinitesimal because the actual volume is negligible compared to that of the fissured matrix, resulting in a short duration of drawdown transformation (VAN 
EVERDINGEN, 1953). Starting with increased matrix exchange and assuming laminar fracture flow, flow from the adjacent rock to the fracture is parallel, resulting in linear flow. For later times, in case of an infinite horizontal aquifer, the flow can be described by the general radial flow equation as for any reservoir with infinite horizontal extent (GRINGARTEN, 1982).

\subsection{Discrete continuum model}

The discrete conduit-continuum model CFP Mode 1 (CFPM1; SHOEMAKER ET AL., 2008) couples 1-D discrete elements (e.g. conduits) with laminar and turbulent flow to the MODFLOW-2005 continuum simulating laminar Darcian flow [HARBAUGH, 2005]. Laminar pipe flow along the length of the pipe segment $\Delta l_{p}$ is described by the Hagen-Poiseuille equation as [SHOEMAKER ET AL., 2008]

$$
Q_{p}=-\frac{\pi d_{p}{ }^{4} g \Delta h_{p}}{128 v \Delta l_{p} \tau}
$$

with $Q_{p}$ the volumetric flow rate $\left[\mathrm{L}^{3} \mathrm{~T}^{-1}\right], d_{p}$ the pipe diameter $[\mathrm{L}], g$ the gravitational acceleration $\left[\mathrm{LT}^{-2}\right], \Delta h_{p}$ the head losses along the pipe $[\mathrm{L}], v$ the kinematic viscosity of water $\left[\mathrm{L}^{2} \mathrm{~T}^{-1}\right]$ and $\tau$ the tortuosity of the pipe [-].

Exchange flow between the discrete pipe network, which consists of cylindrical pipes, and the matrix continuum is considered by a linear quasi-steady state exchange coefficient $\alpha_{\text {ex }}\left[\mathrm{L}^{2} \mathrm{~T}^{-1}\right]$ at every pipe node (BARENBLATT ET AL., 1960; BAUER ET AL., 2003; SHOEMAKER ET AL., 2008)

$$
Q_{e x}=\alpha_{e x}\left(h_{C}-h_{m}\right)
$$

with $h_{\mathrm{c}}$ the conduit head [L] and $h_{\mathrm{m}}$ the matrix head [L]. According to BAUER ET AL. (2003), the exchange coefficient $\alpha_{\text {ex }}$ is a lumped conductance term representing the geometry of the pipe as well as the properties describing the hydraulic conditions of the interface as

$$
Q_{e x}=2 \pi \frac{d_{p}}{2} \Delta l_{p} \alpha K \tau \Delta h
$$




\section{Chapter 3}

with $K$ the hydraulic conductivity of the matrix continuum $\left[\mathrm{LT}^{-1}\right], \alpha$ the inverse fissure spacing $\left[\mathrm{L}^{-1}\right]$ and $\Delta h$ the difference of conduit head $h_{c}$ and matrix head $h_{m}[\mathrm{~L}]$.

REIMANN ET AL. (2014) implemented a fast responding storage to the conduit system, which is in direct hydraulic contact with the pipe network:

$$
h_{C A D S}=h_{c}
$$

with $h_{\text {CADS }}$ the hydraulic head in the CAD storage [L]. The conduit-associated drainable storage (CADS) was implemented to provide an additional storage at every pipe node. Changes of the hydraulic conduit head are directly associated with outflow or inflow from the fast responding storage such as (REIMANN ET AL., 2014)

$$
Q_{C A D S}=\frac{V_{C A D S, t}-V_{C A D S, t-\Delta t}}{\Delta t}
$$

with

$$
V_{C A D S}=l_{C A D S} W_{C A D S}\left(h_{c}-z_{B o t}\right)
$$

with ICADS the length of the storage segment associated with the conduit node $[\mathrm{L}], W_{\text {CADS }}$ the width of the CAD storage $[\mathrm{L}]$ and $z_{\mathrm{Bot}}$ the elevation of the conduit bottom [L]. The head-related inflow from the storage is immediately available at the pipe node resulting in additional discharge of the pipe segment.

\subsection{Application of CFPM1 for traditional pumping test analysis}

According to KRUSEMANN AND DE RIDDER (1991), most of the analytical solutions assume an idealized flow domain consisting of a confined infinite aquifer domain with uniform thickness. The hydraulic heads prior to pumping with a constant pumping rate are horizontally distributed.

For the comparison of pumping tests, dimensionless parameters are used to erase the influence of hydraulic properties or the pumping rate on the 
drawdown curve. For homogeneous, isotropic and confined aquifers the dimensionless parameters can be defined as (BERTRAND AND GRINGARTEN, 1978; SPANE AND WURSTNER, 1993)

$$
\begin{aligned}
& S_{D}=\left(\frac{2 \pi T}{Q_{p}}\right) \Delta S \\
& C_{D}=\frac{C}{2\left(x_{f}^{2} S \pi\right)} \\
& t_{D}=\frac{T t}{x_{f}^{2} S}
\end{aligned}
$$

with $\Delta s$ the water level change inside the conduit [L], $C$ the wellbore storage constant $\left[\mathrm{L}^{2}\right], T$ the matrix transmissivity $\left[\mathrm{L}^{2} \mathrm{~T}^{-1}\right]$ and $S$ the matrix storativity [-]. As an additional tool for the interpretation of pumping tests the dimensionless drawdown derivative $S_{D}{ }^{\prime}[-]$ is suitable to detect minor changes in the drawdown behavior (SPANE AND WURSTNER, 1993) and is defined as (BOURDET ET AL., 1983)

$$
S_{D}^{\prime}=\frac{\partial s_{D}}{\partial \ln \left(t_{D} / C_{D}\right)}
$$

The applied CFPM1 model set-up is appropriate to fulfill the requirements of an idealized aquifer. A large extent of the model domain $(113,000 \mathrm{~m} \times$ $113,000 \mathrm{~m}$ ) is suitable to represent a quasi-infinite aquifer by avoiding boundary effects. The uniform aquifer thickness is $b=250 \mathrm{~m}$ with a bottom elevation of $0 \mathrm{~m}$. The matrix is considered as a single confined layer with initial hydraulic heads of $500 \mathrm{~m}$. The storativity of the layer is $S=2.5 \times 10^{-2} \mathrm{~m}^{-1}$ and the transmissivity $T=2.5 \times 10^{-2} \mathrm{~ms}^{-1}$. The following set-ups consider a single straight pipe. The pumping well, with a constant pumping rate of $Q_{p}=0.5 \mathrm{~m}^{3} \mathrm{~s}^{-1}$, is centrally located in the pipe. The pumping time is suitable to investigate effects from the inner boundary conditions affecting the drawdown at the beginning of pumping. Each pipe consists of a defined number of pipe nodes which are connected by pipe sections of length $\Delta I=20 \mathrm{~m}$ and pipe diameter $d_{p}=1 \mathrm{~m}$. Due to the limitation of most analytical solutions, i.e. infinite pipe conductivity, the pipe flow is simulated by the laminar Hagen-Poiseuille equation. The set-up uses a stepwise increase of the spatial discretization of the model domain from $1 \mathrm{~m}$ directly at the pipe to a cell size of $100 \mathrm{~m}$. 


\section{Chapter 3}

\subsection{Parameter transformation}

\subsubsection{Skin damage factor}

In traditional pumping test analysis, the skin damage factor $S_{f}$ is used to explain pressure differences between the wellbore and the adjacent rock. In general, the skin conductance changes the shape of the drawdown curve, especially at the beginning of water abstraction. According to Equation 3.4, CFPM1 uses the exchange coefficient $\alpha_{e x}$ to regulate the exchange flow. Therefore, the exchange coefficient accounts for pressure head differences between matrix and pipe. The MODFLOW Multi-Node Well Package (MFMNW2, KORNIKOW ET AL., 2009) also considers a well-to-cell conductance term similar to the exchange coefficient of CFMP1. Different input options allow splitting the conductance term into terms accounting for different flow restrictions for horizontal well segments, both numerically and conceptually based. The linear well-loss coefficient B is used to quantify head losses of the interface between the wellbore and the matrix, e.g. formation damages or gravel packs and can be defined as (KORNIKOW ET AL., 2009)

$$
B=\frac{S_{f}}{2 \pi K \Delta l}
$$

MF-MNW2 also considers a linear aquifer-loss coefficient A for the determination of exchange flow between matrix cell and wellbore node. This coefficient accounts for cell-to-well head losses for finite-differences models and is a function of the ratio of the cell size (effective external radius, $r_{o}[\mathrm{~L}]$ ) and the pipe diameter $r_{w}[\mathrm{~L}]$ (KORNIKOW ET AL., 2009). The aquifer-loss coefficient is defined as (KORNIKOW ET AL., 2009):

$$
A=\frac{\ln \left(\frac{r_{o}}{r_{w}}\right)}{2 \pi b \sqrt{K_{x} K_{y}}}
$$

with

$$
r_{0}=0.28 \frac{\sqrt{\Delta x^{2} \sqrt{\frac{K_{y}}{K_{x}}}+\Delta y^{2} \sqrt{\frac{K_{x}}{K_{y}}}}}{\sqrt[4]{\frac{K_{y}}{K_{x}}}+\sqrt[4]{\frac{K_{x}}{K_{y}}}}
$$


where $b$ is the saturated thickness of the cell and $\Delta x, \Delta y$ the grid spacing in $\mathrm{x}$ and y direction.

The reciprocal sum of the linear well-loss and the linear aquifer-loss coefficient is used as a conductance term between wellbore and matrix, similar to the exchange coefficient of Equation 3.4.

Figure 3.2 presents the dimensionless drawdown for four different skins ranging from a skin damage factor of $S_{f}=1$ (Fig. 3.2a) to a skin damage factor of $S_{f}=0.001$ (Fig. 3.2d). The figures compare the drawdown computed with the mentioned skin damage factor according to the analytical Equation 3.1 and the numerical drawdown using the exchange coefficient according to Equation 3.16, as well as only considering the linear well-loss coefficient $B(A=0)$. The applied parameter values are presented in Table 3.1. The exchange coefficient value is specified per unit meter along the pipe.

Table 3.1: Parameter values for the two exchange coefficient terms (according to Eq. 3.16).

\begin{tabular}{|c|c|c|c|c|}
\hline & $S_{f}$ & $\mathrm{~A}\left[\mathrm{sm}^{-2}\right]$ & $\mathrm{B}\left[\mathrm{sm}^{-2}\right]$ & $(\mathrm{A}+\mathrm{B})^{-1}\left[\mathrm{~m}^{2} \mathrm{~s}^{-1}\right]$ \\
\hline$\vec{F}$ & 1.0 & 338.09 & 79.58 & $2.39 \mathrm{E}^{-3}$ \\
\hline 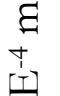 & $1.0 \mathrm{E}^{-1}$ & 338.09 & 7.96 & $2.89 \mathrm{E}^{-3}$ \\
\hline$\stackrel{0}{\circ}$ & $1.0 \mathrm{E}^{-2}$ & 338.09 & $7.96 \mathrm{E}^{-1}$ & $2.95 \mathrm{E}^{-3}$ \\
\hline$\stackrel{11}{*}$ & $1.0 \mathrm{E}^{-3}$ & 338.09 & $7.96 \mathrm{E}^{-2}$ & $2.96 \mathrm{E}^{-3}$ \\
\hline
\end{tabular}

For short times, the analytical pipe drawdown raises with increased skin damage factor following nearly horizontal lines for high skin damage factors. Decreasing the skin damage factor and therefore increasing the exchange flow results in a reduction of the pipe drawdown. For a low skin damage factor $\left(S_{f}=0.001\right)$ the analytical drawdown shows defined linear flow conditions with a half-unit slope on the diagnostic plot, hence the skin damage factor causes no additional pressure drop. The drawdown curves of the computed exchange coefficient, considering only $\mathrm{B}$, underrate the drawdown at the beginning of pumping. Differences in drawdown between the analytical and the numerical solution are high for high skin damage factors. However the numerical model is not able to represent the analytical drawdown behavior. The applied values 


\section{Chapter 3}

are too low and therefore the linear well-loss coefficient B is not sufficient to represent the skin factor in the CFPM1.
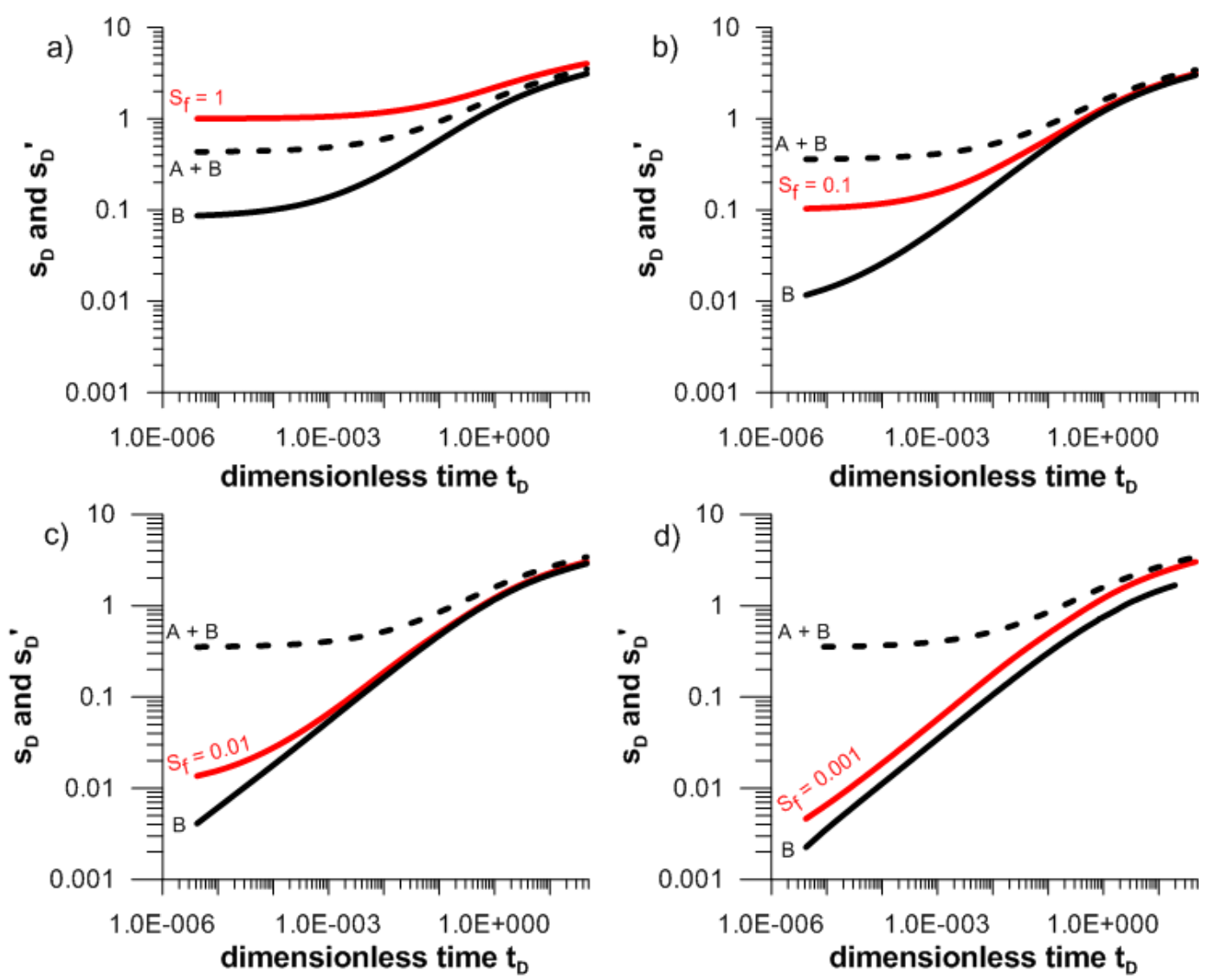

- analytical drawdown - numerical drawdown B - - numerical drawdown A+B

Fig. 3.2: Comparison of the analytical and the numerical drawdown behavior of the CFPM1 for a) $S_{f}=1$; b) $S_{f}=0.1$; c) $S_{f}=0.01$; d) $S_{f}=0.001$ without the consideration of wellbore storage.

For a skin damage value of $S_{f}=1$ (Fig. 3.2a) both linear coefficients underrate the analytical drawdown, whereas the drawdowns of the combined coefficients $(\mathrm{A}+\mathrm{B})$ for the lower skin damage values (Fig. 3.2b/c/d) are higher compared to the analytical solution. In all cases, drawdowns, consisting of the linear well-loss coefficient and the linear aquifer-loss coefficient $(\mathrm{A}+\mathrm{B})$, are approximately equal. This is the consequence of the applied set-up with one single layer of $250 \mathrm{~m}$ thickness. The cell thickness is by far the largest cell side and according to Equation 3.15 the computed effective external radius $\left(r_{o}=35 \mathrm{~m}\right)$ exceeds the pipe diameter $\left(d_{p} / 2=0.5 \mathrm{~m}\right)$. Hence the linear aquifer-loss coefficient dominates the well-loss coefficient. Figure 2 shows that the linear well-loss coefficient is also not able to represent the analytical drawdown for the given skin damage values $S_{f}$. An additional pressure term is demanded to 
counterbalance the influence of the linear aquifer-loss coefficient. Therefore, the reciprocal exchange coefficient will be extended by an empirical calibration coefficient (ECC).

$$
\alpha_{e x}=\left[\frac{S_{f}}{2 \pi K \Delta l}+\frac{\ln \left(\frac{r_{o}}{r_{w}}\right)}{2 \pi b \sqrt{K_{x} K_{y}}}+E C C\right]^{-1}
$$

The empirical calibration coefficient is also applied to consider effects caused by the different functioning and geometries (plane fracture vs. cylinder with finite volume) as well as different representations of the skin and the halffracture length. According to Equation 3.2, the skin of the analytical solution considers a finite plane damage zone around the fracture. The dimension of the skin is very small compared to the fracture length. Furthermore, the analytical solution integrates the drawdown along the half-fracture length instead of computing a single value per unit length. The initial exchange coefficient value needs to be calibrated on the analytical drawdown curve. This can be done manually as in this analysis or by a calibration tool, e.g. PEST (DOHERTY, 2015). The calibration needs to be done for one skin damage factor only. According to Table 3.1, the exchange coefficient is related linearly to the skin damage factor. By increasing the skin damage factor $S_{f}$ by one order of magnitude the linear well-loss coefficient B increases by the same value. As a result, the exchange coefficient also decreases by a factor of ten. The linear aquifer-loss coefficient is constant, as long as the discretization of the model domain and pipe remain unchanged. The composition of the exchange coefficient according to Equation 3.16 and the influence caused by the three exchange terms will be further analyzed. Table 3.2 lists the applied parameters as well as the exchange term values. 


\section{Chapter 3}

Table 3.2: Parameter values for the three exchange coefficient terms (according to Eq. 3.17).

\begin{tabular}{|c|c|c|c|c|c|c|}
\hline & $S_{f}$ & factor & $\begin{array}{c}\alpha_{e x} \\
{\left[\mathrm{~m}^{2} \mathrm{~s}^{-1}\right]}\end{array}$ & $\begin{array}{c}\mathrm{A} \\
{\left[\mathrm{sm}^{-2}\right]}\end{array}$ & $\begin{array}{c}\mathrm{B} \\
{\left[\mathrm{sm}^{-2}\right]}\end{array}$ & $\begin{array}{l}\text { ECC } \\
{\left[\mathrm{sm}^{-2}\right]}\end{array}$ \\
\hline 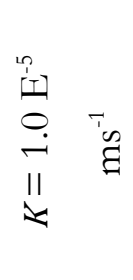 & $\begin{array}{c}1.0 \\
1.0 \mathrm{E}^{-1} \\
1.0 \mathrm{E}^{-2} \\
1.0 \mathrm{E}^{-3}\end{array}$ & $1.0 \mathrm{E}^{-1}$ & $\begin{array}{l}1.07 \mathrm{E}^{-4} \\
1.07 \mathrm{E}^{-3} \\
1.07 \mathrm{E}^{-2} \\
1.07 \mathrm{E}^{-1}\end{array}$ & 3380.85 & $\begin{array}{c}795.77 \\
79.58 \\
7.96 \\
7.96 \mathrm{E}^{-1}\end{array}$ & $\begin{array}{c}183064.74 \\
15263.71 \\
-1516.39 \\
-3194.41\end{array}$ \\
\hline 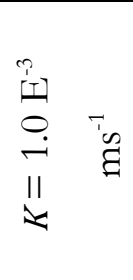 & $\begin{array}{c}1.0 \\
1.0 \mathrm{E}^{-1} \\
1.0 \mathrm{E}^{-2} \\
1.0 \mathrm{E}^{-3}\end{array}$ & $1.0 \mathrm{E}^{1}$ & $\begin{array}{c}1.07 \mathrm{E}^{-2} \\
1.07 \mathrm{E}^{-1} \\
1.07 \\
10.68\end{array}$ & 33.80 & $\begin{array}{c}7.96 \\
7.96 \mathrm{E}^{-1} \\
7.96 \mathrm{E}^{-2} \\
7.96 \mathrm{E}^{-3}\end{array}$ & $\begin{array}{c}1830.00 \\
152.64 \\
-15.16 \\
-31.94\end{array}$ \\
\hline $\begin{array}{l}\Xi \\
0 \\
1 \\
11 \\
\Sigma\end{array}$ & $\begin{array}{c}1.0 \\
1.0 \mathrm{E}^{-1} \\
1.0 \mathrm{E}^{-2} \\
1.0 \mathrm{E}^{-3}\end{array}$ & $2.0 \mathrm{E}^{-1}$ & $\begin{array}{l}2.14 \mathrm{E}^{-4} \\
2.14 \mathrm{E}^{-3} \\
2.14 \mathrm{E}^{-2} \\
2.14 \mathrm{E}^{-1}\end{array}$ & 210.03 & $\begin{array}{c}79.58 \\
7.96 \\
7.96 \mathrm{E}^{-1} \\
7.96 \mathrm{E}^{-2}\end{array}$ & $\begin{array}{c}93331.08 \\
9144.09 \\
725.39 \\
-116.48\end{array}$ \\
\hline 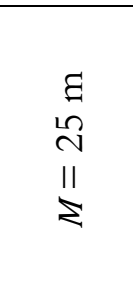 & $\begin{array}{c}1.0 \\
1.0 \mathrm{E}^{-1} \\
1.0 \mathrm{E}^{-2} \\
1.0 \mathrm{E}^{-3}\end{array}$ & $1.0 \mathrm{E}^{-1}$ & $\begin{array}{l}1.07 \mathrm{E}^{-4} \\
1.07 \mathrm{E}^{-3} \\
1.07 \mathrm{E}^{-2} \\
1.07 \mathrm{E}^{-1}\end{array}$ & 154.91 & $\begin{array}{c}79.58 \\
7.96 \\
7.96 \mathrm{E}^{-1} \\
7.96 \mathrm{E}^{-2}\end{array}$ & $\begin{array}{c}187006.86 \\
18561.27 \\
1716.70 \\
32.25\end{array}$ \\
\hline 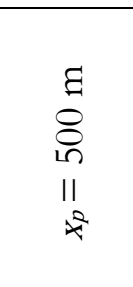 & $\begin{array}{c}1.0 \\
1.0 \mathrm{E}^{-1} \\
1.0 \mathrm{E}^{-2} \\
1.0 \mathrm{E}^{-3}\end{array}$ & $3.4 \mathrm{E}^{-1}$ & $\begin{array}{c}3.10 \mathrm{E}^{-3} \\
3.10 \mathrm{E}^{-2} \\
3.10 \mathrm{E}^{-1} \\
3.10\end{array}$ & 338.09 & $\begin{array}{c}79.58 \\
7.96 \\
7.96 \mathrm{E}^{-1} \\
7.96 \mathrm{E}^{-2}\end{array}$ & $\begin{array}{c}6033.95 \\
299.12 \\
-274.36 \\
-331.71\end{array}$ \\
\hline 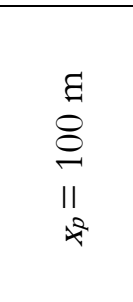 & $\begin{array}{c}1.0 \\
1.0 \mathrm{E}^{-1} \\
1.0 \mathrm{E}^{-2} \\
1.0 \mathrm{E}^{-3}\end{array}$ & $7.4 \mathrm{E}^{-2}$ & $\begin{array}{c}1.44 \mathrm{E}^{-2} \\
1.44 \mathrm{E}^{-1} \\
1.44 \\
14.4\end{array}$ & 338.09 & $\begin{array}{c}79.58 \\
7.96 \\
7.96 \mathrm{E}^{-1} \\
7.96 \mathrm{E}^{-2}\end{array}$ & $\begin{array}{l}971.23 \\
-207.15 \\
-324.99 \\
-324.28\end{array}$ \\
\hline
\end{tabular}

According to Equation 3.4 and 3.5 the exchange coefficient $\alpha_{\text {ex }}$ is a linear function of the hydraulic matrix conductivity $K$. Therefore, changes of the 
hydraulic matrix conductivity can be linearly transferred to the exchange coefficient. The hydraulic matrix conductivity is also part of the linear aquiferloss as well as the linear well-loss coefficient. According to Equation 3.16, the change of the two terms is reciprocal to the hydraulic conductivity. The ratio between the three exchange terms stays constant by changing the hydraulic conductivity.

Figures 3.3a and 3.3b present a reasonable match between the analytical and the numerically computed drawdown for all applied skin damage factors. Drawdown differences are generally low during the entire duration of pumping. The drawdown behavior is well represented also in terms of the beginning of the transition period between linear and radial flow starting approximately at $t_{D}=0.1$. The dimensionless residua confirm the overall small discrepancies between analytical solution and the result of CFPM1. Differences are low for a hydraulic conductivity of $K=1.0 \times 10^{-5} \mathrm{~ms}^{-1}$. For a hydraulic conductivity of $K=1.0 \times 10^{-3} \mathrm{~ms}^{-1}$, the dimensionless residua are low at the beginning and increase at approximately $t_{D}=0.05$. This time level equals the beginning of the transition period. The difference during the transition period can be explained by a different flow behavior, visible at the derivative curve of Figure 3.3b (and even more pronounced in Fig. 3.3f). The analytical drawdown curve increases steeply, resulting in a shallow slope of the derivative curve and hence positive residual values during this period. Those differences can be explained by the earlier start of Darcian flow in the analytical solution which can also be considered as minor conceptual difference. Nevertheless, the relative error caused by the drawdown discrepancy is less than $5 \%$. In Figure $3.3 \mathrm{~b}$ the drawdown curves for the skin damage factor of $S_{f}=1.0 \times 10^{-3}$ are not presented because of numerical instability of the CFPM1 model.

The thickness of the confined layer changes the transmissivity of the model domain. The thickness, and therefore also the transmissivity, is not part of the exchange coefficient according to Equation 3.5. Nevertheless, according to Equation 3.16 the exchange coefficient is linearly related to the transmissivity. The thickness of the layer changes the linear aquifer-loss coefficient A due to the decrease of the layer thickness, which is one of the cell edges. The linear well-loss coefficient stays constant for the relative skin damage factors. 


\section{Chapter 3}

The applied exchange coefficient, adjusted by the factor of 0.2 and 0.1 for a layer thickness of $M=50 \mathrm{~m}$ respectively $M=25 \mathrm{~m}$, approximates the analytical drawdown adequately (Fig. 3.3c/d). The dimensionless residua are small for the entire time of the pumping interval and, therefore, is the accuracy of the drawdown comparable to the one presented in Figure 3.4a and 3.4b. 

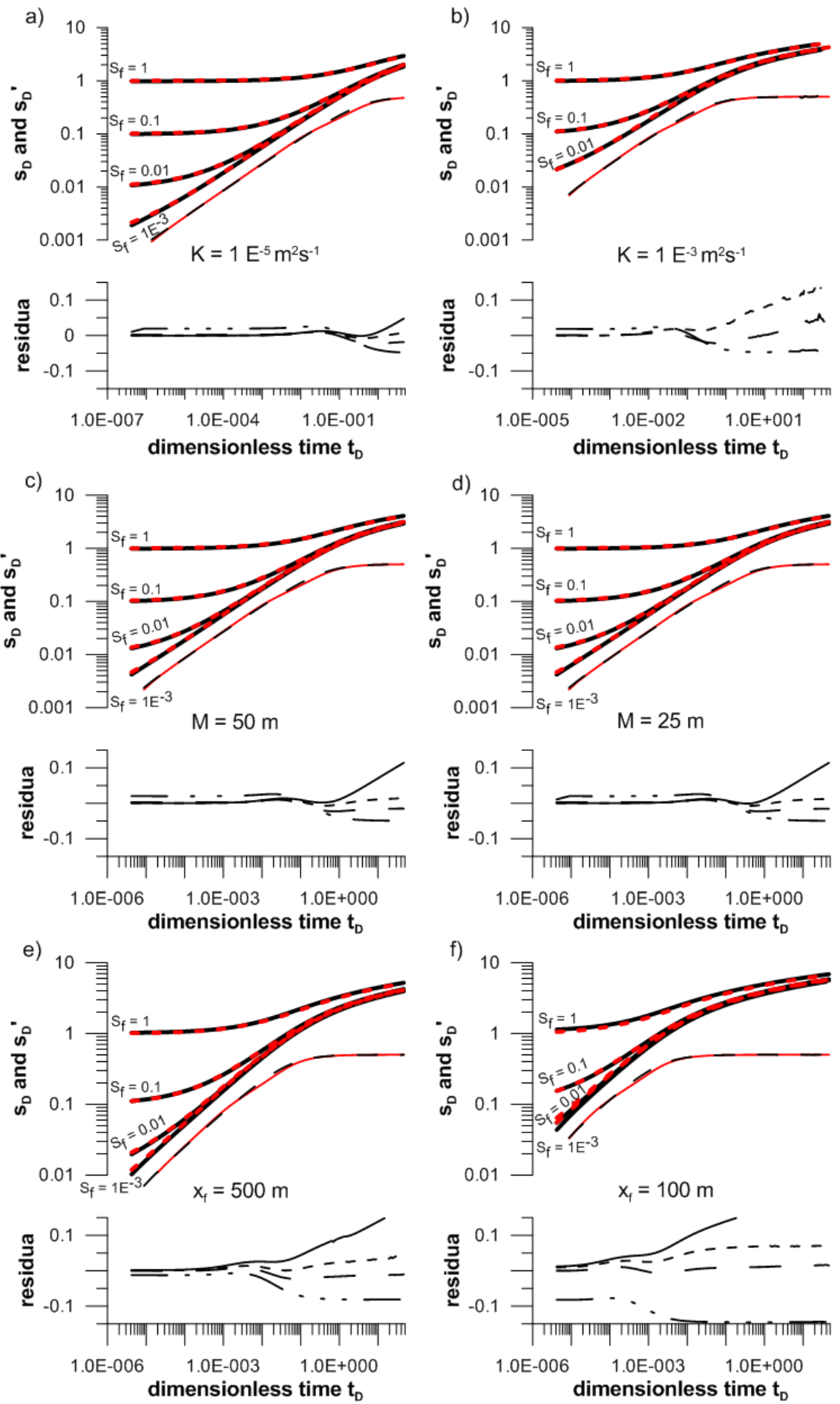

- CFPM1 drawdown - CFPM1 derivative - - analytical drawdown - analytical derivative

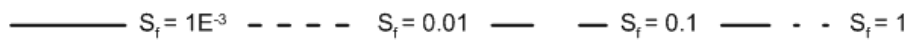

Fig. 3.3: Comparison of the analytical and the numerical drawdown behavior for different skin damage values in terms of dimensionless drawdown, derivative and residua for a) a hydraulic conductivity of $K=1.0 \times 10^{-5} \mathrm{~m}^{2} \mathrm{~s}^{-1}$; b) a hydraulic conductivity of $K=1.0 \times 10^{-3} \mathrm{~ms}^{-1}$; c) a layer thickness of $M=50 \mathrm{~m}$; d); a layer thickness of $M=25 \mathrm{~m}$; e) a pipe half-length of $x f=500 \mathrm{~m}$ and $\mathrm{f}$ ) a pipe half-length of $x_{f}=100 \mathrm{~m}$ without the consideration of wellbore storage. 


\section{Chapter 3}

According to Equation 3.16, the pipe half-length $x_{f}$ is neither part of the exchange coefficient nor of one of the two linear loss coefficients. Therefore, the values of $\mathrm{A}$ and $\mathrm{B}$ do not change, whereas the value for the exchange coefficient differs from the initial one. The changing factor cannot be directly calculated, thus the exchange coefficient needs to be calibrated again. Figure 3.4 presents the calibration results for a half-pipe length of $x f=10 \mathrm{~m}$ up to $X f=1500 \mathrm{~m}$ for the introduced set-up. The results can be approximated by a potential function. For the presented half-pipe lengths, a linear function on a log-log plot is sufficient to describe the relationship between the exchange coefficient $\alpha_{e x}$ and the skin damage factor. With decreasing half-pipe length, the drawdown difference between small skin values assimilates. Drawdown differences between analytical and numerical drawdown increase for the given set-up. One reason is the already mentioned differences of the flow pattern during the transition period, which starts early for a short pipe half-length. An adjustment of the spatial discretization with finer cell sides in horizontal as well as vertical direction could buffer the discrepancy and is highly recommended for applying case studies on a local scale.

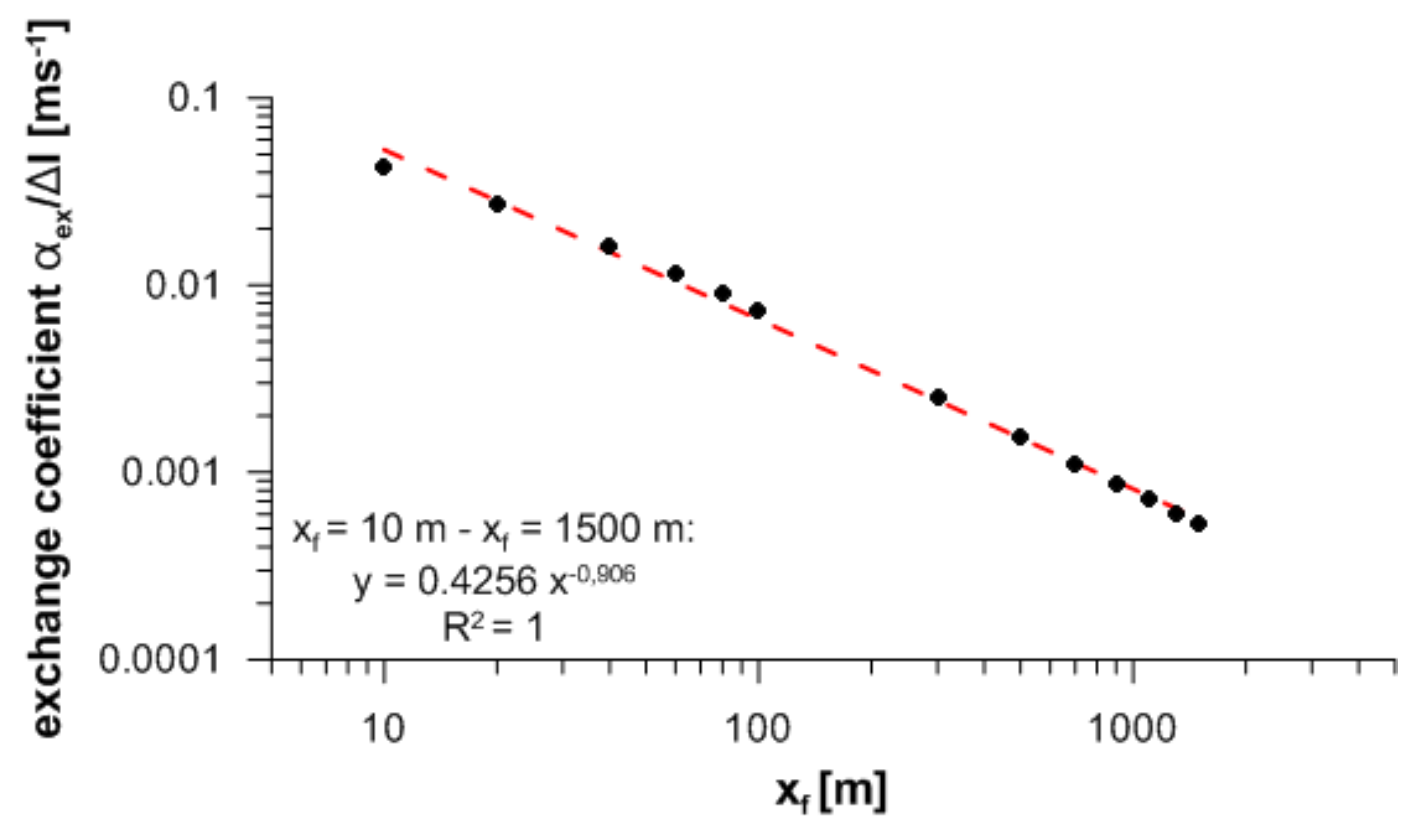

Fig. 3.4: Calibration curve for the exchange coefficient $\alpha_{\text {ex }}$ per unit length $\Delta l$ related to the half-pipe length for a parameter range of $x_{f}=10 \mathrm{~m}$ up to $x_{f}=1500 \mathrm{~m}$.

Summarizing the results, the exchange coefficient $\alpha_{\text {ex }}$ is able to represent the analytical transient drawdown curve of a horizontal fracture considering the skin damage value. The analysis shows that the exchange coefficient is related to the 
spatial discretization of the control volume as well as to the hydraulic and spatial parameters describing the model domain and therefore the whole system.

\subsubsection{Dimensionless wellbore storage}

The wellbore storage constant $C\left[\mathrm{~L}^{2}\right]$ is a function of the casing radius and defined as (MOENCH, 1984; NOVAKOWSKI, 1990)

$$
C=r_{c}^{2} \pi
$$

where $r_{\mathrm{c}}$ is the well casing radius [L]. The casing radius describes the area affected by hydraulic head changes leading to wellbore storage (MOENCH, 1984). According to CINCO-LEY ET AL. (1978), the same effect as caused by wellbore storage can be created by the storage of a highly conductive fracture. The circular area (around a vertical bore well) describes the same area as the horizontal CAD-storage (Eq. 3.7). Therefore, the casing radius for highly conductive pipes, assuming only minor pressure drops along the conduit, can be described as a function of the CAD-storage as

$$
r_{c}=\sqrt{\frac{\sum\left(l_{C A D S} W_{C A D S}\right)}{\pi}}
$$

MCCONNELL (1993) mentioned an increase of wellbore storage by a factor of 10 to 100 for wellbores intersected by fractures over a non-fractured wellbore. Joints, faults and fissures only add a marginally proportion of porosity to the well bore storage (WORTHINGTON ET AL., 2000; BOURDET, 2001).

The conduit storage of a single pipe describes the same area affected by the casing radius defined for vertical wellbores (Eq. 3.18). To verify the equation, different CAD widths are compared to different casing radii of the analytical solution (Eq. 3.1). The values of the different storage representations are listed in Table 3.3. Figure 3.4 shows diagnostic plots of analytically calculated drawdown curves for different casing radii (Eq. 3.1) and compared to

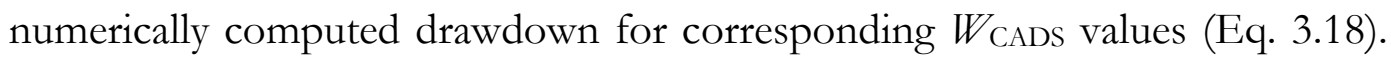
Both the analytical and the numerical representation of the pipe assume a halflength $X f=1,500 \mathrm{~m}$, a pipe diameter $d_{p}=1.0 \mathrm{~m}$ and a skin factor $S_{f}=1.0$. 


\section{Chapter 3}

Table 3.3: Parameter values for the calculation of the dimensionless wellbore storage.

\begin{tabular}{c|c|c|c}
\hline$r_{C}[\mathrm{~m}]$ & $W_{C A D S}[\mathrm{~m}]$ & $C\left[\mathrm{~m}^{2}\right]$ & $C_{D}[-]$ \\
\hline 2.5 & 0.007 & 19.63 & $5.6 \mathrm{E}^{-5}$ \\
5.0 & 0.026 & 78.54 & $2.2 \mathrm{E}^{-5}$ \\
10.0 & 0.105 & 314.16 & $8.9 \mathrm{E}^{-4}$ \\
15.0 & 0.654 & 706.86 & $2.0 \mathrm{E}^{-3}$ \\
\hline
\end{tabular}

The casing radius (conduit storage) only influences the shape of the curves at the beginning of water abstraction. During this period all the different parametrizations show a significant linear unit slope of the diagnostic plots representing wellbore storage. With increased casing radius, the drawdown at early time decreases and the storage provides the major part of the abstracted volume. Because of the low hydraulic gradient between conduit and fractured matrix, the exchange flow is negligible at the beginning of water abstraction. The exchange flow increases with time until the two porosities tend to an equilibrium condition of pressure. During the transition period, where the matrix starts to contribute water to the conduit system, the derivative shows a characteristic hump. After the storage and the transition period, the drawdown curves for all the set-ups show a similar behavior, which can be described by linear flow equations. 


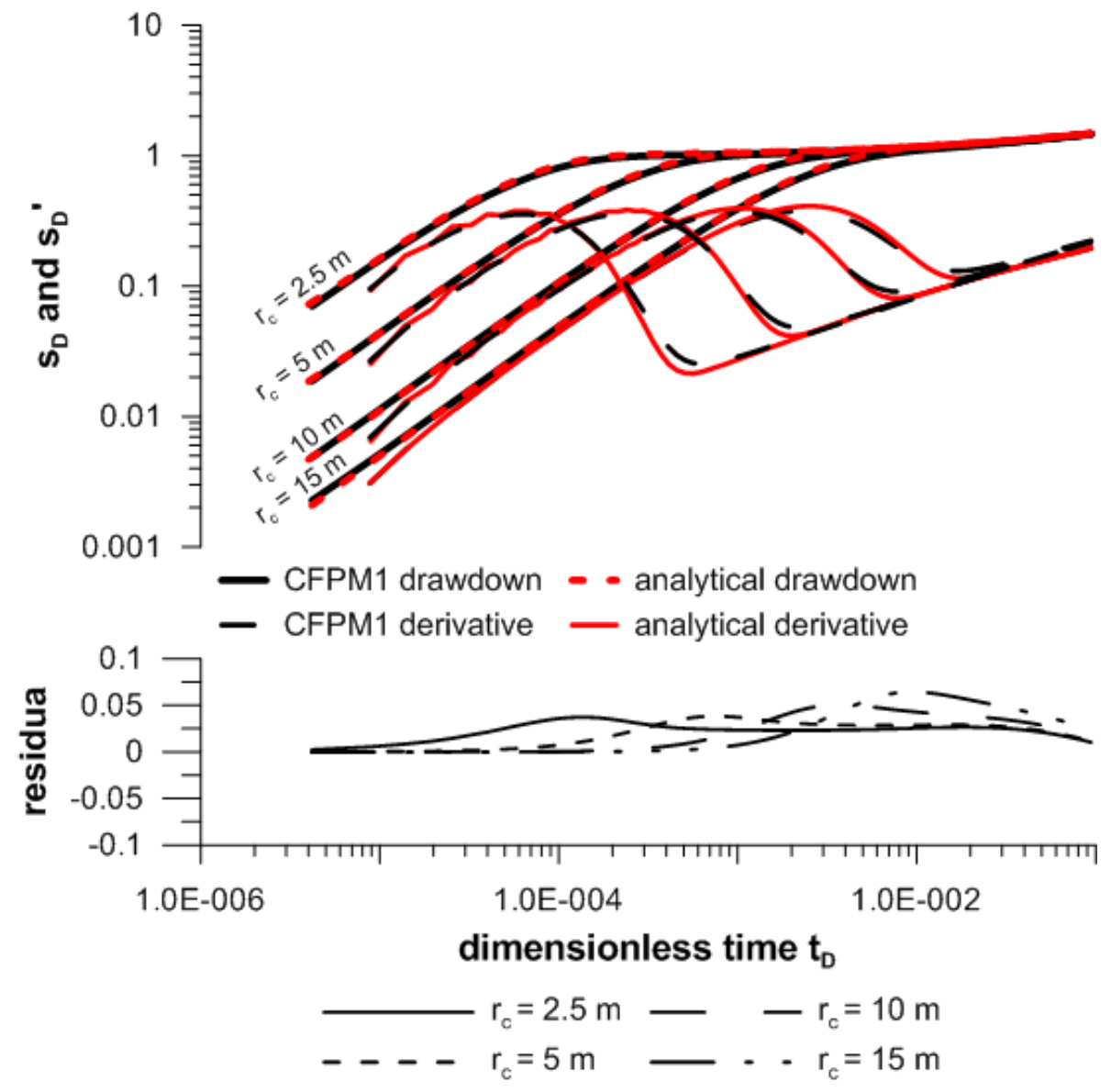

Fig. 3.5: Representation of dimensionless wellbore storage computed by CFPM1 (black curves) and the analytical solution (red curves) for a skin damage factor of $S_{f}=1$.

Figure 3.5 shows an appropriate match of analytically calculated and numerically computed drawdown curves. The residua between analytical and numerical drawdown are close to zero during the entire storage period. The highest drawdown differences can be detected during the transition between storage and linear flow period. The differences are also visible at the derivative curves. The residua start to increase at the end of the storage dominated period. During the transition to linear flow the discrepancy increases resulting into a significant hump just before reaching the linear flow period. The conduit drawdown is underrated by the numerical model, which can be related to the storage value. The discrepancy between the two solutions increases with growing wellbore storage. The discrete numerical model starts slightly faster tending to linear flow. The increased exchange flow therefore damps the drawdown compared to the analytical solution. At the end of linear flow the 


\section{Chapter 3}

drawdown differences, which can be explained by the conceptual differences, are visible.

\subsection{Conclusions}

The analysis shows that the introduced equations for the discrete conduitcontinuum model CFPM1 are able to approximate inner boundary conditions over a larger parameter space. The drawdown of a plane fracture derived by an analytical solution can be approximated with reasonable accuracy. An equation is presented to consider wellbore storage by the fast-responding storage of CFPM1. Furthermore, the relationship between the analytical skin damage factor and the numerical exchange coefficient, frequently applied for source/loss boundary conditions of different MODFLOW packages (e.g. MNW2), is analyzed.

The analysis is limited to a single layer model, but presents the dualism of the exchange coefficient. As long as ECC cannot be defined, the parameter serves as a calibration parameter. However, the results show that the calibration needs to be executed only once. Afterwards, assuming a constant spatial discretization as well as a constant well screen length, the exchange coefficient can be adjusted manually, for example for the analysis on the effect of the skin damage value. The separation of different exchange terms also has the advantage that further processes, resulting in pressure differences between the pipe and the matrix, can be added.

The set-up of the analyses is primary chosen to represent idealized conditions during pumping tests in karst aquifer systems. The presented results can be used for the interpretation of pumping tests in mature karst systems characterized by highly conductive features, e.g. solution enlarged fractures, conduits, caves. For this purpose, one enhancement of the exchange coefficient can be the implementation of non-linear exchange flow. Based on the similarity to the representation of horizontal wellbores CFPM1 can most likely be applied for the analysis of horizontal wellbore tests due to the advantages over analytical solutions, i.e. the discrete parametrization of the pipe segments or the possibility to consider turbulent flow. 
For the application of the discrete-continuum model CFPM1 on the interpretation of horizontal wellbore tests further tests are demanded. The presented approach is limited to infinite conductivity along the pipe. Those flow patterns are unlikely to be present in modern horizontal wells due to the advanced technique invented during the last decades. With increased abstraction rate and length of the well screen, changes of the flow pattern can occur, e.g. transition zones of laminar and turbulent inside as well as non-uniform skin zones around the wellbores, which query the validity of the infinite conductivity and uniform flux solutions (OZKAN, 2001). Due to the coupling of a turbulent discrete pipe to a continuum representing laminar Darcian flow by an exchange coefficient representing the skin damage factor even analyses on a long term basis are possible. 


\section{Chapter 3}

\section{References}

Agarwal, R. G., Al-Hussainy, R. and Ramey, H. J. (1970): An investigation of wellbore storage and skin effect in unsteady liquid flow: I. Analytical treatment, SPE J., 10-03, 279-290.

Bauer, S., Liedl, R. and Sauter, M. (2003): Modeling of karst aquifer genesis: Influence of exchange flow, Water Resour. Res., Vol.39, Nr.10, doi:10.1029/2003WR002218.

Barenblatt, G. I., Zheltov, I. P. and Kochina, I. N. (1960): Basic concepts in the theory of seepage of homogeneous liquids in fissured rock, Journal of Applied Mathematics and Mechanics (PMM), 24(5), 1286-1303.

Beauheim, R. L., Roberts, R. M. and Avis, J. D. (2004): Well testing in fractured media: Flow dimensions and diagnostic plots, Journal of Hydraulic Research, 42 (Extra Issue), 69-76.

Bertrand, L. and Gringarten, A. C. (1978): Détermination des caractéristiques hydrauliques des aquifères fissurés par pompage d'essai en régime transitoire Application aux nappes de la craie, Final report 78 SGN 669 GEG, BRGM, Orléans.

Birk, S., Geyer, T., Liedl, R. and Sauter, M. (2005): Process-based interpretation of tracer tests in carbonate aquifers, Ground Water, Vol. 43, 3, 381-388.

Bourdet, D. (2001): Well test analysis: The use of advanced interpretation models, Elsevier, Amsterdam.

Bourdet, D., Whittle, T. M., Douglas, A. A. and Pirard, Y. M. (1983): A new set of type curves simplifies well test analysis, WORLD OIL, 196, 95-106.

Cinco-Ley, H., Samaniego-V., F. (1981): Transient pressure analysis for fractured wells, SPE J., 7490, 1749-1766. 
Cinco-Ley, H., Samaniego-V., F., Dominguez-A., N. (1978): Transient pressure behaviour for a well with a finite-conductivity vertical fracture, SPE J., 6014, 253-264.

Doherty, J. (2015): Calibration and uncertainty analysis for complex environmental models: PEST - complete theory and what it means for modelling the real world, Watermark, Brisbane, Australia.

Ehlig-Economides, C. A. and Economides, M. J. (2000): Formation Characterization: Well and Reservoir testing, In: Reservoir stimulation, Chapter 2, edited by M. J. Ehlig-Economides and K. J. Nolte, Wiley, Chichester.

Gallegos, J. J., Hu, B. X. and Davis, H. (2013): Simulating flow in karst aquifers at laboratory and sub-regional scales using MODFLOW-CFP, Hydrogeology Journal, 1749-1760; doi:10.1007/s10040-013-1046-4.

Gringarten, A. C. (1982): Flow-test evaluation of fractured reservoirs, In: Recent trends in hydrogeology, edited by: Narasimhan, T.N., Geological Society of America, Special Paper 189, 237-262.

Gringarten, A. C., Ramey (Jr.), H. J. and Raghavan, R. (1974): Unsteady-state pressure distributions created by a well with a single infinite-conductivity vertical fracture, SPE J., 14, 347-360.

Harbaugh, A.W. (2005): MODFLOW-2005, The U.S. Geological survey modular ground-water model - The Ground-Water Flow Process: U.S Geological Survey Techniques and Methods 6-A16.

Jenkins, D. N. and Prentice, J. K. (1982): Theory for aquifer test analysis in fractured rocks under linear (nonradial) flow conditions, Ground Water, Vol. 20, No.1, 12-21.

Kornikow, L. F., Hornberger, G. Z., Halford, K. J. and Hanson, R. T. (2009): Revised multi-node well (MNW2) package for MODFLOW ground-water flow model, US Geological Survey Techniques and Methods, 6-A30. 


\section{Chapter 3}

Krusemann, G. P and de Ridder, N. A. (1991): Analysis and evaluation of pumping test data, Institute for Land Reclamation and Improvement (ILRI), Wageningen.

McConnell, C. L. (1993): Double porosity well testing in the fractured carbonate rocks of the Ozarks, Ground Water, 31(1), 75-83.

Moench, A. F. (1984): Double-porosity model for a fissured groundwater reservoir with fracture skin, Water Resources Research, Vol. 20, No. 7, 831-846.

Novakowski, K. S. (1990): Analysis of aquifer test conducted in fractured rock: A review of the physical background and the design of a computer program for generating type curves, Ground Water, Vol.28, No.1, 99-107.

Ozkan, E. (2001): Analysis of horizontal-well responses: contemporary vs. conventional, SPE Reservoir Evaluation \& Engineering, Vol. 4(4), doi:10.2118/72494-PA.

Park, E. and Zhan, H. (2002): Hydraulics of a finite-diameter horizontal well with wellbore storage and skin effect, Advances in Water Resources, 25, 389-400.

Reimann, T., Rehrl, C., Shoemaker, W. B., Geyer, T. and S. Birk (2011): The significance of turbulent flow representation in single-continuum models, $W$ ater Resources Research, Vol. 47, W09503, doi:10.1029/2010WR010133.

Reimann, T. Giese, M. Geyer, T. Liedl, R. Maréchal, J.-C. and Shoemaker, W. B. (2014): Representation of water abstraction from a karst conduit with numerical discrete-continuum models, Hydrol. Earth Syst. Sci., 18, 227-241, doi:10.5194/hess-18-227-2014.

Renard, P. (2005): 151: Hydraulic of wells and well testing, In: Encyclopedia of hydrological sciences, Part 13. Groundwater, edited by M. Anderson, John Wiley \& Sons Ltd, New York, DOI10.1002/0470848944.hsa154a.

Shoemaker, W. B., Kuniansky, E. L., Birk, S., Bauer, S. and Swain, E. D. (2008): Documentation of a Conduit Flow Process (CFP) for MODFLOW-2005: U.S. Geological Survey Techniques and Methods, Book 6, Chapter A24. 
Spane (jr.), F. A. and Wurstner, S. K. (1993): A computer program for calculating pressure derivatives for use in hydraulic test analysis, Ground $W$ ater, 31(5), 814-822.

Theis, C. V. (1935): The relation between the lowering of the piezometric surface and the rate and duration of discharge of the well using groundwater storage, Trans. AGU, 16, 519-524.

van Everdingen, A. F. (1953): The skin effect and its influence on the productive capacity of a well, Trans. AIME, 198, 171-176.

van Everdingen, A. F and Hurst, W. (1949): The application of the Laplace transformation to flow problems in reservoirs, Trans. AIME, 186, 305-342.

Walker, D. D. and Roberts, M. R. (2003): Flow dimension corresponding to hydrogeologic conditions, Water Resources Research, 39(12), 1349.

Warren, J. E. and Root, P. J. (1963): The behavior of naturally fractured reservoirs, SPE J., 3: 245-255.

Worthington, S. R. H., Ford, D. C. and Davies, G. J. (2000): Matrix, fractures and channel components of storage and flow in a Paleozoic limestone aquifer, In: Groundwater flow and contaminant transport in carbonate aquifers, edited by: I. D. Sasowsky and C. M. Wicks, 113-128.

Xu, Z., Hu, B. X., Davis, H. and Cao, J. (2015): Simulating long term nitrate-N contamination processes in the Woodville Karst Plain using CFPv2 with UMT3D, Journal of Hydrology, 524, 72-88, doi:10.1016/j.hydrol.2015.02.024. 


\section{Chapter 4}

\section{Turbulent and laminar flow in karst conduits under unsteady flow conditions - interpretation pumping tests by discrete conduit-continuum modeling}

Markus Giese ${ }^{1,3}$, Thomas Reimann² ${ }^{2}$ Vincent Bailly-Comte ${ }^{3}$, Jean-Christophe Maréchal ${ }^{3}$, Martin Sauter ${ }^{1}$, Tobias Geyer ${ }^{4}$

Manuscript:

Giese, M., Reimann, T., Bailly-Comte. V., Maréchal, J.-C., Sauter, M. and Geyer, T.: Turbulent and laminar flow in karst conduits under unsteady flow conditions - interpretation of pumping tests by discrete conduit-continuum modeling, Water Resources Research, 54, doi:10.1002/2017WR020658.

${ }^{1}$ Geoscientific Centre, University of Goettingen, Göttingen, Germany

${ }^{2}$ Institute for Groundwater Management, TU Dresden, Dresden, Germany

${ }^{3}$ Bureau de Recherches Géologiques et Minières (BRGM)- D3E/NRE, Montpellier, France

${ }^{4}$ Landesamt für Geologie, Rohstoffe und Bergbau (LGRB) im Regierungspräsidium Freiburg, Freiburg, Germany 


\section{Abstract}

Due to the duality in terms of (1) the groundwater flow field and (2) the discharge conditions, flow patterns of karst aquifer systems are complex. Estimated aquifer parameters may differ by several orders of magnitude from local (borehole) to regional (catchment) scale because of the large contrast in hydraulic parameters between matrix and conduit, their heterogeneity and anisotropy. One approach to deal with the scale effect problem in the estimation of hydraulic parameters of karst aquifers is the application of large-scale experiments such as long-term high-abstraction conduit pumping tests, stimulating measurable groundwater drawdown in both, the karst conduit system as well as the fractured matrix. The numerical discrete conduitcontinuum modeling approach MODFLOW-2005 Conduit Flow Process Mode1 (CFPM1) is employed to simulate laminar and non-laminar conduit flow, induced by large-scale experiments, in combination with Darcian matrix flow. Effects of large-scale experiments were simulated for idealized settings. Subsequently, diagnostic plots and analyses of different fluxes are applied to interpret differences in the simulated conduit drawdown and general flow patterns.

The main focus is set on the question to which extent different conduit flow regimes will affect the drawdown in conduit and matrix depending on the hydraulic properties of the conduit system, i.e. conduit diameter and relative roughness. In this context, CFPM1 is applied to investigate the importance of considering turbulent conditions for the simulation of karst conduit flow. This work quantifies the relative error that results from assuming laminar conduit flow for the interpretation of a synthetic large-scale pumping test in karst. 


\section{Chapter 4}

\subsection{Introduction}

Pumping tests and the interpretation of pressure or drawdown curves are frequently applied and essential tools for solving petroleum engineering or hydrogeological problems. In general, pumping tests are used to assess the hydraulic characteristics of aquifer systems (GRINGARTEN, 1982; KRUSEMAN AND DE RIDDER, 1991). Besides the prediction of the overall system behavior, a wide range of specialized interpretation methods are available to quantify well and aquifer specific parameters (e.g. BOURDET ET AL., 1983).

Especially during the last few decades, fractured rock aquifers became the focus of attention as potential groundwater resources (e.g. NASTEV ET AL., 2004; LERAY ET AL., 2013; GUIHENEUF ET AL., 2014) and waste repositories (e.g. MACQUARrIE AND MAYER, 2005; JOYCE ET AL., 2014; FOLLIN ET AL., 2014; TSANG ET AL., 2015). A wide variety of analytical techniques were developed to characterize fractured rock aquifers by pumping test evaluation (see also: AGARWAL ET AL., 1970; GRINGARTEN, 1982; BOURDET, 2001). Karstified aquifers, as a specific group of fractured aquifer systems, display considerable complexity due to the large contrast in hydraulic parameters within the coupled conduit-matrix system. Even among karst aquifers, hydraulic parameters of conduit, fissures and the porous matrix may vary by several orders of magnitude from local to catchment scale (e.g. SAUTER, 1992; KIRÁLY, 2002). As one example the tabulation of traditionally analyzed aquifer tests and specific capacity tests for karstified Floridan Aquifer systems (mixed areas of large mature conduits and areas of preferential flow layers - large horizontal dissolution features) indicate a range of six orders of magnitude (KUNIANSKY AND BELLINO, 2016). The highly permeable karst conduits, draining the fissured rock matrix, are the most important hydraulic features adding a fast flow component to the groundwater discharge. Depending on the degree of karstification, a variety of karst conduit systems with different hydraulic properties prevail. QUINLAN AND EWERS (1985) divide karst systems into three categories: (1) diffuse karst systems with slightly developed karstic features and mainly laminar matrix flow (2) mixed flow karst systems with laminar matrix flow and non-linear (turbulent) flow in solution-enlarged structures and (3) conduit flow karst systems, where predominantly turbulent flow conditions prevail in the mature conduit systems. Especially the conduit diameter can range 
from a few centimeters in initially enlarged fractures (e.g. WHITE, 2002) up to predominant conduit structures with a large diameter of quasi-infinite hydraulic conductivity (e.g. MARÉCHAL ET AL., 2008). Except for carbonate aquifers with a rather vuggy porosity as preferential flow path, randomly located individual boreholes are likely to miss these highly permeable features and can, therefore, only represent the hydraulic parameters in the vicinity of the wellbore, i.e. that of the fissured/fractured matrix (SAUTER, 1992; WhITE, 2002; Worthington, 2009). MARÉCHAL ET AL. (2008) showed that long-term groundwater abstraction, with defined abstraction rate, directly from the conduit system can be a useful tool to characterize karst aquifers on catchment scale, e.g. to derive general flow patterns from the analysis of diagnostic plots (GIESE ET AL., 2017).

Plotting pressure or drawdown curves and their derivatives with respect to time on a log-log graph (diagnostic plots) is a useful tool to obtain qualitative (identification of dominant flow regimes at specific times) and quantitative (estimation of hydraulic parameters) information about an aquifer system (GRINGARTEN, 1982). A frequently applied method is type-curve matching where pressure or drawdown curves are compared to a set of analytical model solutions and the best fit is chosen to assess the hydraulic parameters (GRINGARTEN, 1987; BOURDET, 2001). One drawback of the type-curve matching technique is the ambiguity in interpretation (e.g. KRUSEMAN AND DE RIDDER, 1991; RENARD, 2005) complicating the selection of the 'correct' theoretical model, most likely to produce erroneous hydraulic parameters (Gringarten, 1982; Kruseman AND DE RIDDER, 1991). All theoretical models have in common that they are based on ideal conditions that do not represent natural aquifer conditions (KRUSEMAN AND DE RIDDER, 1991). Especially the assumption of laminar flow restricts the applicability of these solutions to karstic aquifers due to the limitations of Darcy's law in quantifying turbulent flow conditions. Darcy's law is only valid for low flow velocities with small hydraulic gradients or media with narrow openings, requirements which are not achieved for water abstraction in the vicinity of or directly from the conduit system (KRUSEMAN AND DE RIDDER, 1991). According to GALVÃO ET AL. (2016) pumping test analyses in karst systems based on laminar flow, e.g. Theis type-curve matching, underestimate the hydrological characteristics of the conduit system. 


\section{Chapter 4}

The dimensionless Reynolds number $(R e)$, representing the ratio of inertial forces versus viscous forces, is used to indicate the actual state of flow. By increasing the flow velocity the force of inertia also increases. Flow becomes turbulent when the inertial forces overcome the viscous forces. The transition from laminar to turbulent flow is defined by the critical Reynolds number $\left(N_{R e}\right)$, a guiding value depending on the hydraulic properties of the fluid and flow media, e.g. smoothness of the grains or pore walls, pore diameter and tortuosity of the connected pore space (SHOEMAKER ET AL., 2008A). In porous media, flow is fully turbulent at Reynolds numbers above 100 and Darcy's law is only applicable for Reynolds numbers below 10 (BEAR, 1972). Pipe flow is usually considered to be gradually turbulent if the Reynolds numbers exceeds 2000 (e.g. DREYBRODT, 1988). Conduits, as preferential flow paths in karst aquifers, are considered as pipe structures and, therefore, the onset of turbulent flow is considered for Reynold numbers of approximately $N_{R e}=500$ (WHITE, 2002) to $N_{R e}=2000$ (SHOEMAKER ET AL., 2008B). Even though the break point between laminar and non-laminar flow has to be determined for every single karst system those hydrodynamic thresholds (i.e. $N_{R e}$ ) are also frequently applied in predefined ranges for the numerical computation of flow in idealized representations (e.g. REIMANN ET AL., 2011) or on a catchment scale (e.g. HALIHAN ET AL., 2000; SHOEMAKER ET AL., 2008A) of karst systems. Those predefined values normally represent break points of artificial pipe systems with a smoother wall roughness and straight courses.

The conceptual laminar pipe flow model assumes a parabolic cross sectional velocity distribution inside a circular pipe. Averaging the velocity results in the Hagen-Poiseuille equation, which is frequently used for laminar pipe and/or horizontal well bore flow (e.g. DIKKEN, 1990; SHOEMAKER ET AL., 2008B). For non-laminar flow, the cross sectional velocity is rather uniformly distributed which is caused by pipe roughness. This flow condition can be described by the Colebrook-White equation. The ratio of roughness height to conduit diameter, referred to as relative roughness, can be high for karst conduits, e.g. 0.25 measured by JEANNIN (2001) or even higher as concluded by ATKINSON (1977). The increased mean roughness height, a non-geometrical parameter which may be caused by debris load or collapses along the flow path result in the onset of turbulence at lower Reynolds numbers and, therefore, in an increase of energy losses along the conduit flow path. Consequently, turbulent flow increases the 
hydraulic gradient for a defined flow rate (DIKKEN, 1990). Under these conditions, specific discharge is no longer linear to the head gradient (BOURDET, 2001). Those pressure differences along the flow path can also be characterized as finite conductivity, a description both used for fracture flow (e.g. CinCO-LEY ET AL., 1978) and flow inside horizontal wells (e.g. DiKKEN, 1990). The restriction in flow also changes the entire flow pattern in terms of increasing matrix inflow in the vicinity of the wellbore already at early times of water abstraction (CINCO-LEY ET AL., 1978; BOURDET, 2001). During this period, the drawdown signal is a superposition of linear flow in the highly conductive feature and radial flow in the matrix resulting in bi-linear flow conditions which is represented by a quarter-slope line in the diagnostic plots (CinCO-LEY AND SAMANIEGO-V., 1981; BOURDET, 2001).

The Reynolds number, describing the state of flow, and the relative roughness define the geometric friction factor $(f)$. For natural karst conduit systems the friction factor is normally higher by several orders of magnitude compared to manmade pipe systems (JEANNIN, 2001; SPRINGER, 2004; WORTHINGTON AND SOLEY, 2017). Especially in sections with debris load or collapses along the flow path the friction factor increases (ATKINSON, 1977; PETERSON AND WICKS, 2006). In general the friction factor of natural karst systems can vary in a wide range between $f=0.1$ and $f=340$ (JEANNIN, 2001). WORTHINGTON AND SOLEY (2017) analyzed the effect of turbulent flow in different karst aquifers and concluded that turbulent flow evidently increases hydraulic head and therefore needs to be considered on catchment scale. Depending on the hydraulic properties of the karst aquifer, conduit flow is already predominantly turbulent under base flow conditions (e.g. HALIHAN ET AL., 2000; White, 2002; WORTHINGTON AND SOLEY, 2017). Consequently, model approaches for the interpretation of general flow conditions in a karst aquifer considering laminar as well as turbulent flow are capable of better representing the flow physics and, therefore, have major advantages compared to solutions solely based on Darcian flow.

The dual flow concept of karst aquifers has been incorporated into different distributive numerical groundwater flow models (SAUTER ET AL., 2006) using different conceptual models (e.g. single continuum: DOUMMAR ET AL., 2012; MAYAUD ET AL., 2016; double continuum: KORDILLA ET AL., 2012; discrete conduit-continuum models: DE ROOIJ ET AL., 2013; GALLEGOS ET AL., 2013; 


\section{Chapter 4}

SALLER ET AL., 2013; OEHLMANN ET AL., 2015). One numerical discrete conduit-continuum modeling approach is CFPM1 for MODFLOW-2005 (SHOEMAKER ET AL., 2008A). CFPM1 simulates laminar and turbulent pipe flow coupled through linear head dependent water transfer with a laminar flow matrix continuum. This allows the hydraulic simulation of complex karst aquifer systems. Integrating further hydraulic features such as fast-responding drainable storage (conduit-associated drainable storage - CADS), CFPM1 is capable of representing the characteristic drawdown of large-scale pumping tests in karst aquifers (REIMANN ET AL., 2014).

Depending on the degree of karstification, different types of conceptual models are being applied. KOVÁCS ET AL. (2005) distinguish between matrix restricted flow for mature and conduit influenced flow models for karst systems with initially enlarged flow features, depending on the general baseflow pattern of the aquifer system. Both conceptual models can be separated by a threshold depending on parameters describing the degree of heterogeneity (i.e. hydraulic and geometric properties). Currently, literature provides only a few case studies examining the influence of the hydraulic conduit properties on the flow behavior on catchment scale. Although the conduits can (and likely do) dominate the flow on catchment scale the published case studies normally do not focus on the hydraulic properties of conduits especially on relative roughness. PETERSON AND WICKS (2006) quoted that slight changes of the roughness significantly affect the simulated spring discharge as well as solute transport. Regardless, many case studies generally assume constant hydraulic roughness along conduits (SALLER ET AL., 2013) or argue an insensitivity with respect to hydraulic head, spring discharge and residence time for a welldeveloped karst aquifer (GALLEGOS ET AL., 2013). OEHLMANN ET AL. (2015) applied a variable roughness coefficient linearly coupled to the conduit diameter, with a positive roughness slope towards the spring. Because of the absence of a single large diameter conduit at the moderately karstified study area the authors interpret the calibrated hydraulic conduit properties as a lumped value of a conduit bundle.

The consideration of turbulent flow in conduits interacting with a discrete matrix continuum has already been addressed in several studies (e.g. SHOEMAKER ET AL., 2008A; REIMANN ET AL., 2011). In this study, drawdown differences as well as flow pattern changes resulting from the application of 
laminar and turbulent flow of numerically idealized karst conduits are presented and discussed with respect to the maturity of karst aquifer systems. Analytical equations for laminar and turbulent conduit flow are employed to explain the respective differences in head loss without any knowledge about the systems' critical Reynolds number. Therefore the relative error caused by the application of laminar flow equations for different karst system representations is quantified. Thanks to the applied discrete conduit-continuum approach, simulations of matrix drawdown restricted by either the hydraulic conduit or the hydraulic matrix parameter can be compared. Therefore this paper provides a guideline for the necessity of the application of turbulent flow equations in the interpretation of general flow pattern in different categories of karst systems. Another focus is set on the general problem of the application of the Reynolds number on karstic flow at regional scale. Commonly, information about the mean flow velocity of karst conduits is available from tracer experiments. In contrast, the conduit system dimension (i.e. volume, diameter and length), which is needed for the calculation of the Reynolds number, is difficult to determine on a regional scale. Normally numerical models demand critical Reynolds numbers to discriminate between laminar and turbulent flow regimes. Due to the complexity of the hydraulic properties of karst conduits the application of such values on regional scale cannot be proven. Therefore the study also presents the differences in head losses as a function of the hydraulic conduit properties for a defined flow velocity (i.e. drawdown signal).

\subsection{Methods and applied tools}

\subsubsection{Numerical solution - discrete conduit-continuum model CFPM1}

The applied numerical method to simulate laminar Darcian flow in the fractured porous matrix continuum is based on the block-centered finite difference groundwater flow model MODFLOW-2005 (HARBAUGH, 2005) according to

$$
\frac{\partial}{\partial x}\left(K_{x x} \frac{\partial h_{m}}{\partial x}\right)+\frac{\partial}{\partial y}\left(K_{y y} \frac{\partial h_{m}}{\partial y}\right)+\frac{\partial}{\partial z}\left(K_{z z} \frac{\partial h_{m}}{\partial z}\right) \pm W=S_{S}\left(\frac{\partial h_{m}}{\partial t}\right)
$$




\section{Chapter 4}

with $K$ the hydraulic conductivity in $\mathrm{x}, \mathrm{y}$ and $\mathrm{z}$ direction $\left[\mathrm{LT}^{-1}\right], h_{m}$ the head in the matrix cell [L], $W$ the volumetric flux per unit volume $\left[\mathrm{T}^{-1}\right], S_{s}$ the specific storage $\left[\mathrm{L}^{-1}\right]$ and time $t[\mathrm{~T}]$.

The discrete conduit-continuum model CFPM1 (SHOEMAKER ET AL., 2008a) couples a discrete conduit network consisting of nodes connected by cylindrical pipes to the MODFLOW-2005 continuum. Head loss along the pipe $\Delta h_{c}[\mathrm{~L}]$ is computed by the Darcy-Weisbach equation

$$
\Delta h_{c}=f \frac{\Delta l_{p} v^{2}}{2 g d_{p}}
$$

with $f$ the friction factor $[-], \Delta I_{p}$ the length of pipe [L], $V$ the mean flow velocity [ $\left.\mathrm{LT}^{-1}\right], g$ the gravitational acceleration [ $\mathrm{LT}^{-2}$ ] and $d_{p}$ the pipe diameter [L]. The Hagen-Poiseuille equation describes laminar flow as [SHOEMAKER ET AL., 2008]

$$
Q_{p}=-\frac{\pi d_{p}^{4} g \Delta h_{c, l a m}}{128 v \Delta l_{p} \tau}
$$

with $Q_{P}$ the volumetric flow rate $\left[\mathrm{L}^{3} \mathrm{~T}^{-1}\right], v$ the kinematic viscosity of water $\left[\mathrm{L}^{2} \mathrm{~T}^{-1}\right], \Delta \mathrm{h}_{\mathrm{c}, \text { lam }}$ the laminar head loss $[\mathrm{L}]$ and $\tau$ the tortuosity of the pipe [-]. Turbulent flow is computed based on the Colebrook-White equation as [SHOEMAKER ET AL., 2008]

$$
Q_{p}=-\sqrt{\frac{\mid \Delta h_{c}, \text { turb } \mid g d_{p}{ }^{5} \pi^{2}}{2 \Delta l_{p} \tau}} \log \left[\frac{2.51 v}{\sqrt{\frac{2\left|\Delta h_{c, t u r b}\right| g d_{p}^{3}}{\Delta l_{p} \tau}}}+\frac{k_{c}}{3.71 d_{p}}\right] \frac{\Delta h_{c, t u r b}}{\mid \Delta h_{c}, \text { turb } \mid}
$$

with $\Delta h_{c, t u r b}$ the turbulent head loss [L] $k_{c}$ the mean roughness height [L].

Exchange flow $Q_{e x}\left[\mathrm{~L}^{3} \mathrm{~T}^{-1}\right]$ between the pipe network and the matrix continuum is calculated by a linear quasi-steady state exchange coefficient $\alpha_{e x}$ $\left[\mathrm{L}^{2} \mathrm{~T}^{-1}\right]$ as (BARENBLATT ET AL., 1960; BAUER ET AL., 2003; SHOEMAKER ET AL., 2008A)

$$
Q_{e x}=\alpha_{e x}\left(h_{C}-h_{m}\right)
$$


with $h_{c}$ the conduit head [L]. BAUER ET AL. (2003) introduced the exchange coefficient $\alpha_{e x}$ as a lumped conductance term representing the hydraulic characteristics as well as the geometry of the interface between conduit and matrix as

$$
\alpha_{e x}=2 \pi r_{w} \Delta l_{p} \alpha K \tau
$$

with $r_{W}$ the pipe radius [L] and $\alpha$ a factor which might be interpreted as inverse fissure spacing $\left[\mathrm{L}^{-1}\right]$.

\subsubsection{Idealized pumping test analyses}

To avoid the superposition of different heterogeneities on the drawdown curve, the CFPM1 model set-ups are based on the general requirements of an idealized aquifer (KRUSEMAN AND DE RIDDER, 1991):
a) constant transmissivity within the model domain of "infinite areal" extent
b) constant pumping rate, and
c) horizontal distribution of the hydraulic head prior to pumping

Dimensionless parameters are used for the interpretation of diagnostic plots to keep the curves independent of the magnitude of the physical parameter (BOURDET, 2001). According to BERTRAND AND GRINGARTEN (1978) and SPANE AND WURSTNER (1993) the dimensionless terms for a homogeneous, isotropic and confined aquifer are

$$
\begin{aligned}
& S_{D}=\left(\frac{2 \pi T}{Q_{p}}\right) \Delta s \\
& C_{D}=\frac{C}{2\left(x_{f}^{2} S_{s} \pi\right)} \\
& t_{D}=\frac{T t}{x_{f}^{2} S}
\end{aligned}
$$

with $S_{D}$ the dimensionless drawdown [-], $S$ the drawdown [L], $T$ the matrix transmissivity $\left[\mathrm{L}^{2} \mathrm{~T}^{-1}\right], C_{D}$ the dimensionless wellbore storage $[-], C$ the wellbore storage constant $\left[\mathrm{L}^{2}\right], X_{f}$ the fracture half-length $[\mathrm{L}], t_{D}$ the dimensionless time [-] and $S$ the matrix storativity [-]. 


\section{Chapter 4}

Frequently used tools for pumping test analysis are diagnostic plots presenting drawdown and additional drawdown derivative displayed on a loglog graph. The dimensionless drawdown derivative $S_{D}$ ' [-] with respect to the natural logarithm of dimensionless time $t_{D}[-]$ divided by the dimensionless wellbore storage $C_{D}[-]$ is given by BOURDET ET AL. (1983) as

$$
S_{D}^{\prime}=\frac{\partial s_{D}}{\partial \ln \left(t_{D} / C_{D}\right)}
$$

The following analysis is focused on general flow pattern differences between laminar and turbulent conduit flow for an idealized single straight conduit and can be separated into two different parts. The first part aims at the interpretation of quantitative differences in head loss between laminar and turbulent flow equation for different conduit parameters. Therefore, the analytical flow equations introduced in chapter 4.2 are applied. This analysis assumes an isolated conduit without exchange flow with the matrix. The second part of the analysis is focused on the general flow pattern inside the conduit and the influences on matrix drawdown. This part evaluates the results of the discrete conduit-continuum model CFPM1, which also considers exchange flow with the matrix. Diagnostic plots are used to explain flow pattern differences.

\subsection{Results}

Due to the defined hydraulic signal introduced by the water abstraction from the conduit and the preexisting nature of the conduit system, the head loss along the conduit is the only variable of the laminar and turbulent flow equation (see Eq. 4.3 and 4.4). According to equation 4.2 the head loss is a function of the mean flow velocity, the conduit diameter and the friction factor. The friction factor includes information about the pipe roughness and the actual flow conditions indicated by the Reynolds number. According to the ColebrookWhite equation (Eq. 4.4) head loss is a function of total flow, pipe diameter, mean roughness height and tortuosity. Each of these parameters will be investigated regarding the influence on the drawdown behavior of a single conduit without knowledge of the systems' critical Reynolds number. 


\subsubsection{Analytical head loss differences}

Head loss along the conduit with defined pumping rate can be calculated by the analytical Hagen-Poiseuille (laminar flow) and Colebrook-White (turbulent flow) equations. Here, the differences are calculated for a conduit length of $\Delta I=1 \mathrm{~m}$. A defined signal of $Q_{p}=0.25 \mathrm{~m}^{3} \mathrm{~s}^{-1}$ close to the pumping well (even distribution of an abstraction rate $Q_{a b s}=0.5 \mathrm{~m}^{3} \mathrm{~s}^{-1}$ in both directions) is used as flow rate according to equation 4.3 and 4.4 .
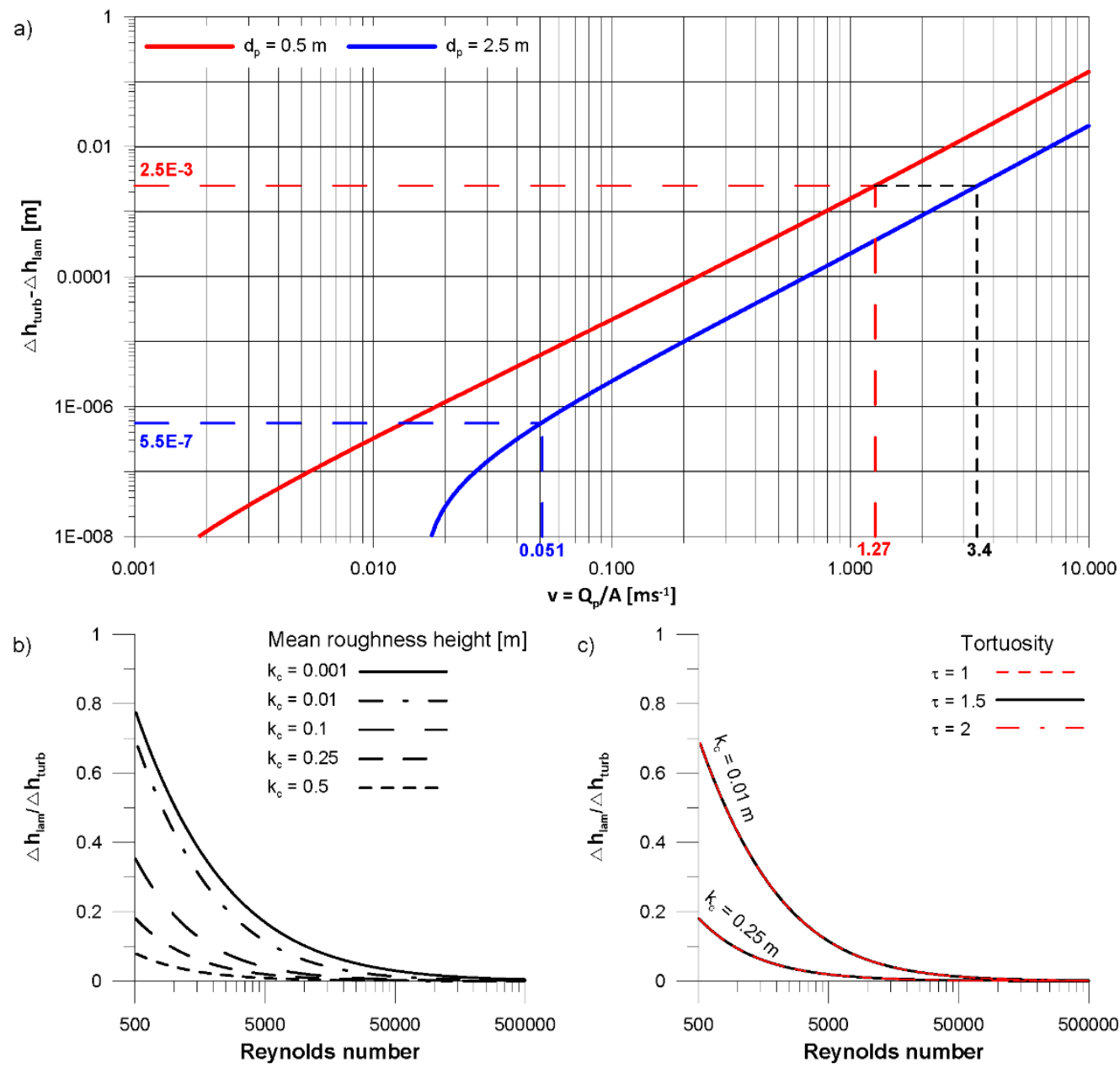

Fig. 4.1: Influence of different conduit characteristics on the conduit flow processes: a) Analytical head loss differences between laminar and turbulent for an isolated conduit of $1 \mathrm{~m}$ length and a flow rate $Q_{p}=0.25 \mathrm{~m}^{3} \mathrm{~s}^{-1}$, b) ratio of laminar and turbulent head loss for a conduit diameter of $d_{p}=0.5 \mathrm{~m}$ and different roughness heights and c) ratio of laminar and turbulent head loss related to tortuosity changes for a conduit diameter of $d_{p}=0.5 \mathrm{~m}$ with mean roughness heights of $k_{c}=0.01 \mathrm{~m}$ and $k_{c}=0.25 \mathrm{~m}$.

Figure 4.1a presents the head loss differences calculated by the analytical equations for laminar and turbulent flow pattern for two different conduit 


\section{Chapter 4}

diameters $\left(d_{p}=0.5 \mathrm{~m}\right.$ and $d_{p}=2.5 \mathrm{~m}$ ) plotted against flow velocity. Both conduits are artificially smooth with a mean roughness height of $k_{c}=1 \times 10^{-4} \mathrm{~m}$. Due to different cross-sectional areas, flow velocities inside the conduit differ depending on the conduit diameter. According to the basic flow velocity equation $V=Q_{p} / A$ with $Q_{p}=0.25 \mathrm{~m}^{3} \mathrm{~s}^{-1}$ and $A=\pi\left(d_{p}^{2} / 4\right)$ the mean flow velocities for the applied conduit diameter of $d_{p}=0.5 \mathrm{~m}$ and $d_{p}=2.5 \mathrm{~m}$ are $V 0.5=1.27 \mathrm{~ms}^{-1}$ and $V 2.5=0.051 \mathrm{~ms}^{-1}$ respectively. Therefore, also the calculated Reynolds numbers differ. The Reynolds number for the conduit with a conduit diameter of $d_{p}=0.5 \mathrm{~m}$ is $R e=5.6 \times 10^{5}$ whereas the Reynolds number for the larger conduit diameter can be calculated as $R e=1.1 \times 10^{5}$.

Assuming a constant flow rate, the head loss differences between laminar and turbulent flow for the conduit diameter of $d_{p}=2.5 \mathrm{~m}$ are lower compared to a small diameter. The example in Figure 1a shows a difference of four orders of magnitude. The head loss difference along the conduit segment with a diameter $d_{p}=0.5 \mathrm{~m}$ is $h_{c, \text { turb }}-h_{c, \text { lam }}=2.5 \times 10^{-3} \mathrm{~m}$ whereas a diameter $d_{p}=2.5 \mathrm{~m}$ accounts for head loss differences of $h_{c, t u r b}-h_{c, l a m}=5.5 \times 10^{-7} \mathrm{~m}$. Even for the same velocity and therefore a higher abstraction rate $\left(Q_{p}=6.2 \mathrm{~m}^{3} \mathrm{~s}^{-1}\right)$ the head loss differences are lower by one order of magnitude. The same head loss differences between the two types of conduits can be derived by an increase in abstraction rate in the conduit with a diameter $d_{p}=2.5 \mathrm{~m}$. To generate a similar head loss differences of $h_{c, t u r b}-h_{c, \text { lam }}=2.5 \times 10^{-3} \mathrm{~m}$ the flow rate has to be increased to $Q_{p}=16.7 \mathrm{~m}^{3} \mathrm{~s}^{-1}\left(V 2.5=3.4 \mathrm{~ms}^{-1}\right)$ with a Reynolds number of $R e=7.4 \times 10^{6}$ (Fig. 4.1a).

Figure $1 \mathrm{~b}$ analyzes the effect of the mean roughness height on the head loss differences for a conduit diameter of $d_{p}=0.5 \mathrm{~m}$. An increase in mean roughness height decreases the effective flow cross-sectional area or, to mention the effect, increases the probability of eddies and cross flow. As a result the head loss difference along the flow paths increases. Figure $4.1 \mathrm{~b}$ shows the ratio of laminar and turbulent head loss as a function of the Reynolds number for different roughness heights. Already for small Reynolds numbers head loss differences up to $20 \%$ are observed. The significance of head loss differences rises with increasing mean roughness heights. For Reynolds numbers similar to those in the above example $\left(R e \approx 5 \times 10^{5}\right)$ all curves show significant head loss differences. 
The tortuosity is a factor accounting the effective conduit length. Applying a constant flow rate an increase in conduit length needs to be counterbalanced by an increase in head gradient. Figure 4.1c presents the head loss ratio for two different mean roughness heights of Figure $1 \mathrm{~b}\left(k_{c}=0.01 \mathrm{~m}\right.$ and $\left.k_{c}=0.25 \mathrm{~m}\right)$ for three different tortuosity values: a) $\tau=1$, b) $\tau=1.5$ and c) $\tau=2$. The three curves representing different tortuosity values for defined mean roughness heights are virtually congruent. Therefore, the impact of tortuosity changes on head loss is insignificant within a reasonable range of values.

\subsubsection{Numerical flow pattern differences}

The quasi-infinite aquifer is considered by the large horizontal extent of the discrete conduit-continuum model domain to avoid the effects of the no-flow (Neumann) boundary conditions in the matrix continuum on the general flow pattern. The matrix continuum with an extent of 113,000 $\mathrm{m} \times 113,000 \mathrm{~m}$ has a bottom elevation of $0 \mathrm{~m}$ with an aquifer thickness of $b=250 \mathrm{~m}$. The area around the pumping well, located in the center of the domain, is discretized with $1 \mathrm{~m}$ cell length perpendicular to the conduit. The spatial discretization increases stepwise up to a cell length of $100 \mathrm{~m}$. The spatial discretization along the conduit is set to a cell length of $20 \mathrm{~m}$. The fissured matrix is considered as a confined layer. The hydraulic parameters of the fissured matrix are $K_{m}=1 \times 10^{-4} \mathrm{~ms}^{-1}$ and $S_{S}=1 \times 10^{-4} \mathrm{~m}^{-1}$. The well has a constant pumping rate of $Q_{a b s}=0.5 \mathrm{~m}^{3} \mathrm{~s}^{-1}$, implemented as (negative) Neumann boundary condition (CFPM1 - CRCH Package), for a duration of $T_{\text {total }}=6 \times 10^{7} \mathrm{~s}$. Groundwater temperature is set to $15^{\circ} \mathrm{C}$.

All of the following set-ups consider a single conduit with a length of $L_{p}=3,000 \mathrm{~m}$ subdivided into 150 sections each with a section length of $20 \mathrm{~m}$ (total number of nodes: 151). The conduit nodes are located in the center of the matrix cell. No wellbore/conduit storage is assumed. The wellbore is centrally arranged at node 76 . The uniform matrix-conduit exchange is considered with $\alpha K=0.01 \mathrm{~s}^{-1}$ (Eq. 4.6). The roughness height is constant along the conduit with $k_{c}=1 \times 10^{-4} \mathrm{~m}$, representing a very smooth conduit, and the tortuosity for all conduit segments is set to $\tau=1$. The applied critical Reynolds numbers secure the calculation according to either the Hagen-Poiseuille (laminar flow) or Colebrook-White (turbulent flow) equation without any transition during the model time $T_{\text {Total. }}$ The interpretation of drawdown and flow processes (Fig. 4.2, 


\section{Chapter 4}

Fig. 4.3) is performed for one of the conduit end nodes 1 (N1) and node 76 (N76) containing the pumping well.

\subsubsection{Influence on conduit flow pattern - conduit diameter}

Figure $4.2 \mathrm{a}$ and $4.2 \mathrm{~b}$ present diagnostic plots of two different parameterizations according to the above mentioned conduit diameters. Differences between turbulent and laminar flow regimes become apparent for a conduit diameter of $d_{p}=0.5 \mathrm{~m}$. The drawdown curve derived from the turbulent flow equation (Fig. 4.2a) shows higher conduit drawdown during all periods of pumping. Especially in the beginning of groundwater abstraction drawdown differences are significant and the diagnostic plots do not show the typical shape of linear flow conditions. The diagnostic plot shows a quarter unit slope and therefore bi-linear flow conditions can be assumed. This flow behavior is a clear evidence of reduced conduit conductivity (finite conductivity conduit). This finding is also supported by the head difference along the conduit (Fig. 4.2g).

Figure 4.2c shows the conduit flow during the pumping test for the small conduit diameter. Due to the additional head losses caused by turbulent flow, flow towards the pumping well is reduced at the beginning of pumping. As a consequence, the exchange flow in the vicinity of the pumping well is high but constantly declining with increasing conduit flow (Fig. 4.2e). At the tips of the conduit the drawdown increases only slightly resulting in an insignificant exchange flow during this early stage of pumping (Fig. 4.2e). Hydraulic head differences between the pumping well and the tips of the conduit create a continuously rising hydraulic gradient (Fig. 4.2g) which increases the conduit flow towards the pumping well (Fig. 4.2c). As a consequence the exchange flow at the pumping well drops and the increased head difference between matrix and conduit increases at the same time the exchange flow rate between the matrix and the conduit tips (N1, Fig. 4.2e). According to the general definition of linear flow (dominating inflow at the conduit end) the point of intersection roughly indicates a flow pattern change from bi-linear to linear flow. The linear flow period lasts only for a short period before all fluxes and also the hydraulic gradient approach steady state condition (Fig. 4.2c/e/g). During 'steady-state' radial flow $\Delta h_{1500 m}$, the head difference between pumping well and the tip of the conduit, equals $1.4 \mathrm{~m}$ which amounts to a total head loss of $9.3 \times 10^{-4} \mathrm{~m}$ per conduit meter. 


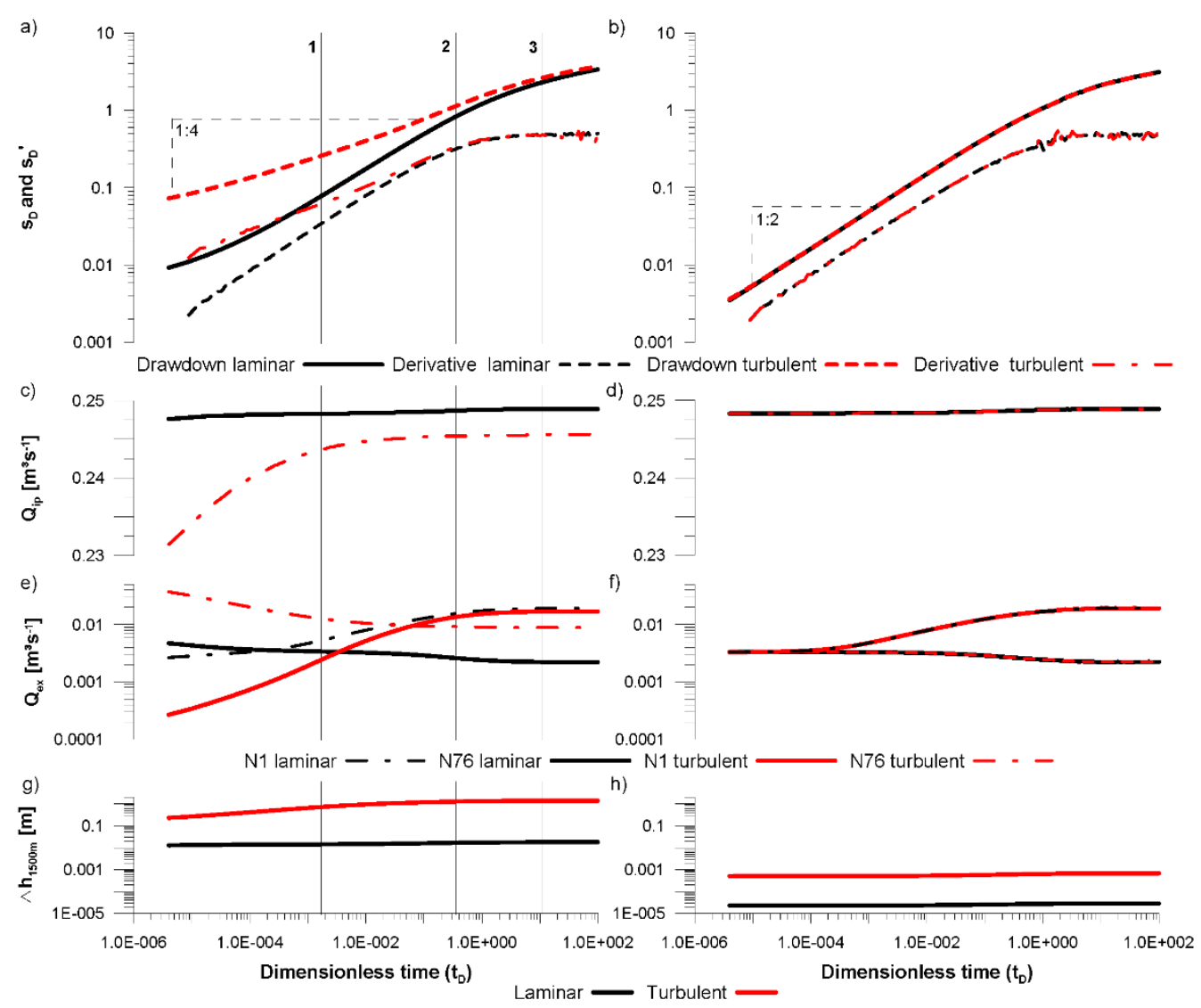

Fig. 4.2: Influence of different conduit diameters on the conduit flow processes; left: for a conduit diameter of $d_{p}=0.5 \mathrm{~m}$ and right: for a conduit diameter of $d_{p}=2.5 \mathrm{m:} \mathrm{a} / \mathrm{b}$ ) Diagnostic plots; c/d) Conduit flow towards the pumping well; e/f) Exchange flow at the pumping well (N76) and the tip of the conduit (N1); g/h) hydraulic head difference between pumping well (N76) and conduit tip (N1).

Applying the laminar flow equation on the small diameter conduit $\left(d_{p}=0.5 \mathrm{~m}\right)$ results in a lower head loss along the conduit. Therefore, the conduit flow towards the pumping well nearly reaches the flow maximum at the start of pumping (Fig. 4.2c). The exchange flow rate in the vicinity of the pumping well is lower compared to that for turbulent flow (Fig. 4.2e). At the beginning of pumping the exchange flow rate is nearly constant along the conduit. Hence, the point of intersection between the exchange flow curves, indicating the start of linear flow, is reached early in time. During the period of radial flow condition, flow patterns are comparable to those for turbulent flow conditions. At the end of the pumping period the head difference between pumping well and the tip of the conduit is $\Delta h_{1500 m}=1.8 \times 10^{-2} \mathrm{~m}$. The head loss difference along the conduit between turbulent and laminar flow conditions is $\Delta h_{c, t u r b}-\Delta h_{c, \text { lam }}=9.2 \times 10^{-4} \mathrm{~m}$ for the given parameterization. This value 


\section{Chapter 4}

approximately equals that of the analytical solution considering conduit flow without matrix exchange. The exchange flow with the matrix accounts for the minor differences between the analytical and numerical result.

The laminar as well as the turbulent flow behavior of the conduit with a conduit diameter $d_{p}=2.5 \mathrm{~m}$ is comparable to that of the laminar flow equation for the small diameter conduit $\left(d_{p}=0.5 \mathrm{~m}\right)$. At the start of pumping the exchange flow is constant along the conduit and both diagnostic plots already indicate linear flow (Fig. 4.2b). Drawdown inside the conduit is uniform during the entire duration of pumping which results in negligible head differences along the conduit (Fig. 4.2h). This characterization of the flow components based on drawdown curves analyses shows that the head loss difference between laminar and turbulent flow conditions is negligible. This also fits the results of the analytical flow equations (Fig. 4.1a). The hydraulic conduit parameters do not affect the linear flow pattern. Due to the uniform matrix exchange, flow is only restricted by the hydraulic properties of the interface and the matrix.

\subsubsection{Influence on conduit flow pattern - mean roughness height}

The influence of roughness height changes on the general flow behavior is presented in Figure 4.3. Figure 4.3a shows a diagnostic plot for mean roughness heights of $k_{c}=0.01 \mathrm{~m}$ and $k_{c}=0.25 \mathrm{~m}$ (cf. Fig. 4.1b) for a conduit diameter of $d_{p}=0.5 \mathrm{~m}$. The other parameters are similar to those introduced in chapter 4.3.2.

Compared to the smooth conduit of Chapter 4.3.2.1 a raise of the mean roughness height influences the conduit flow properties, e.g. increase the turbulent core zone. The interferences caused by the wall roughness, decrease the conductivity and thus the flux along the conduit (Fig. 4.3b). Therefore the effect of flow restriction is further increased, causing a higher exchange flow rate in the vicinity of the pumping well (Fig. 4.3c) as well as increased matrix inflow near the pumping well (Fig. 4.3d). The effects of increased mean roughness height on conduit drawdown are similar to those already explained above in Figure 4.2. One exception is presented by the drawdown curve scenario with a mean roughness height of $k_{c}=0.25 \mathrm{~m}$. With a roughness height equal to the radius of the conduit $\left(k_{c} / d_{p}=0.5\right)$ the flow restriction along the conduit is so high that the flux along the conduit is less than half of that of the initial set-

up. Due to reduced conduit flow, groundwater is mainly abstracted from the 
matrix resulting in radial flow conditions already during early times of the pumping test (Fig. 4.3a).

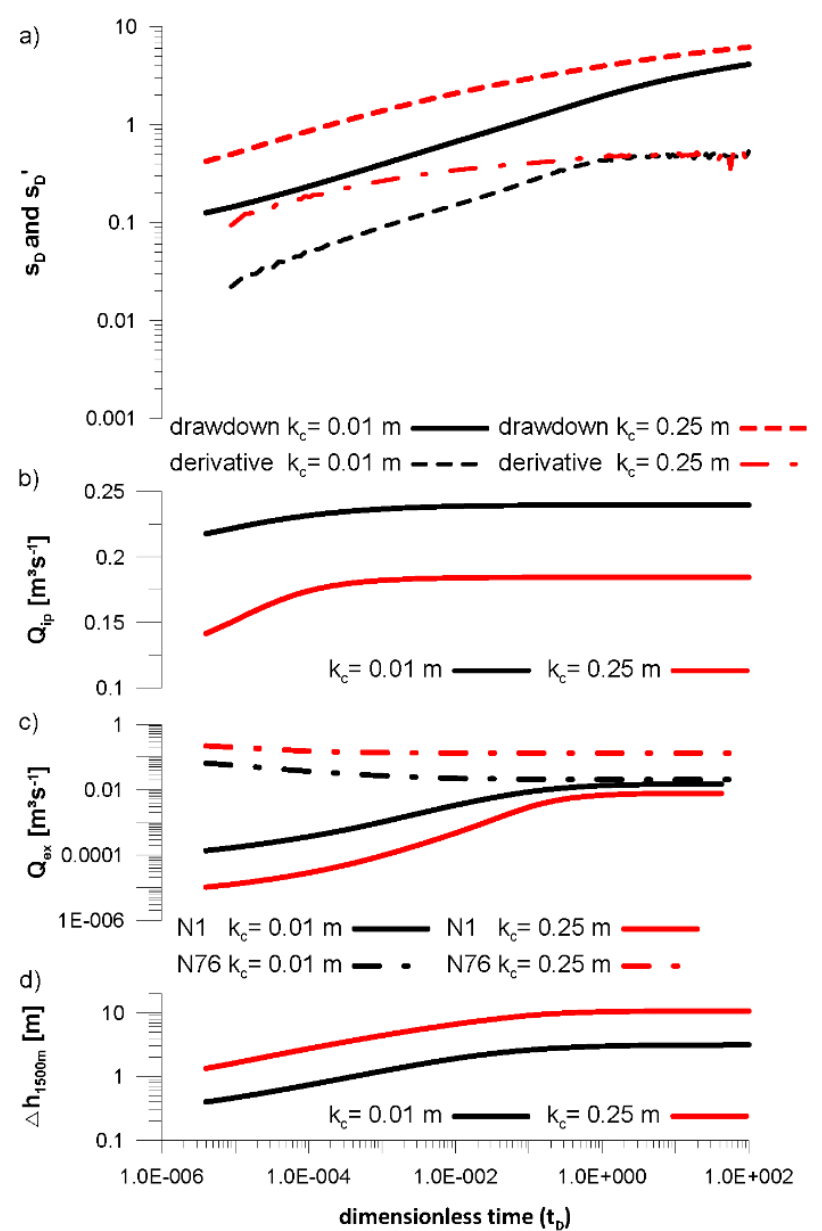

Fig. 4.3: Influence of roughness height on the conduit flow processes: Comparison for turbulent flow conditions for a mean roughness height of $k_{c}=0.01 \mathrm{~m}$ (black curves) and $k_{c}=0.25 \mathrm{~m}$ (red curves): a) Diagnostic plots; b) Conduit flow towards the pumping well (N76); c) Exchange flow at the pumping well and the tip of the conduit; d) hydraulic head difference between pumping well (N76) and conduit tip (N1).

\subsubsection{Influence of conduit drawdown on matrix heads}

Beside the differences in conduit drawdown also differences in matrix drawdown can be observed caused by turbulent flow in small diameter conduits. Figure 4.4 shows the matrix drawdown of a 5,000 $\mathrm{m} \times 5,000 \mathrm{~m}$ area around the conduit center (node 76) during (bi) linear flow, transition period and radial flow for the model parameterization described in chapter $4.3 .2\left(d_{p}=0.5 \mathrm{~m}\right)$. Figure 4.4 presents the matrix drawdown at the time steps marked in Figure 4.2a. 


\section{Chapter 4}

For laminar flow condition the head losses inside the conduit are low resulting in a more or less uniform drawdown along the conduit. As a consequence the exchange flow from the adjacent matrix (cf. Fig. 4.2e) as well as the matrix drawdown is nearly uniform along the conduit (Fig. 4.4, laminar).

laminar

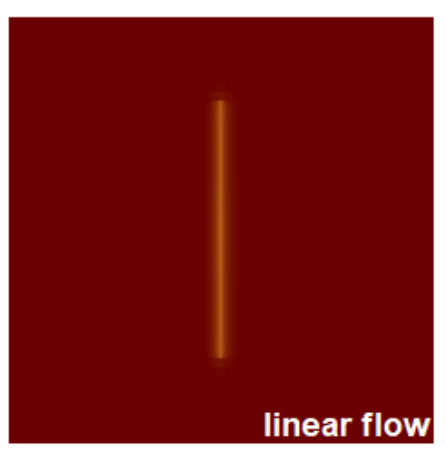

turbulent

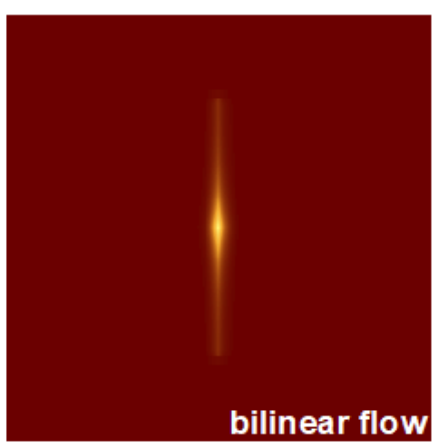

0.75

Drawdown $[\mathrm{m}]$
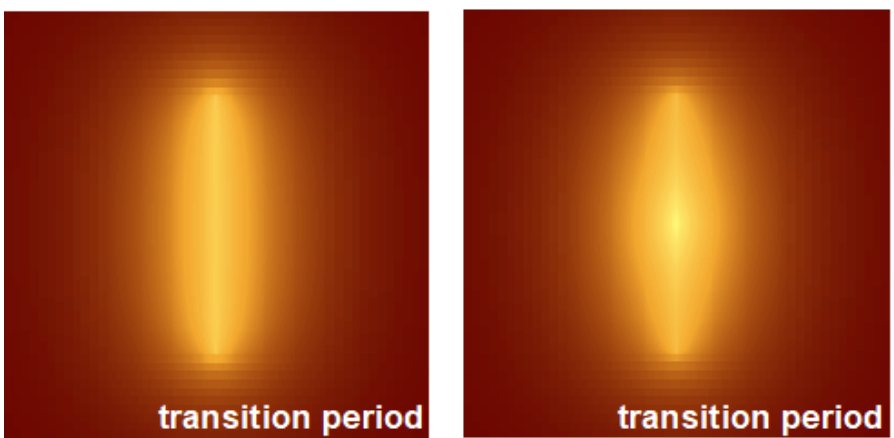

3.60

0.00

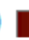

Drawdown [m]

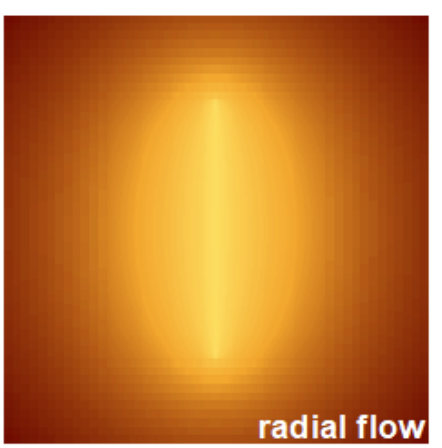

2.50

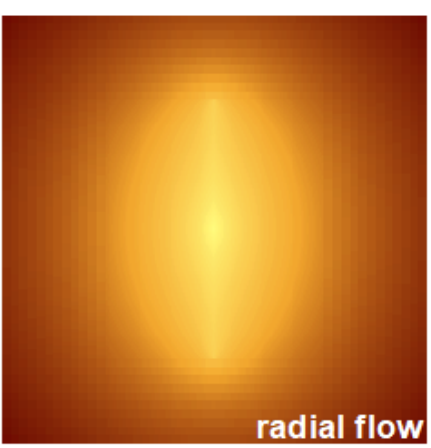

8.40

\section{Drawdown $[\mathrm{m}]$}

drawdown difference $[\mathrm{m}]$

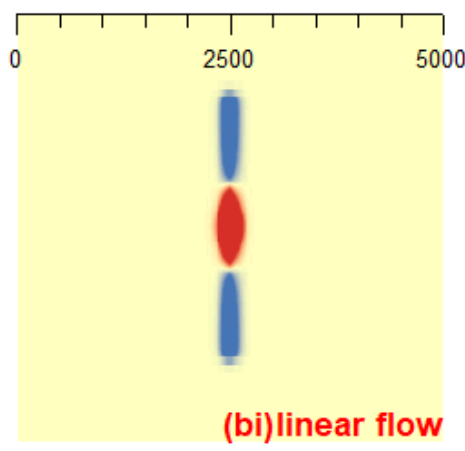

$-0.12$
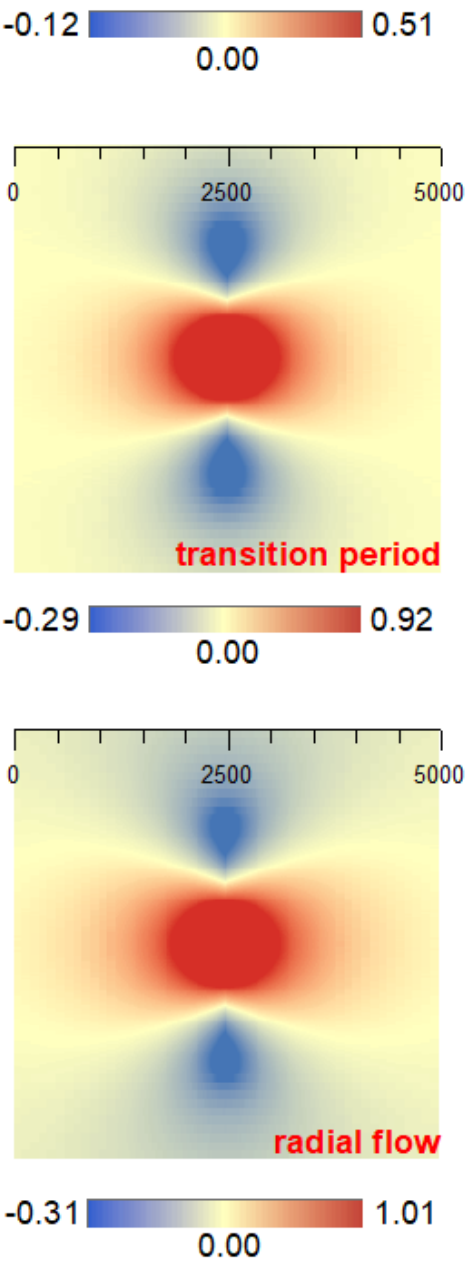

Fig. 4.4: Matrix head distribution along a horizontal conduit $\left(d_{p}=0.5 \mathrm{~m}\right)$ during large-scale constant groundwater abstraction at the time steps marked in Fig.4.2. Left: Head distribution along a conduit with laminar flow; middle: Head distribution along a conduit with turbulent flow, right: drawdown differences between the two flow conditions showing higher spatial matrix 
drawdown during turbulent flow in red and higher spatial matrix drawdown of laminar flow in blue.

The head distribution shows significant spatial differences for turbulent flow conditions. These differences become apparent in conduit as well as matrix heads. The quadratic conduit head losses, caused by turbulence, result in a distinctive head gradient along the conduit (Fig. 4.2g). Flow restrictions affect conduit flux as well as the exchange flow rate between conduit and matrix. As a consequence of the decreased flux the drawdown at the pumping well increases (Fig. 4.2a). The reduced conduit flux causes a high matrix flux towards the pumping well. Hence, matrix exchange flow (Fig. 4.2e) and the resulting matrix drawdown are non-uniform along the conduit (Fig. 4.4). Linear conduit flow superimposed by radial flow inside the adjacent rock towards the well generates bi-linear flow conditions. The hydraulic parameters of the conduit clearly influence the flow pattern of the matrix and, therefore, flow can be considered as conduit influenced. Compared to laminar flow conditions the drawdown in the vicinity of the pumping well is higher, decreasing with distance to the well towards the tips of the conduit. Because of the reduced flux the conduit drawdown at the conduit end is lower than for laminar flow conditions. This affects matrix exchange flow and hence results in a reduced matrix drawdown. The matrix drawdown differences are also presented in Figure 4.4. Positive head differences mark the location where the turbulent conduit flow increases the matrix drawdown and negative head differences were obtained in locations where laminar flow increases the matrix drawdown.

The general flow behavior does not change until the start of the transition period. The differences in matrix drawdown adjacent to the pumping well further increase as well as the differences at the conduit tips. For linear flow, groundwater abstraction from the matrix is still uniform along the conduit. With increasing pumping duration and expanding cone of depression, the differences of flow pattern between laminar and turbulent flow conditions vanish, but the overall drawdown difference increases. 


\section{Chapter 4}

\subsection{Discussions}

According to the results of Chapter 4.3, head losses and flow pattern are highly related to the hydraulic properties of the conduit. Literature provides different critical Reynolds numbers for the transition between laminar to turbulent conduit flow even the break point between laminar and turbulent flow needs to be determined by physical experiments. Figure 5 shows the analytical head loss differences as well as the calculated friction factor as a function of the mean roughness for a single conduit with a diameter $d_{p}=0.5 \mathrm{~m}$. The calculation are based on two different Reynolds numbers: $R e=500$ (Fig. 4.5a, $Q_{p}=2.2 \times 10^{-4}$ $\mathrm{m}^{3} \mathrm{~s}^{-1}, v=1.1 \times 10^{-3} \mathrm{~ms}^{-1}$ ) and $R e=10,000$ (Fig. 4.5b; $Q_{p}=4.5 \times 10^{-3} \mathrm{~m}^{3} \mathrm{~s}^{-1}, v=$ $\left.2.3 \times 10^{-2} \mathrm{~ms}^{-1}\right)$.

The results presented in Figure 4.5a can be divided at least into 2 different parts. Below a relative roughness of $k_{c} / d_{p}=0.01$ the head loss differences are low and uniform. Also the calculated friction factor (based on Eq. 4.2), divided into a laminar and turbulent portion is nearly constant. Due to the independence of the laminar head loss from the mean roughness height the laminar friction factor is constant along the abscissa. Starting at a relative roughness of $k_{c} / d_{p}=0.01$ the turbulent friction factor steadily increases. At a relative roughness of $k_{c} / d_{p}=1$ the turbulent friction factor is $f=0.75$ but the head loss difference $h_{c, \text { turb }}-h_{c, \text { lam }}=1 \times 10^{-7} \mathrm{~m}$ is still insignificant. In Figure $4.5 \mathrm{~b}$ the head loss differences are generally higher because of the increased flow rate. Nevertheless the friction factor for a relative roughness of $k_{c} / d_{p}=1$ is comparable to that for a Reynolds number of $R e=500$. Therefore, this part can be referred to as hydraulic rough. The friction factor only depends on the relative roughness. Hence, the range between $k_{c} / d_{p}=0.01$ and $k_{c} / d_{p}=1$ describes the transition period between laminar and turbulent flow. For a Reynolds numbers $R e=10,000$ significant head loss differences, able to change the flow pattern, can only be derived by friction factors higher than approximately $f=10$. According to Figure $4.5 \mathrm{~b}$ these friction factors can only be achieved by a relative roughness beyond $k_{c} / d_{p}=1$. 

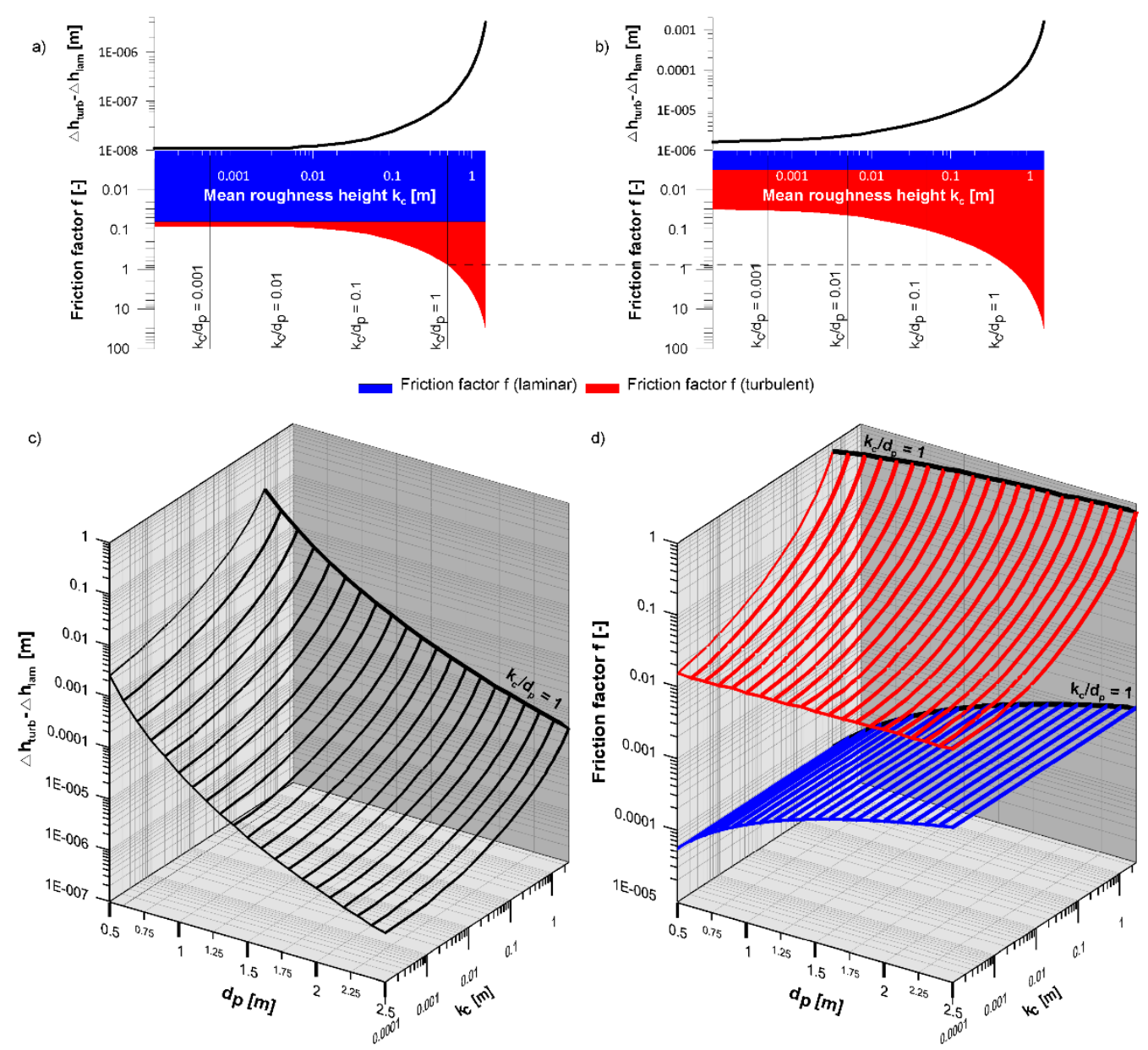

Fig. 4.5: Head loss difference between laminar and turbulent flow and friction factor for different hydraulic conduit parameter for a flow rate $Q_{p}=0.25 \mathrm{~m}^{3} \mathrm{~s}^{-1}$ : a) Head loss difference and friction factor for $R e=500\left(d_{p}=0.5 \mathrm{~m}\right)$, b) Head loss difference and friction factor for $R e$ $\left.=10,000\left(d_{p}=0.5 \mathrm{~m}\right), \mathrm{c}\right)$ head loss difference for different conduit diameters and mean roughness heights and d) friction factor for different conduit diameters and mean roughness heights.

Normally, for regional scale the hydraulic properties of karst conduits are partly or totally unknown. Figure $4.5 \mathrm{c}$ present head loss differences between laminar and turbulent flow conditions and Figure $4.5 \mathrm{~d}$ calculated friction factors per conduit meter related to the conduit diameter and the mean roughness height. The mean roughness height covers the whole range from artificially smooth $\left(k_{c}=0.001 \mathrm{~m}\right)$ to the respective conduit diameter $\left(k_{c} / d_{p}=1\right)$. The conduit diameter ranges between $d_{p}=0.5 \mathrm{~m}$ and $d_{p}=2.5 \mathrm{~m}$. The values presented in Figure $4.5 \mathrm{c}$ and $4.5 \mathrm{~d}$ are based on equation 4.3 and 4.4 with a flow rate $Q_{p}=0.25 \mathrm{~m}^{3} \mathrm{~s}^{-1}$ and no knowledge of the critical Reynolds number and which equation actually applies. The calculated mean velocity ranges between 


\section{Chapter 4}

$V 0.5=1.27 \mathrm{~ms}^{-1}$ and $V 2.5=0.05 \mathrm{~ms}^{-1}$ and is therefore higher than that applied in the example presented in Figures 4.5a and 4.5b.

Slightly developed karst systems, e.g. the Gallusquelle catchment (e.g. SAUTER, 1992; OEHLMANN ET AL., 2015), commonly do not have apparent large conduit structures. Based on the results of a calibrated distributed parameter flow and transport model OEHLMANN ET AL. (2015) concluded that the surface to volume ratio is high for the conduit network. Flow is likely to be dominated by bundles of small scale karst flow features. According to Figure $4.5 \mathrm{c}$, the head loss differences, between laminar and turbulent flow, are highest for conduits of small diameter combined with high mean conduit roughness. Therefore the application of a laminar instead of a turbulent flow equation for parameter estimation is likely to lead to significant errors. The analyses of large scale pumping tests in karst systems with slightly enlarged flow features, well connected to the fissured matrix, or for systems with only a low permeability contrast would reveal a high exchange flow in the vicinity of the pumping well leading to bilinear flow (see also Chapter 4.3). For conduit networks with high conduit storage, not illustrated here, a higher volume of water will be drained from the storage most probably masking the response of conduit flow during early times.

Mixed flow karst systems and mature karst systems are dominated by dissolution enlarged conduit systems with (partly) large conduit diameter, for example the Cent Fonts catchment (MARÉCHAL ET AL., 2008). For a constant conduit diameter the differences in head loss are insignificant, even for high mean roughness values (Fig. 4.5c). Based on this assumption and employing linear flow equations, parameter estimations can be considered as relatively accurate in mature karst systems. This could also explain the results of GALLEGOS ET AL. (2013) in terms of the insensitivity with regard to mean roughness on sub-regional scale during base flow in a well-developed karst aquifer (cf. KUNIANSKY, 2016). The errors of the estimated parameters will be insignificant even for high pumping rates as used during the large scale pumping test at the Cent Fonts catchment. According to the results the approximation of quasi-infinite hydraulic conductivity by MARÉCHAL ET AL. (2008) can be confirmed. 
The applied set-ups for the numerical conduit-continuum model use an idealized parametrization. The parameter combinations are used to minimize the effects on drawdown behavior caused by processes other than the type of flow (laminar/turbulent) in the karst conduit. One of these processes is the exchange with the limestone matrix especially influencing the drawdown at the beginning of pumping. Another simplification is related to the storativity. Changing the matrix storativity has a negligible influence on the drawdown curve and does not influence the general flow pattern. Furthermore, all set-ups do not consider fast-responding storage in karst conduits, which mask the drawdown behavior at the beginning of pumping. The effect of fast-responding conduit storage is already described by REIMANN ET AL. (2014) and GIESE ET AL. (2017).

Additionally, the above stated results for turbulent flow in karst conduits are computed with the Colebrook-White equation. This equation applies to pressurized flow at moderate Reynolds numbers (transition zone of laminar and turbulent flow) and small diameter pipes with natural roughness. Increased roughness, for example, due to deposits or the natural shape of karst conduits, are not considered. Therefore, the use of the Colebrook-White equation already idealized flow conditions and the applicability on certain karst aquifer systems must be examined in detail.

\subsection{Conclusions}

The above analysis shows the need for the consideration of turbulent flow in karst aquifer modeling and characterization especially for those aquifer systems defined as karst systems with slightly enlarged flow features. Turbulent flow may result in restricted flow inside the conduit, also referred to as finite conductivity. The influence of turbulent flow conditions on drawdown is especially large for a high relative roughness (small conduit radii and high mean roughness height). For those conditions turbulent flow cannot be neglected in the simulation of flow physics. Otherwise the extent of water level drawdown will be overestimated at the beginning of pumping. Hence, assuming laminar flow conditions will result in an underestimation of the conduit dimension. The determination of information with respect to the conduit geometric and hydraulic properties, which is always a critical aspect in karst aquifer 


\section{Chapter 4}

characterization, is required. Due to non-linearity of hydraulic head and discharge using turbulent flow equations it is not possible to apply only one (dimensionless) parameter, e.g. $k_{c} / d_{p}$ describing the head losses during turbulent flow. As a consequence the parameters describing the conduit geometry, especially the roughness, will serve as a calibration parameter for numerical models applied in slightly developed karst aquifers. For mature karst systems with well-developed tertiary porosity (conduit systems) approaches applying laminar flow equations will be sufficient. The analysis proofs for different Reynolds numbers and flow rates that the relative roughness must be high for causing significant head loss differences between laminar and turbulent flow pattern. Specifically for conduit systems with less developed connectivity to the adjacent fissured matrix this assumption is adequate. Mature karst systems with collapses or high debris load along the preferential flow path can be a possible exception. For those systems relative roughness as well as the friction factor are high (ATKINSON, 1977). The other possible exceptions might be systems at high flow conditions, even though observations of karst systems with broad conduit diameter (e.g. Wakulla spring, Cent Fonts) show laminar flow behavior for Reynolds numbers clearly indicating turbulent flow.

Different studies show that the friction factor for preferential flow path in karst aquifers can be higher than $f=1$ (JEANNIN, 2001). According to Figure $4.5 \mathrm{~d}$ those values can only be the result of relative roughness higher than $k_{c} / d_{p}=1$. SPRINGER (2004) provides one approach to separate the total head loss into three different origins: a) skin head loss, b) head loss as consequence of expansion and c) head loss caused by flow orientation. The local scale analysis of a cave reveals that the head loss caused by skin effects is comparable low to the other two. Macroscopic channel expansions and bends, in general crosssection changes, account for major head losses (SPRINGER, 2004; WORTHINGTON AND SOLEY, 2017). Especially for the large-scale modeling of karst systems the separation of the total head loss in different trigger is difficult. Therefore it seems reasonable to consider the roughness as a lumped parameter reflecting roughness as well as geometrical conduit properties of the collection of preferential flow paths. 


\section{Acknowledgements}

This project was funded by the Deutsche Forschungsgemeinschaft (DFG) under grants no. LI 727/11-2 and GE 2173/2-2 and by the BRGM under grants no. PDR13D3E91 and PDR14D3E61. The authors thank Harihar Rajaram, Eve Kuniansky, Zexuan $\mathrm{Xu}$ and one anonymous reviewer for constructive comments that significantly improved the manuscript. We also express our appreciation to Rudolf Liedl from the TU Dresden for his internal review. All input data for the CFPM1 are available for download: DOI:10.5281/zenodo.1122635. 


\section{Chapter 4}

\section{References}

Agarwal, R. G., Al-Hussainy, R. and Ramey, H. J. (1970): An investigation of wellbore storage and skin effect in unsteady liquid flow: I. Analytical treatment, SPE J., 10-03, 279-290.

Atkinson, T.C. (1977): Diffuse flow and conduit flow in limestone terrain in the Mendip Hills, Somerset (Great Britain), Journal of Hydrology, 35, 93-110.

Barenblatt, G. I., Zheltov, I.P. and Kochina, I. N. (1960): Basic concepts in the theory of seepage of homogeneous liquids in fissured rock, Journal of Applied Mathematics and Mechanics (PMM), 24(5), 1286-1303.

Bauer, S., Liedl, R. and Sauter, M. (2003): Modeling of karst aquifer genesis: Influence of exchange flow, Water Resources Research, Vol.39, Nr.10, doi:10.1029/2003WR002218.

Bear, J. (1972): Dynamics of Fluid in porous media, Dover Publications, New York.

Bertrand, L. and Gringarten, A. C. (1978): Détermination des caractéristiques hydrauliques des aquifères fissurés par pompage d'essai en régime transitoire Application aux nappes de la craie, Final report 78 SGN 669 GEG, BRGM, Orléans (in French).

Bourdet, D., Whittle, T. M., Douglas, A. A. and Pirard, Y. M. (1983): A new set of type curves simplifies well test analysis, WORLD OIL, 196, 95-106.

Bourdet, D. (2001): Well test analysis: The use of advanced interpretation models, Elsevier, Amsterdam.

Cinco-Ley, H., Samaniego-V., F. and Dominguez-A., N. (1978): Transient pressure behaviour for a well with a finite-conductivity vertical fracture, SPE J., 6014, 253-264.

Cinco-Ley, H. and Samaniego-V., F. (1981): Transient pressure analysis for fractured wells, SPE J., 7490, 1749-1766. 
de Rooij, R., Perrochet, P. and Graham, W. (2013): From rainfall to spring discharge: Coupling conduit flow, subsurface matrix flow and surface flow in karst systems using a discrete-continuum model, Advances in water resources, 61, 21-41, doi:10.1016/j.advwatres.2013.08.009.

Dikken, B. J. (1990): Pressure drop in horizontal wells and its effect on production performance, SPE J., 19824, 1426-1433, doi:10.2118/19824-PA.

Doummar, J., Sauter, M. and Geyer, T. (2012): Simulation of flow processes in large scale karst systems with an integrated catchment model (Mike She) Identification of relevant parameters influencing spring discharge, Journal of Hydrology, 426-427, 112-123, doi:10.1016/j.jhydrol.2012.01.021.

Dreybrodt, W (1988): Processes in Karst Systems - Physics, Chemistry, and Geology, Springer-Verlag, Berlin.

Follin, S., Hartley, L., Rhen, I., Jackson, P., Joyce, S., Roberts, D. and Swift, B. (2014): A methodology to constrain the parameters of a hydrogeological discrete fracture network model for sparsely fractured crystalline rock, exemplified by data from the proposed high-level nuclear waste repository site at Forsmark, Sweden, Hydrogeology Journal, Vol. 22, No. 2, 313-331; doi:10.1007/s10040-0131080-2.

Gallegos, J. J., Hu, B. X. and Davis, H. (2013): Simulating flow in karst aquifers at laboratory and sub-regional scales using MODFLOW-CFP, Hydrogeology Journal, 1749-1760; doi:10.1007/s10040-013-1046-4.

Galvão, P., Halihan, T. and Hirata, R. (2016): The karst permeability scale effect of Sete Lagoas, MG, Brazil, Journal of Hydrology, 532, 149-162, doi:10.1016/j.jhydrol.2015.11.026.

Giese, M., Reimann, T., Liedl, R., Maréchal, J.-C., and Sauter, M. (2017): Application of the flow dimension concept for numerical drawdown data analyses in mixed flow karst systems. Hydrogeology Journal, doi:10.1007/s10040016-1523-7. 


\section{Chapter 4}

Gringarten, A. C. (1982): Flow-test evaluation of fractured reservoirs, In: Recent trends in hydrogeology, edited by: Narasimhan, T.N., Geological Society of America, Special Paper 189, 237-262.

Gringarten, A. C. (1987): Type-curve analysis: What it can and cannot do, Journal of Petroleum Technology, 39(1), 11-13.

Guiheneuf, N., Boisson, A., Bour, O., Dewandel, B., Perrin, J., Dausse, A., Viossanges, M., Chandra, S., Ahmed, S. and Marechal, J.-C. (2014): Groundwater flows in weathered crystalline rocks: Impact of piezometric variations and depth-dependent fracture connectivity, Journal of Hydrology, 511, 320-334; doi: 10.1016/j.jhydrol.2014.01.061.

Halihan, T., Sharp, J. and Mace, R.E. (2000): Flow in the San Antonio segment of the Edwards aquifer: matrix, fractures, or conduits?, In: Groundwater Flow and Contaminant Transport in Carbonate Aquifers, edited by: Sasowski, I.D. and Wicks, C.M., Balkema, Rotterdam, Netherlands, 129-146.

Harbaugh, A.W. (2005): MODFLOW-2005, The U.S. Geological survey modular ground-water model - The Ground-Water Flow Process: U.S Geological Survey Techniques and Methods 6-A16.

Jeannin, P.Y. (2001): Modelling flow in phreatic and epiphreatic karst conduits in the Hölloch cave (Muotatal, Switzerland), Water Resources Research, Vol. 37, No. 2, 191-200

Joyce, S., Hartley, L., Applegate, D., Hoek, J. and Jackson, P. (2014): Multi-scale groundwater flow modeling during temperate climate conditions for the safety assessment of the proposed high-level nuclear waste repository site at Forsmark, Sweden, Hydrogeology Journal, Vol. 22, No. 6, 1233-1249; doi:10.1007/s10040014-1165-6.

Kiraly, L. (2002): Karstification and groundwater flow. In: Proceedings of the conference on evolution of karst: from prekarst to cessation. PostojnaLjubljana, pp. 155-190. 
Kordilla, J., Sauter, M., Reimann, T. and Geyer, T. (2012): Simulation of saturated and unsaturated flow in karst systems at catchment scale using a continuum approach, Hydrol. Earth Syst. Sci., 16, 3909-3923, doi:10.5194/hess16-3909-2012.

Kovács, A., Perrochet, P., Király, L. and Jeannin, P.-Y. (2005): A quantitative method for the characterisation of karst aquifers based on spring hydrograph analysis, Journal of Hydrology, 303, 152-164, doi:10.1016/j.hydrol.2004.08.023.

Krusemann, G. P. and. de Ridder, N. A (1991): Analysis and evaluation of pumping test data, Institute for Land Reclamation and Improvement (ILRI), Wageningen.

Kuniansky, E. L. (2016): Simulating groundwater flow in karst aquifers with distributed parameter models - Comparison of porous-equivalent media and hybrid flow approaches, U.S. Geological Survey Scientific Investigations Report 2016-5116, doi:10.3133/sir201665116.

Kuniansky, E. L., and Bellino, J. C. (2016): Tabulated transmissivity and storage properties of the Floridan aquifer system in Florida and parts of Georgia, South Carolina, and Alabama (ver. 1.1, May 2016), U.S. Geological Survey Data Series 699.

Leray, S., de Dreuzy, J. R., Bour, O. and Bresciani, E. (2013): Numerical modeling of the productivity of vertical to shallowly dipping fractured zones in crystalline rocks, Journal of Hydrology, 481, 64-75, doi:10.1016/j.jhydrol.2012.12.014.

MacQuarrie, K. T. B. and Mayer, K. U. (2005): Reactive transport modeling in fractured rock: A state-of-the-science review, Earth-Science Review, 72, 3-4, 189227, doi:10.1016/j.earscirev.2005.07.003.

Maréchal, J.-C., Ladouche, B., Dörflinger, N. and Lachassagne, P. (2008): Interpretation of pumping tests in a mixed flow karst system, Water Resources Research, Vol.44, W05401, doi:10.1029/2007WR006288. 


\section{Chapter 4}

Mayaud, C., Wagner, T., Benischke, R. and Birk, S. (2016): Understanding changes in the hydrological behaviour within a karst aquifer (Lurbach system, Austria), Carbonates Evaporites, doi:10.1007/s13146-013-0172-3.

Nastev, M., Savard, M. M., Lapcevic, P., Lefebvre, R. and Martel, R. (2004): Hydraulic properties and scale effects investigation in regional rock aquifers, south-western Quebec, Canada, Hydrogeology Journal, Vol. 12, Nr. 3, 257-269, doi:10.1007/s10040-004-0340-6.

Oehlmann, S., Geyer, T., Licha, T. and Sauter, M. (2015): Reducing the ambiguity of karst aquifer models by pattern matching of flow and transport on catchment scale, Hydrol. Earth Syst. Sci., 19, 893-912, doi:10.5194/hess-19-8932015.

Peterson, E. W. and Wicks, C. M. (2006): Assessing the importance of conduit geometry and physical parameters in karst systems using the storm water management model (SWMM), Journal of Hydrology, 329, 294-305.

Quinlan, J. F. and Ewers, R. O. (1985): Ground water flow in limestone terranes: Strategy rationale and procedure for reliable, efficient monitoring of ground water quality in karst areas, In: Proceedings of the national symposium and exposition on aquifer restoration and ground water monitoring (5th, Columbus, Ohio), National Water Well Association, Worthington, Ohio, 197-243.

Reimann, T., Rehrl, C., Shoemaker, W.B., Geyer, T. and Birk, S. (2011): The significance of turbulent flow representation in single-continuum models, $W$ ater Resources Research, Vol. 47, W09503, doi:10.1029/2010WR010133.

Reimann, T., Giese, M., Geyer, T., Liedl, R., Maréchal, J.-C. and Shoemaker, W. B. (2014): Representation of water abstraction from a karst conduit with numerical discrete-continuum models, Hydrol. Earth Syst. Sci., 18, 227-241, doi:10.5194/hess-18-227-2014.

Renard, P. (2005): 160: Hydraulic of wells and well testing, In: Encyclopedia of hydrological sciences, Part 13. Groundwater, edited by M. Anderson, John Wiley \& Sons Ltd, New York, doi:10.1002/0470848944.hsa154a. 
Saller, S. P., Ronayne, M. J. and Long, A. J. (2013): Comparison of a karst groundwater model with and without discrete conduit flow, Hydrogeology Journal, 21, 1555-1566, doi:10.1007/s10040-013-1036-6.

Sauter, M. (1992): Quantification and forecasting of regional groundwater flow and transport in a karst aquifer (Gallusquelle, Malm, SW Germany), Tübinger Geowissenschaftliche Arbeiten, Part C, 13, 151.

Sauter, M., Kovacs, A., Geyer, T. and Teutsch, G. (2006): Modellierung der Hydraulik von Karstgrundwasserleitern - Eine Übersicht, Grundwasser (11)3; 143-153, (in German).

Shoemaker, W. B., Cunningham, K. J., Kuniansky, E. L. and Dixon, J. (2008a): Effects of turbulence on hydraulic heads and parameter sensivities in preferential groundwater flow layers, Water Resources Research, Vol. 44, W03501, doi:10.1029/2007WR006601.

Shoemaker, W. B., Kuniansky, E. L., Birk, S., Bauer, S. and Swain, E. D. (2008b): Documentation of a Conduit Flow Process (CFP) for MODFLOW-2005: U.S. Geological Survey Techniques and Methods, Book 6, Chapter A24.

Spane (jr.), F. A. and Wurstner, S. K. (1993): A computer program for calculating pressure derivatives for use in hydraulic test analysis, Ground Water, 31(5), 814-822.

Springer, G. S (2004): A pipe-based, first approach to modeling closed conduit flow in caves, Journal of Hydrology, 289, 178-189, doi:10.1016/j.jhydrol.2003.11.020.

Tsang, C. F., Neretnieks, I. and Tsang, Y. (2015): Hydrologic issues associated with nuclear waste repositories, Water Resources Research, Vol. 51, 6923-6972, doi:10.1002/2015WR017641.

White, W. B. (2002): Karst hydrology: recent developments and open questions, Engineering Geology, 65, 85-105. 


\section{Chapter 4}

Worthington, S. R. H. (2009): Diagnostic hydrogeologic characteristics of a karst aquifer (Kentucky, USA), Hydrogeology Journal, 17, 1665-1678, doi:10.1007/s10040-009-0489-0.

Worthington, S. R. H. and Soley, R. W. N. (2017): Identifying turbulent flow in carbonate aquifers, Journal of Hydrology, 552, 70-80, doi:10.1016/j.jhydrol.2017.06.045. 


\section{Chapter 5}

\section{Scale-dependent hydraulic characterization by large-scale pumping tests for idealized mature karst aquifers applying discrete conduit- continuum models}

\subsection{Introduction}

Additional to the maturity of karstification, which influences the global response of the system, the interconnection between adjacent rock and fissured system is relevant to represent the complex flow pattern and transport phenomena of karstic aquifer systems. The classification of karst systems by QUINLAN AND EWERS (1985) and QUINLAN ET AL. (1991) is based on hydraulic aquifer properties on local and regional scale. Those hydraulic properties (e.g. porosity scale, permeability) and the resulting effects (e.g. turbulent/laminar flow, variation in annual discharge performance, physio-chemical properties of the spring water) are quantitatively described and under normal field condition not easy to investigate. Hence, karst spring discharge is frequently analyzed to characterize (parts of) the system on regional scale. Based on the hydrograph analysis, parameters describing the flow system can be estimated by conceptual process studies. MANGIN (1975) used the spring hydrograph for characterizing the maturity of the vadose and the phreatic zone of different karstic springs in France. After his definition each of the zones dominates the water contribution at different periods of the flood event. At the beginning of the event direct recharge into the vadose zone dominates the spring discharge. GEYER ET AL. (2008) stated that the direct recharge dominates the first part of the flood event even with a relatively low ratio of direct recharge to total recharge. Beside the percentage of direct and diffuse recharge, which is difficult to assess, EISENLOHR ET AL. (1997) also quoted the frequency of hydrological events and 


\section{Chapter 5}

the structure of the karst system as main influences affecting the shape of spring hydrograph during flood events. The frequency of hydrological events influences the antecedent reservoir storage. The initial hydraulic gradient between conduit and matrix, the permeability difference and the head gradient along the conduit govern the exchange flow between conduit and matrix and therefore affect the exponential recession of spring hydrographs after flood events (KOVÁCS ET AL., 2005; BAILLY-COMTE ET AL., 2010).

The recession behavior of the first part as well as the second part, representing the total volume of the phreatic zone, is approximated by mathematical functions to obtain information regarding the different compartments, i.e. the recession coefficient is related to the hydraulic diffusivity of the system (MANGIN, 1975; GEYER ET AL., 2008). According to BAILLYCOMTE ET AL (2010), the spring recession results from pressure equilibrium of two different porosities in karst aquifers. Assuming limited exchange the slope of the recession curve will be steep for a high degree of karstification and low for an isolated system without efficient storage (BAILLY-COMTE ET AL., 2010). The two parts of the recession process are linked by a transition period that cannot be explained by one of the mathematical functions (KOVÁCS ET AL., 2005). Therefore, EISENLOHR ET AL. (1997) extended the conceptual two reservoir model by a third one representing transient phenomena in the interface between conduits and matrix. KOVÁCS AND PERROCHET (2008) showed that different parts of the hydrograph limb do not necessary represent systems with different permeability but rather can be expressed by an infinite number of exponential functions of a single two-dimensional square block. According to WARREN AND ROOT (1963), different degrees of interconnection of two media can be linked to property changes on laboratory up to local scale.

The importance of a hydraulic interface on the spring hydrograph was already addressed by ATKINSON ET AL. (1973) who concluded from tracer experiments that exchange flow occurs between the conduit and a region surrounding the conduit during flood events. During the period of the rising limb, exchange flow occurs from the conduit to the interface region whereas the flow direction is opposite during the recession period. Recently, BINET ET AL. (2017) considered the interface between conduit and matrix as 'underground byporbeic zone' with continuous flow exchange. A sensitivity analysis on the exchange flow of a river sink/river rise system revealed that the exchange flow is driven by interface 
properties rather than by hydraulic matrix conductivity. MOORE ET AL. (2010) also described permeability changes along karstic features in eogenetic karst systems for a conceptual description of dissolution processes. This zone of significant amount of dissolution and resulting erosion is referred to as 'friable halo' and can range from centimeter to meter scale. In telegenetic karst systems the exchange flow with the low permeable matrix will enlarge the connected fractures (FORD AND WILLIAMS, 2007).

As described in Chapter 3, the concept of a variable conductive interface and a fast responding storage is used to describe inner boundary conditions of horizontal wellbore tests. Therefore, CFPM1 is able to represent the hydraulic properties of the fractured rock system surrounding the conduit on a local scale. Idealizing the highly conductive feature by a conduit with a constant diameter, the CAD-storage and the exchange coefficient are able to represent the effects caused by an interface between the conduit and the low conductive matrix. Based on the conceptual interpretation of the exchange coefficient (cf. Eq. 2.3; BAUER ET AL., 2003) the interface can also be expressed in terms of the double porosity approach. The geometric parameter $\alpha$ (cf. Eq. 2.1 and Eq. 2.3) represents the effective fracture density around the conduit (cf. Fig. 5.1) and $K$ the interconnected fissured matrix conductivity. Both parameters are further related to the degree of karstification and potentially increase with proceeding rock dissolution at different scales. Assuming a single conduit with constant diameter as only highly conductive karst feature, changes of the flow behavior in the vicinity of the conduit can also be considered as consequence of localized karstification processes (Fig. 5.1). In contrast to other conceptual models the shape factor $\alpha$ cannot be defined as single parameter for the CFPM1 but is part of the exchange coefficient $\alpha_{e x}$ (cf. Eq. 2.3). According to Equation 2.3 this lumped conductance term also considers the matrix conductivity and therefore two parameters that can be associated with pressure differences between matrix and conduit. 


\section{Chapter 5}

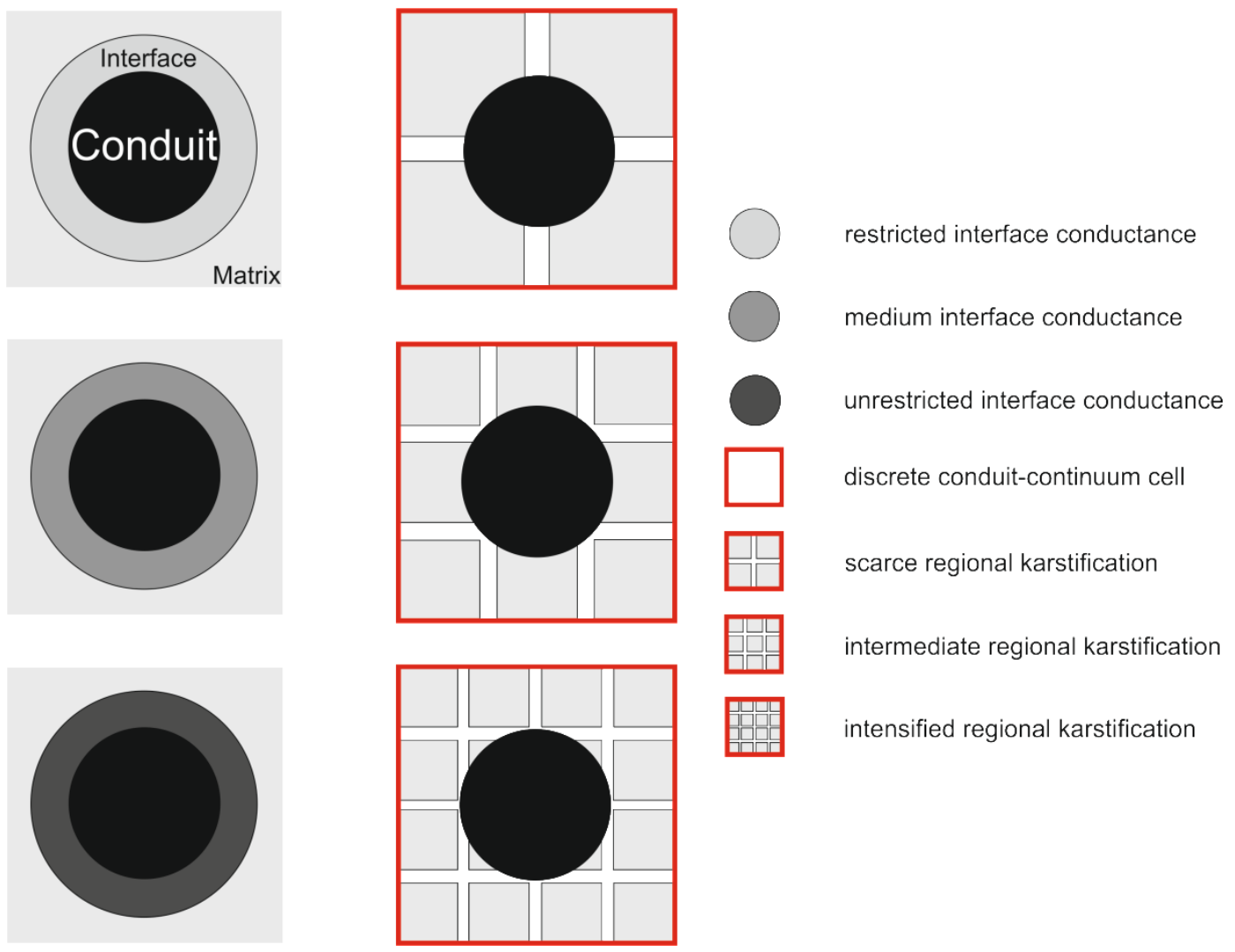

Fig. 5.1: Conceptual representation of the CFPM1 interface by the double porosity approach.

\subsection{Analytical two media interaction}

According to GRINGARTEN (1987) different flow patterns can be described by the double-porosity model during water abstraction ranging between (1) restricted interporosity flow and (2) unrestricted interporosity flow. The flow behavior is related to the interface between the two media and is defined for restricted interporosity flow as significant skin and can be absent for unrestricted interporosity flow. Two parameters, namely interporosity flow coefficient and storativity ratio, are used to describe the interaction of two media (WARREN AND ROOT, 1963). During water abstraction, flow to the pumping well is restricted to the highly permeable system (fissures) and therefore, no direct flow is considered from the less-permeable system (matrix) to the abstraction well (MOENCH, 1984; GRINGARTEN, 1987). 
The interporosity flow coefficient $\lambda[-]$ describes the flow between the two porosities during water abstraction for a pumping well with the radius $r w[\mathrm{~L}]$ defined as (GRINGARTEN, 1984; MOENCH, 1984)

$$
\lambda=\alpha r_{\mathrm{w}}^{2} \frac{K}{K_{f}}
$$

with $\alpha$ the shape factor related to the geometry of the interface $\left[\mathrm{L}^{-2}\right], K$ the hydraulic matrix conductivity [LT-1], $K_{f}$ the hydraulic conductivity of the fissured system [LT-1]. According to WARREN AND ROOT (1963) the interporosity flow coefficient indicates the degree of macroscopic heterogeneity and therefore the restriction of flow between the two porosities. A small $\lambda$-value is related to a strong conductivity contrast (with a well-developed fissured system) delaying the total system response. For high values of $\lambda>>1$, the aquifer system shows a homogeneously behavior during hydraulic stress test.

The storativity ratio $\omega[-]$ is a measure of the storage capacity of the fissured system (WARREN AND ROOT, 1963) and for confined conditions defined as (KRUSEMANN AND DE RIDDER, 2001)

$$
\omega=\frac{S_{\mathrm{fs}}}{\mathrm{S}+S_{\mathrm{fs}}}
$$

with $S_{f s}$ the storativity of the fissured system [-] and $S$ the storativity of the matrix [-]. The dimensionless wellbore storage ranges between $\omega=0$ and $\omega=$ 1. For $\omega=0$ the water is completely stored inside the matrix blocks. For a value of $\omega=1$ the only accessible storage is provided by the fissured systems.

\subsection{Results}

\subsubsection{Interpretation of numerical model parameter}

Chapter 3.4.1 introduced the dimensionless skin damage factor $S_{f}$, which also represents pressure drops in the interface during water abstraction from highly conductive features. Additional to the pressure drop of the skin, discrete numerical models also need to consider the influence of the discretization of the model domain. Nevertheless, the results of Chapter 3 proved that a linear relationship between the analytical skin damage factor and the numerical 


\section{Chapter 5}

exchange coefficient exists. Therefore, the skin damage factor $S_{f}[-]$ will be used as a dimensionless equivalent of the interporosity flow coefficient. The linear relationship between skin damage factor $S_{\text {fand }}$ exchange coefficient $\alpha_{e x}$ can be stated as (cf. Eq. 3.17)

$$
\propto_{e x}=\left[\frac{s_{f}}{2 \pi K \Delta l}+\frac{\ln \left(\frac{r_{o}}{r_{w}}\right)}{2 \pi b \sqrt{K_{x} K_{y}}}+E C C\right]^{-1}
$$

with $\Delta l$ the length of the conduit segment associated to the conduit node [L], $r_{o}$ the effective external radius [L], $b$ the saturated thickness of the cell $[\mathrm{L}]$, and $E C C$ the empirical calibration coefficient $\left[\mathrm{L}^{2} \mathrm{~T}^{-1}\right]$. In contrast to the interporosity flow coefficient $\lambda$, the skin damage factor $S_{f}$ is high in case of flow restrictions between matrix and conduit. Due to the conceptual description of the exchange coefficient $\alpha_{e x}$ the skin damage factor of CFPM1 cannot be zero. Therefore, from the conceptual point of view the simulation of unrestricted water transfer between fissured matrix and conduit is not possible. However the analysis in Chapter 3 shows that it is possible to simulate nearly unrestricted exchange flow.

Chapter 3 also introduced the dimensionless wellbore storage which can be used to describe the interaction of the storage between two different compartments as

$$
C_{D}=\frac{C}{2\left(x_{f}^{2} S_{s} \pi\right)}
$$

with

$$
C=r_{c}^{2} \pi
$$

where $C$ is the wellbore storage constant [ $\left.\mathrm{L}^{2}\right], X_{f}$ is the pipe half-length [L], $S_{S}$ specific storage $\left[\mathrm{L}^{-1}\right]$ and $r_{c}$ the casing radius [L]. Following the definition of the dimensionless wellbore storage, for a dimensionless wellbore storage of $C_{D}=0$ fast responding CAD-storage is absent. All storage is provided by the fissured matrix and therefore equals the conceptual karst model of DROGUE (1992). For values above $C_{D}=0$ both porosities contribute water for abstraction scenarios. With increasing dimensionless wellbore storage $C_{D}$ more drainable water is directly connected to the conduit system. Referring to the CAD-storage concept (REIMANN ET AL., 2014), this water is provided by solution-enlarged fractures 
and karst cavities without active flow, created by dissolution processes along the conduit system.

For the following analysis the dimensionless drawdown $S_{D}$, the dimensionless time $t_{D}$ and the dimensionless drawdown derivative $S_{D}$ ' are defined as (cf. Chapter 3, Chapter 4)

$$
\begin{aligned}
& s_{D}=\left(\frac{2 \pi T}{Q_{p}}\right) \Delta s \\
& t_{D}=\frac{T t}{x_{f}^{2} S} \\
& s_{D}{ }^{\prime}=\frac{\partial s_{D}}{\partial \ln \left(t_{D} / C_{D}\right)}
\end{aligned}
$$

with $T$ the matrix transmissivity $\left[\mathrm{L}^{2} \mathrm{~T}^{-1}\right], Q_{p}$ the pumping rate $\left[\mathrm{L}^{3} \mathrm{~T}^{-1}\right], \Delta s$ the water level change inside the conduit [L] and $t$ the time [T]. Furthermore the model set-up is identical to the one used in Chapter 3.

\subsubsection{Results of the reference scenario}

A diagnostic plot of the idealized pumping test with a skin damage factor of $S_{f}=0.1$ and a dimensionless wellbore storage of $C_{D}=0.001$ is presented in Figure 5.2. Figure 5.2 also shows the flow components introduced in Chapter 4.1 . 


\section{Chapter 5}

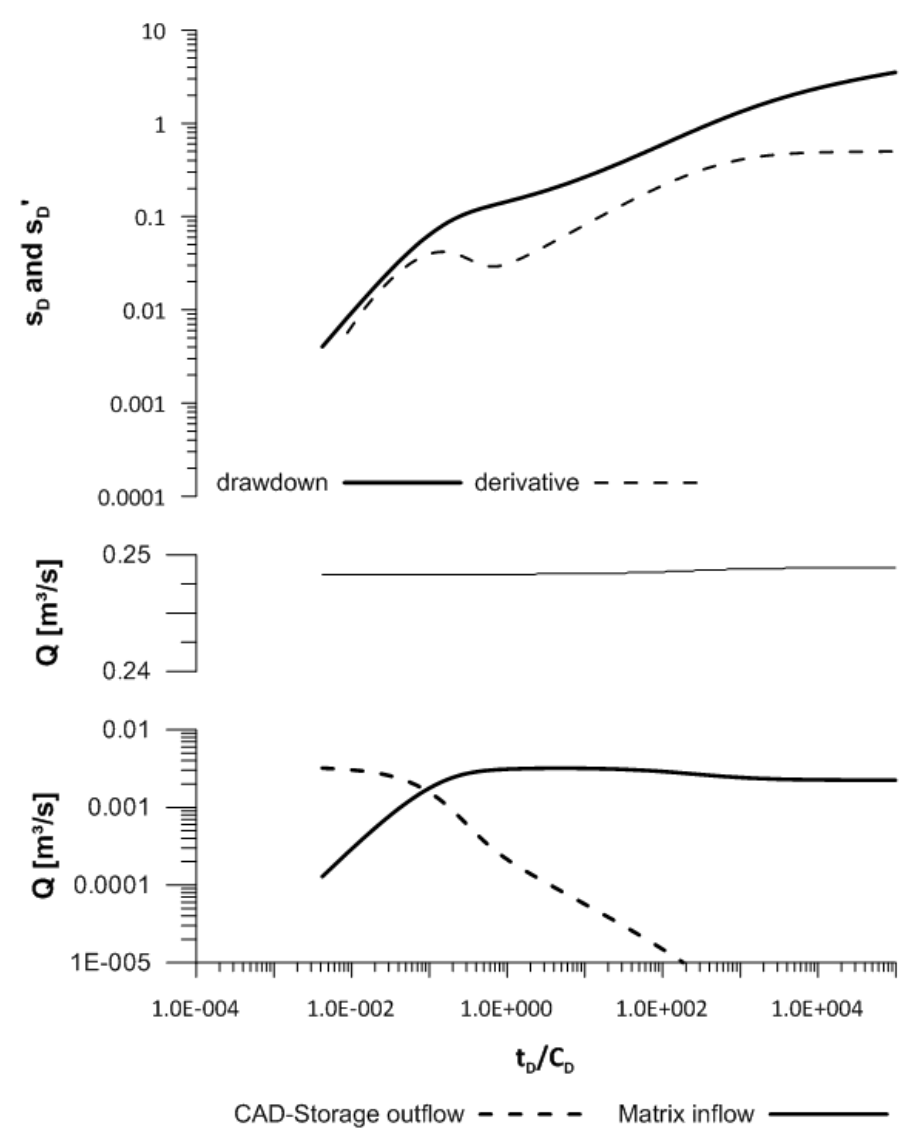

Fig. 5.2: Simulation results for the reference scenario: log-log plot of drawdown and drawdown derivative as well as volumetric rates at the pumping well during water abstraction.

The pumping well abstracts water directly from the conduit node. Due to the direct linkage between conduit and CAD-storage (cf. Eq. 2.5) and as an immediate response to the hydraulic head drop inside the conduit node CADstorage releases water to the conduit system (Fig. 5.4; REIMANN ET AL., 2014). Conduit drawdown generates a hydraulic gradient between conduit and matrix and, therefore, water flows from the matrix to the conduit system (Fig. 5.2, Eq. 2.2). As a consequence of its high hydraulic conductivity, the conduit provides most of the water resulting in a high water volume $Q_{i p}$ flowing towards the pumping well (Fig. 5.2). Over time the exchange flow increases as a consequence of the hydraulic gradient. During the same time CAD-storage release decreases until the exchange flow exceeds the direct storage release. Approximately at the same time a change of drawdown behavior can be observed. The curves presented by the diagnostic plot leave the unit slope that represents the storage flow period. The drawdown per dimensionless time step decreases and the drawdown derivative starts to describe the characteristic derivative hump. 
Therefore, this time step can be declared as the end of the conduit storage period and the beginning of the first flow transition. During the first transition period drawdown inside the conduit is deflated as a consequence of increasing exchange flow at the pumping node (Fig. 5.2). In comparison to the conduit the signal slowly propagates inside the matrix. Hence the hydraulic gradient between conduit and low permeable matrix still increases at the conduit tail during linear flow. As a direct consequence the flow volume towards the pumping well rises during linear flow (Fig. 5.2). Starting at $t_{D} / C_{D}=1,000$, the derivative curve stabilizes indicating radial flow conditions at the end of the pumping test. Subsequently, the drawdown behavior is dominated by the continuum and depends on the hydraulic parameters of the matrix.

The initial set up is used as reference for the following parameter analysis.

\subsubsection{Effects of dimensionless wellbore storage variation}

Figure 5.3 shows the influences of the dimensionless wellbore storage (Eq. 5.4) on drawdown and drawdown derivative. For the following set-ups the values of the dimensionless wellbore storage are changed. According to Equation 5.4 a $W_{\text {CADS }}$ increase of one order of magnitude results in a dimensionless wellbore storage of $C_{D}=0.01$ and a decrease of the same order of magnitude in an dimensionless wellbore storage of $C_{D}=0.0001$. The matrix storativity $S$ changes the dimensionless wellbore storage inversely. 


\section{Chapter 5}

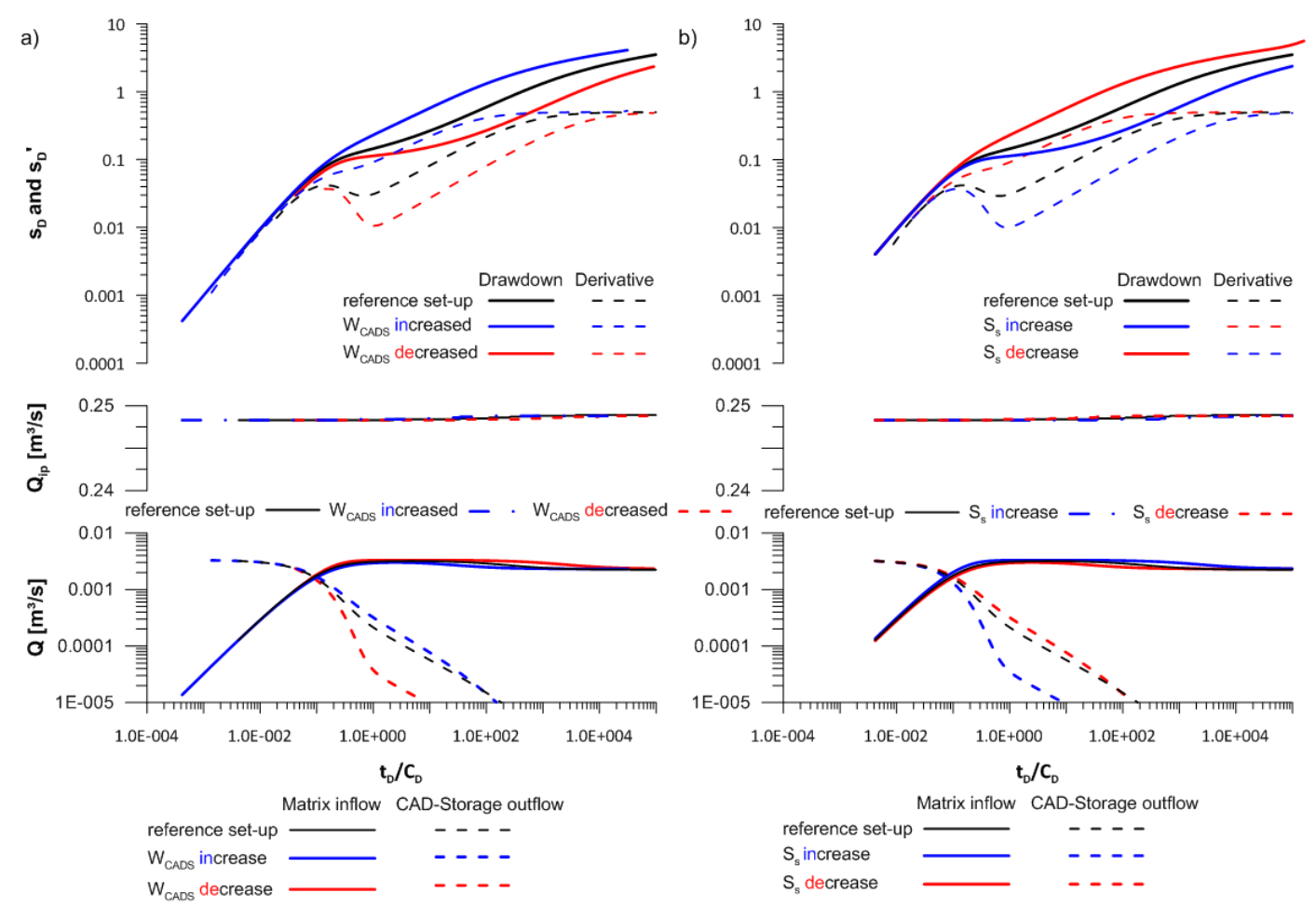

Fig. 5.3: Simulation results for dimensionless wellbore storage changes: a) log-log plot of drawdown and drawdown derivative as well as mass fluxes at the pumping well during the abstraction period for variable $W_{C A D S}$, b) $\log$-log plot of drawdown and drawdown derivative as well as mass fluxes at the pumping well during the abstraction period for variable $S_{s}$.

A variation of the CAD-storage width directly affects the water volume released by unit conduit head drop. Decreasing the $W_{C A D S}$ value shifts the drawdown curve upwards along the unit slope curve representing the storage period (Fig 5.3a). Compared to the reference set-up, the higher initial conduit drawdown results in an increased hydraulic potential between conduit and matrix and hence increased water transfer from the matrix (Fig 5.3a). Simultaneously, the conduit storage period is shortened and the elongated first transition starts earlier in time. The time shift is a consequence of a comparatively high storage difference leading to non-uniform water release per unit head drop in both systems. In case of a lower storage release per unit conduit head drop, a long lasting water transfer from the matrix can be detected (Fig. 5.3a). Compared to the reference scenario, the derivative shows a distinctive minimum before reaching the linear flow period. The half-unit slope of the derivative, representing linear flow conditions, already starts during the period where the conduit drawdown is affected by the matrix exchange flow. 
In Figure 5.3b the matrix storage is varied by one order of magnitude whereas conduit storage (CAD-storage) is kept constant. Therefore, the drawdown and drawdown derivative at early times (storage period) are comparable for all scenarios. During the first transition period the curve shapes are affected by different matrix storage values. Increased matrix storativity buffers the matrix drawdown and hence forces a higher hydraulic gradient between conduit and matrix. The flow behavior of the different parametrizations is similar to those already explained for the same dimensionless wellbore storage values of Figure 5.2. A significant difference to the initial set up is the propagation of the drawdown signal inside the matrix. Drawdown propagation inside the matrix is related to hydraulic diffusivity, which is defined as ratio of matrix conductivity and storage. Consequently, drawdown propagates faster with decreased matrix storage and vice versa. Therefore the linear flow period ends earlier with decreased matrix storage.

Summarizing the results of the variation of the storage components of Figure 5.3, the dimensionless wellbore storage influences the first transition period as well as the linear flow period. A decrease of the dimensionless wellbore storage $C_{D}$ leads to a long lasting transition period with increased exchange flow whereas an increase of the dimensionless wellbore storage shortens the transition. Furthermore, it can be concluded that increased conduit storage can superimpose the linear flow period and hence only a short lasting or even no conduit dominated flow period can be detected. The linear flow period is also be shortened by decreased matrix storativity as a consequence of fast drawdown propagation inside the matrix.

\subsubsection{Effects of skin damage factor variation}

The skin damage factor $S_{f}$ depends on the ratio of the matrix conductivity $K$ and the exchange coefficient $\alpha_{e x}$ (Eq. 5.3). Changes of the skin damage factor affect the conductance of the interface between conduit and matrix. Figure 5.4 shows the differences in drawdown caused by altering the skin damage factor by one order of magnitude.

With decreased exchange coefficient, the exchange flow declines for a specific head gradient between matrix and conduit (cf. Eq. 2.2). Therefore, exchange flow varies for the same conduit drawdown, which affects the 


\section{Chapter 5}

duration of the initial storage period (Fig. 5.4b). For low exchange coefficient values the storage period lasts for a longer duration of time. This results in higher hydraulic gradients at the beginning of the transition period. As a consequence, the exchange flow increases and drawdown inside the conduit is clearly damped during the transition period.
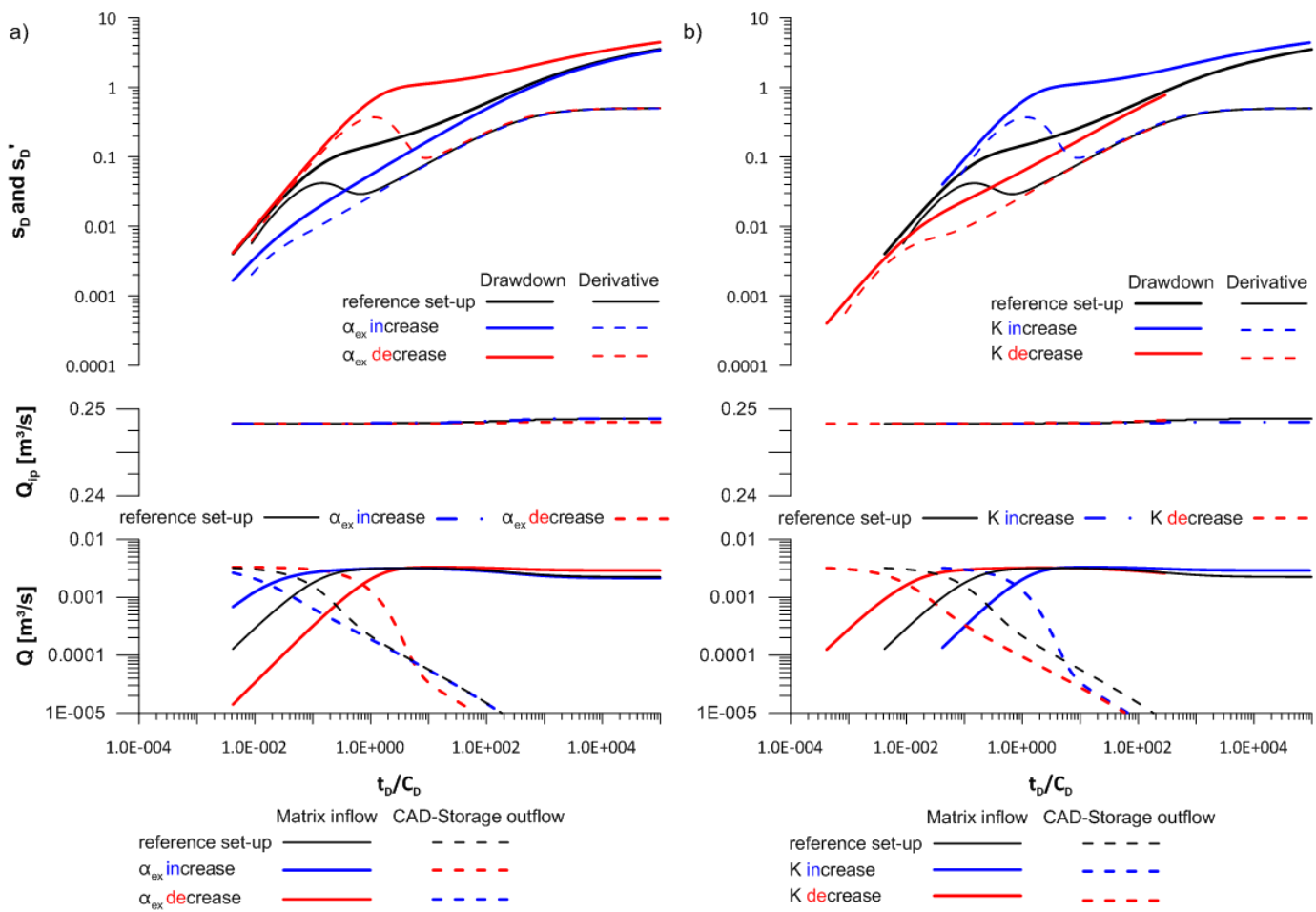

Fig. 5.4: Simulation results for skin damage factor changes: a) log-log plot of drawdown and drawdown derivative as well as mass fluxes at the pumping well during the abstraction period for variable $\alpha_{e x ;}$ c) $\log$-log plot of drawdown and drawdown derivative as well as mass fluxes at the pumping well during the abstraction period for variable $K_{\mathrm{fm}}$.

Similar to the changes of the matrix storativity the duration of the storage period is not affected but the matrix conductivity has an influence on the propagation of the drawdown signal inside the matrix. Low matrix conductivity hampers the flow between adjacent matrix cells (cf. Eq. 2.4). Consequently the matrix flow to the drawdown affected cells surrounding the conduit is lower. As a consequence the cone of depression is steep in the vicinity of the conduit. With slow propagation of the drawdown signal the duration of the linear flow period increases.

Summarizing the results, it can be stated that high skin damage factors extends the storage period due to high conductivity differences of the fissured 
matrix and the interface. For high skin damage factors exchange flow is restricted by the interface conductance. With a decrease of the skin damage factor the flow is restricted by the low matrix conductivity leading to a long lasting linear flow period.

\subsection{Hydraulic interface properties of mixed-flow karst systems}

The parameter study shows the different influences of the hydraulic parameters on the drawdown and the derivative curve. The different set-ups have in common that a radial flow period is reached at the end of the pumping test characterizing the hydraulic permeability on regional scale. Differences between the described parameter settings can be detected during the storage period as well as the transition period. The different parametrizations also influence the duration and shape of the linear flow regime. Beside the discussed parameters the linear flow period is also influenced by the conduit length and the development of the conduit network. Here, these effects are excluded. As already mentioned the transition period characterizes the pressure equilibrium stage between the conduit and the matrix systems. Changes of the hydraulic parameters therefore influence the shape of the drawdown curve. Based on this conclusion a collection of different type curves correspond to different hydraulic settings can be created characterizing the influence of the interface between conduit and fissured matrix. All set ups consider a single conduit of the length $L=3000 \mathrm{~m}$ and constant diameter. The laminar Hagen-Poiseuille flow equation is applied to achieve quasi-infinite conductivity along the conduit.

Figure 5.5 consist of 9 different diagnostic plots representing different interface properties. Every diagnostic plot combines two different pairs of drawdown and derivative curve: (a) the black curves present the drawdown behavior associated to changes of the hydraulic matrix parameters and (b) the red curves present the drawdown behavior associated to changes of the hydraulic conduit parameters. Both collections of diagnostic plots can also be found in Appendix I (matrix parameter variation) and Appendix II (conduit parameter variation) supplemented by the parameter values. The colored dots represent the time of pumping start. Therefore the curves are not congruent but 


\section{Chapter 5}

they represent the same flow behavior (in different time intervals), which will be further discussed.

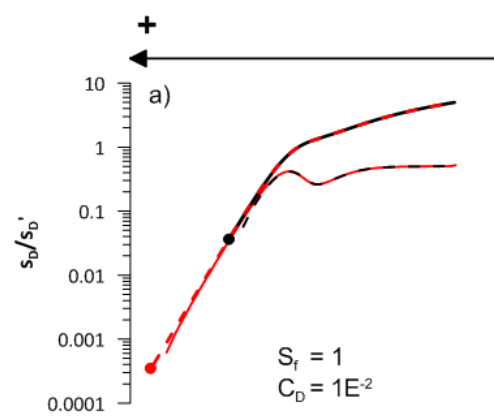

b)

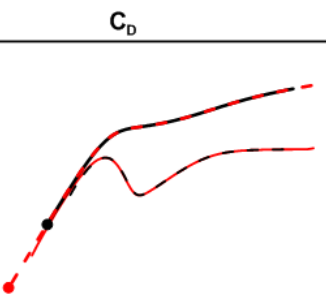

$\mathrm{S}_{\mathrm{f}}=1$

$\mathrm{C}_{\mathrm{D}}=1 \mathrm{E}^{-3}$
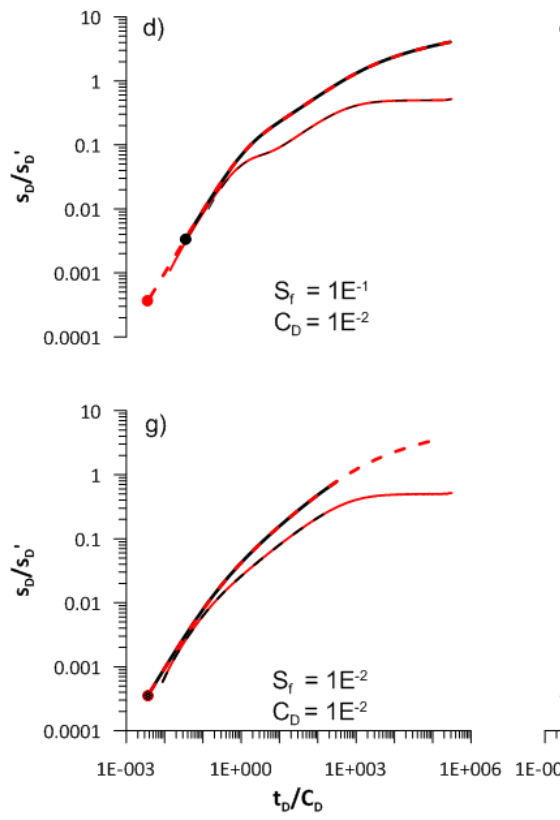

e)

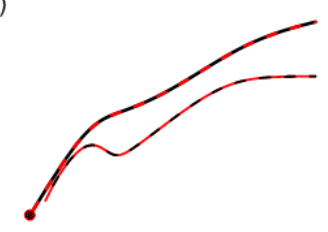

$\mathrm{S}_{\mathrm{f}}=1 \mathrm{E}^{-1}$

$\mathrm{C}_{\mathrm{D}}=1 \mathrm{E}^{-3}$

h)

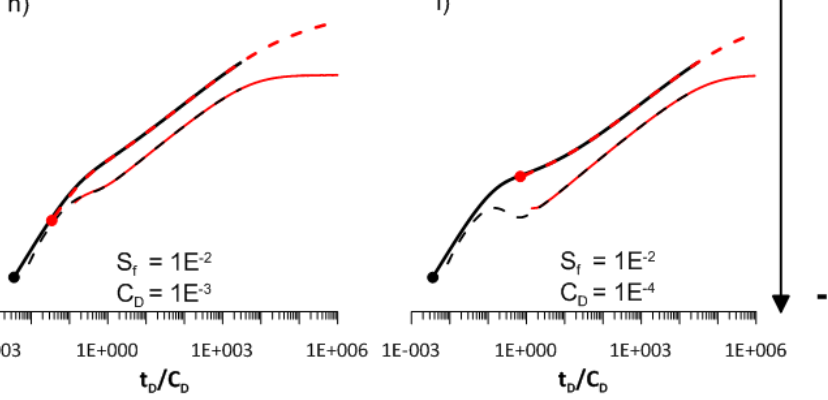

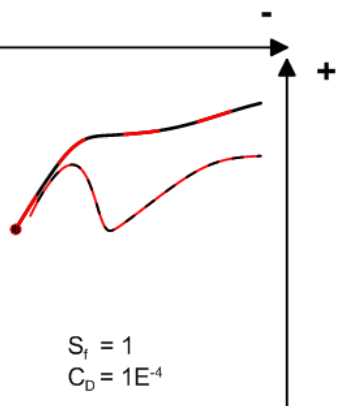

f)

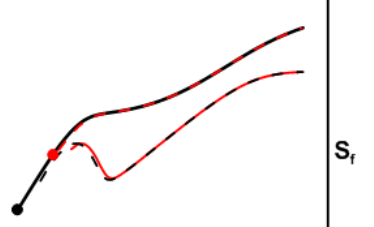

$S_{f}=1 E^{-1}$

$\mathrm{C}_{\mathrm{D}}=1 \mathrm{E}^{-4}$

Fig. 5.5: Dimensionless type curves for a single conduit of $L=3000 \mathrm{~m}$ depending on the dimensionless wellbore storage and the skin damage factor. Black lines represent conduit associated parameter changes; red lines represent the fissured matrix associated parameter changes

Along the rows the dimensionless wellbore storage decreases from left to right with values ranging of $C_{D}=0.01$ to $C_{D}=0.0001$. Values of $C_{D}=0$ would represent the double-fissured porosity approach (DROGUE, 1992) without any storage associated to the conduit system. For small $C_{D}$ values it can be assumed that the conduit is mainly intersected by joints, faults and fissures with marginal porosity (e.g. WORTHINGTON ET AL., 2000, BOURDET, 2001). For high $C_{D}$ values a fast-responding storage is provided by fractures or solution enlarged features hydraulically connected to the conduit (e.g. MCCONNELL, 1993). Along the columns the type curves change as a function of the skin damage factor, 
ranging from $S_{f}=0.01$ to $S_{f}=1$. Small skin damage factors of $S_{f}=0.01$ do not add an additional interfacial pressure drop and the conductivity differences between interface and matrix are high. With increasing skin damage values the flow restriction of the interface increases.

The diagnostic plots of Figure 5.5 represent the diversity of mixed flow karst systems. Depending on the hydraulic properties of the (fissured) matrix and the conduit system, characteristic flow field conditions can be observed. Those changes can be detected on different catchment scales as presented by Figure 5.6.

Local effects
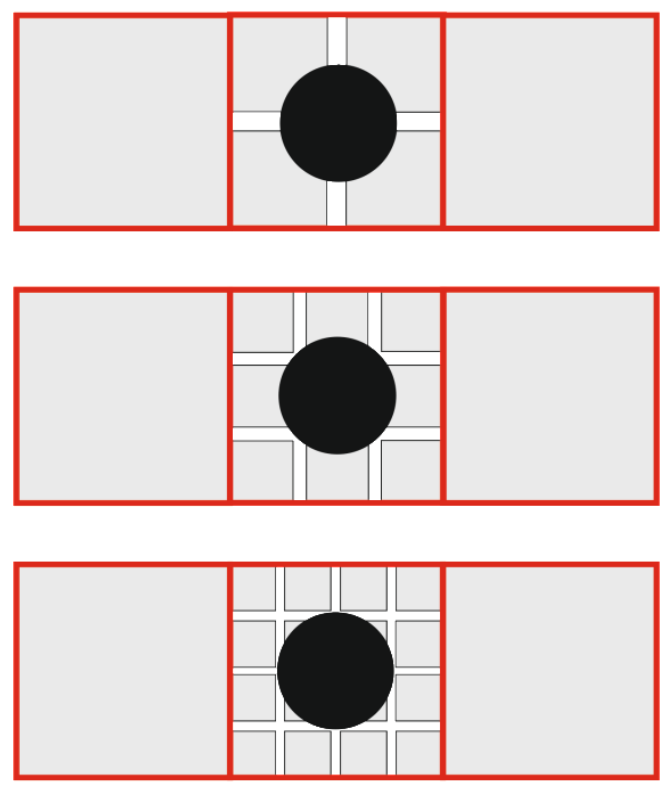

scarce local karstification

intermediate local karstification

intensified local karstification
Regional effects
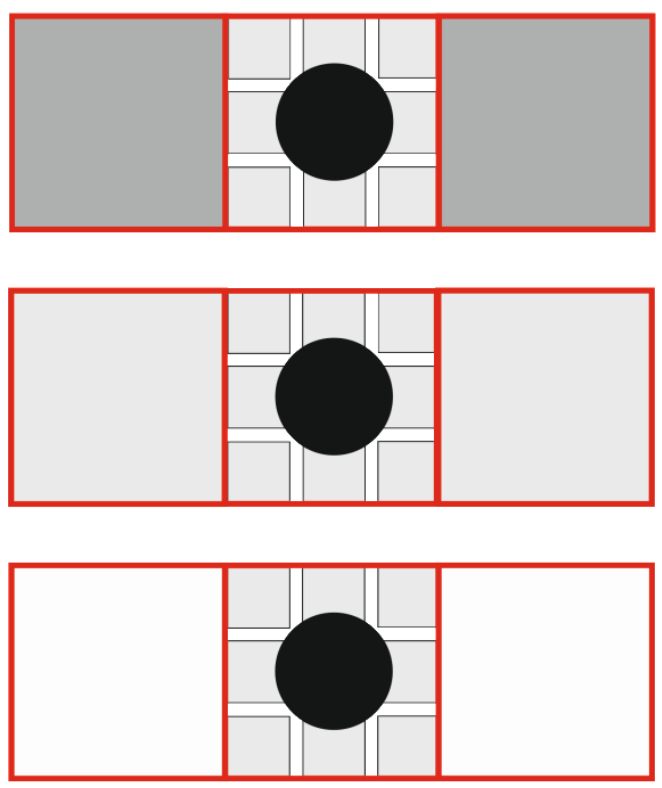

scarce regional karstification

intermediate regional karstification

intensified regional karstification

Fig. 5.6: Schematic representation of different degrees of local and regional karstification.

Based on the hydraulic properties different conceptual karst systems can be defined. The models of Figure 5.5a-c are characterized by a flow restriction of the interface between the conduit and the (fissured) matrix. A low permeability on a local scale (Fig. 5.6) that can be associated with a low degree of macroscopic heterogeneity around the conduit causes high hydraulic gradients in the vicinity 


\section{Chapter 5}

of the conduit. The transition period between storage period and linear flow is, compared to the other diagnostic plots, extended. In contrast, the cone of depression inside the matrix has a shallow slope due to the generally high hydraulic matrix conductivity, which is characteristic for a uniformly karstified aquifer. The generally high degree of karstification is also an additional explanation for the high hydraulic gradients between the conduit and the matrix, i.e. on a local scale. That can be the result of turbulent exchange flow or restricted inflow from additional karstic features in the vicinity of the conduit. Under certain circumstances the interface can also be affected by debris load or collapsed structures.

The diagnostic plots of Figure 5.5g-i represent karst systems with high skin permeability (cf. Fig. 5.6). The hydraulic gradient in the vicinity of the conduit is low resulting in short transition periods. Due to the low hydraulic conductivity of the fissured matrix the cone of depression has a shallow slope on regional scale. The conceptual model is dominated by localized karstification and flow restriction caused by the matrix. The characteristics are similar to karst catchments referred to as matrix restricted karst flow systems.

Apart from the interface permeability the diagnostic plots of Figure 5.5 present differences of storage distribution. The fast-responding storage is characterized by the storage area instead of volume. Therefore, the storage volume, related to the recent precipitation history, is not considered. An increased fast-responding storage (Fig. 5.5.a/d/g) extends the duration of the storage period. This effect is intensified by high skin damage factors. Hence the linear flow period is nearly completely masked by the storage period and afterwards the diagnostic plots of Figure 5.5a tend to radial flow (cf. Theis type curve). In case of a small fast-responding storage area combined with a low skin damage factor the storage period is absent. Changes of the matrix storativity influence the diffusivity of the matrix. With decreased matrix storage and hence increased diffusivity (Fig. $5.5 \mathrm{a} / \mathrm{d} / \mathrm{g}$ ) the cone of depression extends more rapidly inside the matrix. This results in a short linear flow period.

Figure 5.5 shows that the influences of the interface hydraulics are multifaceted. Different degrees of storativity and permeability contrasts between the highly conductive conduits and the (fissured) matrix change the overall flow behavior during pumping tests. Those differences can be related to 
different conceptual models of the local scale of the karst aquifers as illustrated in Figure 5.6.

\subsection{Conclusions and Discussion}

The interpretation of the influence of dimensionless wellbore storage and skin damage factor on drawdown behavior combines the double porosity approach applied for simulation of karst hydraulics and observed skin effects during pumping tests on local scale. The concept is focused on the drainage ability of the conduit concerning the adjacent rock. With different parameterization representing different hydraulic conditions around the conduit a wide range of different type curves can be simulated. The differences of the hydraulic conditions are related to the degree of karstification (conduit porosity). Depending on dissolution, enlargement of conduits, progressive development and interconnection of the fissured/fractured system on local scale (macroscopic heterogeneities) the flow between conduit and adjacent rock shows different degrees of flow restriction. The dimensionless wellbore storage and skin damage factor are able to describe these complex differences of macroscopic heterogeneities and gradually different hydraulics. The results show that an interface between fissured matrix and conduit is important to beware the physical meaning of the matrix conductivity.

The usage of idealized parameters along the conduit (e.g. homogeneous exchange coefficient, CAD-storage width and diameter) and idealized initial conditions simplifies the complex field conditions. The natural head distribution inside a karstic catchment with head differences between matrix and conduit before the start of pumping will change the shape of the drawdown curve. For example, a rainfall event with high percentage of direct recharge into the conduit system just before the start of the pumping test may introduce an apparent negative skineffect due to the additional water volume in the conduit system. Another important point, which is not focused in this work, is the differences of the drawdown curves for confined and unconfined karstic aquifer or even the change from confined to unconfined conditions during pumping. 


\section{Chapter 5}

\section{References}

Atkinson, T. C., Smith, D. I., Lavis, J. J. and Whitaker, R. J. (1973): Experiments in tracing underground waters in limestones, Journal of Hydrology, 19, 323-349.

Bailly-Comte, V., Martin, J. B., Jourde, H., Screaton, E. J., Pistre, S. and Langston, A. (2010): Water exchange and pressure transfer between conduits and matrix and their influence on hydrodynamics of two karst aquifers with sinking streams, Journal of Hydrology, 386, 55-66, doi:10.1016/j.jhydrol.2010.03.005.

Binet, S., Joigneaux, E., Pauwels, H., Abéric, P., Fléhoc, Ch. and Bruand, A. (2017): Water exchange, mixing and transient storage between a saturated karstic conduit and the surrounding aquifer: Groundwater flow modeling and inputs from stable water isotopes, Journal of Hydrology, 544, 278-289, doi:10.1016/j.hydrol.2016.11.042.

Bourdet, D. (2001): Well test analysis: The use of advanced interpretation models, Elsevier, Amsterdam.

Cinco-Ley, H. and Samaniego-V., F (1981): Transient pressure analysis: Finite conductivity fracture case versus damaged fracture case, SPE 10179, 56th annual fall technical conference and exhibition of the society of Petroleum Engineers of AIME, San Antonio, Texas.

Drogue, C. (1992): International Contribution to Hydrogeology, 13, Verlag Heinz Heise, Hannover, Germany, 133-149.

Eisenlohr, L., Bouzelboudjen, M., Király, L and Rossier, Y. (1997): Numerical versus statistical modelling of natural repsonse of a karst hydrogeological system, Journal of Hydrology, 202, 244-262.

Ford, D. and Williams, P. (2007): Karst Hydrogeology and Geomorphology, John Wiley \& Sons Ltd, Chichester. 
Geyer, T., Birk, S., Liedl, R. and Sauter, M. (2008): Quantification of temporal distribution of recharge in karst systems from spring hydrographs, Journal of Hydrology, 348, 452-463, doi:10.1016/j.jhydrol.2007.10.015.

Gringarten, A. C. (1984): Interpretation of tests in fissured and multilayered reservoirs with double-porosity behavior: theory and practice, Journal of Petroleum Technology, April, 549-564.

Gringarten, A. C. (1987): How to recognize "Double-porosity" systems from well tests, Journal of Petroleum Technology, June, 631-633.

Kovács, A. and Perrochet, P. (2008): A quantitative approach to spring hydrograph decomposition, Journal of Hydrology, 352, 16-29.

Kovács, A., Perrochet, P., Király, L. and Jeannin, P.-Y. (2005): A quantitative method for the characterisation of karst aquifers based on spring hydrograph analysis, Journal of Hydrology, 303, 152-164, doi:10.1016/j.jhydrol.2007.12.009.

Krusemann, G. P and de Ridder, N. A. (1991): Analysis and evaluation of pumping test data, Institute for Land Reclamation and Improvement (ILRI), Wageningen.

Mangin, A. (1975): Contribution à l'étude hydrodynamique des aquiféres karstiques, PhD thesis, Université de Dijon, France.

Maréchal, J.-C., Ladouche, B., Dörflinger, N. and Lachassagne, P. (2008): Interpretation of pumping tests in a mixed flow karst system, $W$ ater Resources Research, Vol.44, W05401, DOI10.1029/2007WR006288.

McConnell, C. L. (1993): Double porosity well testing in the fractured carbonate rocks of the Ozarks, Ground Water, 31(1), 75-83.

Moench, A. F. (1984): Double-porosity models for a fissured groundwater reservoir with fracture skin, $W$ ater Resources Research, Vol. 20, No.7, 831-846.

Moore, P. J., Martin, J. B., Screaton, E. J. and Neuhoff, P. S. (2010): Conduit enlargement in an eogenetic karst aquifer, Journal of Hydrology, 393, 143-155, DOI10.1016/j.jhydrol.2010.08.008. 


\section{Chapter 5}

Quinlan, J. F. and Ewers, R. O. (1985): Ground water flow in limestone terranes: Strategy rationale and procedure for reliable, efficient monitoring of ground water quality in karst areas, In: Proceedings of the national symposium and exposition on aquifer restoration and ground water monitoring (5th, Columbus, Ohio), National Water Well Association, Worthington, Ohio, 197-243.

Quinlan, J. F., Smart, P. L., Schindel, G. M., Alexander (Jr.), E. C., Edwards, A. J. and Smith, A. R. (1991): Recommended administrative/regulatory definition of karst aquifer, principles for classification of carbonate aquifers, practical evaluation of vulnerability of karst aquifers, and determination of optimum sampling frequency at springs, In: Hydrogeology, ecology, monitoring, and management of ground water in karst terranes conference (3rd, Nashville, Tennessee), National ground water association, Dublin, Ohio.

Reimann, T., Giese, M., Geyer, T., Liedl, R., Maréchal, J.C. and Shoemaker, W. B. (2014): Representation of water abstraction from a karst conduit with numerical discrete-continuum models, Hydrol. Earth Syst. Sci., 18, 227-241, DOI10.5194/hess-18-227-2014.

Warren, J. E. and Root, P. J. (1963): The behavior of naturally fractured reservoirs, SPE J., 3: 245-255.

White, W. B. (2002): Karst hydrology: recent developments and open questions, Engineering Geology, 65, 85-105, 2002.

Worthington, S. R. H., Ford, D. C. and Davies, G. J. (2000): Matrix, fractures and channel components of storage and flow in a Paleozoic limestone aquifer, In: Groundwater flow and contaminant transport in carbonate aquifers, edited by: I. D. Sasowsky and C. M. Wicks, 113-128. 


\section{Appendix I}
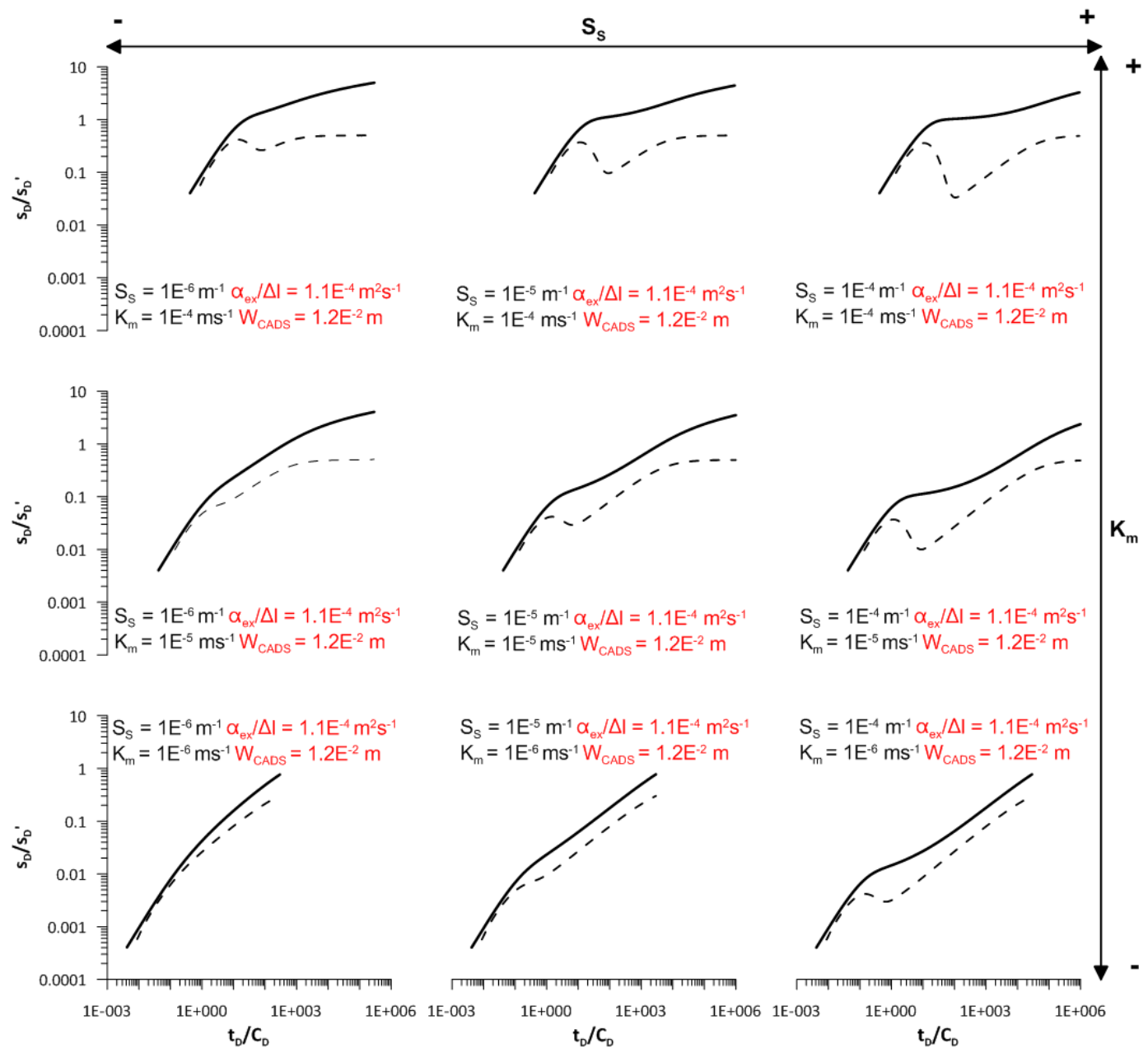

$\mathrm{S}_{\mathrm{S}}=1 \mathrm{E}^{-4} \mathrm{~m}^{-1} \alpha_{\mathrm{ex}} / \Delta \mathrm{l}=1.1 \mathrm{E}^{-4} \mathrm{~m}^{2} \mathrm{~s}$ $\mathrm{K}_{\mathrm{m}}=1 \mathrm{E}^{-6} \mathrm{~ms}^{-1} \mathrm{~W}_{\mathrm{CADS}}=1.2 \mathrm{E}^{-2} \mathrm{~m}$

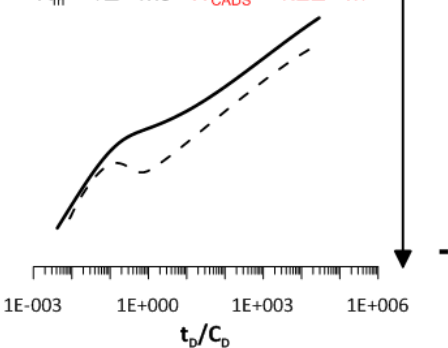




\section{Chapter 5}

\section{Appendix II}
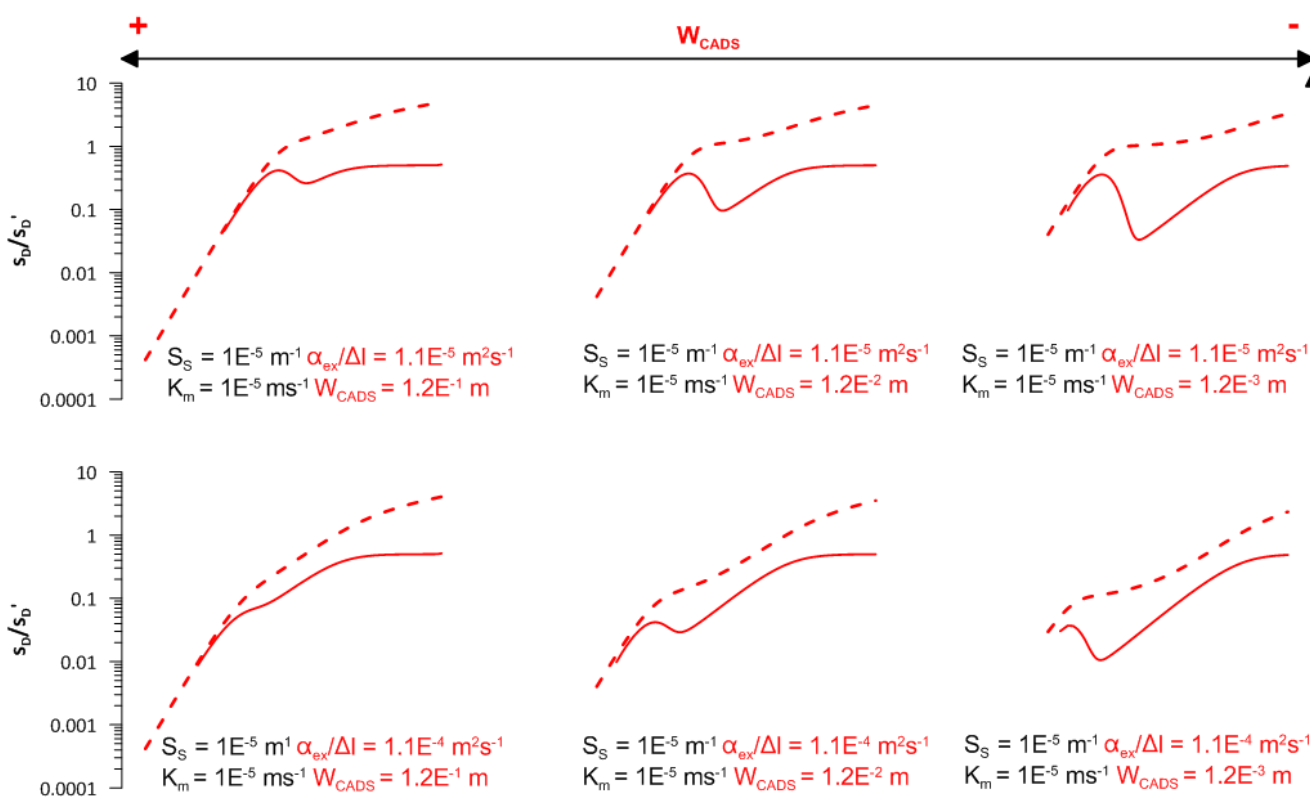

$\mathrm{S}_{\mathrm{S}}=1 \mathrm{E}^{-5} \mathrm{~m}^{-1} \alpha_{\mathrm{ex}} / \Delta \mathrm{l}=1.1 \mathrm{E}^{-4} \mathrm{~m}^{2} \mathrm{~s}$ $\mathrm{K}_{\mathrm{m}}=1 \mathrm{E}^{-5} \mathrm{~ms}^{-1} \mathrm{~W}_{\mathrm{CADS}}=1.2 \mathrm{E}^{-2} \mathrm{~m}$

$\mathrm{S}_{\mathrm{S}}=1 \mathrm{E}^{-5} \mathrm{~m}^{-1} \alpha_{e x} / \Delta \mathrm{l}=1.1 \mathrm{E}^{-4} \mathrm{~m}^{2} \mathrm{~s}$ $0.0001 \mathrm{~K}_{\mathrm{m}}=1 \mathrm{E}^{-5} \mathrm{~ms}^{-1} \mathrm{~W}_{\mathrm{CADS}}=1.2 \mathrm{E}^{-1} \mathrm{~m}$
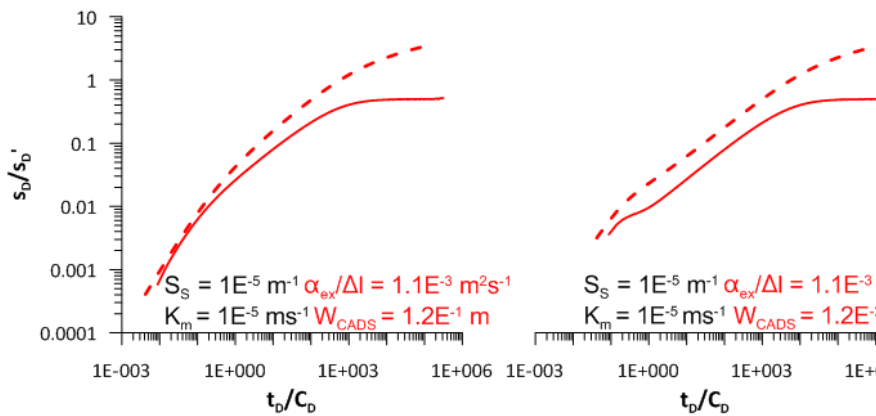

$\mathrm{S}_{\mathrm{S}}=1 \mathrm{E}^{-5} \mathrm{~m}^{-1} \alpha_{\mathrm{ex}} / \Delta \mathrm{l}=1.1 \mathrm{E}^{-3} \mathrm{~m}^{2} \mathrm{~s}^{-1} \quad \mathrm{~S}_{\mathrm{S}}=1 \mathrm{E}^{-5} \mathrm{~m}^{-1} \alpha_{\mathrm{ex}} / \Delta \mathrm{l}=1.1 \mathrm{E}^{-3} \mathrm{~m}^{2} \mathrm{~s}$ $\mathrm{K}_{\mathrm{m}}=1 \mathrm{E}^{-5} \mathrm{~ms}^{-1} \mathrm{~W}_{\mathrm{CADS}}=1.2 \mathrm{E}^{-2} \mathrm{~m} \quad \mathrm{~K}_{\mathrm{m}}=1 \mathrm{E}^{-5} \mathrm{~ms}^{-1} \mathrm{~W}_{\text {CADS }}=1.2 \mathrm{E}^{-3} \mathrm{~m}$ $t_{D} / C_{D}$ $1 E+000 \quad 1 E+003 \quad 1 E+006 \quad 1 E-003$ $1 E+000 \quad 1 E+003$ 


\section{Chapter 6}

\section{Application of the flow dimension concept for numerical drawdown data analyses in mixed karst systems}

Markus Giese ${ }^{1,3}$, Thomas Reimann ${ }^{2}$, Rudolph Liedl ${ }^{3}$, Jean-Christophe Maréchal ${ }^{3}$, Martin Sauter ${ }^{1}$

\section{Manuscript:}

Giese, M., Reimann, T., Liedl, R., Maréchal, J.-C. and Sauter, M. (2017): Application of the flow dimension concept for numerical drawdown data analyses in mixed karst systems, Hydrogeology Journal, doi:10.1007/s10040-016-1523-7.

${ }^{1}$ Geoscientific Centre, University of Goettingen, Göttingen, Germany

2Institute for Groundwater Management, TU Dresden, Dresden, Germany

${ }^{3}$ Bureau de Recherches Géologiques et Minières (BRGM)- D3E/NRE, Montpellier, France 


\section{Chapter 6}

\section{Abstract}

A numerical discrete conduit-continuum model is employed to investigate large-scale groundwater abstraction in karst aquifers. The application of largescale experiments is one approach to deal with the scale problem in hydraulic parameter assessment, caused by significant contrasts of hydraulic parameters in a karst aquifer. Here, conduit drawdown is evaluated by diagnostic plots and by considering the apparent flow dimension. These tools are frequently used for the interpretation of hydraulic borehole tests by analytical solutions. In contrast to existing analytical solutions, a numerical groundwater model allows the incorporation of the effect of complex parameter distributions. The objective is to demonstrate the application of diagnostic plots and flow dimension analysis for a systematic analysis of the effect of different boundary conditions as well as sink/source terms for idealized two-dimensional mixed karst aquifer systems, which ultimately extends existing analytical solutions and, therefore, contributes to the interpretation of measured field data. The analysis is focused on the apparent flow dimension and shows the extension of the cross-sectional flow area for selected models. The results are used to evaluate the large-scale pumping test of the karstified Cent Fonts catchment (Languedoc, France). The inverse calibration of two realistic, but still simplified, catchment models reveals that the apparent flow dimension supplies useful information about the general flow pattern during the Cent Fonts pumping test. The flow dimension after the end of the storage period can be explained by a large contribution of exchange flow resulting in a strong influence of radial flow on regional, i.e. kilometer scale. 


\subsection{Introduction}

Karst aquifers are characterized by solution enlarged features, such as conduits, embedded in a fractured/fissured matrix, resulting in distinctive heterogeneity and anisotropy of hydrodynamic characteristics. In mixed flow karst systems, flow and storage occur in both conduit and matrix, interacting through direct linkage (QUINLAN AND EWERS, 1985). As a result of the significant contrast in hydraulic parameters between conduit and matrix, flow patterns in karst aquifers are extremely complex. Due to the commonly unknown geometry and hydraulic characteristics of the conduit system, especially position and structure, hydraulic characterization of karst aquifers is a challenge (GEYER ET AL., 2013). Large-scale system stimulation with defined signals, i.e. massive pumping tests (MARÉCHAL ET AL., 2008), can provide a unique system reaction of required drawdown in the highly conductive and flow dominating conduits as well as stimulation at regional, i.e. catchment scale.

Plotting drawdown $s$ versus time $t$ on a $\log$-log graph is a useful tool to obtain qualitative and quantitative information about aquifer systems (GRINGARTEN, 1982). The application of such plots together with analytical solutions allows parameter identification for simplified situations. Drawdown derivative analysis (diagnostic plots) is an advanced method to characterize the responding system including the wellbore (BOURDET ET AL., 1983).

The second derivative of the drawdown with respect to time results in the apparent flow dimension (BARKER, 1988), providing additional insights into the system behavior, especially regarding the geometry of the flow system. Consequently, the interpretation of pumping tests can be enhanced by additional analysis of the corresponding flow dimension without any further exploration effort. So far, the flow dimension has been mainly applied as a calibration parameter for analytical interpretation of local-scale hydraulic testing. In general, analytical solutions require a predefined flow dimension for parameter estimation (BEAUHEIM ET AL., 2004). Thereby the flow dimension already defines the overall system geometry although variations in drawdown are controlled by processes such as hydraulic property differences on local scale (e.g. double porosity). Both, karst hydraulic properties and the flow dimension are highly scale dependent (BEAUHEIM ET AL., 2004). A combination of 


\section{Chapter 6}

diagnostic plots and flow dimensional analysis can be useful to identify heterogeneities such as acting boundary conditions (WALKER AND ROBERTS, 2003) and, therefore, provides useful information about the regional flow pattern of karst systems.

Numerical models allow an extension of existing analytical solutions to more complex situations and remove conditional restrictions such as requirements for homogeneous aquifer structures or predefined flow regimes. Several possible conceptual interpretations of karst aquifers can be further analyzed thereby reducing ambiguities. In combination with inverse methods for parameter estimation, such numerical models can significantly enhance system understanding and allow additional analyses, e.g. about parameter uncertainty and resulting exploration demand.

Different approaches are available to simulate the dual flow behavior of karst aquifers (SAUTER ET AL., 2006). Lumped parameter models are frequently used to simulate flow processes in karst aquifers (e.g. GEYER ET AL., 2008; MARÉCHAL ET AL., 2008; BAILLY-COMTE ET AL., 2010; SCHMIDT ET AL., 2014) but are not able to consider spatially heterogeneous distributions. The drawback of lumped parameter models is the significant simplification of flow dynamics. They can represent the 'global signal' but are not able to represent flow on different scales. Distributed models consider the spatial variation of aquifer properties. Here, the discrete conduit-continuum approach (DCC) explicitly accounts for conduits embedded in a continuum, representing the fissured/fractured matrix (e.g. KIRALY, 1998; LIEDL ET AL., 2003; DE ROOIJ ET AL., 2013). A publicly available DCC model is the Conduit Flow Process (CFP) module for MODFLOW-2005 (SHOEMAKER ET AL., 2008). Recently, CFP was upgraded to simulate large-scale water abstraction (REIMANN ET AL., 2014).

This study aims at the extension of current hydraulic methods of karst aquifer characterization, typically based on spring responses interpretation, by systematic analysis of numerical representations of large-scale pumping tests. The apparent flow dimension is used to characterize the influence of large-scale heterogeneities on the general flow pattern of mixed flow karst systems instead of the classical transmissivity and storage coefficient assessment. 
After introducing the analysis tools (diagnostic plots and flow dimension), the influence of the most common boundary conditions and sink/source terms will be analyzed for idealized 2-D representations of karst catchments in terms of cross-sectional flow area changes. Subsequently, the method will be used to interpret the large scale pumping test at the Cent Fonts catchment (MARÉCHAL ET AL., 2008) with further consideration of inverse application of a DCC model. The apparent flow dimension, appropriate for the reduction of the large number of possible conceptual models, is used to support the computed results in terms of flow pattern during groundwater abstraction. Therefore major simplifications of the conceptual model (e.g. conduit parameters, conduit structure) are accepted, focusing on the analysis of influences during reservoir flow. The estimated parameter values of the inverse calibration provide the best solutions for the given conceptual models but should not be used as unique interpretation of the Cent Fonts pumping test.

\subsection{Methods for pumping test analysis in karst systems}

\subsubsection{Traditional pumping test analyses}

\subsubsection{Diagnostic plots}

A common tool for pumping test interpretation is the use of diagnostic plots, presenting drawdown $s[\mathrm{~L}]$ and drawdown derivative $s^{\prime}[\mathrm{L}]$ on a log-log graph (e.g. BOURDET ET AL., 1983; RENARD ET AL., 2009) as

$$
s^{\prime}=\frac{\partial s}{\partial \ln t}
$$

with time $t[\mathrm{~T}]$.

Diagnostic plots allow to differentiate at least three main periods during pumping: 1) early time response, which is mainly influenced by direct storage (wellbore and/or conduit storage); 2) intermediate time response, which is influenced by unrestricted reservoir flow (linear, radial and spherical flow); and 3) late time response, which is mainly influenced by reservoir boundary conditions (e.g. SPANE AND WURSTNER, 1993; EHLIG-ECONOMIDES AND ECONOMIDES, 2000; BOURDET, 2001). Each flow period can be linked to certain flow patterns influencing the slopes of the diagnostic plot. Figure 6.1 


\section{Chapter 6}

represents schematically various derivative curves (after EHLIG-ECONOMIDES ET AL., 1994).

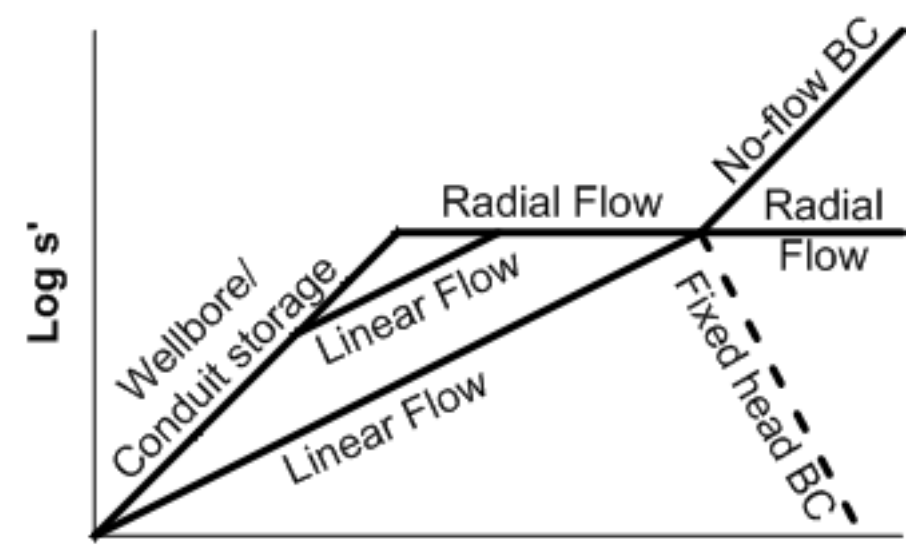

Log Time

Fig. 6.1: Schematic representation of the drawdown derivative in a diagnostic plot representing different flow regimes (modified after EHLIG-ECONOMIDES ET AL., 1994).

\subsubsection{Flow dimension}

The flow dimension $n$ is an additional tool to identify flow patterns on different scales, and can be calculated as the second derivative of drawdown with respect to time (BEAUHEIM ET AL., 2004):

$$
n=s^{\prime \prime}=-2 \frac{\partial \log \left(s^{\prime}\right)}{\partial \log (t)}+2
$$

With the assumption of constant hydraulic conductivity and storage, the flow dimension $n$ is able to describe the system geometry (BEAUHEIM ET AL., 2004). The flow dimension can be defined as a simplified illustration of the crosssectional flow area $A(r)_{n}$ (BARKER 1988; BEAUHEIM ET AL. 2004):

$$
A(r)_{n}=b^{3-n} \propto_{n} r^{n-1}
$$

with $b$ the extent of the flow zone $[\mathrm{L}], r$ the drawdown radius $[\mathrm{L}], \Gamma(x)$ the gamma function and the area $\alpha$ (see appendix A of BARKER, 1988):

$$
\propto_{n}=\frac{2 \pi^{n} / 2}{\Gamma(n / 2)}
$$

According to BARKER (1988), the flow dimension is defined for values between zero and three with: $n=0$ : pumping from a closed reservoir; $n=1$ : 
linear flow; $n=2$ : radial flow; and $n=3$ : spherical flow. Nevertheless the flow dimension can also be defined for values between these integer dimensions especially for highly heterogeneous media (e.g. BEAUHEIM ET AL., 2004).

According to WALKER AND ROBERTS (2003) the flow dimension describes the flow area change with distance to the wellbore but does not necessarily represent the space filling nature of the flow. For a flow dimension of $n=0$ the area affected by pumping does not vary with distance and therefore cannot be described by a cross-sectional flow area $\left(A(r)_{n}=0\right)$. Hence the drawdown area is limited to a certain point/area (storage). During early time response on pumping (storage period) matrix contributions are negligible (BOURDET, 2001) and, consequently, storage effects create a unit slope on log-log plots (cf. Fig. 6.1; e.g. EHLIG-ECONOMIDES AND ECONOMIDES, 2000) representing a flow dimension of $n=0$.

With a constant flow dimension of $n=1$ the cross-sectional flow area is $A(r)_{n}$ $=2 b^{2}$ representing the one-dimensional flow towards a plane (Fig. 6.2a). For a confined aquifer the extent of the flow zone $b$ is equal to the thickness of the layer. Therefore the flow area is a function of the extent of the plane and is not related to the area influenced by pumping. During linear flow conditions the conduit/fracture tips contribute a significant part of the flow (BOURDET, 2001). Drawdown relates to the perpendicular distance from the fracture/conduit resulting in parallel flow lines (Fig. 6.2c) and is, consequently, not a function of the pumping well radius (JENKINS AND PRENTICE, 1982). According to EHLIGECONOMIDES AND ECONOMIDES (2000) drawdown and drawdown derivative curves result in two linear parallel lines with half-slope during linear flow (cf. Fig. 6.1).

For a flow dimension of $n=2$ the cross-sectional flow area is $A(r)_{n}=2 \pi r b$ representing two-dimensional, radial flow (Fig. 6.2b). The cross-sectional flow area changes with increasing distance from the wellbore and therefore is a function of the linear increase of the Darcian flow area with increasing radius $r$ (BARKER, 1988). 


\section{Chapter 6}
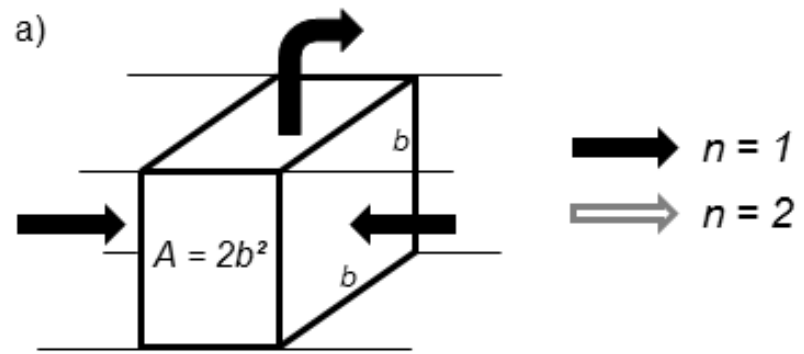

b)

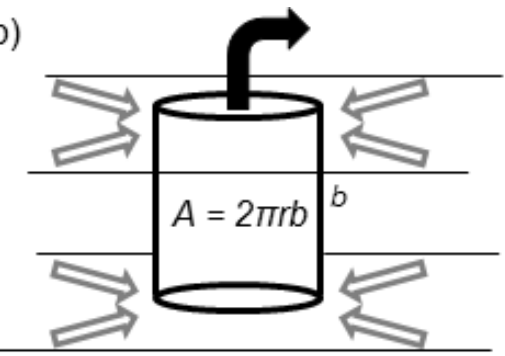

c)

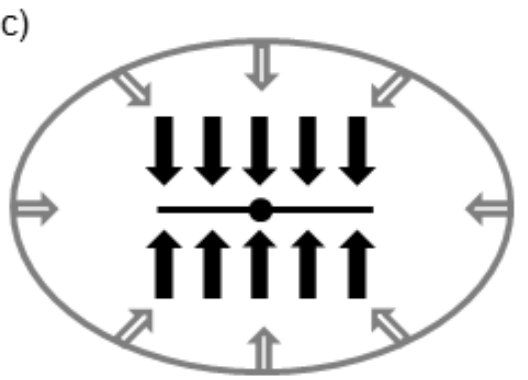

Fig. 6.2: Flow geometries for integral dimensions: (a) one-dimensional flow towards a plane $(n=1)$, (b) two-dimensional flow towards a cylinder (borehole) $(n=2)$ and (c) a top view of the corresponding flow lines (modified after BARKER, 1988).

According to DOE (1991) the flow dimension can be either interpreted as the consequence of heterogeneity, the variation in geometry or for more complex cases, the combination of both. Hence it is normally used as a calibration parameter for existing analytical solutions with homogeneous parameter distributions. In case of an a priori known flow dimension $n$ the calibration of the hydraulic parameter provides a relatively unique result. Otherwise, the lack of constraints potentially allows an infinite number of possible solutions (ROBERTS ET AL., 1999).

Especially large-scale pumping test data display the effect of the superposition of different heterogeneities on regional scale. In addition to those heterogeneities, introduced by changes in the hydraulic characteristics of the porous/fractured media or changes in fracture/conduit properties, the analysis of large-scale pumping tests also has to consider the effects of different boundary conditions (e.g. Neumann-BC, Dirichlet-BC or Cauchy-BC) and areal boundary conditions (e.g. recharge, leaky aquifer). WALKER AND ROBERTS (2003) provide analytical solutions, based on the superposition of wells and image wells (e.g. FERRIS ET AL., 1962), to calculate the resulting flow dimension for the above mentioned boundary conditions including all limitations such as radial Darcian flow $(n=2)$ as general flow patterns. Here, linear Neumann-BC (no-flow $\mathrm{BC}$ ) causes a decrease of the flow dimension after reaching the linear 
boundary condition. The Neumann-BC reflects the drawdown signal back into the model domain reducing the increase of cross-sectional flow area with time. The effect of the reflected drawdown signal and the signal originated by the wellbore combine and increase the drawdown between the $\mathrm{BC}$ and the wellbore. In a closed model domain surrounded by Neumann-BCs, the drawdown at any point in the domain is proportional to time and therefore the flow becomes steady state (BOURDET, 2001). According to WALKER AND ROBERTS (2003) the Dirichlet-BC (constant head BC) also influences the flow pattern, stabilizing the flow dimension at a value of $n=4$. Hence the linear Dirichlet-BC superimposes radial flow.

The apparent flow dimension subdivides system responses into extreme values depending on the type of flow system stimulated by the hydraulic trigger. Each extreme value is specified by a certain flow pattern. For a large-scale abstraction in a mixed karst aquifer system the extreme values define the endmember of conceptual karst systems: diffuse and conduit flow karst systems. Therefore, the apparent flow dimension can be used to differentiate at least between flow conditions dominated by the conduit system (linear flow) or the fractured/fissured matrix (radial flow). This kind of information can be used to choose an appropriate conceptual model of the karst systems which can be further enhanced by heterogeneities until the degree of simplification and the degree of uncertainty fit the requirements of the analysis.

\subsubsection{Numerical discrete-conduit continuum model}

The applied numerical method is based on the block-centered finite difference groundwater flow model MODFLOW-2005 (HARBAUGH, 2005) that simulates laminar Darcian flow in a confined 2D matrix continuum as

$$
\frac{\partial}{\partial x}\left(K_{x x} \frac{\partial h_{\mathrm{m}}}{\partial x}\right)+\frac{\partial}{\partial y}\left(K_{y y} \frac{\partial h_{\mathrm{m}}}{\partial y}\right) \pm W=S_{\mathrm{s}}\left(\frac{\partial h_{\mathrm{m}}}{\partial t}\right)
$$

with $K$ the hydraulic conductivity in x and y directions $\left[\mathrm{LT}^{-1}\right], h_{m}$ the head of the matrix cell $[\mathrm{L}], W$ the volumetric flux per unit volume $\left[\mathrm{T}^{-1}\right]$, and $\mathrm{S}_{\mathrm{s}}$ the specific storage $\left[\mathrm{L}^{-1}\right]$.

The DCC code CFP Mode 1 (CFPM1; SHOEMAKER ET AL., 2008) couples a discrete conduit network to the MODFLOW-2005 continuum. The discrete 


\section{Chapter 6}

conduit network consists of nodes connected by cylindrical pipes. Head loss due to pipe flow $\Delta h_{p}[\mathrm{~L}]$ is computed with the Darcy-Weisbach equation

$$
\Delta h_{\mathrm{p}}=f \frac{\Delta l_{\mathrm{p}} v_{\mathrm{p}}^{2}}{2 g d_{\mathrm{p}}}
$$

with $f$ the friction factor [-], $d_{p}$ the pipe diameter [L], $g$ the gravitational acceleration $\left[\mathrm{LT}^{-2}\right]$, and $\Delta l_{p}$ the length of pipe [L]. The friction factor is approximated for laminar conditions with the Hagen-Poiseuille equation and for turbulent flow with the Colebrook-White equation (for further details see SHOEMAKER ET AL., 2008).

Exchange flow between the pipe network and the matrix continuum is considered by a linear quasi-steady state exchange coefficient $\alpha_{e x}\left[\mathrm{~L}^{2} \mathrm{~T}^{-1}\right]$ (BARENBLATT ET AL., 1960; BAUER ET AL., 2003; SHOEMAKER ET AL., 2008)

$$
Q_{\mathrm{ex}}=\alpha_{\mathrm{ex}}\left(h_{\mathrm{c}}-h_{\mathrm{m}}\right)
$$

with $h_{\mathrm{c}}$ the conduit head [L] and $h_{m}$ the matrix head [L].

REIMANN ET AL. (2014) implemented a fast responding storage to the conduit system. Features such as solution-enlarged fractures or other cavities are assumed to provide additional storage but do not participate in the flow processes of the conduit system. The conduit-associated drainable storage (CADS) is in direct hydraulic contact with the pipe network:

$$
h_{\mathrm{CADS}}=h_{\mathrm{c}}
$$

with $h_{C A D S}$ the hydraulic head in the CAD storage [L]. Due to the direct linkage, changes of the conduit hydraulic head are directly associated with outflow or inflow from storage such as (REIMANN ET AL., 2014)

$$
Q_{\mathrm{CADS}}=\frac{V_{\mathrm{CADS}, t}-V_{\mathrm{CADS}, t-\Delta t}}{\Delta t}
$$

with

$$
V_{\mathrm{CADS}}=l_{\mathrm{CADS}} W_{\mathrm{CADS}}\left(h_{\mathrm{c}}-z_{\mathrm{Bot}}\right)
$$


with lCADS the length of the storage segment associated with the conduit node [L] and $Z$ Bot the elevation of the conduit bottom [L]. Equation 6.10 introduces

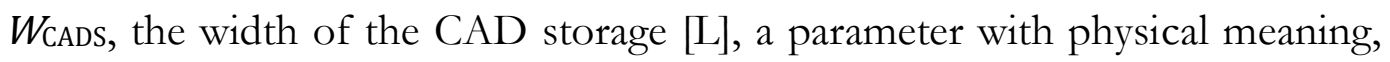
which can be determined by inverse calibration especially at the beginning of a pumping test or during major pumping rate changes (MARÉCHAL ET AL., 2008; REIMANN ET AL., 2014).

Further, REIMANN ET AL. (2014) added a fixed head limited flow boundary condition (FHLQ; BAUER ET AL., 2005) to CFPM1. The FHLQ boundary condition allows to switch between a fixed head boundary, as an approximation for spring outflow, and a fixed flow boundary (e.g. to limit inflow during pumping):

$$
\mathrm{FHLQ}=\left\{\begin{array}{rr}
h_{\mathrm{c}}=H, & Q \leq Q_{\mathrm{L}} \\
Q=Q_{\mathrm{L}}, & \text { else }
\end{array}\right.
$$

with $H$ the fixed head value $(\mathrm{FH})[\mathrm{L}], Q$ the discharge at the boundary $\left[\mathrm{L}^{3} \mathrm{~T}^{-1}\right]$ and $Q_{\mathrm{L}}$ the limiting discharge (LQ) $\left[\mathrm{L}^{3} \mathrm{~T}^{-1}\right]$.

\subsection{Effects of karst heterogeneities on the apparent flow dimension}

For karst systems, only sparse information is available about the behavior of diagnostic plots and flow dimensions as a function of conduit structures. To overcome this limitation, CFPM1 is used to systematically investigate the apparent flow dimensions for varying aquifer systems under consideration of real karst systems. Therefore, an idealized 2D numerical DCC model is established, representing the Cent Fonts karst system during a large scale pumping test (MARÉCHAL ET AL., 2008; REIMANN ET AL., 2014).

The matrix continuum has an areal extent of 8,500 x 3,500 $\mathrm{m}^{2}$. The uniform thickness of the confined layer is $250 \mathrm{~m}$ with a bottom elevation of $0 \mathrm{~m}$. The uniform initial hydraulic head prior to pumping is set to $h_{i n i}=500 \mathrm{~m}$. Outer boundaries are varied during the analysis according to Figure 6.3. The conduit, located in the center of the domain, is surrounded by matrix cells with $\Delta x=$ $1 \mathrm{~m}$, with a stepwise increase up to $\Delta x=20 \mathrm{~m}$. Along the idealized conduit, the 


\section{Chapter 6}

cells also have a spatial discretization of $\Delta y=20 \mathrm{~m}$. In total the model domain consists of 205 (in x-direction) $\times 425$ (in y-direction) cells. The hydraulic parameters of the homogeneous, isotropic matrix continuum are $K_{\mathrm{m}}=1 \times 10^{-4} \mathrm{~ms}^{-1}, S_{\mathrm{s}}=1 \times 10^{-4} \mathrm{~m}^{-1}$ and the uniform exchange coefficient is $\alpha_{\mathrm{ex}}=0.031 \mathrm{~m}^{2} \mathrm{~s}^{-1}$. The conduit diameter is $3.5 \mathrm{~m}$ and roughness height is set to a low value of $0.01 \mathrm{~m}$. The pumping well is placed in the conduit and has a constant pumping rate of $Q_{p}=0.4 \mathrm{~m}^{3} \mathrm{~s}^{-1}$ for a duration of $T_{\text {total }}=5 \times 10^{6} \mathrm{~s}$. In general, the conduit related parameters (i.e. low conduit roughness and large conduit diameter) are chosen to prevent turbulent flow from significantly dominating other effects explicitly discussed here. Rather, the model set-up focuses on the investigation of the influence of heterogeneities on the flow dimension during and at the end of reservoir flow.

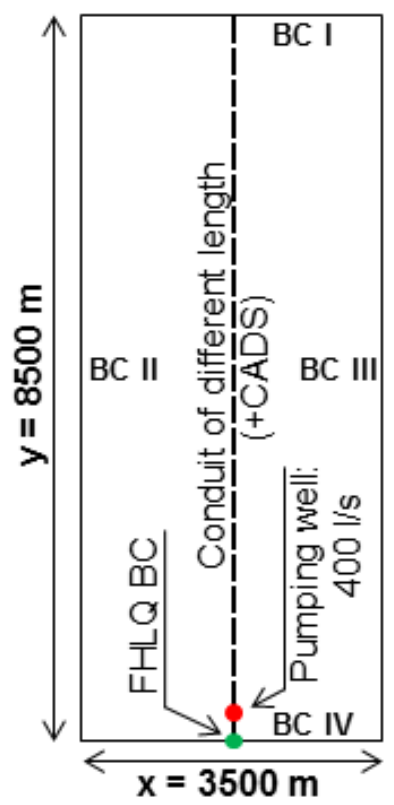

\begin{tabular}{|c|c|c|c|c|}
\hline & & \multicolumn{3}{|c|}{ Effect of... } \\
\hline & & \multirow{2}{*}{$\frac{\text {...conduit length }}{\text { No-flow }}$} & \multicolumn{2}{|c|}{ boundary conditions } \\
\hline \multirow{4}{*}{$\begin{array}{l}\frac{x}{2} \\
\stackrel{\frac{\pi}{2}}{2}\end{array}$} & $\mathrm{BCl}$ & & Fixed head & \\
\hline & $\mathrm{BC} \|$ & No-flow & No-flow & $\frac{0}{0}$ \\
\hline & BC III & No-flow & No-flow & $\stackrel{\mathscr{D}}{\underline{\underline{t}}}$ \\
\hline & BCIV & No-flow & No-flow & + \\
\hline $\begin{array}{l}\text { 늘 } \\
\text { ㄷ } \\
\text { ㅇ } \\
\text { U }\end{array}$ & $\begin{array}{l}\text { length } \\
{[\mathrm{m}]}\end{array}$ & $\begin{array}{c}8500 \\
3000 \\
600 \\
600+\text { CADS }\end{array}$ & $\begin{array}{c}8500 \\
\text { FHLQ BC }\end{array}$ & \\
\hline
\end{tabular}

Fig. 6.3: (a) Schematic representation of the numerical model domains for the following analysis, and (b) a chart of the used specifications.

\subsubsection{Effects of conduit length on catchment scale}

Conduit length is varied to analyze the effect on the flow dimension of a bounded model domain (Fig. 6.3): 8,500 m, 3,000 m and $600 \mathrm{~m}$. Model results in terms of matrix heads are compared for two times representing different flow periods and flow configurations (1498 and 31,664 min). 


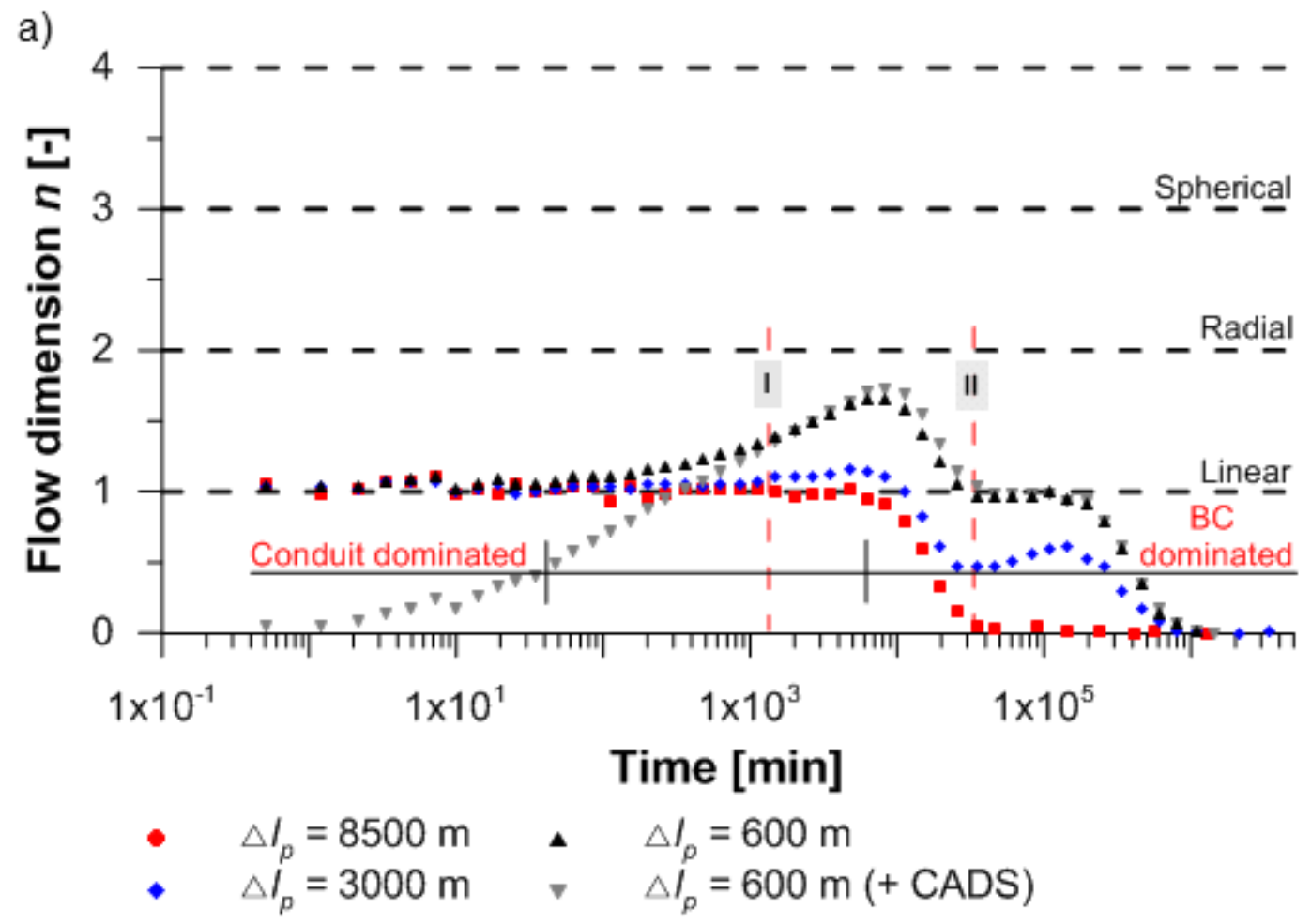

b)

Conduit length: $8500 \mathrm{~m}$

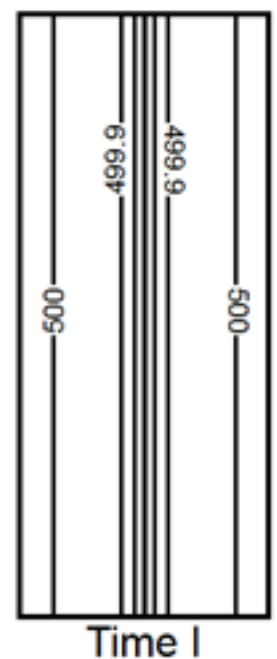

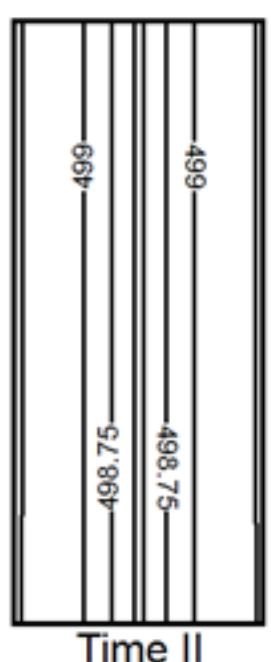

c)

Conduit length: $600 \mathrm{~m}$
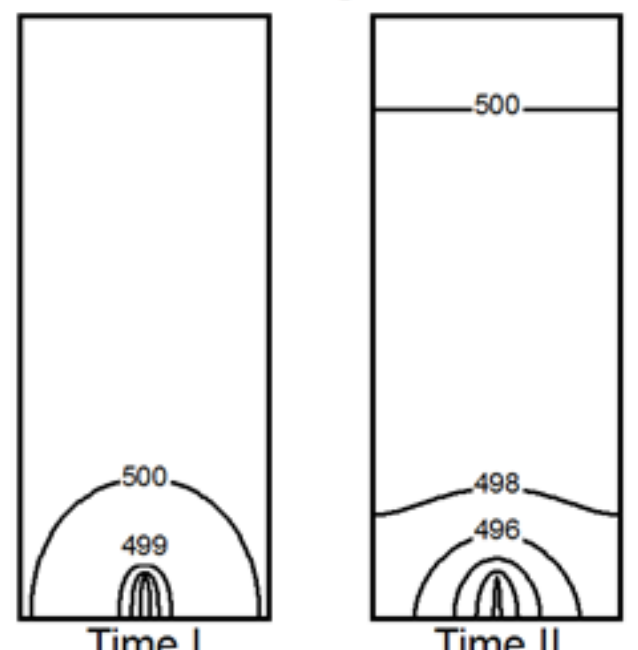

Fig. 6.4: (a) Simulation results showing flow dimension for the single conduit, with conduit length of $600 \mathrm{~m}$ (black triangles), additional with CAD-storage (grey triangle), conduit length $3000 \mathrm{~m}$ (blue diamonds) and conduit length $8500 \mathrm{~m}$ (red dots). Representation of the drawdown behavior of the (b) $8000 \mathrm{~m}$ conduit and (c) $600 \mathrm{~m}$ conduit at times I and II as marked in (a).

In general, reservoir boundary conditions affect the flow behavior during pumping at late stages. In case of the $8,500 \mathrm{~m}$ conduit, the top and bottom noflow boundaries (no-flow BC I and IV in Fig. 6.3) are reached after a few minutes of pumping. Matrix drawdown disperses only parallel to the conduit in 


\section{Chapter 6}

the direction of BC II and III (Fig. 6.4b). Consequently, the flow dimension shows linear flow behavior $(n=1)$ for a period of almost four log cycles (Fig. 6.4). At the end of linear flow, at $t=6,000 \mathrm{~min}$, the flow dimension starts to drop as a consequence of increased drawdown caused by reflection of the drawdown signal by the no-flow BC II and III (Fig. 6.4b). The flow dimension decreases to $n=0$ indicating pumping from a closed reservoir (Fig. 6.4a). Hence for the given set-up, this period can be defined as BC dominated.

Similar to the long conduit, the other two conduits show a linear flow behavior at the beginning of pumping. This period can be identified as conduitdominated. Afterwards the drawdown behavior changes because of the different proportions of conduit length to catchment extent.

The $600 \mathrm{~m}$ long conduit shows a short linear flow period lasting for approximately one and a half log cycles. Subsequently the flow dimension describes a sigmoid curve tending towards radial flow (Fig. 6.4a). During this period the cross-sectional flow area extends in the direction of BC II and III. In contrast to the $8,500 \mathrm{~m}$ conduit, the short conduit is only bounded by $\mathrm{BC}$ IV. Hence the cross-sectional flow area can also propagate into the direction of $\mathrm{BC}$ I forming a semi-oval cone of depression (Fig. 6.4c). The increase of flow dimension is prevented by the no-flow BC II and III. At this time the expansion direction of the $600 \mathrm{~m}$ conduit is already restricted in the up-gradient direction (towards BC I, cf. Fig. 6.4c). This expansion along two no-flow BCs is comparable to the flow behavior of the bounded conduit and consequently also results in a linear flow dimension of approximately $n=1$ (Fig. 6.4a).

With the addition of a fast responding storage to the conduit (ICADS $\mathrm{x}$ $\left.W_{\text {CADS }}=3000 \mathrm{~m}^{2}\right)$ the flow behavior changes during the early period of water abstraction. Figure $6.4 \mathrm{a}$ shows the effect of the dominating storage release resulting in a short period with a flow dimension of $n=0$. Already during the conduit dominated flow period the flow dimension increases, as a consequence of the already described effects of the short conduit. Minor differences to the $600 \mathrm{~m}$ conduit without storage during boundary condition effects, are due to the delaying effect of the storage at the beginning of pumping.

Because of differences in conduit length, the cross-sectional flow area of the 3,000 m conduit can still expand into the direction of BC II and III at the tip of 
the conduit. Hence the flow dimension continuously increases until the influence of the furthermost $\mathrm{BC}$ reaches the wellbore $\mathrm{BC}$ dominated period in Fig. 6.4). At the end of the pumping test all four no-flow BCs influence the drawdown signal in the model domain by reflecting the drawdown signal resulting in steady state flow with a flow dimension of $n=0$.

\subsubsection{Effects of fixed head BC and areal boundary conditions}

The previous scenarios consider only no-flow boundaries in the model domain, because the influence of such boundaries is well defined. However, real karst systems are likely to display further boundaries, for example rivers.

Within the idealized set-up (Fig. 6.3), CFPM1 considers karstic springs by FHLQ BC (Eq. 6.11) with a head fixed at $500 \mathrm{~m}$ representing a fictitious surface elevation of the outlet. To reduce inflow through the fixed head node while pumping, the limiting flow of the FHLQ boundary is set to $0.03 \mathrm{~m}^{3} \mathrm{~s}^{-1}$. The resulting flow dimension is similar to the one of the basic set-up in Figure 6.5a. Hence the implementation of the FHLQ BC does not change the flow behavior during any period of pumping. The FHLQ BC, as well as other direct recharge boundaries (e.g. sinkholes, river loss), only decreases the conduit drawdown but does not influence the general flow pattern.

In addition to no-flow BCs, a model domain can also be delimited by a fixed head boundary (e.g. corresponding to unrestricted inflow of surface water such as lakes or streams). To analyze the influence on dynamic flow conditions, no flow BC I is replaced by a fixed head BC (Fig. 6.3) at a water level of $500 \mathrm{~m}$. Figure 6.5 presents the flow behavior differences caused by a fixed head BC implementation, consideration of diffuse recharge and a combination of both influences.

The fixed head BC starts to influence the flow dimension at the beginning of the intermediate flow period (reservoir flow) at around $t=400 \mathrm{~min}$ (Fig. 6.5a), hence directly after the conduit-influenced period. The fixed head BC allows water inflow into the model domain following water abstraction. Inflow through the fixed head $\mathrm{BC}$ increases with ongoing drawdown. As a consequence, matrix heads are higher in comparison to previous models with no-flow BCs. Therefore, exchange flow increases during intermediate time (see Eq. 6.7) and, consequently, conduit drawdown decreases. In contrast to the no-flow BC 


\section{Chapter 6}

domain, the drawdown does not only expand into the x-direction (Fig. 6.5b). The fixed head BC causes a radial-type flow behavior in the upper part of the model domain resulting in a smooth increase of the flow dimension until noflow BC II and III are reached. With increasing time the inflow of water provided by the fixed head $\mathrm{BC}$ equals the pumping rate of the abstraction well resulting in drawdown to cease. The flow dimension increases above a value of $n=4$ (Fig. 6.5a) and the 'steady state' flow pattern shows a uniform drawdown in the lower part of the domain. In the vicinity of the fixed head BC, differences in drawdown can be observed. Adjacent to the conduit, the matrix drawdown is high. The influence of abstraction vanishes with distance to the conduit location forming a $\mathrm{V}$-shape drawdown cone at the upper most part of the domain (Fig. 6.5b). 


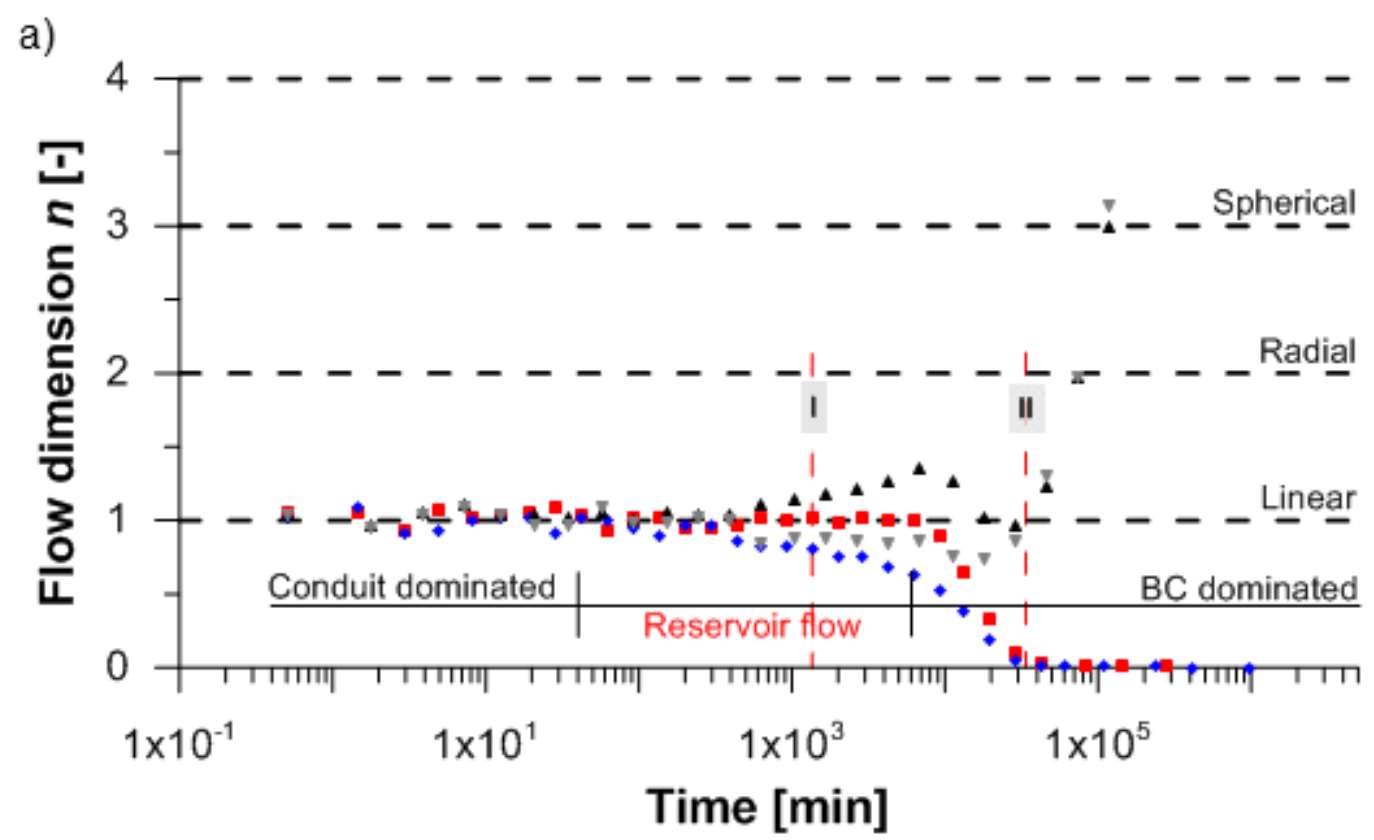

- FHLQBC

- Diffuse recharge

b)

\section{Fixed head BC}

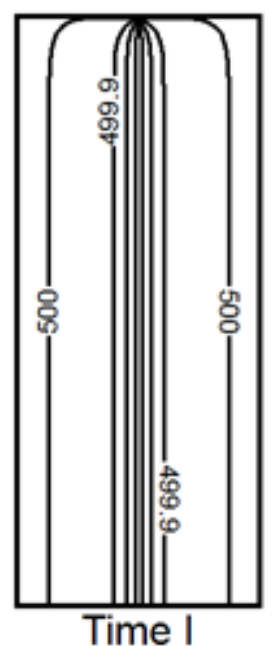

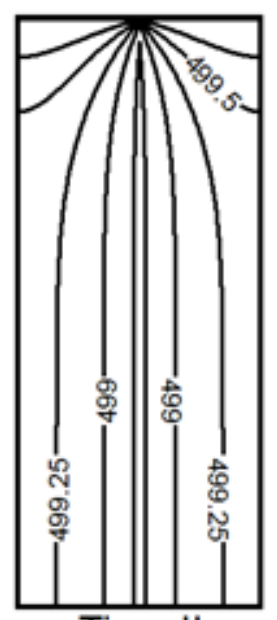

Time II

- Fixed head BC

- Fixed head BC + Diffuse recharge

c)

Fixed head BC + Diffuse recharge

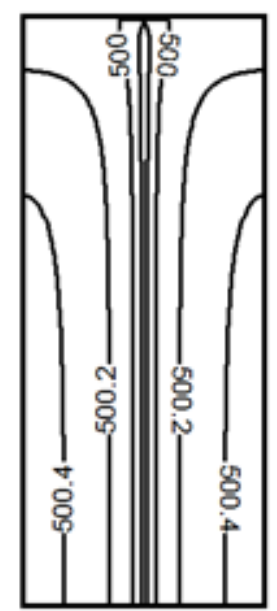

Time I

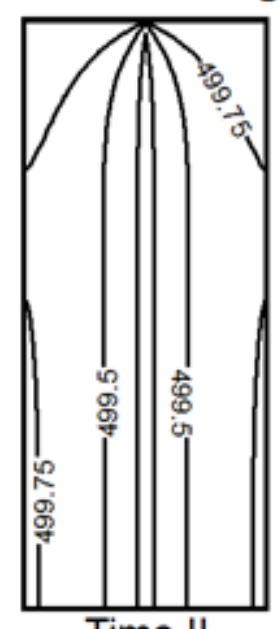

Time II

Fig. 6.5: (a) Simulation results for the single conduit with FHLQ BC (red dots); with diffuse areal recharge (blue diamonds), with BC IV as fixed head BC (black triangle) and the superposition of diffuse areal recharge and constant head BC IV (gray triangle). Representation of the drawdown behavior for the (b) fixed head BC IV and (c) fixed head BC plus diffuse recharge (right) at times I and II as marked in (a).

A numerical representation of real karst catchments can require the consideration of additional boundary conditions and/or sink/source terms. Areal recharge as a consequence of precipitation events or leaky aquifers can be 


\section{Chapter 6}

represented by diffuse source terms. Therefore Figure 6.5a also provides the appropriate flow dimension for a constant areal recharge of $7.5 \times 10^{-10} \mathrm{~ms}^{-1}$.

During the conduit flow period, the flow dimension is the same as that in section 'Effects of conduit length on catchment scale'. Due to the fact that the recharge provides the entire model domain with an equally distributed volume of water, the ratio of recharged water to pumped water increases with an expanding cone of depression. This effect reduces the flow dimension although the cross sectional flow area still increases. The flow dimension slowly tends to $n=0$. In case of an infinite model domain, the cross-sectional area would increase until the area affected by recharge provides an equal volume of water abstracted by the well. The flow dimension of such a steady-state flow system would also be $n=0$.

Model domains representing natural catchments are likely to display different types of $\mathrm{BC}$ and source/sink terms. In addition, Figure 6.5 provides the flow dimension for the combination of a fixed head BC (BC I), no-flow BC (BC II, III and IV) and a diffuse source term.

The early time response of the combined set-up shows a typical linear flow behavior. During intermediate time (period of reservoir flow, Fig. 6.5a) the drawdown curve is influenced by the constant head boundary as well as diffuse recharge. The cross-sectional flow area increases non-uniformly along the domain (Fig. 6.5c). The flow dimension slightly drops below a flow dimension of $n=1$. The contact of the drawdown area with the no-flow BC II and III also results in a decreasing flow dimension (BC dominated period, Fig. 6.5a). Starting at this time, the drawdown curve first shows the influence of the no-flow BC II and III followed afterwards by the particular shape of the constant head BC. The analysis of the flow dimension also shows that the constant head BC overlies the influence of source terms.

The analysis of the idealized 2D-models shows the influence of boundary conditions on the drawdown behavior mainly during reservoir flow of largescale pumping tests. Normally the flow dimension during this period could be explained by the origin of the drawdown signal (plane, cylinder) but the analysis reveals certain combinations of effects leading to 'stable' flow dimensions apart from the integral dimension. The cross-sectional flow area, and hence the flow 
dimension, are influenced by the location and functioning of the applied BCs as well as sink/source terms. Below, the general findings are used to interpret the general flow behavior during the Cent Fonts pumping test.

\subsection{Case study - Cent Fonts (Languedoc, France)}

\subsubsection{General information}

The Cent Fonts spring is located in the Hérault region, north of the city of Montpellier (France). Since 1996 the area has been monitored and has been the focus of numerous studies (e.g. AQUILINA ET AT., 2005; AQUILINA ET AL., 2006; LADOUCHE ET AL., 2006; MARÉCHAL ET AL., 2008).

The spring area drains the La Selle plateau, a sequence of thick limestone and dolomites (Middle and Upper Jurassic), at an elevation of $76.9 \mathrm{~m}$ a.s.l. The Bathonian dolomite beds (Middle Jurassic) have a local thickness of about 150 to $300 \mathrm{~m}$ and form the main phreatic zone of the catchment. In respect to the complex geological history of the karst system an intensive karstification with multiphase karst systems intersecting the saturated zone is expected (BAKALOWICZ, 2015). The base of the Bathonian formation dips towards the direction of the Cent Fonts spring (south-south-east). Locally the Bathonian layers are covered by Upper Jurassic Oxford and Kimmeridge layers. This layer forms a syncline resulting in a decrease of the layer thickness in the center of the catchment.

The catchment (Fig. 6.6a), bounded by the Buèges Valley in the north, the Cévennes fault in the north-west and the Hérault river in the south, has an estimated recharge area of $30 \mathrm{~km}^{2}$. Diffuse recharge through precipitation on the mainly epikarstic surface provides roughly $50 \%$ of the annual mean recharge of the area. The remaining $50 \%$ is provided by the Buèges river sinkhole system located on the northern boundary of the Cent Fonts catchment. The conduit network in the vicinity of the Cent Fonts spring has been explored by divers. According to speleological measurements the mean diameter of the conduit system between the spring and the wellbore, located in a cavernous part, is $3.5 \mathrm{~m}$ (VASSEUR, 1993). 


\section{Chapter 6}

In summer 2005, at the end of a long dry period, a large-scale pumping test coupled with high resolution hydrological and geothermal monitoring program was conducted at the Cent Fonts catchment (LADOUCHE ET AL., 2006; MARÉCHAL ET AL., 2008). Water was abstracted from a well intersecting the explored conduit system. The spring discharge (before pumping start: $\left.0.255 \mathrm{~m}^{3} \mathrm{~s}^{-1}\right)$ stopped within hours after the start of water abstraction. The abstraction test lasted for 38 days with a mean pumping rate of $Q_{p}=0.4 \mathrm{~m}^{3} \mathrm{~s}^{-1}$. Infiltration from the Buèges river was low during the abstraction, ranging between $0.006 \mathrm{~m}^{3} \mathrm{~s}^{-1}$ and $0.08 \mathrm{~m}^{3} \mathrm{~s}^{-1}$. No rainfall was measured weeks in advance and during the abstraction test so that the diffuse recharge was assumed to be very low at the end of the dry season. Monitoring of pumped water indicated that Hérault river water, roughly about $0.03 \mathrm{~m}^{3} \mathrm{~s}^{-1}$, infiltrated into the conduit system during abstraction. The major part of the abstracted water volume was provided by matrix contributions $\left(950,029 \mathrm{~m}^{3}\right)$ even through the average matrix drawdown of $s_{m} \approx 5.1 \mathrm{~m}$ is low at the end of pumping (MARÉCHAL ET AL., 2008).

Figure 6.6b shows the flow dimension during the large-scale experiment analyzed by MARÉCHAL ET AL. (2008). At the beginning of the abstraction phase, a short storage period can be detected. During the transition period, no characteristic double-porosity type behavior was observed (MARÉCHAL ET AL., 2008). Afterwards, the flow behavior tends to become linear, apparently influenced by boundary conditions, with a flow dimension of $n=0.59$. 


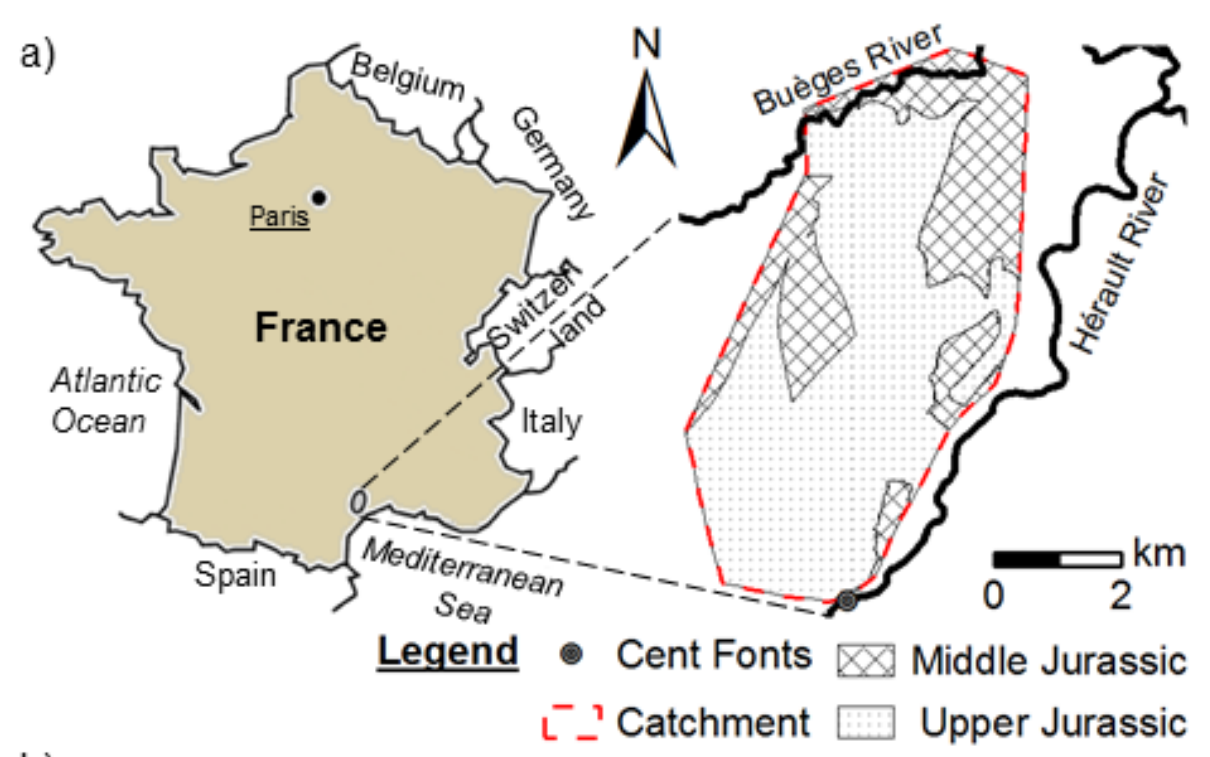

b)

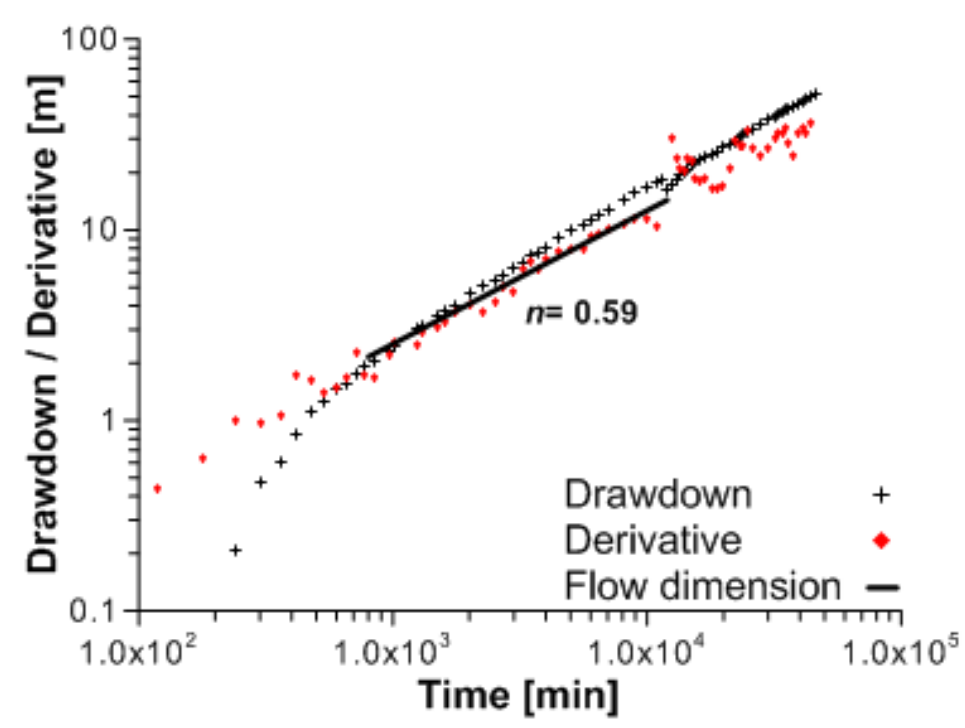

Fig. 6.6: (a) Schematic sketch of the Cent Fonts catchment (REIMANN ET AL., 2014) with addition of geology (MARÉCHAL ET AL., 2008), (b) Log-log diagnostic plot enhanced by the apparent flow dimension (MARÉCHAL ET AL., 2008).

\subsubsection{Conceptual and numerical representation of the Cent Fonts catchment}

A numerical simulation of the large-scale pumping test of the Cent Fonts catchment was already presented by REIMANN ET AL. (2014) by using a highly idealized representation of the catchment. Major simplifications were used to represent the geology as well as the shape of the catchment, represented by a rectangle with the same dimensions as presented in Figure 6.3, bounding a single 


\section{Chapter 6}

layer with a constant thickness of $400 \mathrm{~m}$. Here, this highly idealized numerical model is further refined.

The model domain is based on the catchment area of the Cent Fonts spring (MARÉCHAL ET AL., 2008) and uses an idealized representation of the Cent Fonts geology. The model domain merges Middle and Upper Jurassic layers into one layer with a discrete thickness based on the digital elevation model and information regarding the layer boundaries of the Jurassic formations (Fig. $6.7 b)$.

Two different conceptual models are tested with a similar spatial discretization of the model domain as already described in section 'Effects of karst beterogeneities on the apparent flow dimension': The first one is based on the conceptual model of MARÉCHAL ET AL. (2008) assuming a direct connection between Buèges river sinkhole system and the Cent Font spring. A high resolution time series of Buèges river loss is used to parametrize the river boundary during pumping with defined flow (Neumann BC) as a time-dependent boundary condition (Fig. 6.7a). The second conceptual model assumes a short straight conduit with a total length of 3,000 m. Hence the conduit only drains the lower part of the Cent Fonts catchment. Both set-ups are used to compare the results of a conduit dominated set-up with a set-up influenced by radial flow components.

The Cent Fonts spring is represented by a FHLQ boundary at the southernmost node with a fixed head at $H_{\text {Hérault }}=76.9 \mathrm{~m}$ a.s.l. and inflow limited to $0.03 \mathrm{~m}^{3} \mathrm{~s}^{-1}$ (MARÉCHAL ET AL., 2008). Additional inflow from the Hérault river into the catchment is approximated by the MODFLOW River Package with a riverbed conductance of $0.1 \mathrm{~m}^{2} / \mathrm{s}$. The distance between the FHLQ BC and the wellbore is $100 \mathrm{~m}$ ( 5 nodes). The variable pumping rate is considered using time-dependent input data with a high resolution of $\Delta t=3,600 \mathrm{~s}$. The conceptual model of MARÉCHAL ET AL. (2008) is represented by a single conduit with a total length of $7,500 \mathrm{~m}$, divided into 384 conduit segments each of a length of $20 \mathrm{~m}$, connecting the river loss area with the spring (Fig. 6.7a). The second conceptual conduit model is composed of 149 segments, each of a length of $20 \mathrm{~m}$, starting at the FHLQ BC. The conduit diameter was set to $d_{p}=3.5 \mathrm{~m}$ for all conduit segments based on speleological measurements. The homogeneously distributed surface area of the dewatering conduit network is 
assumed as 1,900 $\mathrm{m}^{2}$ (MARÉCHAL ET AL., 2008). In the numerical model these surface area is represented by CAD storage with a storage width $W_{C A D S}=0.25 \mathrm{~m}$ $(7,500 \mathrm{~m} \times 0.25 \mathrm{~m})$ respectively $W_{C A D S}=0.63 \mathrm{~m}(3,000 \mathrm{~m} \times 0.63 \mathrm{~m})$. The conduit roughness height to define the friction coefficient in the ColebrookWhite approximation was set to $0.01 \mathrm{~m}$ (REIMANN ET AL., 2014). An initial diffuse recharge value of $7.5 \times 10^{-9} \mathrm{~ms}^{-1}$, calculated from the spring discharge before the start of pumping minus the Buèges river loss, is used. During the pumping test the background recharge is represented by $7.5 \times 10^{-10} \mathrm{~ms}^{-1}(10 \%$ of the initial value).
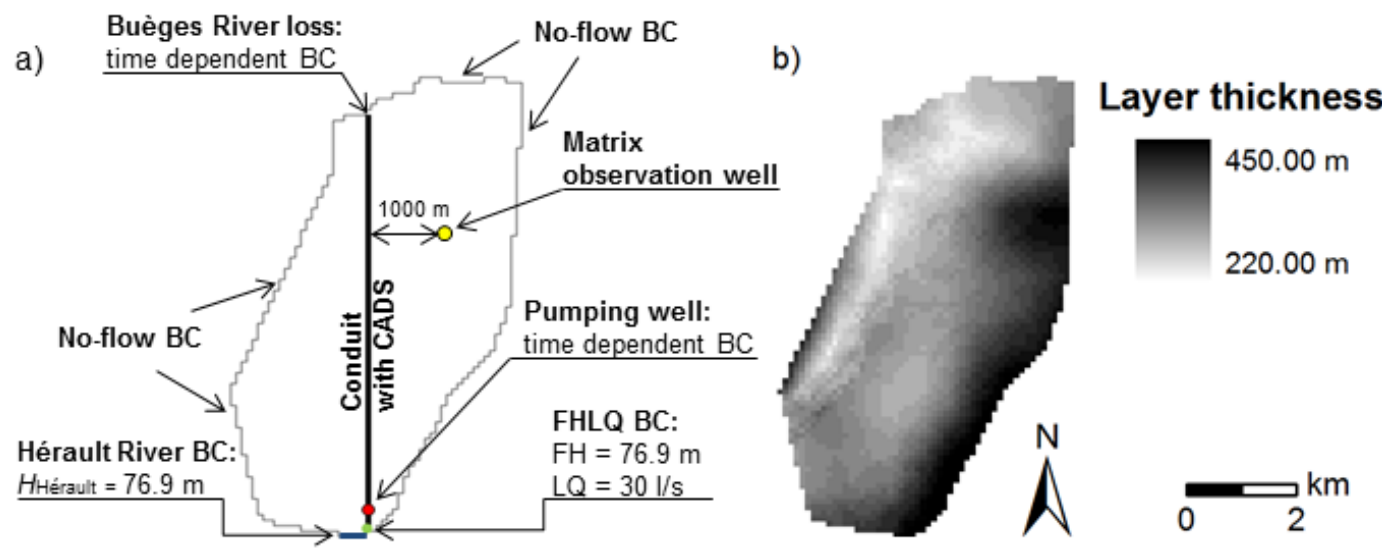

Fig. 6.7: (a): Conceptual representation of the large-scale pumping test scenario of the Cent Fonts catchment, (b) discrete representation of the thickness of the used simplified geology.

The inverse parameter estimation software PEST (DOHERTY, 2015) is applied to estimate selected model parameters. The matrix hydraulic conductivity $K_{\mathrm{m}}$ (upper and lower boundary: $1 \times 10^{-4}$ and $1 \times 10^{-8} \mathrm{~ms}^{-1}$ ), the matrix storage $S_{\mathrm{m}}$ (upper and lower boundary: $2 \times 10^{-1}$ and $1 \times 10^{-4}$ ) and the transfer coefficient $\alpha$ ex (upper and lower boundary: $1 \mathrm{~m}^{2} \mathrm{~s}^{-1}$ and $1 \times 10^{-8} \mathrm{~m}^{2} \mathrm{~s}^{-1}$ ) are defined as calibration variables. The objective function considers the measured conduit drawdown at the pumping well (Fig. 6.6) as well as discrete values of matrix drawdown at the end of pumping. A comparison of computed and apparent flow dimension stated by MARÉCHAL ET AL (2008), see Fig. 6.6, is used to verify the two conceptual models. Because of the unknown position of the observation well relative to the conduit system, the observation well is assumed to be $1,000 \mathrm{~m}$ away from the conduit in case of the direct connection between river loss area and spring (REIMANN ET AL., 2014). The other set-up uses the same position for the observation well. Figure 7 shows a top view of the model domain and the discrete layer thickness. 


\section{Chapter 6}

\subsubsection{Inverse calibration results of the Cent Fonts pumping tests}

Figure $6.8 \mathrm{a}$ and $6.8 \mathrm{c}$ present a comparison of computed conduit heads with the measured data already introduced in Figure 6.6. Additionally Figure 6.8b and $6.8 \mathrm{~d}$ show the diagnostic plot of the computed drawdown including flow dimension for both conceptual models.

Both model set-ups represent the entire pumping experiment reasonably well. In agreement with the results of MARÉCHAL ET AL. (2008), the storage period for both realizations lasts for approximately 1,000 min. During a short transmission period, no characteristic double porosity behavior can be detected. The conduit influenced period cannot be clearly identified from the diagnostic plots, as it is at least partly masked by conduit storage. Referring to the results of the idealized analysis, the period after 1,000 min is already influenced by matrix flow and therefore effects such as boundary conditions of source/sink terms need to be considered.
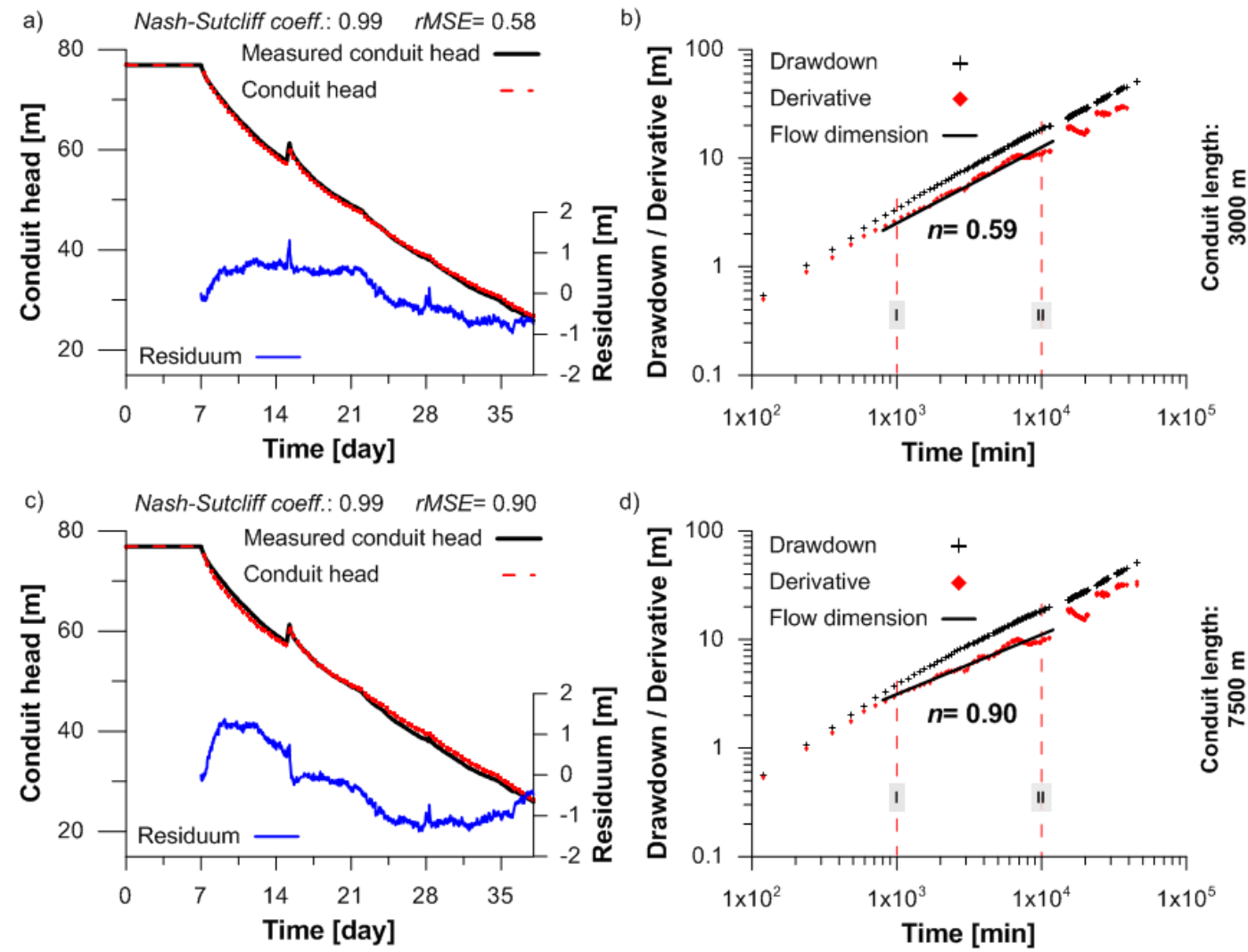

Fig. 6.8: Simulation results for the Cent Fonts large-scale pumping test: (a) Comparison between measured and simulated conduit head during abstraction and (b) diagnostic plot for a conduit length of $3000 \mathrm{~m}$; (c) Comparison between measured and simulated conduit head during abstraction and (d) diagnostic plot for a conduit length of $7500 \mathrm{~m}$. 
The differences between measured and computed heads are low. Especially, the pumping stop (for approximately $6 \mathrm{~h}$ ) during day 14 is well represented by the calculated parameter sets. The Nash-Sutcliff coefficient of 0.99 for both model variants underlines the successful simulation of conduit heads. The rootmean-square error (rMSE) values of both conceptual models are also comparably low, with values of $\mathrm{rMSE}=0.90 \mathrm{~m}$ for the long conduit and $\mathrm{rMSE}=0.58 \mathrm{~m}$ for the short conduit.

The drawdown of the short conduit better represents the beginning of pumping and also reproduces the late time behavior. The drawdown difference at the end of the pumping test is $1.27 \mathrm{~m}$. The representation of the drawdown, during and directly after the pumping has stopped, is better for the long conduit model. At the beginning of pumping and during the intermediate period, the difference between observed and computed drawdown is higher compared to the short conduit. In return, the drawdown difference at the last time step $(0.90 \mathrm{~m})$ is lower. Comparing the diagnostic plot and the apparent flow dimension of both conceptual models clarifies that the short conduit better represents the flow pattern during pumping. The flow dimension (Fig. 6.8b) of $n=0.59$ is equal to that analyzed by MARÉCHAL ET AL. (2008). The flow pattern of the other conceptual model results in a higher flow dimension of $n=0.90$ and is therefore dominated by a strong influence of linear flow during pumping. Hence the comparison of the flood pattern shows a large influence of radial matrix flow during the Cent Fonts pumping test.

The drawdown behavior of both models is presented in Figure 6.9. The flow for the short conduit (Fig. 6.9a) shows a strong radial flow component. Drawdown reaches the no-flow BC earlier, and compared to the long conduit model, over a broader length, resulting in intensive reflection of the drawdown signal and hence steeper head gradients. The irregular shape of the catchment boundary straightens this effect. The flow pattern of the long conduit (Fig. 6.9b) is dominated by linear drawdown along the conduit. Drawdown reaches the eastern and western BC later caused by a centered drawdown along the conduit instead of a widespread drawdown throughout the model domain.

The inverse calibration on the conduit drawdown (and an idealized matrix drawdown) results in the following values for the calibrated parameters. For a conduit length of $7,500 \mathrm{~m}: K_{\mathrm{m}}=2.00 \times 10^{-6} \mathrm{~ms}^{-1}, \quad S_{\mathrm{m}}=0.0009$ and 


\section{Chapter 6}

$\alpha_{\mathrm{ex}}=5.76 \times 10^{-5} \mathrm{~m}^{2} \mathrm{~s}^{-1}$ and for a conduit length of $3,000 \mathrm{~m}$ : $K_{\mathrm{m}}=1.00 \times 10^{-5} \mathrm{~ms}^{-1}, S_{\mathrm{m}}=0.0005$ and $\alpha_{\mathrm{ex}}=4.55 \times 10^{-4} \mathrm{~m}^{2} \mathrm{~s}^{-1}$. The inverse calibration reveals low confidence intervals of the adapted parameters, which means that all are sensitive for the given conceptual model. Nevertheless both calibrated conceptual models result in an overestimated matrix drawdown.

Conduit length: $3000 \mathrm{~m}$

a)

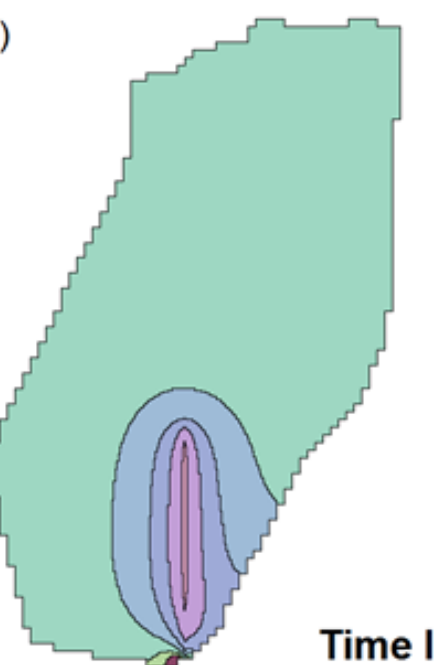

c)

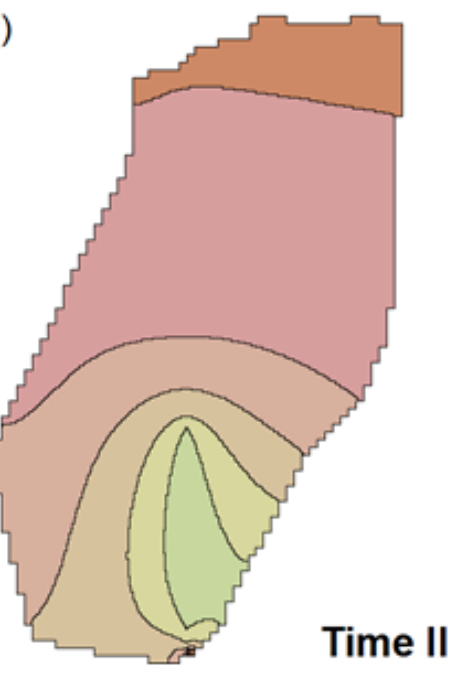

Conduit length:

$7500 \mathrm{~m}$

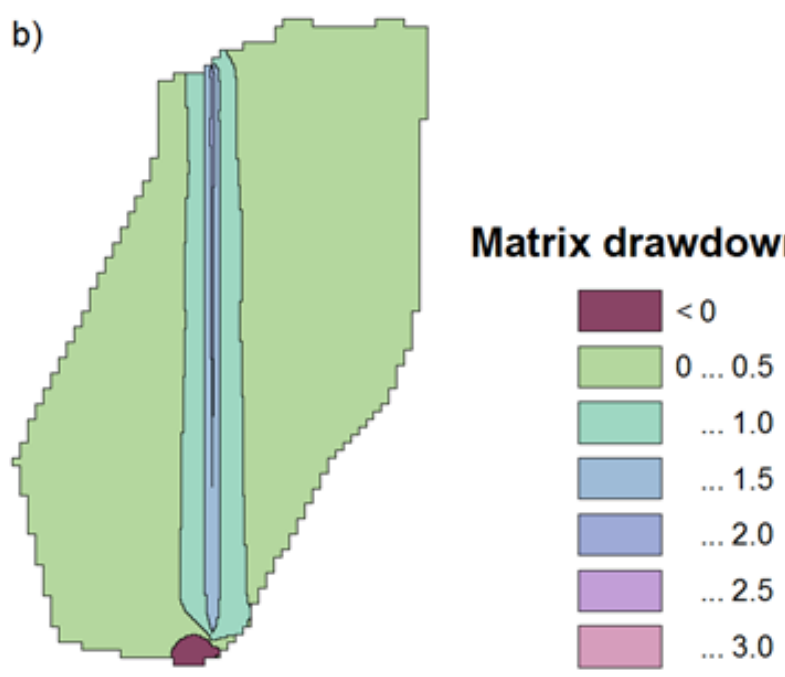

d)

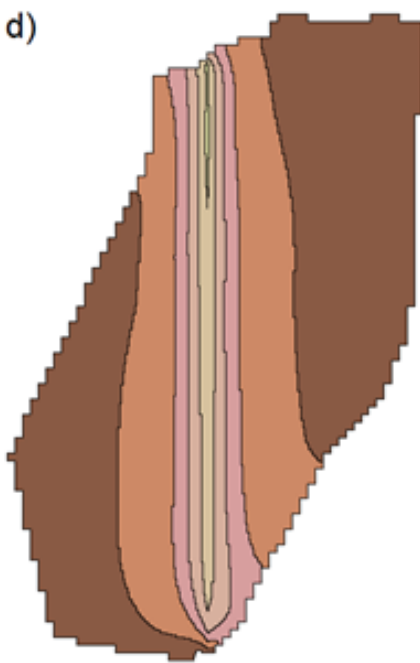

Matrix drawdown [m]

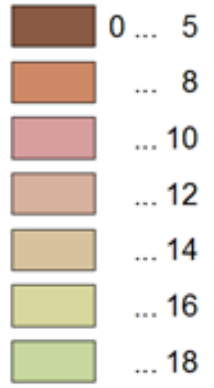

Fig. 6.9: Representation of the drawdown behavior for the simplified Cent Fonts catchment with (a) a conduit length of $3,000 \mathrm{~m}$ and (b) a conduit length of 7,500 m, at times I and II according to Figure 6.8. 


\subsection{Discussion and Conclusions}

In general the drawdown curve within a pumped karst conduit is a superposition of different effects or heterogeneities. The flow dimension at the Cent Fonts pumping test can be explained by storage effects at the beginning of water abstraction combined with a significant influence of radial (matrix) flow during reservoir flow. Several influences can cause significant matrix contribution during pumping. Following the most feasible reasons causing radial flow are mentioned in respect of the Cent Font catchment. The apparent flow dimension during the large scale water abstraction at the Cent Font catchment is $n=0.59$. Based on the results of the idealized analyses different large scale heterogeneities during reservoir flow can be the explanation of flow dimensions between linear flow $(n=1)$ and storage $(n=0)$. All of them can be detected during linear fracture/conduit flow superimposed by radial flow which is defined as bilinear flow and normally a consequence of small conductivity contrast between fissured/fractured matrix and the enlarged karstic features such as conduits (BOURDET, 2001). According to the conceptual karst genesis model of the region by BAKALOWICZ (2015), the small conductivity contrast could be a result of intensive karstification during the Messinian event. Extensive storage capacity is also a consequence of the intensive karstification processes and can be the reason for the over-estimated drawdown with lower simulated matrix contribution of $883,801 \mathrm{~m}^{3}$ accounting for $91 \%$ of the matrix contribution during the pumping test. BAKALOWICZ (2015) describes extensive karstification in different elevations of the thick limestone formations creating multiphase karst systems. With a limestone thickness of 220 to $450 \mathrm{~m}$ (cf. Fig. 6.7) those multiphase karst systems are most likely to exist at the Cent Font catchment. Ancient and therefore lower lying karst features, which are inactive under normal flow conditions, are also able to provide an additional volume of water or are, in case of a high connectivity, even able to transfer water from outside of the assumed recharge area (Fig. 6.7). Those multiphase conduit systems can also act as internal regional scale boundary conditions. Using the principle of superposition of real and image wells (e.g. FERRIS ET AL., 1962) two hydraulically connected pipe segments with the same rate of abstraction would also lead to an 'artificial' no-flow boundary condition at half distance between the segments, decreasing the flow dimension below $n=1$. Non-connected 


\section{Chapter 6}

karstic voids with extensive storage can act as fixed head or constant flow boundary conditions.

The two conceptual models represent different types of karst systems. The long conduit represents a conduit dominated karst system mainly controlled by linear flow; the other system is influenced by a radial flow component, but both are members of the broad range of mixed flow karst systems. A radial flow component for conceptually linear-flow dominated systems (long conduit) can also be developed from influences which are not within the scope of this contribution. Extensive head losses (steep hydraulic gradients) along the conduit as a result of turbulent flow or finite conduit conductivity (deposition/conduit deformation) can be mentioned as examples. Here, those influences are explicitly excluded by the choice of the conceptual model, namely the broad pipe diameter of $d_{p}=3.5 \mathrm{~m}$ and the simplified shape of the single conduit.

Precaution is recommended by the uncertainty of the calibrated parameters. The result shows only one possible parameterization of the given conceptual model. Another fact, which needs to be noticed, is that the objective function only includes conduit drawdown and only discrete values of matrix drawdown for an idealized observation well in terms of the relative location. Therefore the matrix drawdown for both conceptual models is overestimated and not well represented.

According to BOURDET ET AL. (1983) the drawdown behavior needs to be solved iteratively during a pumping test analysis to attain a high degree of confidence. Due to the large number of drawdown-influencing parameters or effects and the resulting superposition of the drawdown signal at the pumping well, numerical models have a strong advantage over analytical solutions. Nevertheless, the model needs a suitable number of parameters or a complex objective function, supported by different information, to reduce the degrees of freedom. The analysis proves that the application of the flow dimension can provide additional information without any further research demand. The flow dimension can be used as an additional objective, characterizing the general flow pattern. The application of different conceptual models starting with a high degree of abstraction is suitable to define the general flow pattern as an extreme value which can be further specified by adding more specific heterogeneities influencing the flow on regional scale. The possibilities of model improvement 
are nearly unlimited apart from the increasing computational effort as a consequence of model complexity which is also linked to the spatiotemporal discretization and the data quality used to support certain concepts. Especially for catchments with a lack of additional information, the flow dimension adds useful information which can be further defined by applying different conceptual models. This work shows an example of a methodology that can be used to investigate a large number of conceptual models in order to exclude those who cannot reproduce measured data.

According to ROBERTS ET AL. (1999) the number of potential solutions can be further reduced by applying additional field observations. Therefore increased model complexity will be the subject of future work focused on different conduit flow conditions, complex conduit structures and consideration of heat transfer during water abstraction. The advantage of such an approach, applying additional field observations, is highlighted by BORGHI ET AL. (2016).

\section{Acknowledgements}

This project was funded by the Deutsche Forschungsgemeinschaft (DFG) under grants no. LI 727/11-2 and GE 2173/2-2 and by the BRGM under grants no. PDR13D3E91 and PDR14D3E61. 


\section{Chapter 6}

\section{References}

Aquilina, L., Ladouche, B. and Dörfliger, N. (2005): Recharge processes in karstic systems investigated through the correlation of chemical and isotopic composition of rain and spring-waters, Applied Geochemistry, 20, 2189-2206, doi 10.1016/j.apgeochem.2005.07.011.

Aquilina, L., Ladouche, B. and Dörfliger, N. (2006): Water storage and transfer in the epikarst of karstic systems during high flow periods, Journal of Hydrology, 327, 472-485, doi 10.1016/j.jhydrol.2005.11.054.

Bailly-Comte, V., Martin, J. B., Jourde, H., Screaton, E. J., Pistre, S. and Langston, A. (2010): Water exchange and pressure transfer between conduits and matrix and their influence on hydrodynamics of two karst aquifers with sinking streams, Journal of Hydrology, 386, 55-66, doi 10.1016/j.jhydrol.2010.03.005

Bakalowicz, M. (2015): Karst and karst groundwater resources in the Mediterranean, Environmental Earth Science, 74, 5-14, doi 10.1007/s12665-0154239-4.

Barenblatt, G. I., Zheltov, I. P. and Kochina, I. N. (1960): Basic concepts in the theory of seepage of homogeneous liquids in fissured rock, Journal of Applied Mathematics and Mechanics (PMM), 24(5), 1286-1303.

Barker, J. A. (1988): A generalized radial flow model for hydraulic tests in fractured rocks, Water Resources Research, Vol. 24, No. 10, 1796-1804.

Bauer, S., Liedl, R. and Sauter, M. (2003): Modeling of karst aquifer genesis: Influence of exchange flow, $W$ ater Resources Research, Vol. 39, No. 10, 1285-1296, doi 10.1029/2003WR002218.

Bauer, S., Liedl, R. and Sauter, M. (2005): Modeling the influence of epikarst evolution on karst aquifer genesis: A time-variant recharge boundary condition for joint karst-epikarst development, Water Resources Research, Vol. 41, W09416, doi 10.1029/2004WR003321. 
Beauheim, R. L., Roberts, R. M. and Avis, J. D. (2004): Well testing in fractured media: Flow dimensions and diagnostic plots, Journal of Hydraulic Research, 42 (Extra Issue), 69-76.

Borghi, A., Renard, P. and Cornaton, F. (2016): Can one identify karst conduit networks geometry and properties from hydraulic and tracer test data?, Advances in Water Resources, 90, 99-115, doi 10.1016/j.advwatres.2016.02.009.

Bourdet, D., Whittle, T. M., Douglas, A. A. and Pirard, Y. M. (1983): A new set of type curves simplifies well test analysis, WORLD OIL, 196, 95-106.

Bourdet, D. (2001): Well test analysis: The use of advanced interpretation models, Amsterdam: Elsevier.

de Rooij, R., Perrochet, P. and Graham, W. (2013): From rainfall to spring discharge: Coupling conduit flow, subsurface matrix flow and surface flow in karst systems using a discrete-continuum model, Advances in Water Resources, 61, 29-41, doi 10.1016/j.advwatres.2013.08.009.

Doe, T. W. (1991): Fractional dimension analysis of constant-pressure well test, In: Proceedings of the 1991 SPE annual technical Conference and Exhibition, Dallas, Texas, SPE paper 22702, Richardson: Society of Petroleum Engineering.

Doherty, J. (2015): Calibration and uncertainty analysis for complex environmental models - PEST: complete theory and what it means for modelling the real word, edited by J. Doherty, Watermark Numerical Computing, Brisbane, Australia.

Ehlig-Economides, C. A., Hegeman, P. and Vik, S. (1994): Guidelines simplify well test analysis, Oil Gas, 92, 33-40.

Ehlig-Economides, C. A. and Economides, M. J. (2000): Formation characterization: Well and reservoir testing, In: Reservoir stimulation 3rd Edition, Chapter 2, edited by M.J. Economides and K.G. Nolte, New York: John Wiley \& Sons Ltd.

Ferris, J. G., Knowles, D. B., Brown, R. H. and Stallman, R. W (1962): Theory of aquifer testing, Geological survey water-supply paper, 1536-E. 


\section{Chapter 6}

Geyer, T., Birk, S., Liedl, R. and Sauter, M. (2008): Quantification of temporal distribution of recharge in karst systems from spring hydrographs, Journal of Hydrology, 348, 452-463, doi 10.1016/j.jhydrol.2007.10.015.

Geyer, T., Birk, S., Reimann, T., Dörfliger, N. and Sauter, M. (2013): Differentiated characterization of karst aquifers: some contributions, Carbonate Evaporites, 28, 41-46, doi 10.1007/s13146-013-0150-9.

Gringarten, A. C. (1982): Flow-test evaluation of fractured reservoirs, In: Recent trends in hydrogeology, edited by: Narasimhan, T.N., Geological Society of America, Special Paper 189, 237-262.

Harbaugh, A. W. (2005): MODFLOW-2005, The U.S. Geological survey modular ground-water model - The Ground-Water Flow Process: U.S Geological Survey Techniques and Methods 6-A16.

Jenkins, .D. N., Prentice, J. K. (1982): Theory for aquifer test analysis in fractured rocks under linear (nonradial) flow conditions, Ground Water, Vol. 20, No.1, 12-21.

Kiraly, L. (1998): Modelling karst aquifers by the combined discrete channel and continuum approach, Bulletin d'Hydrogéologie, 16, 77-98.

Ladouche, B., Dörfliger, N., Maréchal, J.-C., Lachassagne, P., Bakalowicz, M., Valarie, I. and Lenoir, P. (2006): Hydrodynamic behaviour during pumping test and modelling of the Cent Fonts karst system, In: Aquifer Systems Management: Darcy's legacy in a world of impending water shortage, edited by: Chery, L. and de Marsily, G., IAH Selected papers on Hydrogeology, Vol. 10, 303-316.

Liedl, R., Sauter, M., Hückinghaus, D., Clemens, T. and Teutsch, G. (2003): Simulation of the development of karst aquifers using a coupled continuum pipe flow model, Water Resources Research, 39, 1057, doi 10.1029/2001WR001206.

Maréchal, J.-C., Ladouche, B., Dörflinger, N. and Lachassagne, P. (2008): Interpretation of pumping tests in a mixed flow karst system, $W$ ater Resources Research, Vol.44, W05401. doi 10.1029/2007WR006288. 
Quinlan, J. F. and Ewers, R. O. (1985): Ground water flow in limestone terranes: Strategy rationale and procedure for reliable, efficient monitoring of ground water quality in karst areas, In: Proceedings of the national symposium and exposition on aquifer restoration and ground water monitoring (5th, Columbus, Ohio), National Water Well Association, Worthington, Ohio, 197-243.

Reimann, T., Giese, M., Geyer, T., Liedl, R., Maréchal, J.-C. and Shoemaker, W.B. (2014): Representation of water abstraction from a karst conduit with numerical discrete-continuum models, Hydrol. Earth Syst. Sci., 18, 227-241, doi 10.5194/hess-18-227-2014.

Renard, P., Glenz, D., and Mejias, M. (2009): Understanding diagnostic plots for well-test interpretation, Hydrogeology Journal, 17(3), 589-600.

Roberts, R. M., Beauheim, R. L. and Domski P. S. (1999): Chapter 6: Interpretation methodology and objectives, In: Hydraulic testing of Salado Formation evaporites at the waste isolation pilot plant site: Final Report.

Sauter, M., Kovacs, A., Geyer, T. and Teutsch, G. (2006): Modellierung der Hydraulik von Karstgrundwasserleitern - Eine Übersicht (Modeling the hydraulic system of karst aquifers - an overview), Grundwasser (11)3; 143-153 (in German).

Schmidt, S., Geyer, T., Guttman, J., Marei, A., Ries, F. and Sauter, M. (2014): Characterisation and modelling of conduit restricted karst aquifers - Example of the Auja spring, Jordan Valley, Journal of Hydrology, 511, 750-763, doi 10.1016/j.jhydrol.2005.11.054.

Shoemaker, W. B., Kuniansky, E. L., Birk, S., Bauer, S. and Swain, E. D. (2008): Documentation of a Conduit Flow Process (CFP) for MODFLOW-2005: U.S. Geological Survey Techniques and Methods, Book 6, Chapter A24.

Spane (jr.), F. A. and Wurstner, S. K. (1993): A computer program for calculating pressure derivatives for use in hydraulic test analysis, Ground Water, 31(5), 814-822. 


\section{Chapter 6}

Vasseur, F. (1993): Exploration dans l'Hérault. Rétrospective historique des plongées souterraines d'exploration dans le département et secteur limitrophes, Les dossiers CELADON, No.3 (Exploration in the Hérault department. Retrospective history of the underground exploration dives in the neighboring department and section, The dossiers CELADON, No.3), Fédération Française de Spéléologie (in French).

Walker, D. D. and Roberts, R. M. (2003): Flow dimensions corresponding to hydrogeological conditions, Water Resources Research, Vol.39, No.12, 1349, doi 10.1029/2002WR001511. 


\section{Chapter 7}

\section{$7 \quad$ General conclusions and outlook}

\subsection{General conclusions}

Due to the duality of flow and generally large catchment areas of karstic spring, karst aquifer systems are efficient fresh water sources. The duality is a consequence of hydraulic property differences between different karst compartments and adds a high degree of anisotropy. Several conceptual models and approaches are frequently applied to characterize flow in karst aquifers, or to be more precise, the phreatic part of the system. Integral characterization techniques are scarce because of the low understanding and high complexity of different processes and the high data demand to describe those processes sufficiently. Large-scale abstraction tests are suitable to cover the scale of dominant aquifer heterogeneities in the phreatic zone. On the one hand, measured drawdown curves contain information about the conduit system as well as the fissured matrix and therefore about the two interacting components of the characteristic dual flow behaviour. On the other hand, drawdown curves are a spatial and temporal superposition of different heterogeneities, which means that the ambiguity is normally high.

This thesis presents the application of discrete conduit-continuum models to assess karst specific heterogeneities and their spatial distribution. It is focused on the interpretation of the drawdown curve measured inside the triggered conduit. The different chapters examine a variety of heterogeneities which influence the drawdown at (1) early time, (2) intermediate time and (3) late time as well as the transition periods in between.

The early time response of a large-scale pumping test is influenced by direct storage. The consideration of direct storage is essential for karst related analyses. Without a fast responding storage, for example the conduit-associated drainable storage (CADS), the only accessible storage is the matrix storage. This approach 


\section{Chapter 6}

corresponds to the conceptual model of DROGUE (1992), which is only one potential conceptual karst model. For the Cent Fonts catchment (Languedoc, France), as an example of a mixed flow karst system, this conceptual model is non-applicable. The concept of the fast responding storage is well known from pumping test interpretations. The dimensionless wellbore storage can be applied to compare drawdown curves independent from hydraulic properties or the pumping rate. Another dimensionless parameter, which can be defined to affect the drawdown behavior during early time, is the skin damage factor. The skin damage factor accounts for pressure changes in the interface between a highly conductive feature and the matrix.

By using the dimensionless wellbore storage and the skin damage factor for the interpretation of water abstraction directly from idealized karst conduits, a characterization scheme is developed. The characterization scheme considers different degrees of karstification on two different scales and represents the interaction of the conduit and the matrix during the first transition period. The first scale is the local scale, ranging from a centimeter up to a few meters along the conduit. The second scale is the regional scale, defined by the hydraulic matrix parameter. The characterization schema excludes the representation of diffuse flow karst systems. Two flow systems can be distinguished depending on the skin damage factor: (1) matrix restrained flow regimes and (2) interface restricted flow regimes. The interface restricted flow is defined by low exchange permeability. In mature karst systems the low exchange permeability can be explained by additional flow restrictions, for example consequences of turbulent exchange flow, but also restricted inflow form other karstic features in the vicinity of the conduit. The possibility of the extension of the characterization schema on conduit-influenced flow regimes exists. Due to the restricted applicability of the skin damage factor, as well as the dimensionless wellbore storage, an adaption of the parameter or a definition of new parameters is demanded.

Conduit-influenced flow regimes are characterized by restricted conduit conductivity (finite conductivity) influencing karst spring hydrographs (KOVACS ET AL., 2005) as well as the drawdown behavior of large-scale pumping tests. The infinite conduit conductivity is the consequence of increased friction factor and therefore accounts for head gradients along the flow direction. The head losses depend on the mean roughness height and the conduit diameter and to a 
lesser extent on the tortuosity. Finite conduit conductivity influences the flow pattern during linear flow. Due to the increased head losses, the conduit flow is restricted. Consequently, the exchange flow with the matrix increases near the wellbore and is therefore not uniform along the conduit. For finite conduit conductivity, the linear conduit flow is superposed by the radial matrix flow in the vicinity of the wellbore resulting into bilinear flow. The characteristics of bilinear flow are higher conduit drawdown at the beginning of pumping and a smoother slope of the drawdown and derivative curve (quarter-unit slope) as well as increased matrix drawdown in the vicinity of the wellbore. The nonuniform exchange flow along the conduit is the major difference between conduit-influenced flow regimes and matrix restrained flow regimes. For conduit-influenced flow regimes, the application of turbulent flow equations is demanded. Due to the infinite conduit conductivity of matrix-restrained flow regimes, laminar flow equations can be sufficient even for high Reynolds numbers. For those karst systems, the ratios between mean roughness height and conduit diameter are most likely not covered to by traditional Moody diagram (MOODY, 1944) used to predict the friction factor depending on the ratio and the Reynolds number and separate between laminar and turbulent flow.

Traditional tools for pumping test interpretation normally assume an infinite aquifer extent. This assumption is used as a defined flow pattern for the type curve analysis and the estimation of the matrix transmissivity. For the interpretation of large-scale pumping tests, heterogeneities or boundary conditions need to be considered as influencing the drawdown behaviour during reservoir flow. Those boundary conditions influence the shape of the drawdown curve resulting in a flow pattern different to radial flow. Therefore, the extension of the cone of depression is not a function of Darcian flow. The calculation of the transmissivity based on Darcian flow is not valid for flow patterns different to radial flow.

The interpretation of diagnostic plots can be enhanced by the application of the flow dimension concept. The flow dimension is generally applicable to all periods of pumping and adds additional information without further research effort. The application of the flow dimension on the simulation drawdown curve of a DCC model extends the traditional approaches, which are focused on the hydraulic parameter estimation. The flow dimension of a DCC model 


\section{Chapter 6}

represents the flow pattern on large scale as a consequence of superposed heterogeneities and can therefore be used to exclude certain conceptual models or fractions of conceptual model, e.g. boundary conditions. In addition to the forward simulation of different conceptual models (pattern matching), DCC models in combination with calibration tools are also able to estimate hydraulic parameters.

The influences of the hydraulic parameters in respect to the three main periods during pumping tests are summarized in Table 7.1.

Table 7.1: Dominating parameters of the different periods during pumping tests

\begin{tabular}{|c|c|c|c|}
\hline \multicolumn{2}{|c|}{ Period } & Hydraulic parameters & $\begin{array}{l}\text { Dimensionless } \\
\text { parameters }\end{array}$ \\
\hline \multirow{2}{*}{ Early time } & $\begin{array}{l}\text { with fast- } \\
\text { responding } \\
\text { storage }\end{array}$ & $W_{C A D S} \quad \alpha_{e X}$ & \\
\hline & $\begin{array}{l}\text { without fast- } \\
\text { responding } \\
\text { storage }\end{array}$ & $\alpha_{e x} \quad K$ & $S_{f}$ \\
\hline \multirow[b]{2}{*}{$\begin{array}{l}\text { Transition } \\
\text { period }\end{array}$} & $\begin{array}{l}\text { Matrix restrained } \\
\text { flow regime }\end{array}$ & $W_{C A D S} \quad \alpha_{e X} \quad K \quad S$ & $C_{D}, S_{f}$ \\
\hline & $\begin{array}{l}\text { Interface } \\
\text { restricted flow } \\
\text { regime }\end{array}$ & $W_{C A D S} \quad \alpha_{e X} \quad K \quad S$ & $C_{D}, S_{f}$ \\
\hline \multirow{2}{*}{$\begin{array}{c}\text { Intermediate } \\
\text { time }\end{array}$} & $\begin{array}{l}\text { Matrix restrained } \\
\text { flow regime }\end{array}$ & $W_{C A D S} \quad \alpha_{e x} \quad K \quad S \quad L$ & $C_{D}, S_{f}$ \\
\hline & $\begin{array}{l}\text { Conduit } \\
\text { influenced flow } \\
\text { regime }\end{array}$ & $\begin{array}{lll}d & k_{c} & \tau\end{array}$ & \\
\hline $\begin{array}{c}\text { Transition } \\
\text { period }\end{array}$ & & $K S$ & $D$ \\
\hline Radial flow & & $K S$ & $D$ \\
\hline
\end{tabular}

\subsection{Conclusions for the Cent Fonts pumping test}

The measured drawdown curve of the Cent Fonts pumping test is also a spatial and temporal superposition of different heterogeneities. Based on the 
results, the conceptual model of the Cent Fonts catchment can further be enhanced:

- Fast responding storage, provided by solution enlarged fractures or other karst features, is directly connected to the karst conduit in the vicinity of the wellbore. The free-surface area (storage area) of 1,900 $\mathrm{m}^{2}$ calculated by MARÉCHAL ET AL. (2008) seems to be reasonable to represent the storage period, but cannot be evenly distributed along the conduit.

- The assumption of quasi-infinite conductivity for the broad diameter conduit is applicable. Laminar flow equations, resulting in nearly uniform drawdown along the conduit, can be used to represent the flow dynamics. However, this assumption has a restricted validity and cannot be applied on the whole conduit connecting the Buèges River loss with the Cent Fonts spring.

- The conduit system of the Cent Fonts catchment is a sequence of highly conductive conduits and sections of significant head losses, e.g. as a consequence of collapses or debris loads. Due to major head losses within these sections the matrix drawdown increases during the largescale pumping test, masking the signal of the upstream parts of the system. Therefore it is not possible to distinguish between certain conduit systems, i.e. single conduit, branched systems, meshed systems.

\subsection{Future research perspective}

This thesis focused on different karst-specific heterogeneities and their influences on the general flow pattern on a regional scale. Due to the complexity of karst aquifers introduced by the duality of the system, those influences were mostly, with the exception of Chapter 6, analyzed separately and with a certain degree of simplification. The separation of certain heterogeneities gained the process-based knowledge. The analyses are not able to answer all the questions concerning the main goal of the characterization of karst aquifer systems by large-scale experiments and raise karst specific and model related questions. Those issues can be divided into three main topics that are further discussed. 


\section{Chapter 6}

\subsubsection{Interpretation of the large-scale pumping test at the Cent Fonts catchment}

The conceptual model of the Cent Fonts catchment considers a connection of the Buèges River and the Cent Font spring by highly conductive features. MARÉCHAL ET AL. (2008) prove that the connection between the river loss area and the spring, or rather the pumping well, can be described by a quasi-infinite conduit conductivity. In Chapter 6, the drawdown behavior of the single conduit with quasi-infinite conductivity was compared to a single conduit draining the lower parts of the Cent Font catchment and therefore representing a conceptual model that is influenced by radial flow components. The second model can reproduce the measured conduit drawdown and proves a high influence of radial flow, indicated by the flow dimension of $n=0.59$ lasting for one and a half $\log$ cycles. Hence it can be stated that the measured conduit drawdown is not a function of a quasi-infinite conductivity conduit connecting the river loss area of the Buèges River with the Cent Fonts spring. Based on the predictions, especially the expected sequences of highly conductive conduits interrupted by sections with sufficient head losses, the conceptual model of the Cent Fonts catchment can be adjusted. Instead of a single conduit or a conduit network with constant conduit diameter, the conduit geometry should be considered as a (truncated) cone. Starting with a broad conduit diameter, which was measured by cave divers, the cone diameter and therefore the conduit conductivity, is constricted at a certain distance to the pumping well. The conduit volume as well as the length of the cone could be used as calibration parameters. In a first step, the constrained part of the conduit will be uniformly parametrized in the upstream direction. In addition to the conduit drawdown, discrete time series of the matrix drawdown can be applied. The complexity of the model can be increased step-wise, for example by the consideration of heat transfer. The heat signal can be precious for the upstream characterization of the catchment, at least for a rough prediction of the storage and the conduit conductivity (e.g. BIRK, 2002).

\subsubsection{Karst characterization based on recharge signals}

Large-scale abstraction tests are applied on karst as well as fractured aquifer systems to determine the potential water availability. Nevertheless, due to the comparably high technical and financial demand, large-scale water abstraction tests are rarely used for karst aquifer characterization. Chapter 5 presents a 
dimensionless characterization schema based on the drawdown curves. The schema considers different interface and matrix properties. These properties can be linked to conceptual representations of karst systems. The thesis already mentioned similar existing characterization techniques based on the analysis of spring hydrographs derived from field measurements (e.g. MANGIN, 1974) or by numerical modelling (e.g. KOVÁCS ET AL., 2005). The characterization scheme can be compared to the existing approach of KOVÁCS ET AL. (2005) by substitution of the pumping rate with a defined recharge signal. Duo to the idealized conduit flow conditions, the scheme should be able to represent the matrix-restrained karst systems. Considering the results of Chapter 4, CFPM1 is further able to simulate conduit influenced karst systems. Therefore, a feasibility study aiming at the spring hydrograph recession and the further definition of the threshold values is recommended.

According to KOVÁCS ET AL. (2005), the hydraulic and geometric properties of karst systems, which are combined in the characterization scheme in Chapter 5, can be linked to the recession coefficient of karst spring hydrographs. MANGIN (1974) uses the parameter for his karst characterization scheme. In case of MANGIN (1974), the recession coefficient is the global response and therefore provides integral information of the catchment. Drawbacks of the approach are already mentioned in Chapter 1 . The current development state of the CFPM1 only considers the phreatic zone of the karst aquifer system. The vadose and surface zones are not incorporated. For the integral representation of karst catchments, such compartments and processes in terms of infiltration and percolation through the vadose zone need to be considered (e.g. DOUMMAR ET AL., 2012; KORDILLA ET AL., 2012). Another positive aspect of such a model simulating a multi-compartment karst system by coupling the surface and vadose zone on the existing phreatic zone is the spatiotemporal distribution of the precipitation, which extends existing approaches.

\subsubsection{Application of CFPM1 to horizontal wellbore hydraulics}

During the last few decades an intensified application of horizontal wellbores can be observed. Similar to the development of a wide variety of interpretation methods of pumping tests, horizontal wellbores were developed as useful tools, especially in the petroleum industry. A major advantage of horizontal wellbores compared to vertical wellbores is the higher productivity especially for shallow 


\section{Chapter 6}

reservoirs and aquifer systems (e.g. JOSHI, 1991; PARK AND ZHAN, 2002). On this account, the application of horizontal wellbores also continuously increases for water abstraction. Another intended use is the artificial recharge of the aquifer through infiltration or the recovery of thin layer contaminants (PARK AND ZHAN, 2002). However, the operation of horizontal wellbores and wellbore field (collectors) is technically demanding and the maintenance costs are high. In particular, the reconditioning of the horizontal wellbore casings affected by clogging (e.g. iron hydroxide deposit) is costly.

Up to now, the approaches used for the analyses of horizontal wellbore hydraulics are mostly transferred from vertical wells. Therefore, the limitations and the degree of abstraction are similar. Besides the idealized catchment requirements, e.g. infinite aquifer systems, horizontal head distribution before pumping, these analytical solutions also use idealized line source solutions that consider infinite wellbore conductivity (e.g. JOSHI, 1991). For those conditions, the skin damage factor as well as the dimensionless wellbore storage can be applied. The line source solution was also incorporated into numerical models to decrease the degree of abstraction, e.g. by the consideration of a finite wellbore diameter or catchment heterogeneities (e.g. PARK AND ZHAN, 2002; PARK AND ZHAN, 2003)

The degree of abstraction can further be decreased by the application of continuum models. This allows the consideration of the cone of depression interaction of a collector well field (e.g. KELSON, 2012) or the interaction of a single horizontal wellbore with other boundary conditions. One frequently used continuum model is MODFLOW Multi-Node Well Package (MF-MNW2) created to simulate drawdown for long vertical or horizontal wells (KORNIKOW ET AL., 2009). However MF-MNW2 also assumes a uniform hydraulic head along the well and can therefore be referred to as an infinite conductivity solution.

Chapter 4 shows the ability of CFPM1 to represent the analytical drawdown for idealized conditions such as infinite conductivity. Additionally, CFPM1 is able to represent the skin damage factor and dimensionless wellbore storage. The validation of the laminar flow equations (e.g. infinite conductivity, uniform flow) must be at least challenged for modern horizontal wellbores (OZCAN, 2001). Therefore, the CFPM1 can be a useful tool for the interpretation of 
horizontal wellbore hydraulics as well as the evaluation of long-term abstraction tests. Combined with the implemented solute and heat transport, CFPM1 might also be able to focus long-term processes such as interactions with boundary conditions or clogging. Therefore, CFPM1 could be enhanced by further processes likely to affect the flow pattern in or around a horizontal wellbore. 


\section{Chapter 6}

\section{References}

Birk, S. (2002): Characterisation of Karst Systems by Simulating Aquifer Genesis and Spring Responses: Model development and Application to Gypsum Karst, Tübinger Geowisschenschaftliche Arbeiten (TGA), Part C, C60.

Drogue, C. (1992): International Contribution to Hydrogeology, 13, Verlag Heinz Heise, Hannover, Germany, 133-149.

Doummar, J., Sauter, M. and Geyer, T. (2012): Simulation of flow processes in a large scale karst system with an integrated catchment model (Mike She) Identification of relevant parameters influencing spring discharge, Journal of Hydrology, 426-427, 112-123, doi:10.1016/j.jhydrol.2012.01.021.

Joshi, S. D. (1991): Horizontal well technology, PennWell Publishing Company, Tulsa, Oklahoma.

Kelson, V. (2012): Predicting collector well yields with MODFLOW, Ground Water, 50 (6), 918-926.

Kordilla, J., Sauter, M., Reimann, T. and Geyer, T. (2012): Simulation of saturated and unsaturated flow in karst systems at catchment scale using a double continuum approach, Hydrol. Earth Syst. Sci., 16, 3909-3923, doi:10.5194/hess-16-3909-2012.

Kornikow, L. F., Hornberger, G. Z., Halford, K. J. and Hanson, R. T. (2009): Revised multi-node well (MNW2) package for MODFLOW ground-water flow model, US Geological Survey Techniques and Methods, 6-A30.

Kovács, A., Perrochet, P., Király, L. and Jeannin, P.-Y. (2005): A quantitative method for the characterisation of karst aquifers based on spring hydrograph analysis, Journal of Hydrology, 303, 152-164, doi:10.1016/j.hydrol.2004.08.023.

Mangin, A. (1975): Contribution à l'étude hydrodynamique de aquifères karstiques, PhD thesis, Université de Dijon, France. 
Maréchal, J.-C., Ladouche, B., Dörflinger, N. and Lachassagne, P. (2008): Interpretation of pumping tests in a mixed flow karst system, Water Resources Research, Vol.44, W05401, doi:10.1029/2007WR006288.

Moody, L. F. (1944): Friction factors for pipe flow, Transactions of the ASME, $66(8), 671-684$

Ozkan, E. (2001): Analysis of horizontal-well responses: contemporary vs. conventional, SPE Reservoir Evaluation \& Engineering, Vol. 4(4), doi: 10.2118/72494-PA.

Park, E. and Zhan, H. (2002): Hydraulics of a finite-diameter horizontal well with wellbore storage and skin effect, Advances in Water Resources, 25, 389-400.

Park, E. and Zhan, H. (2003): Hydraulics of horizontal wells in fractured shallow aquifer systems, Journal of Hydrology, 281, 147-158. 